\title{
Creation and establishment of transgenic mouse models for Mecp2 gene, causing Rett syndrome
}

\author{
Dissertation \\ zur Erlangung des Doktorgrades \\ der Mathematisch-Naturwissenschaftlichen Fakultäten \\ der Georg-August-Universität zu Göttingen
}

vorgelegt von

Jayamuruga Pandian Arunachalam

aus Madurai (Indien)

Göttingen, Germany, 2007 
D7

Referent:

Korreferent:

Tag der mündlichen Prüfung:
Prof. Dr. med. Wolfgang Engel

PD Dr. S. Hoyer-Fender

3. Mai 2007 


\section{Index}

Abbreviations................................................................

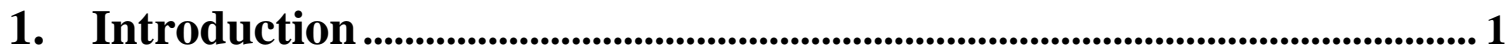

1.1. DNA methylation and neuron gene regulation ........................................... 1

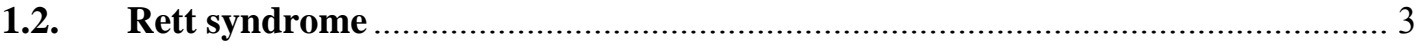

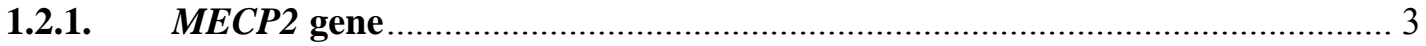

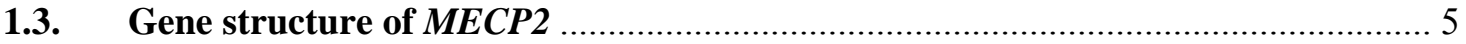

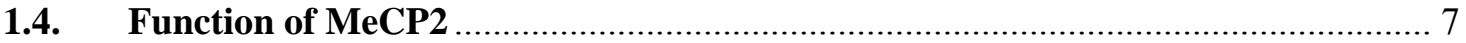

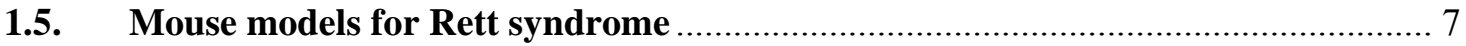

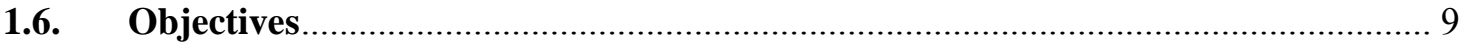

2. Materials and Methods ..................................................................................... 10

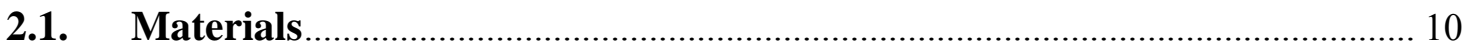

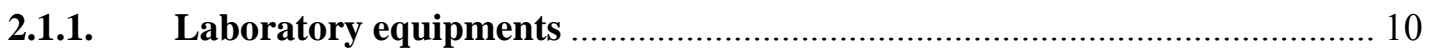

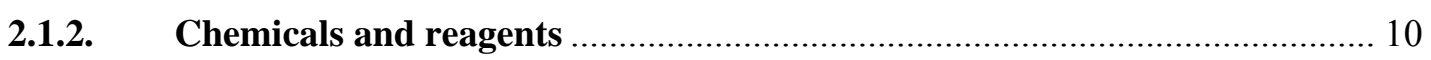

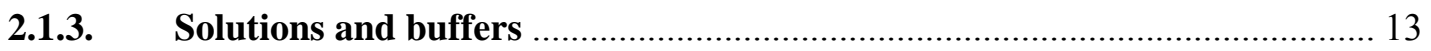

2.1.3.1. Agarose gel electrophoresis............................................................ 13

2.1.3.2. SDS-PAGE (SDS-Polyacrylamide Gel Electrophoresis) ...................... 14

2.1.3.3. Other frequently used buffers and solutions .................................... 14

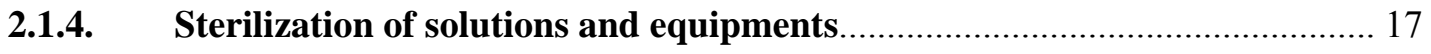

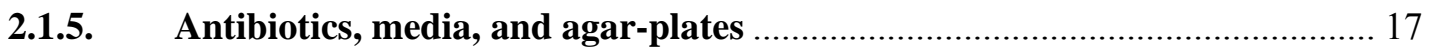

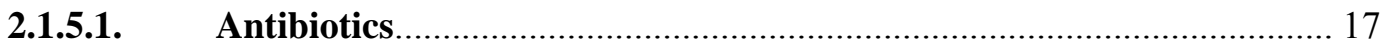

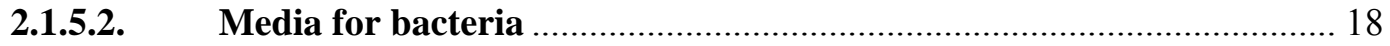

2.1.5.3. Media for cell culture ......................................................................... 19

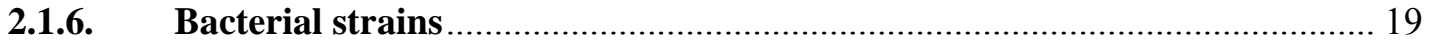

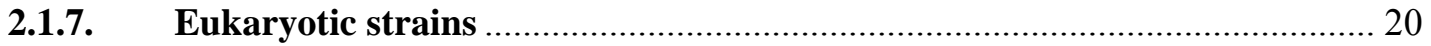

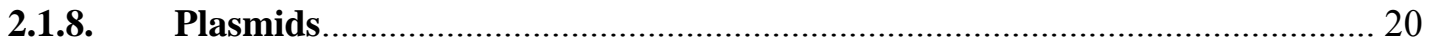

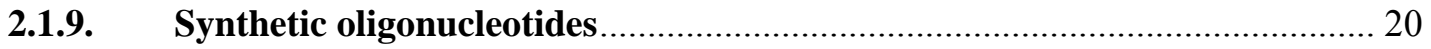

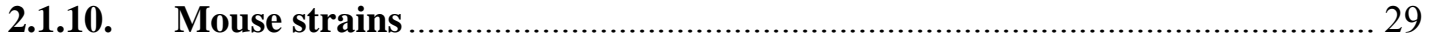

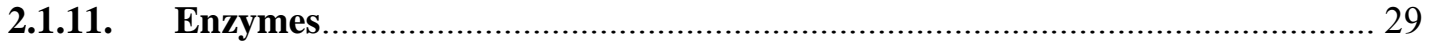

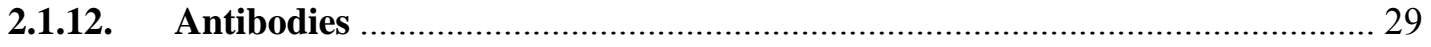

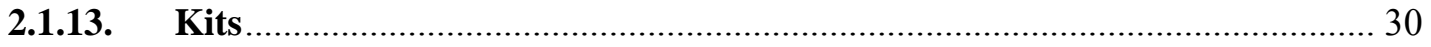

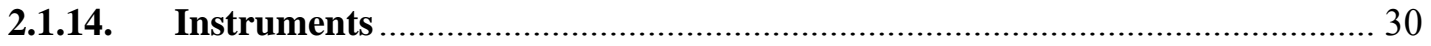




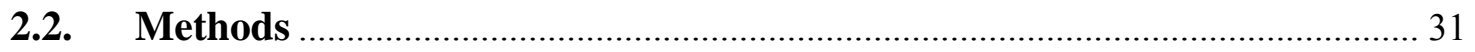

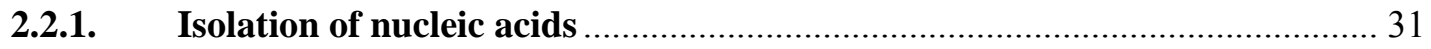

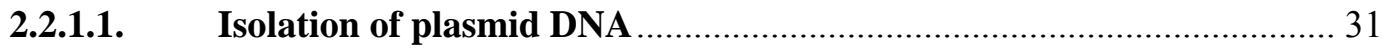

2.2.1.1.1. Small-scale isolation of plasmid DNA (Mini preparation)................. 31

2.2.1.1.2. Large-scale preparation of plasmid DNA (Midi preparation) .......... 32

2.2.1.2. Isolation of genomic DNA from tissue samples.................................. 33

2.2.1.3. Isolation of total RNA from tissue samples and cultured cells ............. 33

2.2.2. Determination of the nucleic acids concentration ......................................... 34

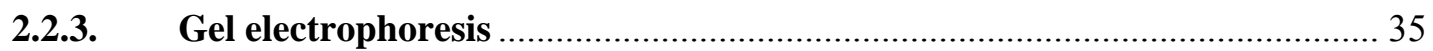

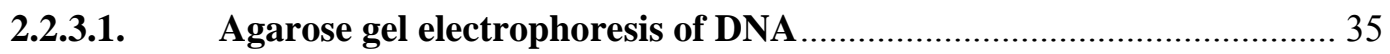

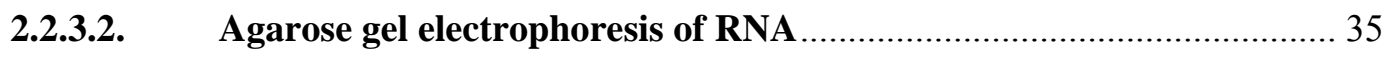

2.2.3.3. DNA and RNA molecular weight ladders ........................................... 36

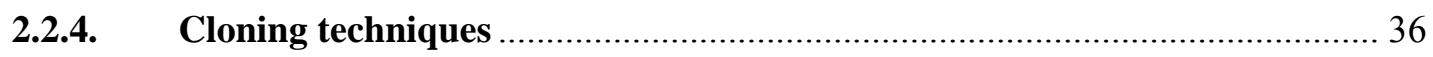

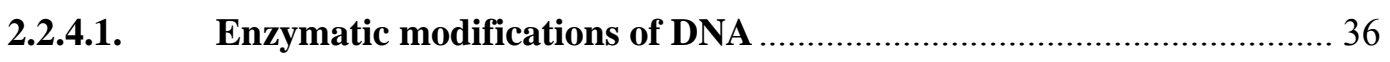

2.2.4.1.1. Restriction enzyme digestion of DNA ................................................. 36

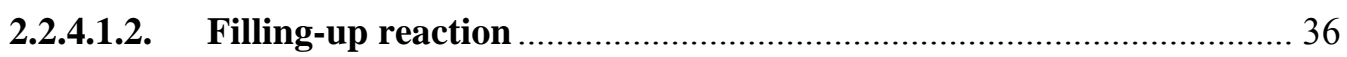

2.2.4.1.3. Dephosphorylation of 5' ends of DNA ….......................................... 37

2.2.4.1.4. Purification by phenol-chloroform extraction

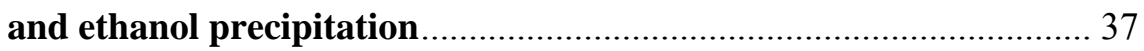

2.2.4.2. Isolation of DNA fragments after agarose gel electrophoresis ............ 37

2.2.4.3. Ligation of DNA fragments............................................................... 38

2.2.4.4. Polymerase Chain Reaction (PCR) ................................................... 38

2.2.4.4.1. PCR amplification of DNA fragments .............................................. 38

2.2.4.4.2. Reverse transcription PCR (RT-PCR) ............................................. 39

2.2.4.4.2.1. Reverse transcription or cDNA synthesis .................................... 39

2.2.4.4.2.2. One step RT-PCR ................................................................... 40

2.2.4.5. Subcloning of PCR and RT-PCR products ..................................... 40

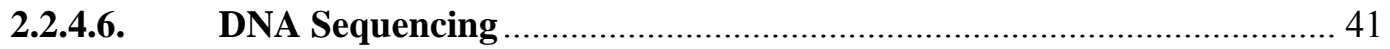

2.2.4.7. Preparation of Electro-competent Escherichia coli bacteria ................ 41

2.2.4.8. Electroporation of the competent bacteria .......................................... 42

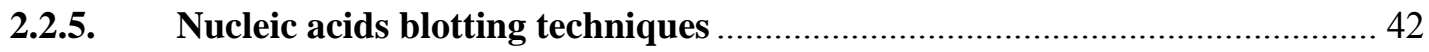

2.2.5.1. Southern blotting of DNA to nitrocellulose filters .............................. 42

2.2.5.2. Northern blotting of RNA onto nitrocellulose filters........................... 43

2.2.5.3. Random Prime method for generation of $P^{32}$ labeled DNA ................. 43 


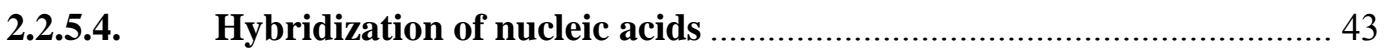

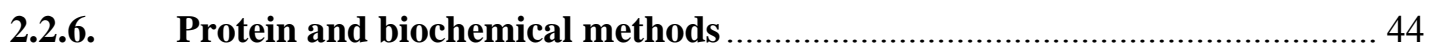

2.2.6.1. Expression of recombinant proteins in Escherichia coli ....................... 44

2.2.6.2. Purification of the proteins from Escherichia coli ................................ 44

2.2.6.3. Isolation of protein from mammalian cells .......................................... 46

2.2.6.4. Isolation of total protein from mouse tissues.................................. 47

2.2.6.5. Determination of protein concentration .......................................... 47

2.2.6.6. SDS-PAGE for the separation of proteins ............................................. 47

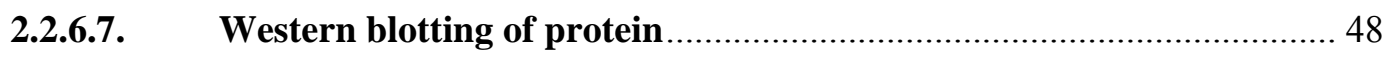

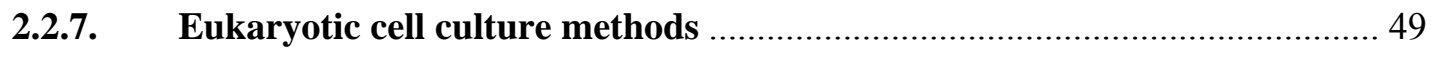

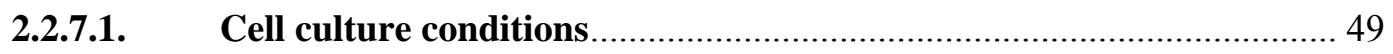

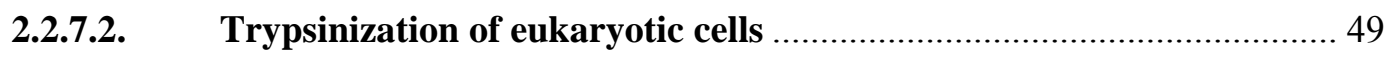

2.2.7.3. Cryopreservation and thawing of eukaryotic cells .............................. 49

2.2.7.4. Transfection of the eukaryotic cells with plasmid ................................ 50

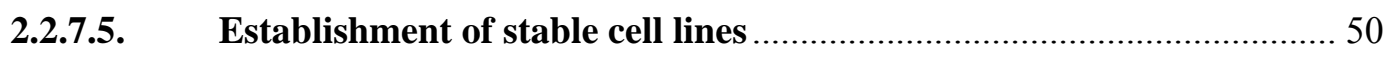

2.2.7.6. Establishment of mouse primary neurons............................................ 50

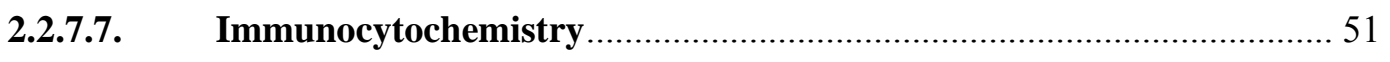

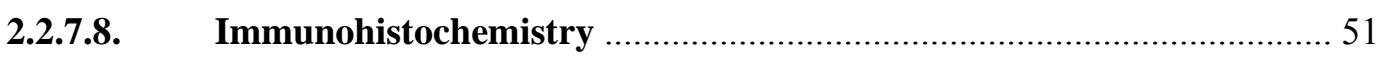

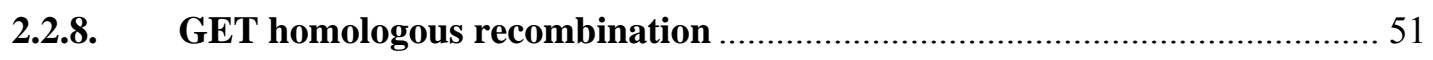

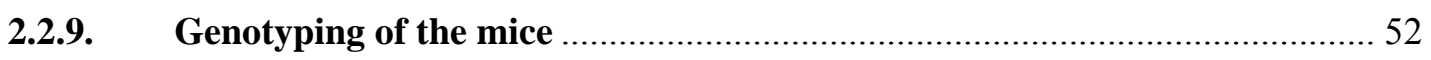

2.2.10. Real time PCR analysis for copy number studies......................................... 53

2.2.11. Analysis of histone acetylation status by immunoblotting ............................ 55

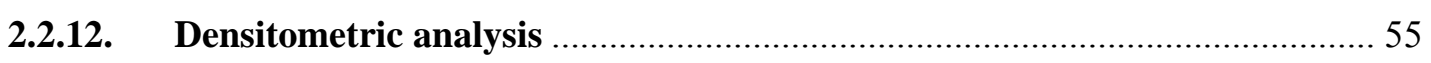

2.2.13. Enzymatic dissociation and FACS isolation of neurons ............................. 55

2.2.14. Phenotypical analysis using open field test. ................................................ 56

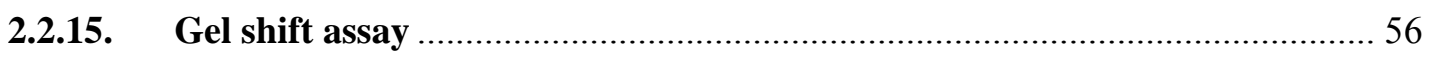

2.2.16. Recovery and culture of preimplantation mouse embryos ........................... 58

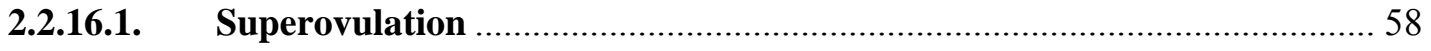

2.2.16.2. Recovery of preimplantation embryos................................................... 58

2.2.16.3. In vitro culture of blastocyst stage embryos........................................ 59

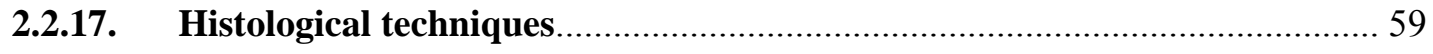

2.2.17.1. Tissue preparation for paraffin embedding ....................................... 59

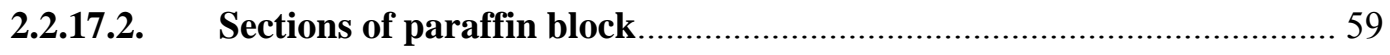

2.2.17.3. Hematoxylin-eosin staining of the histological sections........................ 60 


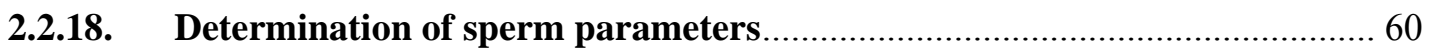

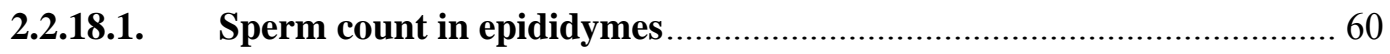

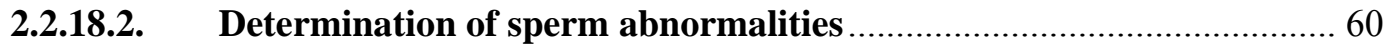

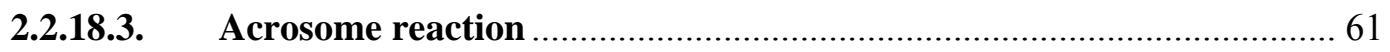

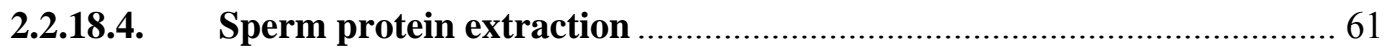

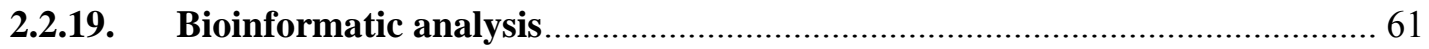

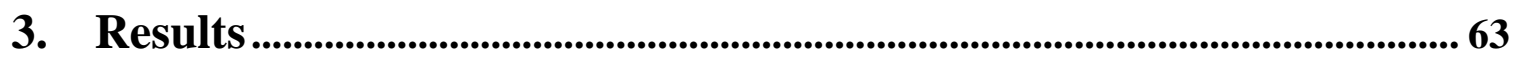

3.1. Creation and establishment of transgenic mouse models

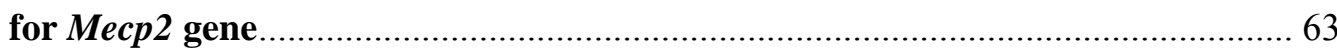

3.1.1. Analysis of upstream sequence of the Mecp2 for promoter activity ............ 63

3.1.2. Expression analysis of the Mecp2 in different cell lines ................................. 64

3.1.3. Transient transfection assay for Mecp2 promoter analysis ........................... 65

3.1.4. Verification of the expression of exon 1 of the Mecp2 gene ..........................66

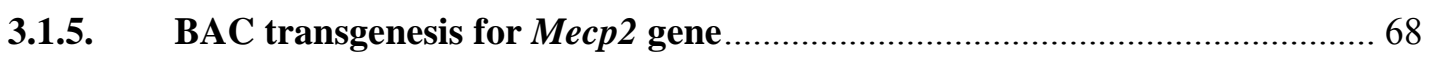

3.1.6. Creation of the transgenic constructs by GET recombination...................... 69

3.1.7. Transfection of the transgenic construct in the cell lines.............................. 72

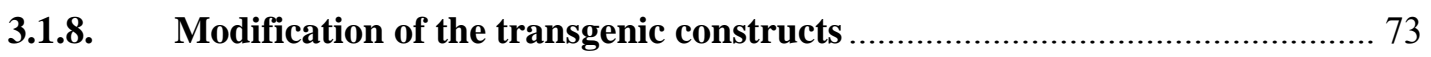

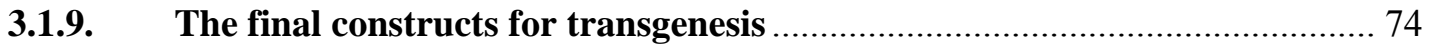

3.1.10. Transmission and expression analysis of the transgene ............................... 78

3.1.11. Mode of inheritance of the Mecp2_WT_EGFP transgene............................. 80

3.1.12. Production of recombinant MeCP2 protein and raising antibody .............. 82

3.1.13. Immunohistochemical analysis of the transgenic

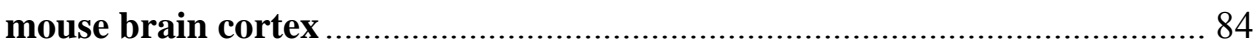

3.1.14. Analysis of number of transgene copies and integrations

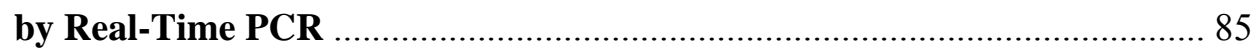

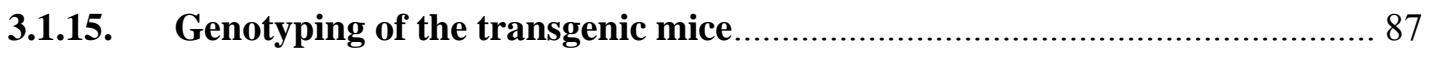

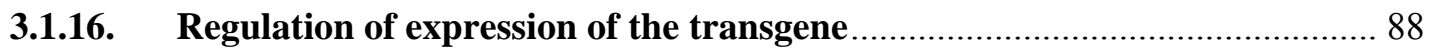

3.1.17. Transgenic protein profiling in comparison with other

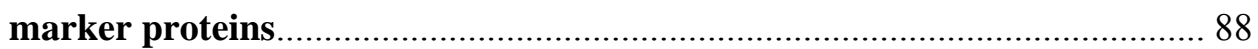

3.1.18. Histone acetylation status of the transgenic animals by HDAC assays

3.1.19. Elucidation of the functionality of the transgene by rescue experiments 
3.1.20. Phenotypical analysis of the transgenic animals......................................... 92

3.1.21. EGFP FACS analysis of the transgenic mouse brain cells.......................... 93

3.1.22. Measurement of Mecp2+/EGFP+ cell number by FACS sorting …............. 93

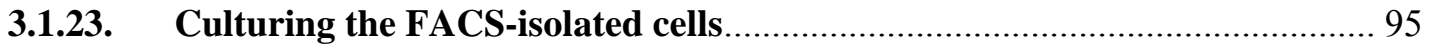

3.1.24. Characterization of Mecp2+/EGFP+ cells ….............................................. 97

3.1.25. Organotrophic and primary neural cultures from

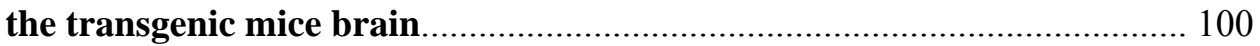

3.1.26. Imaging of Mecp2 at the synapses …....................................................... 102

3.2. Knockin construct for the most frequent mutation

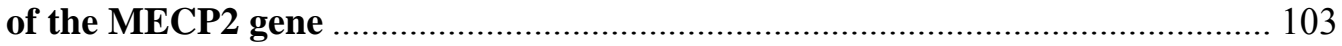

3.3. Identifying the target sequences of MeCP2 protein .......................................... 108

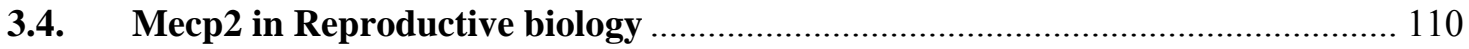

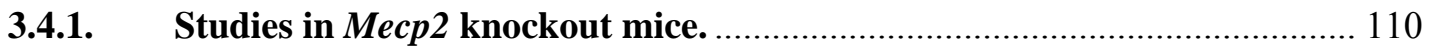

3.4.2. Mecp2 in mouse testicular development and ovary ................................. 111

3.4.3. Mecp2 in mouse embryonic stem (ES) cells ............................................... 115

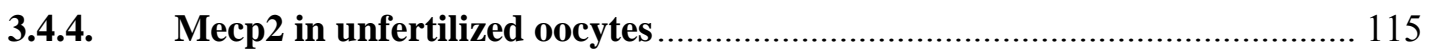

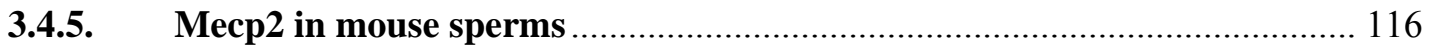

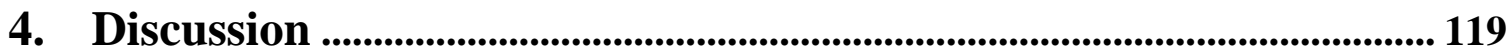

4.1. Creation and characterization of transgenic mouse models

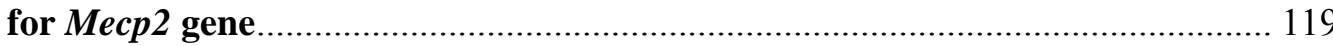

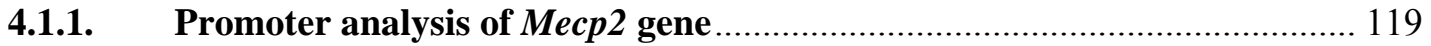

4.1.2. GET recombination and generation of transgenic constructs.................... 119

4.1.3. Establishment of transgenic mouse lines ................................................ 122

4.1.4. EGFP FACS analysis of the transgenic mouse brain cells.......................... 124

4.1.5. Elucidation of the subcellular distribution of Mecp2 ................................ 125

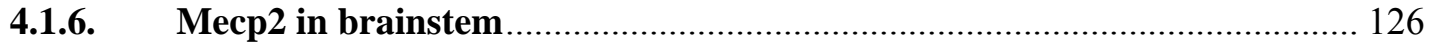

4.2. The importance of mouse models for Rett syndrome ...................................... 126

4.2.1. Summary of existing and expected Mecp2 animal models ......................... 129

4.2.2. Prospective knockin model for the most frequent mutation of the $M E C P 2$ gene.

4.2.3. Potential forthcoming transgenic mouse models for the $M E C P 2$ gene 


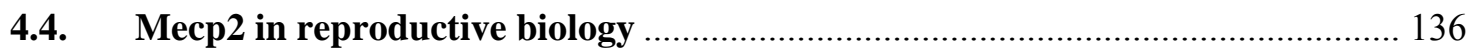

4.5. Measurement of the size of specific affected neurons in Rett syndrome............. 137

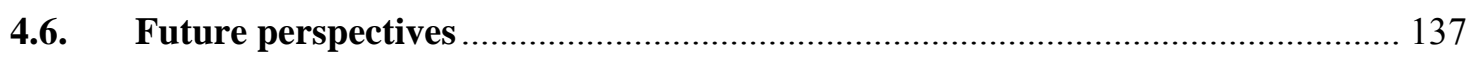

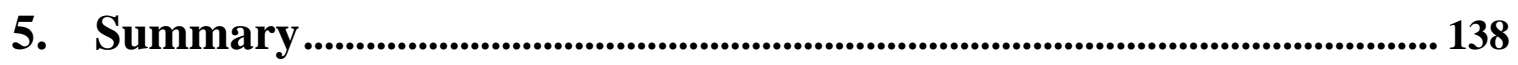

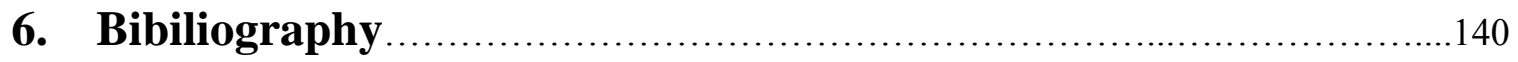

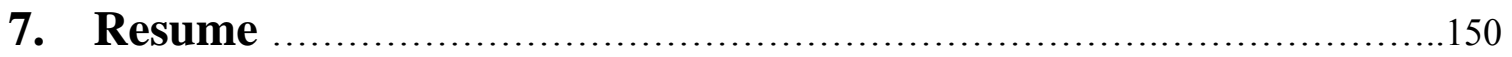

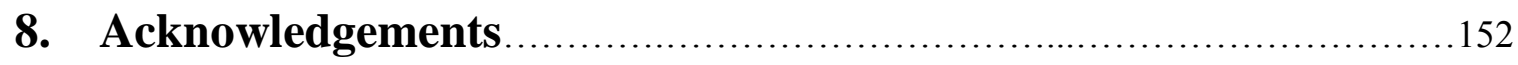




\section{Abbreviations}

\begin{tabular}{|c|c|}
\hline $\mathrm{ABI}$ & Applied Biosystem Instrument \\
\hline APS & Ammonium peroxodisulfate \\
\hline ATP & Adenosintriphosphate \\
\hline $\mathrm{BAC}$ & Bacterial Artificial Chromosome \\
\hline $\mathrm{BCP}$ & 1-bromo-3-chloropropane \\
\hline bFGF & basic fibroblast growth factor \\
\hline $\mathrm{bp}$ & base pair \\
\hline BSA & Bovine serum albumin \\
\hline${ }^{\circ} \mathrm{C}$ & Degree Celsius \\
\hline cDNA & complementary DNA \\
\hline dATP & Desoxyriboadenosintriphosphate \\
\hline $\mathrm{ddH} 2 \mathrm{O}$ & double distilled Water \\
\hline DAPI & Diamidino-2-phenylindole dihydrochloride \\
\hline $\mathrm{dCTP}$ & Desoxyribocytosintriphosphate \\
\hline DMSO & Dimethyl sulfoxide \\
\hline DEPC & Diethylpyrocarbonate \\
\hline DNA & Deoxyribonucleic acid \\
\hline DNase & Deoxyribonuclease \\
\hline dNTP & deoxynucleotidetriphosphate \\
\hline dpc & day post coitus \\
\hline $\mathrm{dT}$ & deoxythymidinate \\
\hline DTT & Dithiothreitol \\
\hline EDTA & Ethylene diamine tetraacetic acid \\
\hline EGFP & Enhanced green fluorescent protein \\
\hline $\mathrm{FCS}$ & Fetal calf serum \\
\hline FITC & Fluorescein isothiocyanate \\
\hline g & Gravity \\
\hline gm & Gram \\
\hline HBS & HEPES buffered saline \\
\hline HDAC & Histone Deacetylase \\
\hline
\end{tabular}




\begin{tabular}{|c|c|}
\hline HEPES & N-(-hydroxymethyl)piperazin,N'-3-propansulfoneacid \\
\hline $\mathrm{H} 3$ & Histone 3 \\
\hline H4K16 & Histone 4 lysine at 16 th amino acid \\
\hline $\operatorname{hr}(\mathrm{s})$ & hour(s) \\
\hline IPTG & Isopropyl- $\beta$-thiogalactopyranoside \\
\hline $\mathrm{kb}$ & kilobase \\
\hline LB & Luria-Bertrani \\
\hline M & molarity \\
\hline mRNA & messenger Ribonucleic acid \\
\hline $\mathrm{MeCP} 2$ & Human Methyl CpG binding protein 2 \\
\hline MECP2 & Human Methyl CpG binding protein 2 gene \\
\hline Mecp2 & Mouse Methyl CpG binding protein 2 \\
\hline Mecp 2 & Mouse Methyl CpG binding protein 2 \\
\hline $\mathrm{mg}$ & milligram \\
\hline $\mathrm{ml}$ & millileter \\
\hline$\mu 1$ & microliter \\
\hline$\mu \mathrm{m}$ & micrometer \\
\hline $\min$ & minute \\
\hline $\mathrm{NaAc}$ & Sodium acetate \\
\hline NBT & Nitro-blue tetrazolium \\
\hline NCBI & National Center for Biotechnology Information \\
\hline $\mathrm{Neo}$ & Neomycin \\
\hline ng & nanogram \\
\hline NLS & Nuclear localisation sequence \\
\hline OD & Optimal density \\
\hline ORF & Open Reading Frame \\
\hline PAGE & Polyacrylamide Gel Electrophoresis \\
\hline PCR & Polymerase chain reaction \\
\hline $\mathrm{pH}$ & Prepondirance of hydrogen ions \\
\hline pmol & picomol \\
\hline PBS & Phosphatebuffersaline \\
\hline
\end{tabular}




$\begin{array}{ll}\text { PBT } & \text { Phosphatebuffersaline }+ \text { Tween } 20 \\ \text { PMSF } & \text { Phenylmethylsulfonyl fuoride } \\ \text { RNA } & \text { Ribonucleic acid } \\ \text { Rnase } & \text { Ribonuclease } \\ \text { Rnasin } & \text { Ribonuclease inhibitor } \\ \text { rpm } & \text { revolution per minute } \\ \text { RT } & \text { Room temperature } \\ \text { RTT } & \text { Rett Syndrome } \\ \text { RT-PCR } & \text { Reverse transcriptase-PCR } \\ \text { SDS } & \text { Sodium Dodecylsulfate } \\ \text { SDS-PAGE } & \text { SDS-Polyacrylamide Gel Electrophoresis } \\ \text { sec } & \text { second } \\ \text { Taq } & \text { Thermus aquaticus } \\ \text { TBE } & \text { Tris-Borate-EDTA-Electrophoresis buffer } \\ \text { TE } & \text { Tris-EDTA buffer } \\ \text { TEMED } & \text { Tetramethylethylene diamine } \\ \text { Tris } & \text { Trihydroxymethylaminomethane } \\ \text { U } & \text { Unit } \\ \text { UV } & \text { Ultra violet } \\ \text { V } & \text { Voltage } \\ \text { WT } & \text { Wild type } \\ & \end{array}$

\section{Symbols of nucleic acid}
A
Adenosine
C Cytidine
G Gaunosine
T Tymidine
U Uridine 


\section{Introduction}

\subsection{DNA methylation and neuron gene regulation}

A chromatin (DNA-protein complex) while acting as an organization of several billion bases of genomic DNA, can also function in the regulation of gene transcription. Chromatin participation in gene regulation is based on physical and chemical adaptations in the vicinity of regulatory DNA sequences (Sharma et al., 2005). The mechanism of regulation is determined by covalent modifications of cytosine bases in DNA and amino acid residues in histone protein tails. So, there is a molecular link between DNA methylation and chromatin remodeling. Activation or repression of gene transcription is correlated with the acetylation status of nucleosomal histone proteins (Neely and Workman, 2002; Neely MD and 2002)).

DNA methylation at the 5' position of cytosine within CpG dinucleotides has been shown in mammals to be essential for several functions, such as cell differentiation, imprinting, $\mathrm{X}$-chromosomal inactivation and repression of transposable elements (Wolffe et al., 1999). These covalent modifications, along with their attendant enzymes and cognate regulatory proteins, are broadly classified under the general term "epigenetic mechanisms".

Some of neurodevelopmental syndromes have been incontrovertibly linked to pathological modifications of epigenetic events, e.g., Rett syndrome, with multiple mutations in the methylated $\mathrm{CpG}$ binding protein, MeCP2 (Amir et al., 1999). Interestingly, it is reported that postmitotic neurons (but not mitotic oligodendrocytes or astrocytes) are especially rich in the prototypic DNA methylating enzyme DNMT1 (DNA methyltransferase 1) (Inano et al., 2000; Veldic et al., 2004). DNA methylation is now considered vital for successful brain development and neuronal maturation (Fan et al., 2001). Proteins with a methyl-CpG-binding domain (MBD) can bind to single methylated CpGs and most of them are involved in transcription control, of which MeCP2 is an archetype. 
The enzymes that perform histone acetylation (histone acetyltransferase, HAT) or histone deacetylation (Histone deacetylases, HDACs) are usually associated with large multiprotein complexes. HDACs are key enzymes in the modification of chromatin structure. The binding of MeCP2 to methylated DNA sites in gene promoters initiates a series of events, including recruitment of HDACs (HDAC1 and HDAC2), deacetylation of histone protein tails and chromatin condensation around the gene promoter, causing transcriptional repression (Fig. 1).

\section{Direct interference with transcription activator factor binding}

a. Active transcription

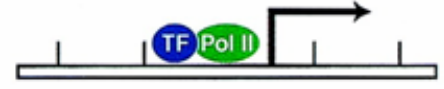

b. Repression by inhibition of TF binding

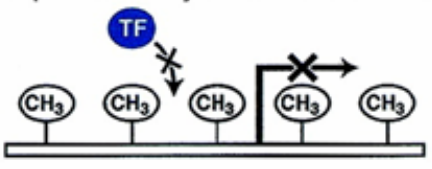

Examples: Methylation sensitive TF: $A P-2, E 2 F, N F k B$ Methylation insensitive TF: $S p 1$

\section{Inactive chromatin structure formation}

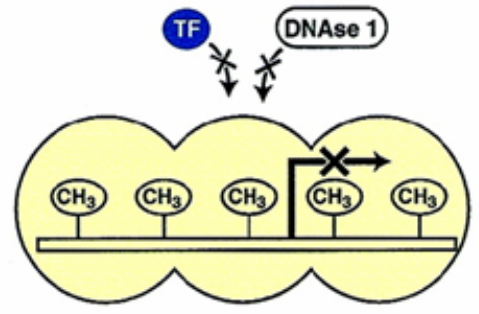

2. Specific transcriptional repressors

a. Active transcription

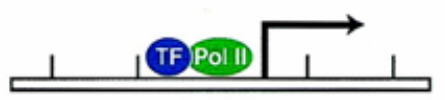

b. Repression by MeCP-1

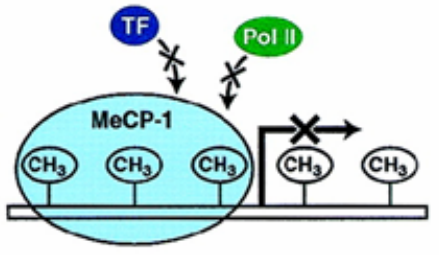

c. Repression by MeCP-2

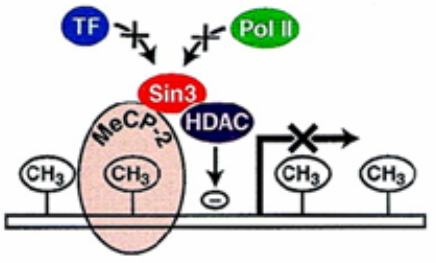

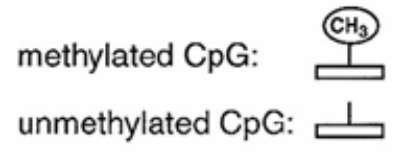

Fig. 1 DNA methylation and transcription repression: The relation between DNA methylation and transcription repression has been depicted in the picture. DNA methylation per se represses the gene expression in some cases (1). Specific transcriptional repressors like methyl $\mathrm{CpG}$ binding proteins, MeCP1 and $\mathrm{MeCP} 2$ binds to methylated DNA sites in gene promoters (2). MeCP2 which can bind specifically even to a single Methyl-CpG pair (and not influenced by sequences flanking the Methyl-CpGs) initiates a series of events, including recruitment of HDACs and other corepressors like Sin3A, deacetylation of histone protein tails and represses the transcription. Chromatin condensation around the gene promoter causes 
transcriptional repression and also protects the DNA (3). TF: Transcription factor, polII: RNA polymerase II, $\mathrm{CH}_{3}$ : Methyl group in the cytosine base at $\mathrm{CpG}$ sites.

\subsection{Rett syndrome}

Rett syndrome is a progressive neurodevelopmental disorder found to be caused by mutations in a protein involved in regulation of gene expression through its interaction with methylated DNA. Rett syndrome (RS or RTT) was discovered by Andreas Rett, when he noticed that two girls who were waiting for his consultation presented the same hand stereotypical movement disorder. Hand stereotypies are one of the characteristic features of RTT and they emerge when purposeful hand use is lost (Rett, 1966). In fact, the first description of two girls with RTT by the pediatrician Andreas Rett was overlooked until Hagberg and colleagues reported (in English, instead of German, as Rett did in 1966) on 35 patients with this distinctive disorder. Rett syndrome is one of the leading causes of mental retardation and developmental regression in girls. The affected children show an early period of normal development until 6-18 months of life and a period of temporary stagnation or regression follows during which the child loses communication and motor skills, and develop respiratory irregularities. The characteristic features of the disease include stereotyped hand movements, gait disturbances, and slowing of the rate of head growth. Social behavior becomes impaired and many girls develop seizures and anxiety (Hagberg et al., 1983).

\subsubsection{MECP2 gene}

Rett syndrome was first described by Amir et al in 1999 that it is caused by mutations in the X-linked dominant $M E C P 2$ gene. More than $80 \%$ of patients with Rett syndrome carry a mutation in the $M E C P 2$ (Hoffbuhr et al., 2002). The estimated prevalence rate of the disease ranges from 1:10,000 to 22,000 (Percy, 2002). Most RTT patients are heterozygous for mutations in the MECP2 gene (Amir et al., 2000). For a long time it was thought to be an X-linked dominant condition lethal in hemizygous males. But since the discovery of the MECP2 gene as the cause of Rett syndrome in 1999, MECP2 mutations have also been reported in males. These males phenotypically have classical Rett syndrome when the mutation arises as somatic mosaicism or when they have an 
extra X chromosome (Moog et al., 2003). In male germ line MECP2 mutations, the type and location of mutation dramatically affect the phenotype. For example severe inactivating mutations cause neonatal encephalopathy (Wan et al., 1999) and these patients rarely live beyond 2 years (Kriaucionis and Bird, 2003). But hypomorphic alleles yield X-linked mental retardation with or without psychosis (Laccone et al., 2002; Meloni et al., 2000). In females, favorable patterns of X-chromosome inactivation (XCI) can alleviate the effects of a particular mutation; the spectrum of phenotypes can thus vary from classic Rett syndrome to milder forms of mental retardation (Couvert et al., 2001) or autism (Carney et al., 2003) and in rare instances, carrier females can be completely asymptomatic owing to heavily skewed XCI (Wan et al., 1999). Molecular diagnostics have proven that variant clinical forms of Rett syndrome also exist (Percy and Lane, 2004).

Disease causing mutations vary from substitutions of conserved residues to deletions and insertions that cause frame shift mutations in MECP2 (Bienvenu et al., 2000; Laccone et al., 2004; Schollen et al., 2003). To date more than 500 different mutations in the MECP2 gene have been identified in patients with RTT (Fig. 2).

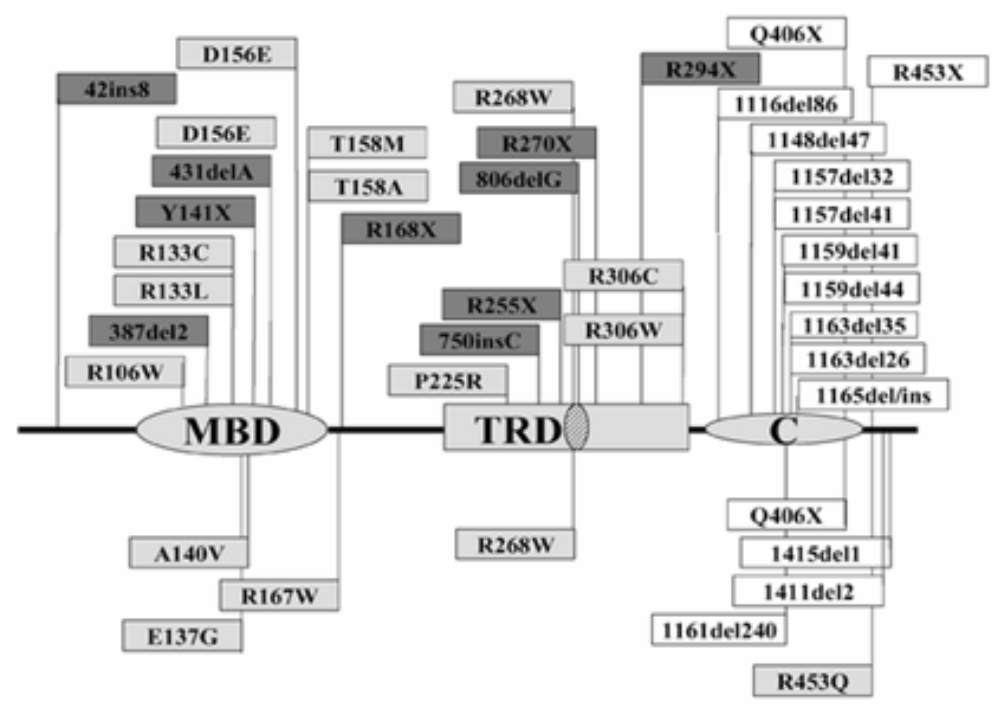

Fig. 2 MeCP2 and location of mutations causing Rett syndrome: Mutations displayed on the top causes Rett syndrome and on the bottom are found in X-linked mental retardations (XLMR). Striped circle: 
Nuclear localization signal (NLS), Gray flags: Early truncating (more severe) mutations, White flags: Latetruncating (less severe) mutations, Light gray flags: Missense mutations, MBD: Methyl binding domain, TRD: transcription repression domain, C: C-terminal domain (for stability of the protein structure). (Renieri et al, 2003).

Some investigators have found a significant genotype-phenotype correlation between MECP2 mutation type and clinical features of Rett syndrome depending on the classification and presence of mutations throughout the MeCP2 protein domains. Most of these mutations are predicted to cause either total or partial loss of function (Yusufzai and Wolffe, 2000). Recent findings demonstrate that, in humans, not only impaired or abolished gene function but also increased MeCP2 dosage causes a distinct phenotype. Moreover, duplication of the $M E C P 2$ region occurs frequently in male patients with a severe form of mental retardation in contrast to a variant form or asymptomatic form of the disorder in females which may be attributed to skewed X inactivation (Ariani et al., 2004). This justifies quantitative screening of MECP2 in Rett patients (Van Esch et al., 2005). It is interesting that, despite the many different mutations and the broad expression of $M E C P 2$, dysfunction of this protein consistently results in a primarily neurological phenotype.

\subsection{Gene structure of $M E C P 2$}

The Mecp 2 gene was first identified in mouse in 1992 by the group of Adrian Bird (Lewis et al., 1992). The human gene MECP2 is positioned in Xq28 and was cloned in 1996 (D'Esposito et al., 1996). It spans $76 \mathrm{~Kb}$ of genomic DNA between the genes coding for the interleukin receptor associated kinase (IRAK1) and a color vision gene (RCP, Red coloured pigment gene). It is composed of 4 exons which are transcribed from telomere to centromere. The open reading frame has a size of 1461 nucleotides and encodes 486 amino acids of MeCP2 protein. It is ubiquitously expressed (Reichwald et al., 2000) and is subject to X-chromosome inactivation. In early 2005, an alternative form of the $\mathrm{MeCP} 2$ protein was described. The new open reading frame initiates transcription in exon 1 and does not contain exon 2. The resulting protein has a different size (498 amino acids instead of 486) and has a different N-terminus (21 amino acids) (Mnatzakanian et al., 2004). Generally, six different transcripts exist (1.8, 7.5 and $10 \mathrm{~kb}$ ) 
and they are generated by the use of three different polyadenylation signals in the 3 ' untranslated region (UTR). The functional studies that were conducted in mouse have lead to important findings concerning the presence of these three polyadenylation signals. The developmental profile of Mecp2 mRNA highlights a potential tissue specific function of the 3'UTR in the regulation of Mecp2 protein synthesis in response to the age specific requirement of Mecp2 function during the life of the mouse (Pelka et al., 2005) (Fig. 3a and Fig. 3b).

(a)

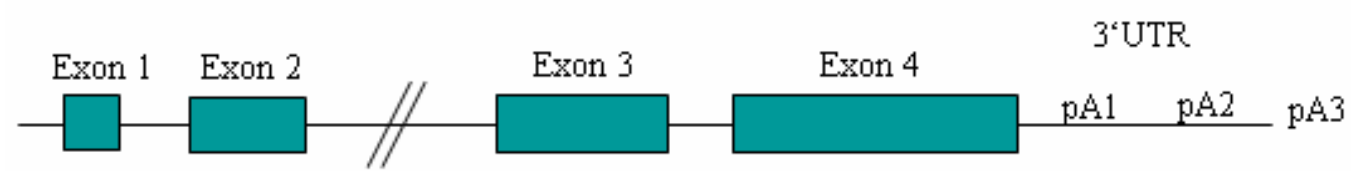

(b)

\section{MeCP2e2}

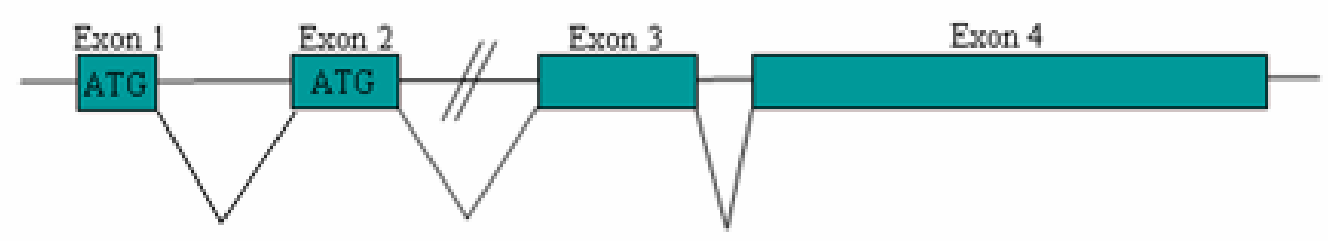

Exon 1 Exon 2 Exon $3 \quad$ Exon 4

\section{MeCP2e1}
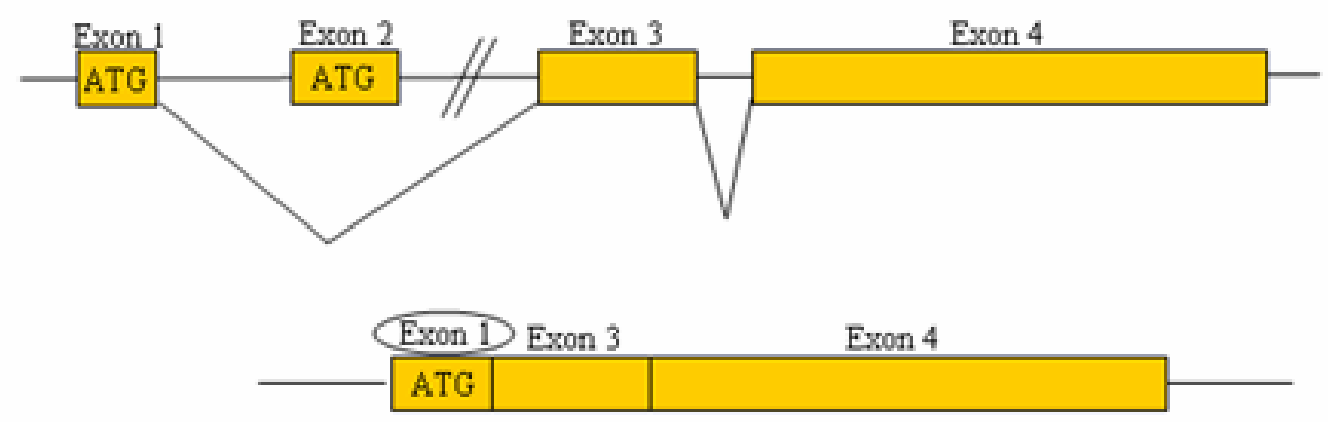

Fig. 3 Gene structure of MECP2: The $M E C P 2$ gene with its 4 exons and the three polyadenylation sites pA1, pA2 and pA3 are pictorially represented (a). The two MeCP2 isoforms with and without exon 2 out of 
alternative splicing between exon 1 and 2, are labeled MeCP2e2 and MeCP2e1, respectively (b). MECP2 thus potentially produces 6 different transcripts.

\subsection{Function of MeCP2}

$\mathrm{MeCP} 2$ is a nuclear protein that binds to methylated DNA. MeCP2 protein (Methyl-CpG binding protein 2), is thought to recruit co-repressor and histone deacetylase complexes to repress gene expression through chromatin modification (Free et al., 2001; Jones et al., 1998; Nan et al., 1998). Mutation in MeCP2 leads to the failure of this mechanism to turn genes off appropriately and may have implications for a wide range of disorders especially neurological disorders. Although MeCP2 is found in most tissues and cell types, highest expression levels are detected in the brain, where it is primarily present in neurons but not in glia (Akbarian et al., 2001; Coy et al., 1999).

In mouse, Mecp2 protein localizes to highly methylated pericentromeric heterochromatin (Shahbazian et al., 2002b). The timing of Mecp2 expression correlates with the maturation of the Central Nervous System (CNS) (Mullaney et al., 2004) and recent reports suggest that $\mathrm{MeCP} 2$ may be involved in the formation of synaptic contacts (Cohen et al., 2003). Although biochemical evidence suggests that MeCP2 acts as a global silencer, transcriptional profiling has failed to detect global changes in gene expression (Tudor et al., 2002). A candidate approach has identified BDNF, a gene involved in neuronal survival, development, and plasticity, as a target for MeCP2 (Chen et al., 2003). MeCP2 may function as a key regulator of activity-dependent neuronal gene expression. These findings are consistent with $\mathrm{MeCP} 2$ playing a role in the maintenance and modulation of neuronal maturity because the onset of Rett syndrome is after neurogenesis, neuronal migration and maturation has occurred. The disorder might affect synaptic maturation, connectivity, or stabilization.

\subsection{Mouse models for Rett syndrome}

To elucidate the mechanisms of the disease by which a dysfunction of MeCP2 causes a very restricted neurological phenotype, several animal models have been generated. Mecp2-null mice and conditional mouse mutants with selective loss of Mecp2 in the 
brain, develop clinical manifestations similar to RTT (Chen et al., 2001; Guy et al., 2001). In a conditional mutant, the Mecp2 gene was deleted early in neurons whereas in the other one, the Mecp2 gene was deleted only in post mitotic differentiated neurons. The phenotype was similar except for a later age onset in the mice carrying a deletion of Mecp2 in post mitotic neurons. These findings indicate that Mecp2 is exclusively required for central nervous system function and suggest that the phenotype is not due to disruption of early brain development.

Recently, Luikenhuis et al, 2004, developed MeCP2 transgenic mice in which they targeted the MeCP2 cDNA into the Tau locus, creating a fusion protein with the first exon of Tau. Although they reported some neurological dysfunction in their homozygous mice, additional studies are required to determine whether the reported dysfunction is due to the excess MeCP2, lack of Tau in the background of excess MeCP2 or a combination of both. Development and characterization of PAC transgenic mice with the human genomic fragment, yielded surprising information about the levels of MeCP2 for neuronal plasticity and function (Collins et al., 2004) but the regulation of the expression of the human genomic fragment in a mouse is yet doubted.

While in vitro and some in vivo studies have shown MeCP2 to be a transcriptional repressor (Nan et al., 1998), the functions in the central nervous system (CNS) remain unclear. Microarray studies using mRNAs from MeCP2 loss of function mice brain tissues as a whole, have detected only minor changes in gene expression (Tudor et al., 2002). Recently, analysis of neuronal cultures from MeCP2 null mice revealed that $\mathrm{MeCP} 2$ binds to regulatory elements of the brain-derived neurotrophic factor promoter and affects its expression (Chen et al., 2003; Martinowich et al., 2003).

But till now there is no study to isolate only the Mecp2 expressing (Mecp2+) cells for transcriptomics analysis. The drawback of using a whole tissue for the comparative expression analysis of a differentially expressed gene within and among the different cell types of the tissue like Mecp2 gene would be overcome by separating out the Mecp2+ cells for the study. Furthermore no reports regarding the comprehensive characterization 
of the Mecp2 expressing (Mecp2+) cells have been made. Hence, we aimed to produce transgenic mouse models expressing mouse Mecp2 tagged with EGFP as a reporter to further characterize the function of Mecp2 protein. The transgenic constructs have been generated by engineering a BAC clone (B22804) containing the entire Mecp 2 gene of the mouse and flanking sequences in a genomic fragment by GET recombination.

Accordingly, our mouse model could be exploited,

a) To isolate the Mecp2+ cells by EGFP Fluorescence Activated Cell Sorting (FACS) for the transcriptomics approach.

b) For differential counting of Mecp2+ cell types, for example, the percentage of different neurotransmitter systems expressing Mecp2 throughout the mouse development which would help to reveal the specific role of Mecp2 in RTT.

c) With the feasibility of live cell imaging, the subcellular distribution of Mecp2 especially in CNS could be elucidated.

d) To compare the size of the specific neurons expressing the Mecp2 marked with EGFP between the wildtype and mutant mouse models.

\subsection{Objectives}

Our aim was to obtain an appropriate functional analysis of Mecp2 by two different transgenic mouse models. First mouse model overexpressed the wild-type Mecp2 labeled at C-terminus with EGFP. The second transgenic model overexpresses an early truncated Mecp2 protein (human mutation truncating the protein after 270 aminoacids), lacking the nuclear localization signal, also labeled at the C-terminus with the EGFP. The investigation of the transgenic mouse lines will not only allow the spatio-temporal analysis of the Mecp2 by tracing the EGFP protein, a detailed functional analysis of Mecp2 could also be accomplished. Furthermore, the mutant transgenic mouse model would help to understand the pathogenesis of Rett syndrome. 


\section{Materials and Methods}

\subsection{Materials}

\subsubsection{Laboratory equipments}

Unless indicated the companies or the distributors were located in Germany.

Cell culture flasks

Culture slides

Dialysis hoses

Disposable filter Minisart

Filter paper 0858

HPTLC Aluminum folio

Hybond $\mathrm{C}+$ (optimized for protein transfer)

Hybond N

Microcentrifuge tubes

Petri dishes

Pipette tips

Roti-plast paraffin

Superfrost slides

Transfection flask

Whatman blotting paper

(GB 002, GB 003 and GB 004)

X-ray films

\subsubsection{Chemicals and reagents}

Acetic acid

Acrylamide

Agar

Agarose

Alkaline phosphatase

Ammonium persulfate
Greiner, Nürtingen

BD bioscience, Heidelberg

Serva, Heidelberg

NMI Sartorius, Göttingen

Schleicher and Schüll, Dassel

Merck, Darmstadt

Amersham, Braunschweig

Amersham, Braunschweig

Eppendorf, Hamburg

Greiner, Nürtingen

Eppendorf, Hamburg

Roth, Karlsruhe

Menzel, Gläser

Lab-Tek/Nalge, USA

Schleicher and Schüll, Dassel

Amersham, Braunschweig

Merck, Darmstadt

Serva, Heidelberg

Roth, Karlsruhe

Roth, Karlsruhe

Boehringer, Mannheim

Sigma, Deisenhofen 
Ampicillin

Ampuwa

L-Arabinose

Bacto-tryptone

Bacto-yeast extract

BCIP

Benzonase

bFGF

Bisacrylamide

Bromophenol blue

Cell culture media

Chloroform

Coomasie G-250

D-Desthobiotin

Dextran sulfate

Diethyl pyrocarbonate (DEPC)

Dimethyl sulfoxid (DMSO)

dNTPs (100 mM)

DNA/RNALadder

DPBS

Dye Terminator Mix

Ethanol

Ethidium bromide

FKS

Formaldehyde

Formamide

Glycerol

Genejuice transfection reagent

HABA (2-[4'-hydroxy-benzene azo]benzoic acid)

HEPES

Hygromycin B
Sigma, Deisenhofen

FreseniusAG, Bad Homburg

Sigma, Deisenhofen

Difco, USA

Difco, USA

Boehringer, Mannheim

Merck, Darmstadt

Sigma, Deisenhofen

Serva, Heidelberg

Sigma, Deisenhofen

Invitrogen, Karlsruhe,

Baker, Deventer, NL

Sigma, Deisenhofen

IBA, Goettingen

Amersham, Braunschweig

Sigma, Deisenhofen

Merck, Darmstadt

TaKaRa, Japan

Gibco/BRL, Karlsruhe

PAN Biotech, Aidenbach

Amersham, Braunschweig

Baker, Deventer, NL

Sigma, Deisenhofen

PAN biotech, Aidenbach

Roth, Karlsruhe

Fluka, Neu Ulm

Roth, Karlsruhe

Novagen, Darmstadt

Sigma, Deisenhofen

Merck, Darmstadt

Calbiochem, USA 


\section{IPTG}

Isoamyl alcohol

Kanamycin

Klenow DNA Polymerase

Leupetin

Lysozyme

Meat extract

$\mathrm{Na}_{2} \mathrm{HPO}_{4}$

$\mathrm{NaCl}$

$\mathrm{NaH}_{2} \mathrm{PO}_{4}$

$\mathrm{NaN}_{3}$

$\mathrm{NaOH}$

NBT

Orange-G

Papain

Pepton

Phenol

PMSF (Phenylmethylsulfonylfluoride)

Protease cocktail

Protein marker

RNase away

RNase Inhibitor

RNA length standard

RNA reagent

Radioactive substances:

$\left[\gamma^{32} \mathrm{PP}\right]-\mathrm{ATP}\left[\alpha^{32} \mathrm{PP}\right]-\mathrm{dCTP}$

Rediprime $^{\mathrm{TM}}$ II

Salmon sperm DNA

Sodium Dodecyl Sulfate (SDS)

ß-Mercaptoethanol

TEMED
Biomol, Hamburg

Fluka, Neu Ulm

Sigma, Deisenhofen

Amersham, Braunschweig

Sigma, Deisenhofen

Sigma, Deisenhofen

Merck, Darmstadt

Merck, Darmstadt

Merck, Darmstadt

Merck, Darmstadt

Merck, Darmstadt

Merck, Darmstadt

Boehringer, Mannheim

Sigma, Deisenhofen

Sigma, Deisenhofen

Roth, Karlsruhe

Roth, Karlsruhe

Sigma, Deisenhofen

Sigma, Deisenhofen

Biorad, München

Biomol, Hamburg

Invitrogen, Eggenstein

Invitrogen, Eggenstein

Biomol, Hamburg

Amersham, Braunschweig

Amersham, Braunschweig

Sigma, Deisenhofen

Serva, Heidelberg

Serva, Heidelberg

Serva, Heidelberg 
Tris

Triton X-100

Tween 20

Urea

Vectashield with DAPI

X-Gal

Xylene cyanol

Xylol

\subsubsection{Solutions and buffers}

\subsubsection{Agarose gel electrophoresis}

TBE Buffer (5X)

Glycerol loading buffer - I

Glycerol loading buffer - II

MOPS Buffer (10X)
Sigma, Deisenhofen

Serva, Heidelberg

Fluka, Neu Ulm

ICN, USA

Vector, Burfingame

Biomol, Hamburg

Bio-Rad, München

Merck, Darmstadt

$225 \mathrm{mM}$ Tris $\mathrm{pH} 8.3$

$225 \mathrm{mM}$ Boric acid

$10 \mathrm{mM}$ EDTA

$10 \mathrm{mM}$ Tris/ $\mathrm{HCl}(\mathrm{pH} 7.5)$

$10 \mathrm{mM}$ EDTA (pH 8)

0.025\% Bromophenol blue

$0.025 \%$ Xylenecyanol

$30 \%$ Glycerol

$10 \mathrm{mM}$ Tris/ $\mathrm{HCl}(\mathrm{pH} 7.5)$

10 mM EDTA (pH 8)

$0.025 \%$ Orange G

$30 \%$ Glycerol

41.8 gms MOPS

$16.6 \mathrm{ml}$ 3.0 M Sodiumacetate

$20.0 \mathrm{ml} 0.5 \mathrm{M}$ EDTA

in 1 litre of DEPC Water

Adjust $\mathrm{pH}$ to 6.75 


\subsubsection{SDS-PAGE (SDS-Polyacrylamide Gel Electrophoresis)}

$40 \%$ Acrylamide stock solution

Acrylamide $29.2 \%(\mathrm{w} / \mathrm{w})$

Bis-acrylamide $0.8 \%(\mathrm{w} / \mathrm{w})$

$10 \%$ Ammonium persulfate in $\mathrm{H}_{2} \mathrm{O}$

SDS loading buffer (4X)

$1 \mathrm{M}$ Tris-cl pH-6.8

$2 \% \mathrm{SDS}$

$0.02 \%$ bromophenol blue

$5 \mathrm{mM}$ beta-2-mercaptoethanol

$5 \%$ glycerol

Running buffer (5X)

$25 \mathrm{mM}$ Tris/HCl (pH 8.3)

$192 \mathrm{mM}$ glycine

$0.1 \%$ SDS

Stacking gel buffer (4X)

$0.5 \mathrm{M}$ Tris $/ \mathrm{HCl}(\mathrm{pH} 6.8)$

$0.4 \%$ SDS

Resolving gel buffer (4X)

1.5 M Tris/ $\mathrm{HCl}(\mathrm{pH} 8.3)$

$0.4 \%$ SDS

\subsubsection{Other frequently used buffers and solutions}

AP buffer

100 mM Tris- $\mathrm{HCl}(\mathrm{pH} 9.5)$

$100 \mathrm{mM} \mathrm{NaCl}$

$50 \mathrm{mM} \mathrm{MgCl} 2$

Blocking solution (immunostaining)

$60 \mu \mathrm{l}$ of horse serum,

$150 \mu 1$ of $10 \%$ Triton X-100

$2790 \mu \mathrm{l}$ PBS 
Bouin's solution

Carrier DNA

Denaturation solution

Depurination solution

PBS buffer

HBS

IPTG

PBT buffer

NBT - Solution
15 volume of picric acid (in $\mathrm{H}_{2} \mathrm{O}$ )

5 volume $37 \%$ formaldehyde

1 volume acetic acid

sonicated salmon sperm DNA, $5 \mathrm{mg} / \mathrm{ml}$

$1.5 \mathrm{M} \mathrm{NaCl}$

$0.5 \mathrm{M} \mathrm{NaOH}$

$0.25 \mathrm{M} \mathrm{HCl}$

$130 \mathrm{mM} \mathrm{NaCl}$

$7 \mathrm{mM} \mathrm{Na}_{2} \mathrm{HPO}_{4}$

$4 \mathrm{mM} \mathrm{NaH}_{2} \mathrm{PO}_{4}$

10mM HEPES

$145 \mathrm{mM} \mathrm{NaCl}$

$22 \mathrm{mM} \mathrm{KCl}$

$5 \mathrm{mM}$ glucose

pH- 7.3

Filter sterilize and store at $4{ }^{\circ} \mathrm{C}$

$0.1 \mathrm{M}$ in ddH2O

Filter sterilize and store at $4{ }^{\circ} \mathrm{C}$

$0.1 \%$ Tween-20 in PBS (1X)

$75 \mathrm{mg} / \mathrm{ml} \mathrm{NBT}$

$70 \%$ Dimethyl formamide 
BCIP - Solution

Protein extraction buffer for animal tissue

Bacterial lysis buffer $100 \mathrm{mM}$ Tris-Cl

Mammalian cells lysis buffer

Semidry transfer buffer (1X)
$50 \mathrm{mg} / \mathrm{ml} \mathrm{BCIP}$

70\% Dimethyl formamide

62mM Tris-cl pH 6.8

$2 \% \operatorname{SDS}$

$5 \mathrm{mM} \beta$-2-Mercaptoethanol

$0.15 \mathrm{mM} \mathrm{NaCl}$

$5 \mathrm{X}$ protease inhibitor cocktail

$500 \mathrm{mM} \mathrm{NaCl}$

$0.5 \mathrm{mM}$ EDTA

$0.1 \% \mathrm{v} / \mathrm{v}$ Triton $\mathrm{X}-100$

$0.1 \% \mathrm{v} / \mathrm{v}$ Tween-20

$8 \%$ glycerol

$250 \mathrm{mM}$ Urea

$5 \mathrm{mM} \beta$-2-Mercaptoethanol

$100 \mu \mathrm{g} / \mathrm{ml}$ PMSF

$1 \mu \mathrm{l} / \mathrm{ml}$ Protease inhibitor cocktail

$50 \mu \mathrm{g} / \mathrm{ml}$ Lysozyme

1 Unit / ml Benzonase

$125 \mathrm{mM}$ Tris-Cl pH 6.8

$2 \% \mathrm{SDS}$

$50 \mathrm{mM} \mathrm{NaH} 2 \mathrm{PO} 4$

$20 \%$ glycerol

$1 \mathrm{mM}$ DTT

$1 \mathrm{mM}$ PMSF

$25 \mathrm{mM}$ Tris $\mathrm{pH} 8.3$

150 mM Glycine

$10 \%$ Methanol 
SSC (20X)

$3 \mathrm{M} \mathrm{NaCl}$

$0.3 \mathrm{M} \mathrm{Na}_{3}$ citrate $(\mathrm{pH} 7.0)$

TE - buffer

$10 \mathrm{mM}$ Tris/ $\mathrm{HCl}(\mathrm{pH} \mathrm{8.0)}$

$1 \mathrm{mM}$ EDTA

Washing solution - I

2x SSC

$0.1 \%$ SDS

Washing solution - II

$0.2 \times \mathrm{SSC}$

\subsubsection{Sterilization of solutions and equipments}

All solutions that are not heat sensitive were sterilised at $121^{\circ} \mathrm{C}, 10^{5} \mathrm{~Pa}$ for $30 \mathrm{~min}$ in an autoclave (Webeco, Bad Schwartau). Heat sensitive solutions were filtered through a disposable sterile filter ( 0.2 to $0.45 \mu \mathrm{m}$ pore size). Plasticwares were autoclaved as above. Glasswares were sterilised overnight in an oven at $220^{\circ} \mathrm{C}$.

\subsubsection{Antibiotics, media, and agar-plates}

\subsubsection{Antibiotics}

Master solution $\quad$ Final concentration

Ampicillin

Chloromphenicol

Kanamycin

Neomycin (G418)

Penicillin

Streptomycin
$50 \mathrm{mg} / \mathrm{ml} \mathrm{H} 2 \mathrm{O}$

$30 \mathrm{mg} / \mathrm{ml}$ Ethanol

$50 \mathrm{mg} / \mathrm{ml} \mathrm{H}_{2} \mathrm{O}$

$100 \mathrm{mg} / \mathrm{ml}$ PBS

$0.1 \mathrm{mg} / \mathrm{ml} \mathrm{PBS}$

$0.1 \mathrm{mg} / \mathrm{ml}$ PBS
$50 \mu \mathrm{g} / \mathrm{ml}$

$30 \mu \mathrm{g} / \mathrm{ml}$

$50 \mu \mathrm{g} / \mathrm{ml}$

$400 \mu \mathrm{g} / \mathrm{ml}$

$10 \mu \mathrm{g} / \mathrm{ml}$

$10 \mu \mathrm{g} / \mathrm{ml}$

Stock solutions were prepared for the antibiotics. The solutions were then filtered through sterile disposable filters and stored at $-20^{\circ} \mathrm{C}$. 


\subsubsection{Media for bacteria}

LB medium ( $\mathrm{pH} 7.2)$ :

$$
\begin{aligned}
& 1 \% \text { Bacto-Tryptone } \\
& 0.5 \% \text { Yeast extracts } \\
& 1 \% \mathrm{NaCl}
\end{aligned}
$$

LB agar:

$$
\begin{aligned}
& 1 \% \text { Bacto-Tryptone } \\
& 0.5 \% \text { Yeast extracts } \\
& 1 \% \mathrm{NaCl} \\
& \text { pH } 7.2 \\
& 1.5 \% \text { Agar }
\end{aligned}
$$

The LB medium was prepared with distilled water, autoclaved and stored at $4^{\circ} \mathrm{C}$.

IPTG / X-Gal plate:

$$
\begin{aligned}
& \text { LB-agar with } \\
& 50 \mu \mathrm{g} / \mathrm{ml} \text { ampicillin } \\
& 100 \mu \mathrm{M} \text { IPTG } \\
& 0.4 \% \text { X-Gal }
\end{aligned}
$$

All other antibiotic plates were prepared similarly. After solidification, the petri dishes with LB agar medium were stored at $4^{\circ} \mathrm{C}$.

Media for protein production

$$
\begin{aligned}
& 1 \% \text { Bacto-tryptone } \\
& 0.5 \% \text { Yeast extracts } \\
& 1 \% \mathrm{NaCl} \\
& 0.25 \% \text { Meat extract }
\end{aligned}
$$




\subsubsection{Media for cell culture}

NS20Y

DMEM

$10 \%$ FKS

$1 \%$ non-essential amino acids

$2 \mathrm{ml}$ penicillin $(100 \mathrm{U} / \mathrm{ml})$

streptomycin $(100 \mu \mathrm{g} / \mathrm{ml})$

HeLa

MEM-alpha

$10 \%$ FKS

$2 \mathrm{ml}$ penicillin $(100 \mathrm{U} / \mathrm{ml})$

streptomycin $(100 \mu \mathrm{g} / \mathrm{ml})$

2 mM L-glutamate

\section{Mouse primary neurons}

- Plating media

DMEM

$10 \%$ FKS

10\% F-12 (Invitrogen)

$2 \mathrm{ml}$ penicillin $(100 \mathrm{U} / \mathrm{ml})$

streptomycin $(100 \mu \mathrm{g} / \mathrm{ml})$

- Feeding media

B-27 media (Invitrogen)

2 mM L-glutamine

$2 \mathrm{ml}$ penicillin $(100 \mathrm{U} / \mathrm{ml})$

streptomycin $(100 \mu \mathrm{g} / \mathrm{ml})$

$20 \mathrm{ng} / \mathrm{ml} \mathrm{bFGF}$

\subsubsection{Bacterial strains}

E. coli XL-1 Blue

Stratagene, USA

E. coli $\mathrm{DH} 5 \alpha$

Invitrogen, Karlsruhe

E. coli $\mathrm{DH} 10 \mathrm{~B}$

Invitrogen, Karlsruhe

E. coli Rosetta-2 DE3

Novagen, Darmstadt 


\subsubsection{Eukaryotic strains}

HeLa: Human Negroid cervix epitheloid carcinoma, obtained from ATCC, USA NS20Y: $\quad$ Mouse neuroblastoma

\subsubsection{Plasmids}

pBluesript SK (+/-)

pGEM-T Easy

Stratagene, USA

pUC19

Promega, USA

pEGFP-1

Fermentas, USA

pEGFP-C1

Clontech, USA

pTriEX-1.1 Neo

Clontech, USA

pET $28 \mathrm{a}+$

Novagen, Darmstadt

Novagen, Darmstadt

\subsubsection{Synthetic oligonucleotides}

The synthetic oligonucleotide primers were ordered from Eurogentec (Köln), Invitrogen (Karlsruhe), IBA (Goettingen), Biomers and Roth (Karlsruhe).

T3

T7

SP6

T3 - New

T7 - New

SP6 - New

GAPDH_F

GAPDH_R
5’>ATTAACCCTTCACTAAAG $<3$ '

5'>TAATACGACTCACTATAGGG $<3$ ',

5'>AGGTGACACTATAGAATAC $<3$ '

5'>TTAACCCTCACTAAAGGGAACAAAAGC $<3$ '

5'>AATACGACTCACTATAGGGCGAATTGG $<3$ '

5'>TTAGGTGACACTATAGAATACTCAAGC $<3$ '

5'> TGCCATCAATGACCCCTTCATTGACC $<3$ '

5'>GGACTCATGACCACAGTCCATGCCAT<3'

Primers used for the Mecp2 expression analysis and other studies

Mecp2_Mus_RT_For 5'>CTGTAGACCAGCTCCAACAGGATTCC $<3$ '

Mecp2_RT_EX1_Maus_F 5'>GGAGGAGGCGAGGAGGAGAGACT<3' 


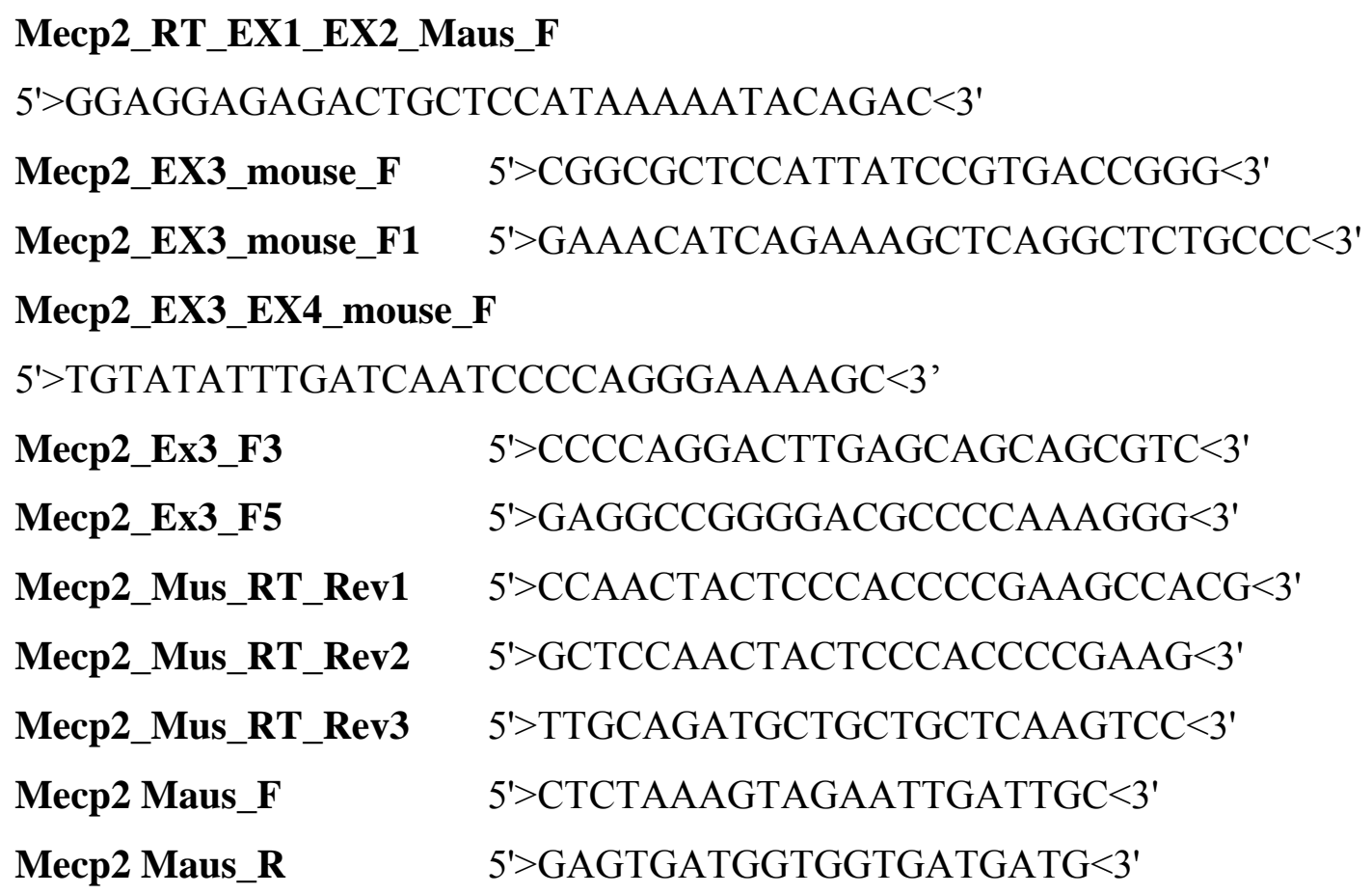

Primers for amplifying and sequencing $M E C P 2$ intron 1:

MeCP2_IVSI_amp_F1: 5'>CGCTTATTGCAGCGCACTCGGTGC $<3^{\prime}$

MeCP2_IVSI_amp_R1: 5'>GAATGGGCGAGAAGGAGGGGGAGG $<3$ '

MeCP2_IVSI_amp_F1_S1: 5'>GGCCGCGGGCGGGGACCCTTGC $<3$ '

MeCP2_IVSI_amp_R1_S1: 5'>GAAGAGGGGCGTCAGGCGAAGG $<3$ '

MeCP2_IVSI_amp_F2: $\quad$ 5'>CCTCTCCCTGGATCGCGCTCTCCCC $<3^{\prime}$

MeCP2_IVSI_amp_R2: 5'>GAGCTTTTTCCCCCTCGGGGTCCATAC $<3^{\prime}$

MeCP2_IVSI_amp_F2_S1: 5'>GGAGCCGTGGGTAGGGGACTGTG $<3$ '

MeCP2_IVSI_amp_R2_S1: 5'>CGCGATGAACTTGCCCCATCTGG $<3$ '

MeCP2_IVSI_amp_F3: 5'>CCAGATGGGGCAAGTTCATCGCGAC $<3^{\prime}$

MeCP2_IVSI_amp_R3:

5'>GCCCATAAAAGCCTATTTCCCTAAATCCTTGG $<3$ '

Primers for creating EGFP Kan/Neo cassette for the recombination in making 'Mecp2_WT_EGFP' transgenic construct:

Mecp2_EGFP_F20

5'>CCGTGACCGAGAGAGTTAGCATGGTGAGCAAGGGCGAGGA<3' 


\section{Mecp2Kan_R20}

5'>TCTGGTGGCTTGTGGGACAGTTTATTCTGTCTTTTTATTGCCG<3'

Mecp2_Famp_60

5'>CCAAGGCCAAACAGAGAGGAGCCTGTGGACAGCCGGACGCCCGTGACCG

AGAGAGTTAGC $<3$

Mecp2_Ramp_60

5'>CAGGTATATACAGATACAGGTAGTTCTGAACACTGCCATGTCTGGTGGCTT

GTGGGACAG $<3^{\prime}$

Mecp2_check_F1

5'> TGGCTTCTGAGCAAGCTGTA $<3$ '

EGFP_Rev1

5'>CCGTTTACGTCGCCGTCCAGC $<3$ '

Kan_check_F3

5'>CGAAATGACCGACCAAGCGACGC $<3$ '

Mecp2_check_R1

5'>GGTTAGGGAGGGCTCAAAAG $<3$ '

Ctrl Mecp2_F1

5'>TCCAGTTTGTTCCTTGTTCACTTA <3'

Ctrl Mecp2_R1

5'>AGCTTCAGCTTTTCGCTTTCTG<3'

Primers for creating EGFP Kan/Neo cassette for the recombination in making 'Mecp2_270_EGFP' transgenic construct:

\section{Mecp2_270_EGFP}

5'>GGCCATTCCTAAGAAACGGGGTGGTATGGTGAGCAAGGGCGAGGA

GCTG $<3^{\prime}$

\section{Mecp2_270_amp}

5'>CCCAGGTCATGGTGATCAAACGCCCTGGCAGAAAGCGAAAAGCTGAAGCG ACCCCCAGGCCATTCCTAAGAAACGGGGT <3'

Primers for creating EGFP Kan/Neo cassette for the recombination in making 'Mecp2 400 EGFP' transgenic construct:

Mecp2_400_EGFP

5'>CTCTGAGGACCCCATCAGCCCCGGCGGTATGGTGAGCAAGGGCGAGGA GCTG $<3^{\prime}$ 


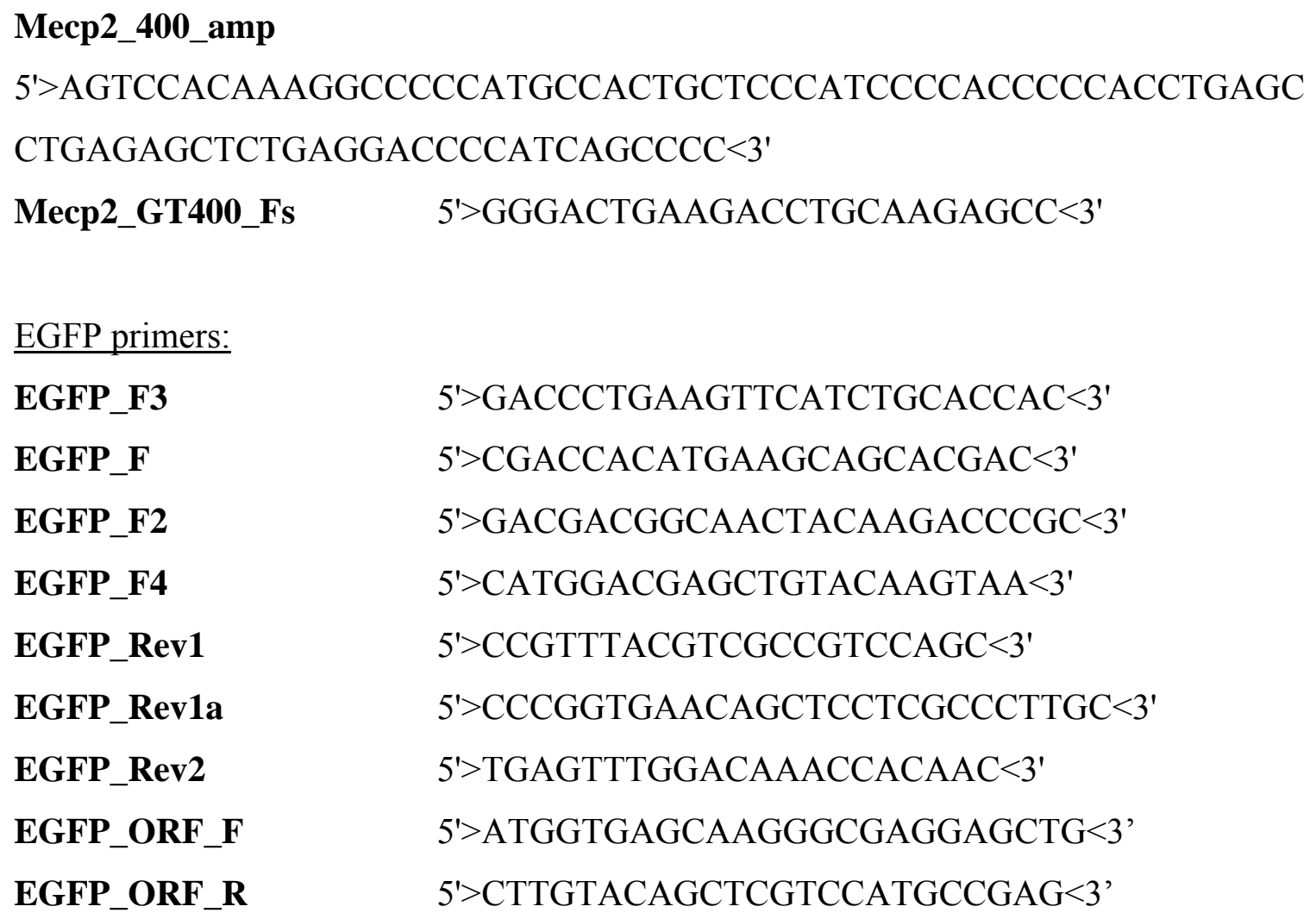

GET recombination primers employed in the modification of the transgenic constructs by deleting the $O p \sin 1$ gene on the 5' side:

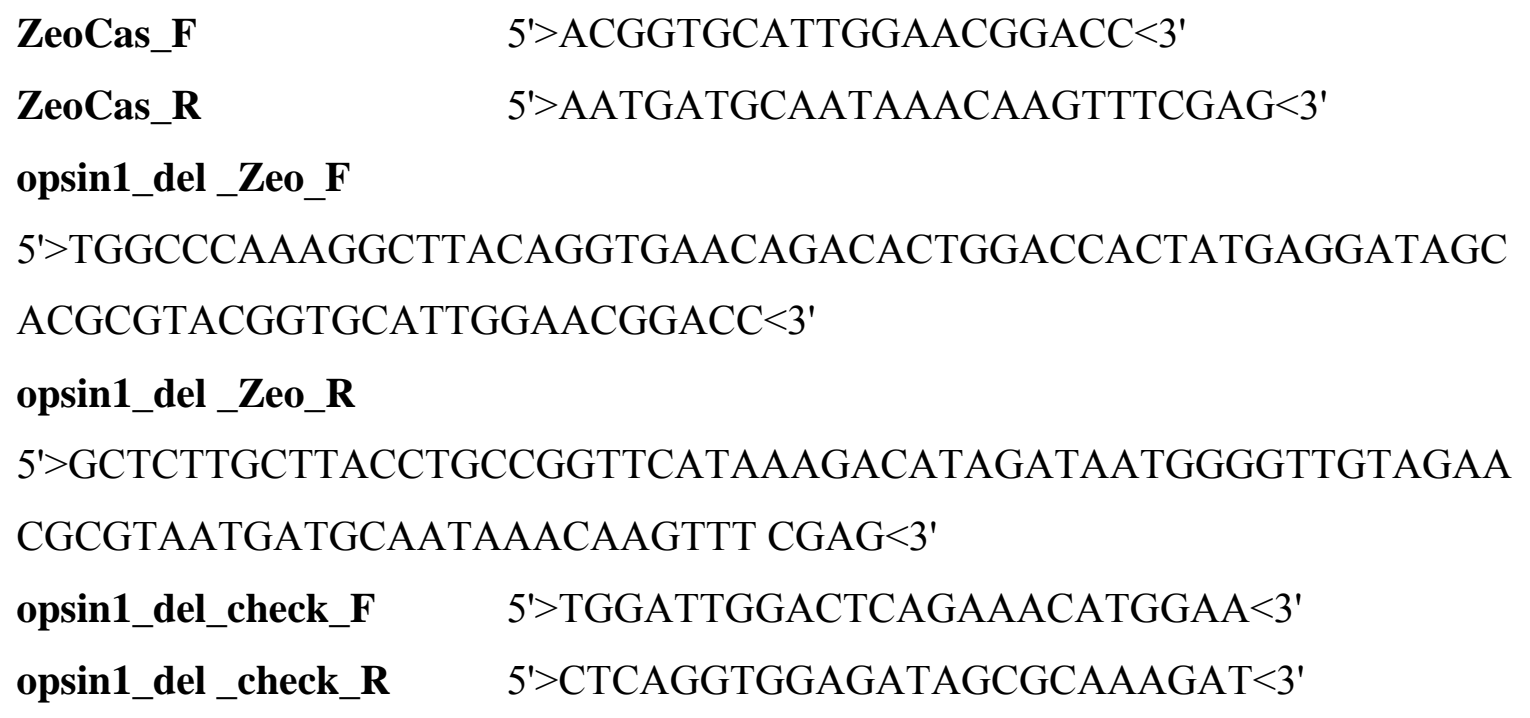


GET recombination primers employed in the modification of the transgenic constructs by deleting the Irakl gene on the 3' side:

Irak1_del_Zeo F

5'>ACCACAGACCTCGGTTCTCCCATTAGGGACTCCCTCCTACGTAGCAGAGCG GCGCGCCCGGTGCATTGGAACGGACC <3'

Irak1_del_Zeo R

5'>AGACAAATAAGGACTGATAGATTGTCTTCCAGGTGTCTACCCCAATGTTAG GCGCGCCAATGATGCAATAAACAAGTTTCGAG<3'

Irak1_del_chk F 5'>ACCAGGCTTGGCATAAACTG<3'

Irak1_del_chk R 5'>GAGGCTGGAGACTGCAGAAG $<3^{\prime}$

Primers to create external probe for the southern blotting:

$\begin{array}{ll}\text { Bac Mecp2 ext_5_F } & \text { 5'>GGCAAGCTTTGCAACTATGTGCC }<3^{\prime} \\ \text { Bac Mecp2 ext_5_R } & \text { 5'>CTCTGTTCTGTTGCTCATTCTTCCCC }<3^{\prime}\end{array}$

pET vector primers:

pET 28_F - New

5'>CGAAATTAATACGACTCACTATAGG $<3$ '

pET 28_R - New 5'>ATGCTAGTTATTGCTCAGCGG<3'

Add-on mutagenesis primers for incorporating c.C473T mutation (p.T158M) (Mecp2e2 isoform) in the BAC clone B22804 by recombination with 'EM7-Zeo rpsL' cassette towards creating a knockin construct:

473m_EM7_F

5'>GATTTTGACTTCATGGTAACTGGGAGAGGGAGCCACGGTGCATTGGAACG

GACCGTG<3'

473m_RPSL_R

5'>GGGCTTCTTAGGTGGTTTCTGCTCTCTCTTAAGCCTTAGGACGCTTCACG

CCAT $<3^{\prime}$

Mecp2_Mouse_473m_F

5'>CTTTTCGCTCTAAAGTAGAATTGATTGCATACTTTGAAAAGGTGGGAGACA CCTCCTTGGACCCTAATGATTTTGACTTCATGGTAACTGGGAGAGGGAGCC<3' 
473m_AMP_R

5'>GTGCCGCTCCCTTTGGGGCGTCCCCGACCCCTGCCAGTTCCTGGAGCTTTG

GGAGATTTGGGCTTCTTAGGTGGTTTCTGCTCTCTC<3'

Mecp2_Mouse_473m_F

5'>CTTTTCGCTCTAAAGTAGAATTGATTGCATACTTTGAAAAGGTGGGAGACA CCTCCTTGGACCCTAATGATTTTGACTTCATGGTAACTGGGAGAGGGAGCC<3'

Mecp2_Mouse_473m_R

5'>GGGGCGTCCCCGACCCCTGCCAGTTCCTGGAGCTTTGGGAGATTTGGGCTT

CTTAGGTGGTTTCTGCTCTCTCCTGGAGGGGCTCCСTCTCCCAGTTACCA<3'

473m_oli_Extn_F1

5'>CTACAGTCCCCAGGGAAAAGCTTTTCGCTCTAAAGTAGAATTGATTGC<3'

473m_oli_Extn_R1

5'>CTCCCAGTGCCGCTCCCTTTGGGGCGTCCCCGACCCCTGCCA<3'

Check_473m_F

Check_473m_R

Check_473m_F2

Check_473m_R2

New_check_473m_F2

New_check_473m_R2
5'>CCGGCAGGTCCTCTGTTTTCAGATCC $<3$ '

5'>CACCTGAACACCTTCTGATGCTGCTGC $<3$ '

5'>CCCACCTTTTCAAAGTATGCAATCA $<3$ '

5'>ACTTTGAAAAGGTGGGAGACACCTC $<3 '$

5'>TAGAACAAGAAGGCCAGGTGGGTA<3'

5'>CTTCACCACTTCCTTGACCTCGAT $<3$ '

Add-on mutagenesis primers for incorporating c.C473T mutation (p.T158M) (Mecp2e2 isoform) in the BAC clone B22804 by recombination with thy $A$ cassette towards creating a knockin construct:

473m_thyA_F1

5'>GATTTTGACTTCATGGTAACTGGGAGAGGGAGCCGCTGCTGCTGGAAGGT GTGGT<3'

473m_thyA_R3

5'>GGGCTTCTTAGGTGGTTTCTGCTCTCTCGGGTAAAAAAACCGACGC ACAC $<3^{\prime}$

\section{BspeI_thyA_F1}

5'>CCCCCCTCCGGATAAGTGAGCTGCTGCTGGAAGGTGTGGT<>3' 


\section{HindIII_thyA_R3}

5'>GGGGGAAGCTTAAGGGTAAAAAAACCGACGCACAC<3'

Mecp2_thyA_R3

5'>GGGAAGCTTTGTCAGAGCCCTACCCATAAGGAGAAGAGACAACAGCTGCC TTTATTCTTGTTGGTTTGCTTTGCAATCCGCTCCGTGTAAAGTTAAGGGTAAA AAAACCGACGCACAC $<3$ '

$$
\begin{array}{ll}
\text { thyA_Int_oli_R1 } & 5^{\prime}>\text { ATGGGAGCTGTCTCAGGTTTGTTC }<3^{\prime} \\
\text { thyA_Int_oli_R2 } & 5^{\prime}>\text { GAAAACAATGTCACCATCTGGGAC }<3^{\prime} \\
\text { thyA_Int_oli_R3 } & 5^{\prime}>\text { AAACTCATCTGCAATTAAGCCGCG }<3^{\prime}
\end{array}
$$

Add-on mutagenesis primers for incorporating c.C473T mutation (p.T158M) (Mecp2e2 isoform) in the BAC clone B22804 by recombination with 'L-Arabinose promoter ccdB killer gene EM7-Zeo' strategy towards creating a knockin construct:

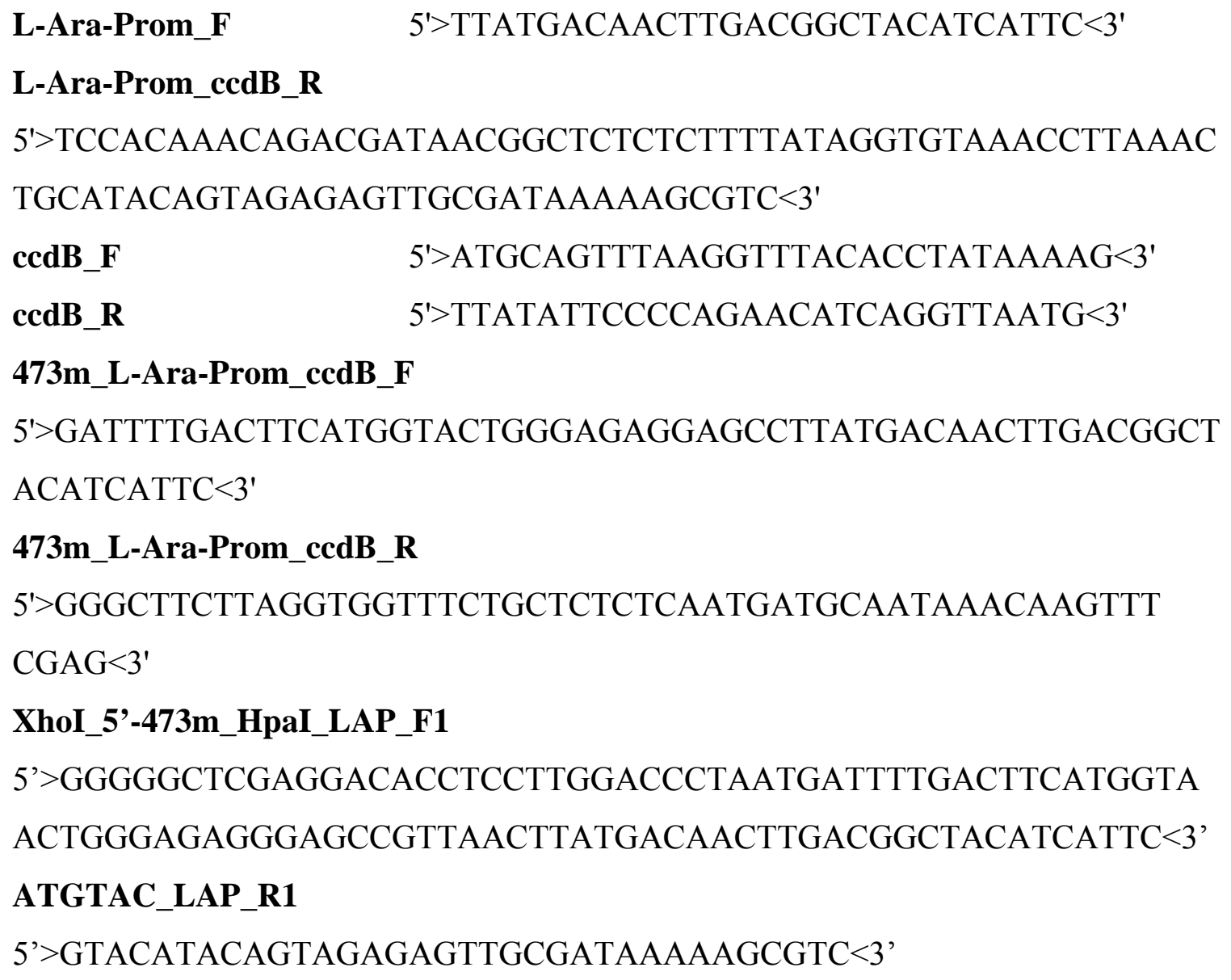




\section{XbaI_3'_SacII_Zeo R1}

5’>CCCCCTCTAGACCAGTTCCTGGAGCTTTGGGAGATTTGGGCTTCTTAGGTG GTTTCTGCTCTCTCCCGCGGTGCAATAAACAAGTTTCGAGGTCGAGTGT<3'

Add-on mutagenesis primers for incorporating c.C473T mutation (p.T158M) (Mecp2e2 isoform) in the BAC clone B22804 by recombination with MluI EM7-Zeo MluI cassette towards creating a knockin construct:

$$
\begin{array}{ll}
\text { EM7-Zeo_R } & \text { 5'>TCAGTCCTGCTCCTCGGCCACGAA }<3 ' \\
\text { EM7-Zeo_F } & \text { 5'>TGTTGACAATTAATCATCGGCATA }<3 '
\end{array}
$$

\section{3m_R}

5'> TCCTGGAGCTTTGGGAGATTTGGGCTTCTTAGGTGGTTTCTGCTCTCTCCTG GAGGGGCTCCCTCTCCCAGTTACCATGAAGTCAAAATCATTAGGGTCC<3'

473m_F

473m_extn_R

473m_extn_F
5'>GTCAGCATATTTTCTATCTCAGTCTC $<3$ '

5'>CGTTTGATCACCATGACCTGGGCA<3'

5'>CCCAAATCTCCCAAAGCTCCAGGA $<3$ '

EM7-Zeo_MluI_473m_R

5'>GAGACTGAGATAGAAAATATGCTGACAAGCTTTCTTCTAAGACATTGTAA GTGAACAAGGAACAAACTGGACGCGTTCAGTCCTGCTCCTCGGCCACGAA<3'

EM7-Zeo_MluI_473m_F

5'>TTTTCAGATCCAGCTGTTTTGGCTTCTGAGCAAGCTGTAACATGGTTTCTAC CCATGCATCTGGCCCGGTACGCGTTGTTGACAATTAATCATCGGCATA<3'

Primers to create loxP neo loxP cassette to be recombined in the Intron 2 of Mecp2 gene in BAC clone B22804 towards creating a knockin construct:

\section{SpeI_lox_neo_F}

5'>CCCCCCACTAGTATAACTTCGTATAGCATACATTATACGAAGTTATTGCGC CGCTACAGGGCGCGTCAGG $<3$ '

\section{EcoRI_lox_neo_R}

5'>GGGGGGGAATTCATAACTTCGTATAATGTATGCTATACGAAGTTATGGAC CGAACCCCGCGTTTATGAACA $<3$ '

NEO_seq_F1 5'>CATGCATCTCAATTAGTCAGCA $<3$ ' 


\begin{tabular}{|c|c|}
\hline NEO_seq_F2 & $5^{\prime}>$ CTGTCCGGTGCCCTGAATGAAC $<3^{\prime}$ \\
\hline NEO_seq_F3 & 5'>ACGGCGAGGATCTCGTCGTGACC<3' \\
\hline NEO_seq_R1 & 5'>CTTTCATAGAAGGCGGCGGTGG $<3^{\prime}$ \\
\hline NEO_seq_R2 & $5^{\prime}>$ CGAGTACGTGCTCGCTCGATGC $<3 '$ \\
\hline NEO_seq_R3 & 5'>CTGGGCGGAGTTAGGGGCGGGA<3' \\
\hline \multicolumn{2}{|l|}{ SacII_BAC_5_F } \\
\hline \multicolumn{2}{|c|}{ 5'>CCCCCCCGCGGGTGGTAAAGACCCATGTGACCCAAG<3' } \\
\hline \multicolumn{2}{|l|}{ SpeI_BAC_5_R } \\
\hline \multicolumn{2}{|c|}{ 5'>CCCCCCACTAGTCATCCCAACAGCAGCTAATCTCATCCC $<3^{\prime}$} \\
\hline \multicolumn{2}{|l|}{ EcoRI_BAC_3_F } \\
\hline \multicolumn{2}{|c|}{ 5'>CCCCGAATTCCGGAGGCTGGAACGAAGGCTCACAAG<3' } \\
\hline \multicolumn{2}{|l|}{ XhoI_BAC_3_R } \\
\hline \multicolumn{2}{|c|}{ 5'>CCCCCCCTCGAGTGGCCCCCTGGGCTTGCCACATG<3' } \\
\hline BAC_Neo_Chk_F & $5^{\prime}>$ GGCAGGTGTCCTTGGATATGGTAGTTGC $<3^{\prime}$ \\
\hline BAC_Neo_Chk_R & 5'> GACCCCTGGCTGCTGCATACTATCTCTG $<3^{\prime}$ \\
\hline
\end{tabular}

$\underline{\text { RFP (Red fluorescent protein) primers: }}$

$\begin{array}{ll}\text { RFP_F } & \text { 5'>ATGGTGCGCTCCTCCAAGAACGTC }<3^{\prime} \\ \text { RFP_R } & \text { 5' }^{\prime}>\text { CAGGAACAGGTGGTGGCGGCCCTC }<3^{\prime}\end{array}$

Rett mouse (Mecp2 knockout mouse) genotyping primers:

$\begin{array}{ll}\text { oIMR1436 } & 5^{\prime}>\text { GGTAAAGACCCATGTGACCC }<3 ' \\ \text { oIMR1437 } & 5^{\prime}>\text { TCCACCTAGCCTGCCTGTAC }<3^{\prime} \\ \text { oIMR1438 } & 5^{\prime}>\text { GGCTTGCCACATGACAA }<3^{\prime}\end{array}$

GEMSA primers used for synthesizing the consensus probes:
Ch_19_p1_Unmeth_F1 5'>GGTTGGAGGGTTGGGGAGTTAGTGTG $<3$ '
Ch_19_p1_Unmeth_R1 5'>CATAATCTACTCTTAACCCCACCTCAAAACA $<3$ '
Ch_19_p1_Meth_F1 5'>GTTTTTTATTTTGTTTATTGGGGTGGGGCG $<3^{\prime}$ 


\section{Ch_19_p1_Meth_R1 \\ 5'> GAAACGAAAACGAAACCGAAACGAAACG $<3$ ' \\ Ch_19_p1_Com_F1 \\ 5'>GGGGTTGGAGGGTTGGGGAGTTAG<3' \\ Ch_19_p1_Com_R1 \\ 5'>CCTCAACCCTCCACCCTACTCACTAAAAT $<3 '$}

\subsubsection{Mouse strains}

Mouse strains B6.129P2(C)-Mecp $2^{\text {tm 1.1Bird } / \mathrm{J}}$ were purchased from, The Jacksons Laboratories, USA and they were bred at the animal facility of the Institute of Human Genetics, Göttingen. Also the C57B16/N, FVB/N, CD_1 strains of mouse were used from the animal facility of the Institute of Human Genetics, Göttingen.

\subsubsection{Enzymes}

Phi29 DNA polymerase

Alkaline phosphatase

DNase

Klenow Fragment

Papain

Pfu Ultra Taq DNA polymerase

Proteinase K

Restriction enzymes (with supplied buffers)

RNase A

RNase inhibitor

Superscript-II

T4 DNA ligase

T4 polynucleotide Kinase

Taq polymerase

Trypsin

\subsubsection{Antibodies}

Anti-tubulin (Mouse monoclonal)

Anti-MeCP2 (Rabbit Polyclonal)

Anti-MeCP2 (Mouse monoclonal)
NEB, USA

Roche, Mannheim

Qiagen, Hilden

Invitrogen, Karlsruhe

Sigma, Deisenhofen

Stratagene, USA

Sigma, Deisenhofen

NEB, USA

Qiagen, Hilden

Invitrogen, Karlsruhe

Invitrogen Karlsruhe

Invitrogen, Karlsruhe

NEB, USA

Qiagen, Hilden

Invitrogen, Karlsruhe
Upstate, USA

Sigma, Deisenhofen 
Anti-MeCP2 polyclonal serum

Eurogentec, Köln

(raised in Rabbit with the recombinant MeCP2e2)

Anti-EGFP (Mouse monoclonal)

Sigma, Deisenhofen

Anti-EGFP (Rabbit polyclonal)

Abcam, USA

Anti-acetylated histone $\mathrm{H} 3$ (Ac H3)

Upstate, USA

Anti-acetylated histone H4 (Ac H4)

Upstate, USA

Secondary antibodies raised in goat for anti-rabbit and anti-mouse IgGs, which were conjugated to alkaline phosphatase and FITC were purchased from Sigma, Deisenhofen.

\subsubsection{Kits}

BAC DNA isolation kit

GenomiPhi DNA amplification kit

Gel shift assay system

CelLytic $^{\mathrm{TM}} \mathrm{NuCLEAR}^{\mathrm{TM}}$ Extraction Kit

Dye Terminator Cycle Sequencing-Kit

DYEnamic ET-Terminator mix

(for DNA sequencing)

Maxi Plasmid Kit

Megaprime DNA Labelling Kit

Montage PCR clean-up columns

QIAquick Gel Extraction Kit

RNA Easy Kit

Rediprime $^{\mathrm{TM}}$ II Random Prime Labeling System
Qiagen, Hilden

Amersham, Braunschweig

Promega, USA

Sigma, Deisenhofen

Applied Biosystem, USA

Amersham, Braunschweig

Qiagen, Hilden

Amersham, Braunschweig

Millipore, USA

Qiagen, Hilden

Qiagen, Hilden

Amersham, Braunschweig

\subsubsection{Instruments}

ABI 3100 Genetic Analyzer

ABI PRISM 377 DNA Sequencer

Autoclave

Centrifuge 5415 D

Centrifuge $5417 \mathrm{R}$

Biophotometer
Applied Biosystem, USA

Applied Biosystem, USA

Webeco, Bad Schwartau

Eppendorf, Hamburg

Eppendorf, Hamburg

Eppendorf, Hamburg 
Cryostat $^{\mathrm{TM}}$

GeneAmp PCR System 9600

Inverted Microscope IX81

Microscope BX60

Megafuge 1.0 R

Neubauer cell chamber

Pipette

Semi-Dry-Blot Fast Blot

TCS SP2 AOBS laser scanning microscope

Thermomixer 5436

Turboblotter $^{\mathrm{TM}}$

UV Stratalinker $^{\mathrm{TM}} 1800$

X-Ray Automatic Processor Curix 60
Leica, Solms

Perkin Elmer, USA

Olympus, Hamburg

Olympus, Hamburg

Heraeus, Hanau

Schütt Labortechnik, Göttingen

Eppendorf, Hamburg

Biometra, Göttingen

Leica, Solms

Eppendorf, Hamburg

Schleicher and Schüll, Dassel

Leica, Bensheim

Agfa, Köln

\subsection{Methods}

\subsubsection{Isolation of nucleic acids}

\subsubsection{Isolation of plasmid DNA}

\subsubsection{Small-scale isolation of plasmid DNA (Mini preparation)}

A single Escherichia coli colony was inoculated in $5 \mathrm{ml}$ of LB medium with the appropriate antibiotic and incubated in a shaker for $16 \mathrm{hrs}$ at $37^{\circ} \mathrm{C}$ with a speed of $160 \mathrm{rpm}$. One $\mathrm{ml}$ of this saturated culture was used for making glycerol stock and rest of the culture was centrifuged at 5000xg for $15 \mathrm{~min}$. Bacterial glycerol stocks were made suspending $500 \mu \mathrm{l}$ bacteria in $300 \mu \mathrm{l} 80 \%$ (v/v) sterile glycerol. The suspension was mixed well and stored at $-80^{\circ} \mathrm{C}$. The pellet was resuspended in $100 \mu$ of solution P1. The bacterial cells were lysed with $200 \mu$ of P2 solution and then neutralised with $150 \mu 1$ of solution P3. The precipitated solution was incubated on ice for $15 \mathrm{~min}$, and centrifuged at $13000 \mathrm{xg}$ at $4^{\circ} \mathrm{C}$. The supernatant was transferred into a new tube and centrifuged again for $10 \mathrm{~min}$ at $13000 \mathrm{xg}$. To the supernatant $1 \mathrm{ml}$ of $100 \%$ ethanol was added to precipitate the DNA. It was then stored on ice for $15 \mathrm{~min}$, centrifuged at full speed for $20 \mathrm{~min}$, and 
finally the pellet was washed with 70\% ethanol and after air dried and dissolved in $30 \mu \mathrm{l}$ of TE buffer.

P1: $\quad 50 \mathrm{mM}$ Tris-Cl, $\mathrm{pH} 8.0$

10 mM EDTA

$100 \mu \mathrm{g} / \mathrm{ml}$ RNase A

P2: $\quad 200 \mathrm{mM} \mathrm{NaOH,}$ $1 \%$ SDS

P3: $\quad 3.0 \mathrm{M}$ Potassium acetate, $\mathrm{pH} 5.5$

\subsection{Large-scale preparation of plasmid DNA (Midi preparation using Qiagen buffers and columns)}

A single clone was inoculated in $2 \mathrm{ml} \mathrm{LB}$ medium with appropriate antibiotic as a preculture for $8 \mathrm{hrs}$ in $37^{\circ} \mathrm{C}$ shaker. This preculture was added in $100 \mathrm{ml} \mathrm{LB}$ medium with appropriate antibiotic at a dilution of $1 / 100$ fold and incubated overnight at $37^{\circ} \mathrm{C}$ with shaking. The saturated culture was centrifuged at $6000 \mathrm{xg}$ for $15 \mathrm{~min}$. The pellet was resuspended in $5 \mathrm{ml}$ of solution P1 and cells were lysed with P2 and P3 as described above. The precipitated solution was centrifuged at $20000 \mathrm{xg}$ for $30 \mathrm{~min}$ at $4{ }^{\circ} \mathrm{C}$. The provided column (Qiagen, Hilden) was equilibrated with $10 \mathrm{ml}$ of QBT solution. After centrifugation, the lysate was poured into this equilibrated column to allow the DNA to bind with the resin present in the bed of the column. The column was then washed twice with $10 \mathrm{ml}$ of solution QC. Finally, the DNA was eluted with $5 \mathrm{ml}$ of QF solution. To precipitate the DNA, $3.5 \mathrm{ml}$ of isopropanol was added to the eluent and mixed thoroughly. The mixture was then centrifuged at $14000 \mathrm{xg}$ for $30 \mathrm{~min}$ at $4^{\circ} \mathrm{C}$. The DNA pellet was washed with $70 \%$ ethanol, air dried and dissolved in $100 \mu \mathrm{l}$ of TE. The following buffer composition was used, 
QBT: $750 \mathrm{mM}$ Sodium chloride

$50 \mathrm{mM}$ MOPS pH 7.0

$15 \%$ Ethanol

$0.5 \%$ Triton $\mathrm{X}-100$

QC: $1 \mathrm{mM}$ Sodium chloride

$50 \mathrm{mM}$ MOPS pH 7.0

$15 \%$ Ethanol

QF: $\quad 1.25 \mathrm{M}$ Sodium chloride

$50 \mathrm{mM}$ Tris/ $\mathrm{HCl}$ pH 8.5

\subsubsection{Isolation of genomic DNA from tissue samples}

Lysis buffer: $100 \mathrm{mM}$ Tris/ $\mathrm{HCl}(\mathrm{pH} 8.0)$

$100 \mathrm{mM} \mathrm{NaCl}$

$100 \mathrm{mM}$ EDTA

$0.5 \%$ SDS

Routinely, $1 \mathrm{~cm}$ of the mouse tails was incubated overnight in $700 \mu \mathrm{l}$ of lysis buffer containing $35 \mu \mathrm{l}$ Proteinase $\mathrm{K}(10 \mu \mathrm{g} / \mu \mathrm{l})$ at $55^{\circ} \mathrm{C}$ for overnight in a Thermomixer 5436 . An equal volume of phenol and chloroform was added to the tissue lysate, mixed by inverting several times, and centrifuged at $8000 \mathrm{xg}$ at room temperature for $5 \mathrm{~min}$. After transferring the upper aqueous layer into a new tube, the same procedure was repeated, first with 1:1 ratio of phenol and chloroform. Finally, the DNA was precipitated with 0.7 volume of isopropanol, washed with 70\% ethanol, and dissolved in 100-200 $\mu \mathrm{l}$ of TE buffer and incubated at $60^{\circ} \mathrm{C}$ for $15 \mathrm{~min}$.

\subsubsection{Isolation of total RNA from tissue samples and cultured cells}

Total RNA isolation reagent (Biomol, Hamburg) is an improved version of the singlestep method for total RNA isolation described first by Chomczynski and Sacchi (1987). 
The composition of reagent includes phenol and guanidine thiocyanate in a monophase solution. In order to avoid any RNase activity, homogeniser used for RNA isolation was previously treated with RNase away and DEPC water and special RNase free Eppendorf cups were used during the procedure. $100 \mathrm{mg}$ tissue sample was homogenised in $1 \mathrm{ml}$ of RNA reagent by using a glass-teflon homogeniser. The sample volume should not exceed $10 \%$ of the volume of reagent used for the homogenisation. The homogenate was vortexed and incubated on ice for $5 \mathrm{~min}$ to permit the complete dissociation of nucleoprotein complexes. Then, $0.2 \mathrm{ml}$ of chloroform was added, vortexed and incubated on ice for $5 \mathrm{~min}$. After centrifuging at $8000 \mathrm{x}$ g for $15 \mathrm{~min}$ at $4^{\circ} \mathrm{C}$, the colourless upper aqueous phase was transferred into a new tube. $500 \mu \mathrm{l}$ of isopropanol was added, solution was mixed by vortexing and RNA was precipitated by centrifugation at $10000 \mathrm{x} \mathrm{g}$ for $1 \mathrm{~min}$. Finally, the pellet was washed with $75 \%$ ethanol, and dissolved in $50-100 \mu \mathrm{l}$ DEPC- $\mathrm{H}_{2} \mathrm{O}$. The RNA was stored at $-80^{\circ} \mathrm{C}$.

Total RNA from eukaryotic cells was isolated with the RNeasy Mini Kit (Qiagen, Hilden) according to the supplier's instructions. The total RNA was treated with RNasefree DNase I (Qiagen, Hilden) according to the user manual and resuspended in 80-100 $\mu \mathrm{l}$ RNase-free water. The measured concentrations varied between 0.5 to $1.0 \mu \mathrm{g}$ per $\mu \mathrm{l}$. $4 \mu \mathrm{l}$ of the RNA mixture was checked on a denaturing agarose gel to verify RNA yield and purity.

\subsubsection{Determination of the nucleic acids concentration}

The concentration of nucleic acids was determined spectrophotometrically by measuring absorption of the samples at $260 \mathrm{~nm}$ and $280 \mathrm{~nm}$. Also the quality of nucleic acids i.e. contamination with salt and proteins was checked by the measurements at 260 and $280 \mathrm{~nm}$. The concentration was calculated according to the formula:

$$
\begin{aligned}
& \mathrm{C}=(\mathrm{E} 260-\mathrm{E} 280) \times \mathrm{fc} \\
& \mathrm{C}=\text { concentration of sample }(\mu \mathrm{g} / \mu \mathrm{l}) \\
& \mathrm{E} 260=\text { ratio of extinction at } 260 \mathrm{~nm} \\
& \mathrm{E} 280=\text { ratio of extinction at } 280 \mathrm{~nm} \\
& \mathrm{f}=\text { dilution factor }
\end{aligned}
$$




$$
\begin{aligned}
& \mathrm{c}=\text { concentration (standard) / absorption (standard) } \\
& \text { for double stranded DNA : } \mathrm{c}=0.05 \mu \mathrm{g} / \mu \mathrm{l} \\
& \text { for single stranded DNA : } \mathrm{c}=0.03 \mu \mathrm{g} / \mu \mathrm{l} \\
& \text { for RNA }: \mathrm{c}=0.04 \mu \mathrm{g} / \mu \mathrm{l}
\end{aligned}
$$

\subsubsection{Gel electrophoresis}

Gel electrophoresis is the technique by which mixture of charged macromolecules, especially nucleic acids and proteins are separated in an electrical field according to their mobility which is directly proportional to macromolecule's charge to mass ratio.

\subsubsection{Agarose gel electrophoresis of DNA}

Agarose gels are used to electrophorese nucleic acid molecules from as small as 50 bases to more than 50 kilobases, depending on the concentration of the agarose and the precise nature of the applied electrical field (constant or pulse). Usually, $1 \mathrm{~g}$ of agarose was added in $100 \mathrm{ml} 0.5 \mathrm{x}$ TBE buffer, and boiled in the microwave to dissolve the agarose, then cooled down to about $60^{\circ} \mathrm{C}$ before adding $3 \mu$ ethidium bromide $(10 \mathrm{mg} / \mathrm{ml})$. This $1 \%$ agarose gel was poured onto a horizontal gel chamber.

\subsubsection{Agarose gel electrophoresis of RNA}

Single-stranded RNA molecules often have complementary regions that can form secondary structures. Therefore, RNA was run on a denaturing agarose gel that contained formaldehyde, and before loading, the RNA was pre-treated with formaldehyde and formamide to denature. $2 \mathrm{~g}$ of agarose was added to $20 \mathrm{ml}$ of 10x MOPS buffer and $148 \mathrm{ml}$ of DEPC water and dissolved by heating in microwave oven. After cooling it to about $50^{\circ} \mathrm{C}, 33.2 \mathrm{ml}$ of formaldehyde (37\%) was added, stirred and poured into a horizontal gel chamber. RNA samples were prepared as follows:

$$
\begin{aligned}
& 10-20 \mu \mathrm{g} \text { RNA } \\
& 2 \mu 110 \times \text { MOPS Buffer } \\
& 3 \mu l \text { Formaldehyde } \\
& 7 \mu l \text { Formamide }(40 \%) \\
& 1 \mu l \text { Ethidium bromide }
\end{aligned}
$$


$5 \mu$ Loading buffer

Samples were denatured at $65^{\circ} \mathrm{C}$ for $10 \mathrm{~min}$ and chilled on ice before loading into the gel. The gel was run at $30 \mathrm{~V}$ at $4^{\circ} \mathrm{C}$ overnight.

\subsubsection{DNA and RNA molecular weight ladders}

To determine the size of the nucleic acid fragments on agarose gels, molecular weight ladders were loaded in parallel.

1 kb DNA Ladder Invitrogen, Karlsruhe

100 bp DNA Ladder Invitrogen, Karlsruhe

0.24-9.5 bp RNA Ladder Invitrogen, Karlsruhe

\subsubsection{Cloning techniques}

\subsubsection{Enzymatic modifications of DNA}

\subsection{Restriction enzyme digestion of DNA}

Restriction enzymes are class of bacterial enzymes that cut DNA at specific sites. In bacteria their function is to destroy foreign DNA, such as that of bacteriophages. This attribute of restriction endonucleases is widely utilized in molecular biology. Restriction enzyme digestions were performed by incubating double-stranded DNA with an appropriate amount of restriction enzyme in its respective buffer as recommended by the supplier, and at the optimal temperature for that specific enzyme. Standard digestions include 2-10 U enzyme per microgram of DNA. These reactions were usually incubated for 1-3 hrs to ensure complete digestion at the optimal temperature for enzyme activity, which was typically $37^{\circ} \mathrm{C}$. However, for genomic DNA digestion the reaction solution was incubated overnight at $37^{\circ} \mathrm{C}$.

\subsection{Filling-up reaction}

To make blunt-end from overhang-end $0.1-4 \mu \mathrm{g}$ of digested DNA was mixed with $0.05 \mathrm{mM}$ dNTPs and 1-5 $\mathrm{U}$ of Klenow fragment with reaction buffer in a total volume of $50 \mu \mathrm{l}$. The reaction was incubated at $37^{\circ} \mathrm{C}$ for $15 \mathrm{~min}$, and then stopped by heating at $75^{\circ} \mathrm{C}$ for $10 \mathrm{~min}$. 


\subsection{Dephosphorylation of 5' ends of DNA}

To prevent the recircularization of plasmids without the insertion of foreign DNA, alkaline phosphatase treatment was performed. Alkaline phosphatase catalyses the hydrolysis of 5'-phosphate residues from DNA. The following items were mixed:

1-5 $\mu \mathrm{g}$ vector DNA,

$5 \mu 110 x$ reaction buffer,

$1 \mu \mathrm{l}$ Alkaline phosphatase (1 U)

in a total volume of $50 \mu \mathrm{l}$ and incubated at $37^{\circ} \mathrm{C}$ for $1 \mathrm{~h}$. The reaction was then stopped by heating at $85^{\circ} \mathrm{C}$ for $15 \mathrm{~min}$. The dephosphorylated DNA was purified by phenol/chloroform extraction and ethanol precipitation.

\subsection{Purification by phenol-chloroform extraction and ethanol precipitation}

Protein impurities were removed by vigorous shaking of nucleic acid solution with an equal volume of phenol-chloroform/isoamyl alcohol mixture (25:24:1). The emulsion was then centrifuged for $1 \mathrm{~min}$, at $10,000 \mathrm{xg}$ at room temperature (RT), and the upper aqueous phase was collected, mixed with an equal volume of chloroform and centrifuged (1 min, RT, 10000xg). Finally, the upper aqueous phase was collected for precipitation. Nucleic acids were precipitated by addition of $\mathrm{NaAc}$ (final conc. $0.3 \mathrm{M}$ ) and 2.6 volume of absolute ethanol. The mixture was then vortexed and centrifuged $\left(5 \mathrm{~min}, 4^{\circ} \mathrm{C}\right.$, and $10000 \mathrm{xg}$ ). The pellet was washed with $70 \%$ ethanol and centrifuged (5 min, RT, $10000 \mathrm{xg})$. After washing, the supernatant was aspirated and the pellet was air dried. The dried pellet was resuspended in sterile RNase free water or TE buffer.

\subsubsection{Isolation of DNA fragments after agarose gel electrophoresis (QIAquick Gel Extraction method)}

This method is designed to extract and purify DNA of $70 \mathrm{bp}$ to 10 kilobase pairs $(\mathrm{kb})$ in length from agarose gels. Up to $400 \mathrm{mg}$ agarose can be processed per spin column. The principle of this method depends on selective binding of DNA to uniquely designed silicagel membrane. Excised DNA fragments in agarose were isolated as described in QIAquick Spin Handbook supplied by producer (Qiagen, Hilden). 


\subsubsection{Ligation of DNA fragments}

The ligation of an insert DNA into a vector (digested with appropriate restriction enzyme) was carried out in the following reaction mix:

30 ng vector DNA (digested)

50-100 ng insert DNA (1:3, vector: insert molar ratio)

$2 \mu 1$ ligation buffer $(5 \mathrm{x})$

$1 \mu \mathrm{l} 4$ DNA ligase $(5 \mathrm{U} / \mu \mathrm{l})$

in a total volume of $10 \mu \mathrm{l}$. Blunt-end ligations were carried out at $16^{\circ} \mathrm{C}$ for overnight, whereas overhang-end ligations were carried out at $16^{\circ} \mathrm{C}$ or RT for few hrs to overnight.

\subsubsection{Polymerase Chain Reaction (PCR)}

The general principle of PCR starts from a pair of oligonucleotide primers that are designed so that a forward or sense primer directs the synthesis of DNA towards a reverse or antisense primer, and vice versa. During the PCR, the Taq DNA polymerase (heat stable polymerase) catalyses the synthesis of a new DNA strand that is complementary to a template DNA from the 5 ' to 3 ' direction by a primer extension reaction, resulting in the production of the DNA region flanked by the two primers. It allows the rapid amplification of specific nucleic acid sequences that may be present at very low concentrations in very complex mixtures.

\subsection{PCR amplification of DNA fragments}

The amplification reactions were performed in automatic thermocyclers. The PCR reaction contains in general, the following substances:

1 ng-10ng Template DNA

$1 \mu \mathrm{l}$ forward primer $(10 \mathrm{pmol} / \mu \mathrm{l})$

$1 \mu \mathrm{l}$ reverse primer $(10 \mathrm{pmol} / \mu \mathrm{l})$

$1 \mu 110 \mathrm{mM}$ dNTPs

$5 \mu 1$ 10x PCR buffer

$1.5 \mu 150 \mathrm{mM} \mathrm{MgCl} 2$

$1 \mu \mathrm{T} \mathrm{Taq}$ DNA polymerase $(5 \mathrm{U} / \mu \mathrm{l})$ 
The reaction mix was made up to $50 \mu \mathrm{dd} \mathrm{H} 20$ and placed in a $200 \mu \mathrm{l}$ reaction tube and placed in thermocycler. A standard PCR program is shown as follows:

Initial denaturation $95^{\circ} \mathrm{C}$ for $5 \mathrm{~min}$

followed by $30-35$ cycles of

$95^{\circ} \mathrm{C}$ for $30 \mathrm{sec}$ (denaturation)

$55^{\circ} \mathrm{C}-65^{\circ} \mathrm{C}$ for $40 \mathrm{sec}$ (annealing, temperature depends on primer's Tm value)

$72^{\circ} \mathrm{C}$ for (extension, time depends on the PCR product, as 1 min for $1 \mathrm{~kb}$ DNA)

and by a final extension, $72^{\circ} \mathrm{C}$ for $10 \mathrm{~min}$, and at $4{ }^{\circ} \mathrm{C}$ for infinite time till the PCR tubes were taken from the PCR machine.

The simplest formula for calculating the Tm (melting temperature) of the primers is:

$\mathrm{Tm}=4^{\circ} \mathrm{C} \mathrm{x}$ (number of G's and C's in the primer) $+2^{\circ} \mathrm{C} x$ (number of A's and T's in the primer)

\subsection{Reverse transcription PCR (RT-PCR)}

\subsection{Reverse transcription or CDNA synthesis}

One to five $\mu \mathrm{g}$ of total RNA was mixed with one $\mu \mathrm{l}$ of oligo (dT)18 primer $(10 \mathrm{pmol} / \mu \mathrm{l})$ in a total volume of $12 \mu \mathrm{l}$. To avoid the possible secondary structure of the RNA, which might interfere with the synthesis, the mixture was heated to $70^{\circ} \mathrm{C}$ for $10 \mathrm{~min}$, and then quickly chilled on ice. After a brief centrifugation, the followings components were added to the mixture:

$4 \mu 15 \mathrm{X}$ First strand buffer

$2 \mu 10.1$ M DTT

$1 \mu 10 \mathrm{mM}$ dNTPs

$1 \mu \mathrm{l}$ Rase inhibitor $(10 \mathrm{U} / \mu \mathrm{l})$

The content of the tube was mixed gently and incubated at $42^{\circ} \mathrm{C}$ for $2 \mathrm{~min}$. Then, $1 \mu \mathrm{l}$ of reverse transcriptase enzyme (Superscript II, Invitrogen) was added and further incubated at $42^{\circ} \mathrm{C}$ for $50 \mathrm{~min}$ for the first strand cDNA synthesis. Next, the reaction was inactivated by heating at $70^{\circ} \mathrm{C}$ for $15 \mathrm{~min}$. One $\mu \mathrm{l}$ of the first strand reaction was used for the further PCR reaction. 


\subsection{One step RT-PCR}

To obtain specific RT-PCR products, the QIAGEN OneStep RT-PCR kit was employed which contains optimized components that allow both reverse transcription and PCR amplification to take place in what is commonly referred to as a "one-step" reaction.

\section{Master mix per reaction:}

5 X Qiagen OneStep RT-PCR buffer $10 \mu 1$

dNTP mix (containing $10 \mathrm{mM}$ of each dNTP) $2 \mu \mathrm{l}$

Forward primer (10 pmol) $1 \mu \mathrm{l}$

Reverse primer (10 pmol) $1 \mu \mathrm{l}$

Qiagen OneStep RT-PCR Enzyme Mix $2 \mu 1$

RNase inhibitor (20 units per $1 \mu \mathrm{l}) 1 \mu \mathrm{l}$

RNase-free water $31 \mu 1$

$2 \mu \mathrm{l}(2 \mu \mathrm{g})$ of total RNA isolated from mammalian cultured cells was added to $48 \mu \mathrm{l}$ of prepared master mix in a PCR tube, the sample was then placed in the thermal cycler and the RT-PCR program was run according to the user manual. The thermal cycler conditions is as follows:

Reverse transcription: $50^{\circ} \mathrm{C}$ for $30 \mathrm{~min}$

Initial PCR activation step: $95^{\circ} \mathrm{C}$ for $15 \mathrm{~min}$

Followed by 40 cycles

Denaturation: $94^{\circ} \mathrm{C}$ for $30 \mathrm{sec}$

Annealing: $56-60^{\circ} \mathrm{C}$ (depending on primers) for $40 \mathrm{sec}$

Extension: $72^{\circ} \mathrm{C}$ for $1 \mathrm{~min}$

After the amplification, the presence of a product was checked on an agarose gel.

\subsubsection{Subcloning of PCR and RT-PCR products}

Taq and other polymerases have a terminal transferase activity that results in the nontemplate addition of a single nucleotide to the $3^{\prime}$ ends of PCR products. In the presence of all 4 dNTPs, dATP is preferentially added. This terminal transferase activity is the basis of the TA - cloning strategy. For cloning of these PCR products generated with Taq polymerase, the pGEM-T or pGEM-T Easy vector systems that has $5^{6} \mathrm{dT}$ 
overhangs were used. The blunt end ligation for the products amplified with Pfu polymerase was carried out using pBluescript (+/-) digested with EcoRV site. The following constituents were mixed:

$50 \mathrm{ng}$ of pGEM-T or pGEM-T Easy or digested pBluescript (+/-) vector

PCR product ( $1: 3$ vector to insert ratio)

$1 \mu 1$ T4 DNA Ligase 10x buffer

$1 \mu 1$ T4 DNA Ligase

in a total volume of $10 \mu \mathrm{l}$. The content was mixed by pipetting and the reaction was incubated overnight at $16^{\circ} \mathrm{C}$. For transformation of the ligation reaction, DH5 $\alpha$ or XL1Blue competent cells were used.

\subsubsection{DNA Sequencing}

The non-radioactive sequencing was achieved with Dye Terminator Cycle SequencingKit (ABI, Weiterstadt). The principle of this is based on the method described by Sanger et al, 1992. The sequencing reaction was carried in a total volume of $10 \mu 1$ containing $1 \mu \mathrm{g}$ plasmid DNA or 100-200 ng purified PCR products, 5 pmol primer and $3 \mu 1$ reaction mix (contains dNTPs, dideoxy dye terminators and Taq DNA polymerase). Elongation and chain termination take place during the following program in a thermocycler: 5 min denaturing followed by 25 cycles $95^{\circ} \mathrm{C} 30 \mathrm{sec}$, denaturing; $55^{\circ} \mathrm{C} 30 \mathrm{sec}$, annealing; $60^{\circ} \mathrm{C}$ 2 min, elongation. After the sequencing reaction, the DNA was precipitated with 1/10 volume $3 \mathrm{M} \mathrm{NaAc}$ and 2.5 volume 100\% ethanol. The pellet was dissolved in $4 \mu \mathrm{l}$ of loading buffer, denatured at $95^{\circ} \mathrm{C}$ for $3 \mathrm{~min}$ and finally loaded onto the sequence gel. The reaction products were analyzed with an automatic sequencing equipment, namely MEGA BACE 1000 (Amersham, Braunschweig). The obtained sequences were analyzed with a BLAST program (Altschul et al, 1990) by using the sequence data base Genbank (www.ncbi.nlm.nih.gov) and EMBL (www.ebi.ac.uk).

\subsubsection{Preparation of Electro-competent Escherichia coli bacteria}

The competent bacterial cells are characterized by a physical cell wall modification that facilitates DNA uptake. LB medium $(50 \mathrm{ml})$ was inoculated with a single colony of Escherichia coli (strain Rosetta DE3, DH5 $\alpha$ and XL1-Blue) and grown overnight at $37^{\circ} \mathrm{C}$ 
and the culture was diluted to 1:50 LB medium and grown at $37^{\circ} \mathrm{C}$ to $\mathrm{OD} 600=0.6$. Bacteria were centrifuged $\left(10 \mathrm{~min}, 4^{\circ} \mathrm{C}, 3000 \mathrm{xg}\right)$ and the pellet was resuspended in $50 \mathrm{ml}$ of ice cold sterile $10 \%$ glycerol $\left(4^{\circ} \mathrm{C}\right)$ and the wash was repeated 3 times in ice cold sterile $10 \%$ glycerol by centrifuging $10 \mathrm{~min}, 4^{\circ} \mathrm{C}$ and $3000 \mathrm{xg}$. The suspension of bacteria was centrifuged $\left(10 \mathrm{~min}, 4^{\circ} \mathrm{C}, 3000 \mathrm{xg}\right)$ and the pellet was resuspended in $1 \mathrm{ml}$ ice cold sterile $10 \%$ glycerol. The mixture was dispensed into aliquots of $100 \mu$, the cups were frozen quickly in liquid nitrogen and stored at $-80^{\circ}$.

\subsubsection{Electroporation of the competent bacteria}

The ligation mix and plasmid DNA was purified over the Montage (Millipore, USA) PCR cleanup column to avoid the occurrence of spark in the cuvette due to the salt concentration. Transformation of the bacteria was done by gently mixing one aliquot of competent bacteria $(100 \mu \mathrm{l})$ with $10 \mu \mathrm{l}$ of ligation reaction or $100 \mathrm{ng}$ of plasmid DNA. Bacteria were transformed through electroporation (Capacitance $25 \mu \mathrm{F}$, Volts $2.5 \mathrm{kV}$ and Resistance 200 ohms). Immediately $600 \mu \mathrm{l}$ of LB medium was added and incubated at $37^{\circ} \mathrm{C}$ in a shaker at a speed of $160 \mathrm{rpm}$ for $1 \mathrm{~h}$ to allow the recovery of bacteria from the electric shock. Bacteria were plated out on LB-agar plates containing the appropriate antibiotic $(50 \mu \mathrm{g} / \mathrm{ml})$ and whenever required, $1 \mathrm{mM}$ IPTG and X-Gal $40 \mathrm{mg} / \mathrm{ml}$ (X-Gal for "blue-white" selection).

\subsubsection{Nucleic acids blotting techniques}

\subsubsection{Southern blotting of DNA to nitrocellulose filters}

In Southern blotting, the transfer of denatured DNA from agarose gels to nitrocellulose membrane is achieved by capillary flow. 20x SSC buffer, in which nucleic acids are highly soluble, is drawn up through the gel into the nitrocellulose membrane, taking with it the single-stranded DNA that becomes immobilised in the membrane matrix. After electrophoresis of DNA, the gel was treated for $10 \mathrm{~min}$ with $0.25 \mathrm{M} \mathrm{HCl}$ for depurination. It was followed by denaturation solution for $30 \mathrm{~min}$ and $30 \mathrm{hrs}$ in neutralization solution. The transfer of the DNA to the nitrocellulose membrane was done in a Turbo-Blotapparatus (Schleicher \& Schuell, Dassel). About 24 Whatman filter papers (GB003) were layered on a Stack Tray followed by 3 Whatman filter papers 
(GB002) and 1 Whatman filter paper GB002 soaked with 2x SSC. The equilibrated nitrocellulose filter that was also soaked with 20x SSC was laid on the top. The agarose gel, which was treated as described above was placed on the filter, and was covered with 3 Whatman filter papers GB002 soaked with 20x SSC. The buffer tray was placed and filled with 20x SSC. Finally a wick, which was soaked with 20x SSC, and the wick cover were put on the top of the blot. The transfer was carried out for overnight. Finally, after disassembling of the blot, the filter was dried on air and the DNA was fixed onto the filter by either baking it at $80^{\circ} \mathrm{C}$ for 2 hrs or by UV-crosslinking in UV Stratalinker 1800 .

\subsubsection{Northern blotting of RNA onto nitrocellulose filters}

For the transfer of RNA onto a nitrocellulose filter, the same procedure as described above (2.2.5.1) was carried out. In this case, however, the gel need not to be denatured, but was transferred directly onto the nitrocellulose filter, as explained in section 2.2.5.1.

\subsubsection{Random Prime method for generation of $P^{32}$ labeled DNA}

Rediprime $^{\mathrm{TM}}$ II Random Prime Labeling System (Amersham, Braunschweig) was used for labelling of DNA probes. The method depends on the random priming principle developed by Feinberg and Vogelstein (1989). The reaction mix contained dATP, dGTP, dTTP, dCTP, Klenow fragment (4 - $8 \mathrm{U}$ ) and random oligodeoxyribonucleotides. Firstly, $10-25 \mathrm{ng}$ of DNA were denatured in a total volume of $46 \mu \mathrm{l}$ in boiling water for $10 \mathrm{~min}$ and quick chilled on ice for $5 \mathrm{~min}$. After pipetting the denatured probe to Rediprime ${ }^{\mathrm{TM}} \mathrm{II}$ Random Prime Labeling System cup, $4 \mu \mathrm{l}$ of $\left[\alpha-\mathrm{P}^{32}\right]$ dCTP $(3000 \mathrm{Ci} / \mathrm{mmol})$ was added to the reaction mixture. The labelling reaction was carried out at $37^{\circ} \mathrm{C}$ for $0.5-1 \mathrm{hr}$. The labeled probe was purified from unincorporated $\left[\alpha-\mathrm{P}^{32}\right]$ dCTP by using microspin columns (Amersham, Braunschweig).

\subsubsection{Hybridization of nucleic acids}

The membrane to be hybridised was equilibrated in 2x SSC and transferred to a hybridisation tube. After adding $8 \mathrm{ml}$ of hybridisation solution and $150 \mu \mathrm{l}$ of sheared salmon DNA, the membrane was incubated for 6 to $8 \mathrm{hrs}$ in the hybridization oven at an appropriate temperature, which was usually $65^{\circ} \mathrm{C}$. Then, the labelled probe was denatured 
at $95^{\circ} \mathrm{C}$ for $10 \mathrm{~min}$, quick chilled on ice, and added to the hybridisation solution, together with $150 \mu \mathrm{l}$ of sheared salmon DNA. The hybridisation was carried out overnight in the oven. Next day, the filter was washed for 10 min with 2x SSC at RT. Finally it was washed with $0.2 \mathrm{x}$ SSC containing $0.1 \% \mathrm{SDS}$ and then with $0.02 \mathrm{x}$ SSC at the hybridization temperature. After drying the filter, it was sealed in plastic foil and exposed to autoradiography overnight to few days (depending on the value of radioactive signal) at $-80^{\circ} \mathrm{C}$. The film was developed in X-ray automatic processor Curix 60. If membrane has to be used again, it was stripped in $0.2 \times \mathrm{SSC}$ at $80^{\circ} \mathrm{C}$, until radioactive signal was no longer detected.

\subsubsection{Protein and biochemical methods}

\subsubsection{Expression of recombinant proteins in Escherichia coli}

Escherichia coli strain Rosette 2 (DE3) (Novagen, Darmstadt) was transformed with plasmid vectors through electroporation. A single colony was inoculated into $10 \mathrm{ml} \mathrm{LB}$ supplemented with $50 \mu \mathrm{g} / \mathrm{ml}$ kanamycin and grown overnight at $37^{\circ} \mathrm{C}$ with shaking. The preculture was diluted and grown in $250 \mathrm{ml} \mathrm{LB}$ supplemented with $50 \mu \mathrm{g} / \mathrm{ml}$ kanamycin, for $5 \mathrm{hrs}$ at $37^{\circ} \mathrm{C}$ and later kept at $4^{\circ} \mathrm{C}$ for an hour. The culture was further diluted in 2.5 litres rich media (2.5 g meat extract per liter of LB), supplemented with $50 \mu \mathrm{g} / \mathrm{ml}$ kanamycin and induced with $1 \mathrm{mM}$ IPTG for about $12 \mathrm{hrs}$ at $30^{\circ} \mathrm{C}$. The cells were collected by centrifugation at $7000 \mathrm{xg}$ for $10 \mathrm{~min}, 4^{\circ} \mathrm{C}$. The pellet can be stored at $-80^{\circ} \mathrm{C}$ for several weeks until use.

\subsubsection{Purification of the proteins from Escherichia coli}

The pellet was resuspended in bacterial lysis buffer $(15 \mathrm{ml} / 1$ liter culture pellet) with $100 \mu \mathrm{g} / \mathrm{ml}$ PMSF, $1 \mu \mathrm{l} / \mathrm{ml}$ Protease inhibitor cocktail (Calbiochem, USA), Lysozyme $50 \mu \mathrm{g} / \mathrm{ml}, 1$ Unit / ml Benzonase (Merck Biosciences) and lysed by vortexing. The lysate was incubated at RT for $10 \mathrm{~min}$, then on ice for $15 \mathrm{~min}$ before being subjected to ultrasonication (50-60 secs duty cycles, 5-6 output) 6 times, 1 minute each with an interval of $2 \mathrm{~min}$ to avoid heat. The lysate was centrifuged at $18000 \mathrm{xg}$ for $25 \mathrm{mins}, 4^{\circ} \mathrm{C}$, then the supernatant was filtered using $0.45 \mu \mathrm{M}$ filters (Millipore, USA) and purified over 
Strep-tactin affinity columns (IBA, Goettingen) using the suppliers protocol with slight modifications of buffers,

Equilibration buffer: $100 \mathrm{mM}$ Tris-Cl

$200 \mathrm{mM} \mathrm{NaCl}$

$0.1 \mathrm{mM}$ EDTA

pH- 8.0

Washing Buffer (W): 100mM Tris-Cl

$500 \mathrm{mM} \mathrm{NaCl}$

$0.5 \mathrm{mM}$ EDTA

$0.1 \%(\mathrm{v} / \mathrm{v})$ Triton X-100

$0.1 \%(\mathrm{v} / \mathrm{v})$ Tween 20

$8 \%$ Glycerol

$5 \mathrm{mM} \beta$-2-Mercaptoethanol or 0.1mM DTT

$\mathrm{pH}-8.0$

Elution Buffer: $\quad$ Buffer W with 110mgs of D-desthiobiotin pH- 8.0

$\underline{\text { Regeneration buffer: }}$ Equilibration buffer with 1mM HABA pH- 8.0

All the buffers were stored at $4^{\circ} \mathrm{C}$ and the $\mathrm{pH}$ was ckecked before use. The elutant was concentrated using Amicon Centrifugal Filter Devices (Millipore, USA) at 700xg and subjected to Hi-Prep 26/60 Sephacryl S-200 High resolution Gel-filtration columns (Amersham, Braunschweig) to remove small and truncated protein contaminants. The Gelfiltration columns were fitted with Peristaltic pump and the following buffers were used,

Gel filtration buffer

Washing buffer,

Wash 1: $0.2 \mathrm{~N} \mathrm{NaOH}$ 
Wash 2: 30\% Iso-propanol

Equlibration buffer: $50 \mathrm{mM} \mathrm{NaPO} 4$

(1M stock was prepared using $5.7 \mathrm{ml} 1 \mathrm{M} \mathrm{Na} 2 \mathrm{HPO} 4$

with $4 \mathrm{ml} 1 \mathrm{M} \mathrm{NaH} 2 \mathrm{PO} 4)$

$0.15 \mathrm{M} \mathrm{NaCl}$ pH 7.0

Running/Elution buffer: Equilibration buffer with 5 to $10 \%$ Isopropanol through varying $\mathrm{pH}$ (5 to 10$)$

All the buffers should be filtered and degassed and stored at $4{ }^{\circ} \mathrm{C}$. Columns were equilibrated with $120 \mathrm{ml}$ of equilibration buffer at the speed of $0.5 \mathrm{ml} / \mathrm{min}$. The protein sample (5 $-10 \mathrm{ml}$ concentrated) was loaded onto the columns at $0.7 \mathrm{ml} / \mathrm{min}$ speed, once the sample enters the columns, the speed was set to $0.1 \mathrm{ml} / \mathrm{min}$. All the fractions were collected and analyzed on SDS-PAGE, after knowing the fraction in which our proteins are present, in subsequently purification the same fraction was collected. The columns

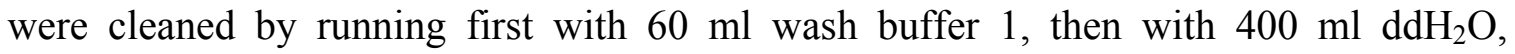
followed by $300 \mathrm{ml} \mathrm{20 \%}$ alcohol, at the speed of $0.7 \mathrm{ml} / \mathrm{min}$ and the columns were stored with $20 \%$ alcohol. Next the purified protein was desalted using PD-10 columns (Amersham, Braunschweig), briefly the columns were equilibrated with approximately $25 \mathrm{ml} \mathrm{ddH_{2 }} \mathrm{O}$. Three $\mathrm{ml}$ of protein sample was loaded to the columns and the flow through was discarded and $4 \mathrm{ml}$ of PBS was used to elute the protein from the columns. The eluted protein was further subjected to EndoTrap Red columns (Profos, Germany) to remove endotoxins following users manual. The protein was quantified using Bradford assay kit according to suppliers protocol (Pierce, USA), and stored at $-80^{\circ} \mathrm{C}$ with $10 \%$ glycerol in aliquots.

\subsubsection{Isolation of protein from mammalian cells}

The cells were harvested at indicated time intervals and the total protein was extracted by suspending $10^{7}$ cells in $200 \mu \mathrm{l}$ cell lysis buffer with $1 \mathrm{mM}$ PMSF, $1 \mu \mathrm{l} / \mathrm{ml}$ Protease inhibitor cocktail (Sigma, Deisenhofen) and incubating on ice for $20 \mathrm{~min}$. Then the sample was sonicated gently to fragment the DNA. The lysate was centrifuged at 9000xg for $10 \mathrm{~min}$, at $4^{\circ} \mathrm{C}$, and the total protein concentration of the supernatant was quantified 
and stored at $-80^{\circ} \mathrm{C}$ in aliquots until use. The nuclear protein from the cells was extracted specifically with the CelLytic ${ }^{\mathrm{TM}}$ NuCLEAR $^{\mathrm{TM}}$ Extraction Kit (Sigma, Deisenhofen) according to the maufacturer's protocol.

\subsubsection{Isolation of total protein from mouse tissues}

Proteins were extracted from fresh or frozen mouse tissues by homogenization in tissue lysis buffer containing protease inhibitors. Lysates were sonicated on ice and centrifuged at $12000 \mathrm{x}$ g for $10 \mathrm{~min}$ at $4^{\circ} \mathrm{C}$. Supernatant, containing membrane, organelles and cytosol proteins was collected, quantified and stored at $-80^{\circ} \mathrm{C}$, or used immediately for Western blot.

\subsubsection{Determination of protein concentration}

To determine the protein concentration, Bio-Rad protein assay was employed which is a dye-binding assay based on the differential colour change of a dye in response to various concentrations of protein. The assay is based on the observation that the absorbance maximum for an acidic solution of Coomasie Blue G-250 shifts from 494 to $595 \mathrm{~nm}$ when the binding to protein occurs. The bovine serum albumin (BSA) stock solution of $1 \mathrm{mg} / \mathrm{ml}$ was diluted in order to obtain standard dilutions in range of $10 \mu \mathrm{g} / \mathrm{ml}$ to $100 \mu \mathrm{g} / \mathrm{ml}$. The Bio-Rad's color reagent was diluted 1:5 with $\mathrm{H}_{2} \mathrm{O}$ and filtered through $0.45 \mu \mathrm{m}$ filters. In a 96-well microtiter plate, $20 \mu \mathrm{l}$ of each standard dilution and the samples to be measured were pipetted with $280 \mu \mathrm{l}$ of the colour reagent. The absorption of the colour reaction was measured at $595 \mathrm{~nm}$ and the protein concentration was determined by extrapolating to the standard curve plotted with the values obtained from the known concentrations of the BSA.

\subsubsection{SDS-PAGE for the separation of proteins}

SDS-PAGE gel electrophoresis is a method for separating proteins within a sample for molecular weight determination. The proteins are denatured and rendered monomeric by boiling in the presence of reducing agents ( $\beta$-mercaptoethanol or DTT) and negatively charged detergent (SDS). The proteins, which normally differ according to their charges, are all coated with the SDS molecules, which are negatively charged. Hence, all the 
proteins in the sample become negatively charged and achieve constant charge to mass ratio. In this way, the separation is according to the size of the proteins. A SDS-PAGE consists of two gels; firstly, a 10 - 12\% separating gel was poured. In order to achieve a smooth boundary between separating and stacking gel, the separating gel was covered with a layer of water. After polymerisation of the separating gel, the water was removed and 4\% stacking gel was poured over it. The samples were boiled in sample buffer for $10 \mathrm{~min}$ at $95^{\circ} \mathrm{C}$ before loading into the gel. The gel was run for 2 hours at a constant current of $30 \mathrm{~mA}$.

\subsubsection{Western blotting of protein}

$\begin{array}{ll}\text { Transfer buffer } & 5.8 \mathrm{~g} \text { Tris-Cl } \\ & 2.92 \mathrm{~g} \text { Glycine } \\ & 3.7 \mathrm{ml} \mathrm{10 \% \textrm {SDS }} \\ & \mathrm{pH} 9.2 \\ & 20 \% \text { methanol } \\ & \mathrm{ddH} 2 \mathrm{O} \text { to } 1000 \mathrm{ml}\end{array}$

50 to $100 \mu \mathrm{g}$ of the protein samples were heated at $75^{\circ} \mathrm{C}$ for $7 \mathrm{~min}$ with SDS loading buffer and resolved on 4 - 20\% precise protein gels (Pierce, USA). After the electrophoresis of proteins on a SDS-PAGE, the nitrocellulose membrane optimized for protein transfer was cut at the size of the gel. Eight pieces of GB004 Whatman filter papers were also cut at the size of the gel. The membrane, gel and the filter papers were soaked for 10 min in transfer buffer and placed on semi dry transfer machine's lower plate and than four papers soaked with transfer buffer were placed over it. The membrane was placed over them and then the gel was placed avoiding any air bubbles. Another four Whatman paper soaked buffer was placed over to complete the sandwich model. The upper plate was placed over this sandwich and the transfer was carried out at $3.5 \mathrm{~mA} / \mathrm{cm}^{2}$ for $2 \mathrm{hr}$. The blotted membrane was treated with Western blot signal enhancer (Pierce, USA) according to supplier's protocol. Then membrane was blocked with 5\% non fat milk in PBS with $0.05 \%$ Tween-20 (PBS-T) for 1-2 hrs. Membrane was then incubated 
separately with blocking solution containing primary antibody for overnight at $4^{\circ} \mathrm{C}$. The membrane was washed 3 times with PBS-T and then incubated with same buffer containing respective secondary antibodies conjugated with alkaline phosphatase (Sigma, Deisenhofen) diluted 1:30,000 for 1hr. Excess antibodies was washed off with PBS-T three times and developed with BCIP/NBT.

\subsubsection{Eukaryotic cell culture methods}

\subsubsection{Cell culture conditions}

All cells were grown in their respective growth media. All the cells were cultured at $37^{\circ} \mathrm{C}$ in a humidified incubator with $5 \% \mathrm{CO}_{2}$ and grown to $80 \%$ confluency.

\subsubsection{Trypsinization of eukaryotic cells}

Cells were washed twice with sterile DPBS and incubated in minimal amount of trypsinEDTA (0.5 g/l trypsin, $0.2 \mathrm{~g} / 1 \mathrm{EDTA})$ (PAN biotech, Aidenbach) at $37^{\circ} \mathrm{C}$ until they had detached from the dish. The process was controlled under an inverted microscope. Trypsin activity was inhibited by addition of growth medium in which the cells were subsequently resuspended. Cell counting was performed, when necessary, using an improved Neubauer chamber, and the cells were plated out or harvested for cryopreservation.

\subsubsection{Cryopreservation and thawing of eukaryotic cells}

Resuspended cells were spun down $\left(1000 \mathrm{xg}\right.$ for $5 \mathrm{~min}$ at $\left.4^{\circ} \mathrm{C}\right)$ in $4 \mathrm{ml}$ growth medium. The supernatant was aspirated and the cells were resuspended $\left(1-5 \times 10^{7}\right.$ cells $\left./ \mathrm{ml}\right)$ in ice cold medium (DMEM or RPMI, 20\% FKS, 10\% DMSO). Cells were kept for 7 days at $-80^{\circ} \mathrm{C}$, checked for their vitality and then stored in liquid nitrogen. For revitalization, frozen cells were quickly thawed at $37^{\circ} \mathrm{C}$ water bath, gently transferred to disposable Falcon (BD Falcon, USA) tubes containing $4 \mathrm{ml}$ growth medium and spun down as described above. Supernatant was discarded by aspiration and cells were plated out after being resuspended in a suitable amount of prewarmed growth medium. 


\subsubsection{Transfection of the eukaryotic cells with plasmid}

Approximately $4 \times 10^{5}$ of the cells were plated on a cell culture slide and cultured overnight in $1 \mathrm{ml}$ DMEM medium containing 10\% FKS and penicillin/streptomycin. Transfection was done using Genejuice transfection reagent according to suppliers (Novagen, Darmstadt) protocol. The cells were then washed with PBS prewarmed to $37^{\circ} \mathrm{C}$. About $2 \mathrm{ml}$ of fresh complete growth medium was applied and cells were incubated at $37^{\circ} \mathrm{C}$. After $24 \mathrm{hrs}$, cell culture slides were fixed and processed for immunostaining.

\subsubsection{Establishment of stable cell lines}

Cells were transfected with pTri-EX-neo1 vector containing MECP2 coding sequences. Transfection was done using Genejuice transfection reagent according to suppliers (Novagen, Darmstadt) protocol. Two days post transfection, cells were selected in medium containing $500 \mu \mathrm{g} / \mathrm{ml}$ neomycin for 6 weeks and maintained thereafter on medium with $200 \mu \mathrm{g} / \mathrm{ml}$ neomycin.

\subsubsection{Establishment of mouse primary neurons}

The mouse brain at specific age was dissected under laminar flow. Under cold condition (on ice) the whole brain region was dissected out carefully and rinsed with HBS. The tissue was minced into small pieces with sterile scalpel in $35 \mathrm{~mm}$ dish containing $200 \mu \mathrm{l}$ HBS under laminar air flow and later treated with $1 \mathrm{ml}$ papain $(2 \mathrm{mg} / \mathrm{ml} \mathrm{HBS})$ for $15 \mathrm{~min}$ at $37^{\circ} \mathrm{C}$. Carefully the supernatant was removed and replaced with $4-6 \mathrm{ml}$ of prewarmed plating media, the clumps were again triturated with $1 \mathrm{ml}$ pipette. Two $\mathrm{ml}$ of this cell solution was added to each $35 \mathrm{~mm}$ L-polyornithine (Sigma, Deisenhofen) coated dishes. The dishes were coated with $2 \mathrm{ml}$ L-polyornithine per dish one day before. Cells were allowed to settle for $15 \mathrm{~min}$ under the flow, then washed once and replaced with prewarmed plating media $(1.5 \mathrm{ml} / 35 \mathrm{~mm}$ dishes $)$. Cells were incubated at $37^{\circ} \mathrm{C}$ in $5 \%$ $\mathrm{CO}_{2}$ incubator for 1 week with media replacement once in the middle. Further, the neurons were maintained on same volume of feeding media with $20 \mathrm{ng} / \mathrm{ml} \mathrm{bFGF}$. 


\subsubsection{Immunocytochemistry}

First, the culture media was removed from the cells in microscopical chambers or dishes and were rinsed with PBS. After that $1 \mathrm{ml}$ 4\% PFA (made fresh) per chamber/dish was added and incubated for $3 \mathrm{~min}$ at RT for fixing the cells. Then, the cells were washed 3 times with PBS and permeabilized by adding $1 \mathrm{ml}$ buffer / plate containing Triton $\mathrm{X}$ (1:1000), 5\% FKS in PBS. The permeabilization was carried out for $10 \mathrm{~min}$ at RT. And after washing, the cells were incubated with the respective diluted primary antibody in a buffer containing PBS and 5\% FBS for $1 \mathrm{hr}$ to overnight at $4{ }^{\circ} \mathrm{C}$. The cells were finally stained with the secondary antibody after washing again and incubating with the secondary antibody in the same buffer applied for primary, for $1 \mathrm{hr}$ at RT. Before microscopical analysis the cells were rinsed 2 times with PBS and mounted with DAPI (Vector, Burfingame)

\subsubsection{Immunohistochemistry}

The slides from $-80^{\circ} \mathrm{C}$ were incubated at room temperature for $30 \mathrm{~min}$, fixed by immersing in cold acetone for $10 \mathrm{~min}$ and air dried before being blocked in a solution containing one part of Roti-Immunoblock (Carl Roth, Germany) and one part of PBS containing 3\% fetal bovine serum for $1 \mathrm{hr}$ at RT. The slides were incubated with primary antibodies at 1:250 dilutions for $18-20 \mathrm{hrs}$ at $4^{\circ} \mathrm{C}$ in humidified chamber with PBS containing 3\% fetal bovine serum and $0.1 \%$ Tween-20. The slides were then washed 3 times for 5 min with PBS and the protein was detected by incubating with respective FITC conjugated secondary goat anti-rabbit IgG at a dilution of 1:500 in PBS for $1 \mathrm{~h}$. Sections were finally washed with PBS twice for $10 \mathrm{~min}$, mounted in Vectorshield mounting medium and DAPI. Images were taken using fluorescence microscope.

\subsubsection{GET homologous recombination (Orford et al., 2000)}

The GET recombination is generally performed in two steps. First, making the desired bacterial cells competent followed by electroporation of pGETrec plasmid. The cells containing pGETrec plasmid were then made competent in a specialized way by inducing the genes present in pGETrec plasmid shortly. Finally, the DNA fragment of interest was electroporated into the cells for the recombination facilitated by pGETrec plasmid. The 
specialized way of making the pGETrec plasmid containing bacterial cells competent and electroporating the DNA fragment is as follows, LB medium $(50 \mathrm{ml})$ was inoculated with a single colony of Escherichia coli (strain DH10B) and grown overnight at $37^{\circ} \mathrm{C}$ and the culture was diluted to 1:50 LB medium and grown at $37^{\circ} \mathrm{C}$ to $\mathrm{OD} 600=0.6$. After growing the culture, the important step would be to induce the culture with $0.2 \% \mathrm{w} / \mathrm{v}$ of L-Arabinose at $30^{\circ} \mathrm{C}$ for exactly $40 \mathrm{~min}$. Bacteria were centrifuged $\left(10 \mathrm{~min}, 4^{\circ} \mathrm{C}\right.$, $3,000 \mathrm{xg})$ and the pellet was resuspended in $50 \mathrm{ml}$ of ice cold sterile $10 \%$ glycerol $\left(4^{\circ} \mathrm{C}\right)$ and the wash was repeated 3 times in ice cold sterile $10 \%$ glycerol by centrifuging $10 \mathrm{~min}$, $4^{\circ} \mathrm{C}, 3,000 \mathrm{xg}$. The suspension of bacteria was centrifuged $\left(10 \mathrm{~min}, 4^{\circ} \mathrm{C}, 3,000 \mathrm{xg}\right)$ and the pellet was resuspended in $1 \mathrm{ml}$ ice cold sterile $10 \%$ glycerol. The mixture was dispensed into aliquots of $100 \mu$, the cups were frozen quikly in liquid nitrogen and stored at $-80^{\circ}$.

The 600-900 ng of the purified PCR fragment or the gel eluted DNA containg $50 \mathrm{bp}$ or more homologous region was then electroporated into the bacteria as described before (2.2.4.8).

\subsubsection{Genotyping of the mice}

The genotypes of all mouse offsprings were analysed by polymerase chain reaction (PCR). For amplification of the specified allele, the genomic DNA was extracted from mouse tails as described in section 2.2.1.2 and pipetted to the following reaction mixture:

$1 \mu 1$ DNA (300-500 ng)

$1 \mu \mathrm{l}$ Forward primer $(10 \mathrm{pmol} / \mu \mathrm{l})$

$1 \mu \mathrm{l}$ Reverse primer $(10 \mathrm{pmol} / \mu \mathrm{l})$

$1 \mu \mathrm{dNTPs}(10 \mathrm{mM})$

$10 \mu 1$ Hot -start Taq (Qiagen, Hilden)

and the volume was made up to $25 \mu \mathrm{H} \mathrm{H}_{2} \mathrm{O}$.

The Mecp2_WT_EGFP (BAC) transgenic mice were genotyped regularly with primers Kan_check_F3 and Mecp2_check_R1 and the reaction mixture was subjected to the following program in the thermocycler: 
Initial denaturation $95^{\circ} \mathrm{C}$ for $15 \mathrm{~min}$

followed by 35 cycles of,

$95^{\circ} \mathrm{C}$ for $30 \mathrm{sec}$ (denaturation)

$55^{\circ} \mathrm{C}$ for $40 \mathrm{sec}$ (annealing)

$72^{\circ} \mathrm{C}$ for $55 \mathrm{sec}$ (extension)

and by a final extension of $72^{\circ} \mathrm{C}$ for $10 \mathrm{~min}$

To differentiate between the Mecp2_WT_EGFP (BAC), Mecp2_270_EGFP (BAC), and Mecp2_400_EGFP (BAC) transgenic mice, primers Ctrl Mecp2_F1 and EGFP_Rev1 were used for the genotyping and as a result the different transgenic mice yielded PCR products of $1274 \mathrm{bp} ; 632 \mathrm{bp}$; and $1028 \mathrm{bp}$ respectively. The integrity of the genomic DNA samples were controled by amplifying with primers Ctrl Mecp2_F1 and Ctrl Mecp2_R1.

The Mecp2 knockout mice were genotyped using primers oIMR1436 (common primer), oIMR1437 (WT primer) / oIMR1438 (Mutant primer) and the reaction mixture was subjected to the following program in the thermocycler:

Initial denaturation $95^{\circ} \mathrm{C}$ for $15 \mathrm{~min}$

followed by 35 cycles of,

$95^{\circ} \mathrm{C}$ for $30 \mathrm{sec}$ (denaturation)

$60^{\circ} \mathrm{C}$ for $1 \mathrm{~min}$ (annealing)

$72^{\circ} \mathrm{C} 1 \mathrm{~min}$ (extension)

and by a final extension of $72^{\circ} \mathrm{C}$ for $10 \mathrm{~min}$

\subsubsection{Real time PCR analysis for copy number studies}

Real-time PCR record fluorescence that is generated in the course of a PCR and report the results as a threshold cycle ( $\mathrm{Ct}$ value) that is the cycle number $(C)$ at which the detected fluorescence crosses a threshold $t$. This threshold is a fluorescence value slightly above the background fluorescence measured before exponential growth starts (as indicated in concerned results section). Thresholds are either calculated according to an algorithm of the real-time PCR software or set manually within the real-time PCR program. Ct values characterize reactions in the early phase of the exponential growth, in 
which low values indicate a high initial target amount and high values the opposite. If a PCR works with an efficiency of one (the amount of product doubles every cycle), the $\mathrm{Ct}$ value can be easily related to the input amount of the target: samples with half the amount of target result in one cycle more than the original $\mathrm{Ct}$ value. Thus, the ability to distinguish $\mathrm{Ct}$ differences of one is essential for distinguishing one-copy from two-copy animals and hemizygous from homozygous animals.

Absolute quantification can be achieved by relating the measured $\mathrm{Ct}$ to a standard curve that can be obtained by diluting a plasmid with a transgene sequence for which the exact DNA concentration and molecular weight is known. Ct values can thereby be related to a distinct number of plasmids, and with knowledge of the molecular weight of the haploid animal genome, the number of molecules (as a simplification, we consider one haploid genome to be one molecule) represented by a certain amount of DNA can be estimated. A given number of DNA molecules yields the same $\mathrm{Ct}$ value as the same number of plasmids, if all molecules contain one copy of the transgene (i.e., if the animal is homozygous). For hemizygous animals with only half the molecules containing the expression cassette, the $\mathrm{Ct}$ value will correspond to a $\mathrm{Ct}$ value for half the number of plasmids. A standard addition, whereby copy-equivalents of plasmids are added to a certain amount of DNA in order to obtain a standard curve, has the advantage that the sample and the standard are exposed to the same inhibitory factors in a DNA solution.

\section{$\underline{\text { Relative quantification by standard curves: }}$}

For copy number and zygosity calculation, absolute quantification of the physical amount of transgene copies is not necessary; relating the $\mathrm{Ct}$ signals to relative standard curves of serial dilutions of the target gene and an endogenous control gene is sufficient to determine if a sample contains as much target as a certain dilution step of the standard. Normalization is performed by dividing the dilution equivalent of the transgene by the dilution equivalent of the endogenous control. The unit-less normalized dilution equivalents require a sample that serves as calibrator, a sample for which the copy number is exactly known typically from a Southern blot. A good calibrator for quantifying copy number is a homozygous animal with one copy of the transgene. 
Samples with half the normalized dilution equivalent as the calibrator are hemizygous; samples with the same normalized dilution equivalent are homozygous for one copy, and so on. This method provides robust values even when transgene and endogenous control amplify with different efficiencies. Relative quantification by standard curves is used for expression analysis (ABI PRISM) (refer Fig. 22).

\subsubsection{Analysis of histone acetylation status by immunoblotting}

Total proteins from the brain of transgenic mice and wild type mice were extracted. The total protein were analyzed by Western blotting (section 2.2.6.7), with rabbit polyclonal antibodies against acetylated histone H3 (1:10,000), acetylated histone H4K16 (1:500) (Upstate, USA). Mouse monoclonal anti-alpha tubulin (Sigma, Deisenhofen) diluted 1:4,000 was used as a positive control to show equal loading of the proteins in the gel. The membrane was processed and probed with secondary antibodies conjugated with alkaline phosphatase (Sigma, Deisenhofen) and developed as described earlier (section 2.2.6.7).

\subsubsection{Densitometric analysis}

The density of the Western blot signals were quantified by Olympus S-100 Imaging Densitometer, quantification of Western blot signals was done using the MacBAS software (Fuji). Band intensity ratios were measured using alpha-tubulin signal as an internal control.

\subsubsection{Enzymatic dissociation and FACS isolation of neurons}

Brains from the mice of desired age were dissected out and washed with cold DPBS. Then the tissue was minced to obtain $1 \mathrm{~mm}$ pieces and was further dissociated in DPBS solution for 45 minutes at $37^{\circ} \mathrm{C}$ with $100 \mathrm{U} / \mu \mathrm{l}$ Papain enzyme and DNase. The suspension were triturated with three glass pipettes of decreasing tip diameter intermittently and the dissociated cells were centrifuged at $900 \mathrm{rpm}$ at room temperature for 5 minutes. To remove excess debris, cell pellets were resuspended in DPBS, and the cell suspension was subjected to centrifugation at $900 \mathrm{rpm}$ at $4{ }^{\circ} \mathrm{C}$. Cell pellets were re-suspended in the primary neuronal plating media, and filtered through a $70 \mu \mathrm{m}$ mesh (BD Falcon, USA). 
Cells were treated with propidium iodide (PI) $(20 \mu \mathrm{g} / \mathrm{ml})$ to label dead cells and sorted on a FACSVantage SE cell sorter (Becton Dickson) for FITC signals (detecting EGFP) and PE signals (detecting PI). Cells were kept on ice pre and post-sorting. For imaging of the FACS-sorted cells, pre-sort and post-sort cells were resuspended in the pating media and plated in 2-4 well chamber slides coated with 1x polyornithine. Cells were allowed to settle for 6 hours at $37{ }^{\circ} \mathrm{C}$, then fixed with $4 \%$ paraformaldehyde (PFA), followed by rinses in 0.1M PBS, and imaged using Zeiss confocal Axioscope II microscope.

Wild-type neuronal cells were used to calibrate the FITC and PE signals. Routinely, 10,000 neurons were obtained in each sort of around $20 \mathrm{~min}$ from the mice. For cell viability, the cells were cultured in the plating media for about a week before imaging. For fixing the cells directly onto the slides, special centrifuge namely, Cytospin was employed, by spinning the cells at $900 \mathrm{~g}$ for $15 \mathrm{~min}$.

\subsubsection{Phenotypical analysis using open field test.}

The open field apparatus consisted of a box $100 \times 100 \mathrm{~cm}$ in size, divided into 10x10 equal squares. The mice were kept in the centre of the squares and he behavioral parameters registered during a 5 min session were as follows:

Positive points for the activity,

(i) the total number of entries into squares (subdivided into movement in outer, middle and inner zones);

(ii) time spent grooming;

Negative points for the activity,

(iii) the number of rears (standing on hind legs with forelegs in air or against the wall);

(iv) defecation; and

(v) time spent immobile.

\subsubsection{Gel shift assay}

The electrophoretic gel shift assay is used to detect sequence specific DNA-binding proteins present in nuclear extracts. For MeCP2 a HeLa nuclear extract is used. In the 
assay, a consensus probe is end-labeled with isotopic phosphorus and detected using autoradiography. A 'gel shift' of radiolabel is observed whenever the DNA binding protein forms a complex with radiolabeled probe (resulting in the detectable label migrating at a higher apparent molecular weight). The 'gel super shift' assay refers to the additional increase in apparent molecular weight resulting from binding a specific antibody to the DNA binding protein prior to reaction with radioactive probe. Hence through the use of a specific antibody and a consensus probe the presence of a specific DNA binding protein in any nuclear extract can be identified.

\section{$\underline{\text { Reagents used: }}$}

Poly $\mathrm{d}(\mathrm{I}) \mathrm{d}(\mathrm{C})$, used as a non-specific inhibitor; $1 \mathrm{X}$ TGE Buffer, prepared as a 10X concentrate of Tris-Glycine-EDTA (TGE) by adding $30.3 \mathrm{~g}$ Tris Cl, $142 \mathrm{~g}$ glycine, $37.2 \mathrm{~g}$ EDTA and deionized water to a final volume of 1.0 liter. The $\mathrm{pH}$ should not be adjusted. For 5\% TGE gel, $60 \mathrm{ml}$ of solution was prepared by mixing $10.5 \mathrm{ml} 30 \%$ polyacrylamide, $6 \mathrm{ml} \mathrm{10X} \mathrm{TGE,} 3 \mathrm{ml}$ glycerol, $40 \mathrm{ml} \mathrm{H} 2 \mathrm{O}, 0.45 \mathrm{ml} \mathrm{10 \%}$ ammonium persulfate and 0.06 $\mathrm{ml}$ TEMED. 5X Binding Buffer was composed of $250 \mathrm{mM} \mathrm{NaCl}, 50 \mathrm{mM}$ Tris $\mathrm{Cl}, 50 \%$ $(\mathrm{v} / \mathrm{v})$ glycerol, $5 \mathrm{mM}$ DTT, $2.5 \mathrm{mM}$ EDTA adjusted to $\mathrm{pH} 7.6$ (Stored $-20^{\circ} \mathrm{C}$ prior to use). The HeLa cell Nuclear Extract was prepared using CelLytic ${ }^{\mathrm{TM}}$ NuCLEAR $^{\mathrm{TM}}$ Extraction Kit (Sigma, Deisenhofen). 30,000-50,000 CPM of ${ }^{32} \mathrm{P}-$ labeled double stranded DNA probe per reaction mixture was used and probe without label (cold) was used as a control.

\section{Procedure:}

The reaction mixture contained the following in a microfuge tube:

poly $\mathrm{dI}-\mathrm{dC}$ to $2 \mathrm{mg} /$ reaction

$4 \mathrm{ml}$ 5X Binding Buffer

\section{$2.5 \mathrm{ml}$ Nuclear Extract}

the volume of $\mathrm{H}_{2} \mathrm{O}$ was added in a total reaction volume of $20 \mathrm{ml}$ including the labeled probe. The contents of the tube were gently mixed. For the supershift assay, $1 \mu \mathrm{g}$ of the antibody was added to the reaction mixture and incubated for $15 \mathrm{~min}$ at room temperature. Then the ${ }^{32} \mathrm{P}$ labeled probe was added and gently mixed. Again the reaction 
was incubated for $15 \mathrm{~min}$ at room temperature. The entire reaction mixture volume was loaded into each lane of a $5 \%$ polyacrylamide gel $(1.5 \mathrm{~mm}$ x $20 \mathrm{~cm}$ x $20 \mathrm{~cm})$ prepared in TGE buffer. Dye was not added to the reaction mixture lane, which may interfere with binding. The dye was run separately in the first and last lanes of the gel. The gel was run at 20 milliamps for 1.5 to $2 \mathrm{~h}$. The gel was dried and autoradiography was performed to visualize banding patterns.

\subsubsection{Recovery and culture of preimplantation mouse embryos}

\subsubsection{Superovulation}

Seven to eight week old female mice were superovulated by intraperitoneal injections of 5 IU of pregnant mare's serum gonadotropin (PMSG) followed 44-48 hrs later by 5 IU of human chorionic gonadotrophin (HCG; Sigma). After the second injection, females were housed overnight with males and were checked by a vaginal plug the following morning. The E0.5 was considered to be 12:00 noon at the day of vaginal plug.

\subsubsection{Recovery of preimplantation embryos}

1-cell to 8-cell stage embryos were flushed from the oviduct of superovulated females. Plugged female mice (1.5-2.5 days pc) were killed by cervical dislocation. The skin and peritoneum were opened with the large transverse incision to expose the abdominal cavity. The oviducts with the upper part of the uterus were dissected and placed into a drop of M2 medium (Sigma, Deisenhofen). Under dissection microscope, the needle attached to a $1 \mathrm{ml}$ syringe was inserted in the fimbrial end of the oviduct. The needle was then held with forceps and oviducts were flashed with $0.05 \mathrm{ml}$ of M2 medium. Embryos were collected with a pipette and washed through several M2 drops. To remove the zona pellucida, embryos were treated in one drop of Tyrode's acid solution and transferred into the drop of M2-medium as soon as their zona pellucida was dissolved. 2 cell and 4 cell stage embryos were incubated in a drop of acutase in order to remove the polar bodies. The collected embryos were washed five times in a drop of PBS and each single embryo was transferred into a PCR cup $(0.2 \mathrm{ml})$ containing $5 \mu \mathrm{dH} 2 \mathrm{O}$. Those samples were used for genotyping. In order to decrease the possible contamination with maternal cells, 2 cell 
stage embryos were cultivated in $\mathrm{M} 16$ medium at $37^{\circ} \mathrm{C}$ and $5 \% \mathrm{CO}_{2}$ until the embryos developed to expected developmental stages as a 4-cell to blastocyst.

\subsubsection{In vitro culture of blastocyst stage embryos}

Embryos were flushed out from the uteri of plugged females at day 3.5 and placed in gelatinized 96-well dish. Embryos were cultured in ES cell medium without the addition of leukemia inhibitory factor. The dish was kept in a humid incubator at $37^{\circ} \mathrm{C}, 5 \% \mathrm{CO}_{2}$ and embryonic outgrowth was scored daily. Every second day, $5 \mu$ of fresh medium was added to the wells.

\subsubsection{Histological techniques}

\subsubsection{Tissue preparation for paraffin embedding}

The freshly prepared tissues were fixed in Bouin's solution for $24-72$ hrs to prevent the alterations in the cellular structure. The tissue to be embedded in paraffin should be free of water. The dehydration process was accomplished by passing the tissue through a series of increasing alcohol concentrations. For this purpose, the tissue was let in $70 \%$, $80 \%, 90 \%, 96 \%$ and $100 \%$ ethanol for at least $1 \mathrm{hr}$ at RT. Later, the ethanol was removed from the tissue by incubating it in isopropanol overnight. Tissue was then incubated in different mixtures of isopropanol/xylol (histoclear) in ratios $3: 1,1: 1$ and 1:3 for $30 \mathrm{~min}$ to $1 \mathrm{hr}$ at RT. Then tissue was incubated in $100 \%$ xylol overnight. Further, tissue was incubated in paraplast at $60^{\circ} \mathrm{C}$ overnight. Before embedding, paraplast was changed at least three times. Finally, the tissue was placed in embedding mould and melted paraffin was poured into the mould to form a block. The block was allowed to cool and was then ready for sectioning or stored at $4^{\circ} \mathrm{C}$.

\subsubsection{Sections of paraffin block}

The paraffin blocks were pre-cut to the optimal size and clamped into the microtome (Hn 40 Ing). The cut-thickness of the paraffin embedded was for $3-7 \mu \mathrm{m}$. The sections were floated on $40^{\circ} \mathrm{C}$ water to allow actual spread and subsequently put onto Superfrost slides. A fine brush was used to transfer the sections to slides. Slides were then dried at $40^{\circ} \mathrm{C}$ 
and incubated in $80^{\circ} \mathrm{C}$ for about 15 min to get rid off excess of paraffin. Slides were then stored at RT for further analysis.

\subsubsection{Hematoxylin-eosin staining of the histological sections}

The stored slides with the paraffin sections were stained by the incubating the slides three times in histoclear (Xylol) for 3 min and in 100\%, 96\%, 80\%, 70\% and 50\% ethanol each for $2 \mathrm{~min}$. After washing $\mathrm{H}_{2} \mathrm{O}$ for $1 \mathrm{~min}$ and the sections were stained for $15 \mathrm{~min}$ in hematoxylin. The slides were then rinsed in running tap water (control) for $10 \mathrm{~min}$, and then in $\mathrm{dH}_{2} \mathrm{O}$ for a min. $0.1 \%$ Eosin and 2 drops of acetic acid were applied for 5 min, and after keeping in $\mathrm{dH}_{2} \mathrm{O}$ for 1 min the slides were again incubated in $50 \%, 70 \%, 80 \%$, $90 \%, 96 \%$ and $100 \%$ ethanol each for $2 \mathrm{~min}$. Finally the slides were incubated two times in histoclear (Xylol) for $3 \mathrm{~min}$.

\subsubsection{Determination of sperm parameters}

\subsubsection{Sperm count in epididymes}

Epididymes of mice were dissected under aseptic condition and put in $0.5 \mathrm{ml}$ of in vitro fertilization (IVF) medium. Spermatozoa were allowed to swim out of the epididymes for $1 \mathrm{hr}$ at $37^{\circ} \mathrm{C}, 5 \% \mathrm{CO}_{2}$. Sperm suspension was diluted $10-40$ times with PBS before counting, when necessary. $5 \mu$ of this suspension was put into Neubauer counting chamber and spermatozoa were counted in 8 independent fields (each having an area of $0.0025 \mathrm{~mm}$ ) under the microscope (Olympus BX60) with 20x magnification. Total spermatozoa were calculated by following formula:

Total Sperm $=$ average No. of sperm $\times 10 \times 500 \times \mathrm{D}$ (D is the dilution factor)

\subsubsection{Determination of sperm abnormalities}

For the determination of sperm abnormalities, sperm suspensions were spread onto Super frost slides, air-dried and fixed in 4\% PFA for $10 \mathrm{~min}$ at RT. Slides were then washed in $\mathrm{H}_{2} \mathrm{O}$ for $1 \mathrm{~min}$ and then stained in haematoxylin for $15 \mathrm{~min}$. Next, slides were washed in running tap water for approximately $10 \mathrm{~min}$ and finally stained with eosin $(0.1 \%+2 \%$ acetic acid) for a min and again washed in $\mathrm{H}_{2} \mathrm{O}$ for 1 min. 200 spermatozoa were counted 
and percentage of normal or abnormal (unusual sperm head shape) sperm was determined.

\subsubsection{Acrosome reaction}

Spermatozoa were isolated and capacitated by incubating for $1 \mathrm{hr}$ at $37^{\circ} \mathrm{C}$ with $5 \% \mathrm{CO}_{2}$. Sperms were transferred into two microcentrifuge tubes and centrifuged for $2 \mathrm{~min}$ at 3000xg. The supernatant was aspirated, leaving only $50 \mu \mathrm{l}$ for resuspension of sperms. $2.5 \mu \mathrm{l}$ of Ionophore A23187 (final concentration $10 \mu \mathrm{m}$ in DMSO) was added to sperm suspension. For negative control $2.5 \mu \mathrm{l}$ of phosphoric acid $(5 \mathrm{mM})$ was added and incubated at $37^{\circ} \mathrm{C}$ for $1 \mathrm{hr}$. The sperms were then fixed in $500 \mu \mathrm{l}$ of $2 \%$ formaldehyde (in PBS) for $30 \mathrm{~min}$ at $4{ }^{\circ} \mathrm{C}$. After completion of fixation, sperms were centrifuged at $4000 \mathrm{xg}$ for 2 min. Sperms were further washed twice with $0.15 \mathrm{mM}$ ammonium acetate. Finally the sperms were resuspended in $100 \mu \mathrm{l}$ of PBS and $30 \mu \mathrm{l}$ of suspension was spread on superfrost slide and air-dried. The slides were stained with Coomasie G-250 in $3.5 \%$ $\mathrm{H}_{2} \mathrm{O}_{2}$ for 2.5 min. Unbound dye was removed by washing several times with water. The slides were mounted with $30 \%$ glycerol and observed under microscope. At least 200 sperms with and without blue head were counted. And, blue head sperms represent those sperms which failed to undergo acrosome reaction.

\subsubsection{Sperm protein extraction}

For sperm protein analysis, mouse cauda epididymal sperms were allowed to disperse in PBS at $37^{\circ} \mathrm{C}$ for $1 \mathrm{hr}$, washed three times in PBS and then suspended in lysis buffer $(\mathrm{NaCl} 150 \mathrm{mM}$, TrisHCl $50 \mathrm{mM}$, Nonidet-P40 1\%), to obtain total sperm protein extracts. After quantification the protein extracts were then subjected to SDS-PAGE and Westen blotting.

\subsubsection{Bioinformatic analysis}

For the analysis of the nucleotide sequences, programs like BLAST, MEGABLAST and other programs from National Center for Biotechnology Information (NCBI) were used (www.ncbi.nlm.nih.gov). And for restriction analysis of DNA NEBcutter V2.0 programm was used (http://tools.neb.com/NEBcutter2/index.php). Information about mouse alleles, 
phenotypes and strains were obtained from the Jackson Laboratory webpage (www.informatics.jax.org). For basic calculations of molecular biology ExPASy tools (www.expasy.ch) and Promega Biomath calculator (http://www.promega.com/biomath/) were employed. Mouse genome sequence and other analysis on mouse genes, transcript and putative proteins were downloaded from Celera discovery system (www.celera.com). Statistical analysis was performed using Statistica software (Statsoft ${ }^{\circledR}$, http://www.statsoftinc.com). 


\section{Results}

\subsection{Creation and establishment of transgenic mouse models for Mecp2 gene}

\subsubsection{Analysis of upstream sequence of the Mecp2 for promoter activity}

The exact promoter region of Mecp2 gene has not yet been characterized well. To have an endogenous pattern of expression of the transgene, it was important to identify the putative promoter of Mecp2 gene. Progressively, around $3 \mathrm{~kb}$ upstream sequence of exon1 of the Mecp2 gene was analysed by, 'Mcpromoter promoter prediction software' (Fig.4).

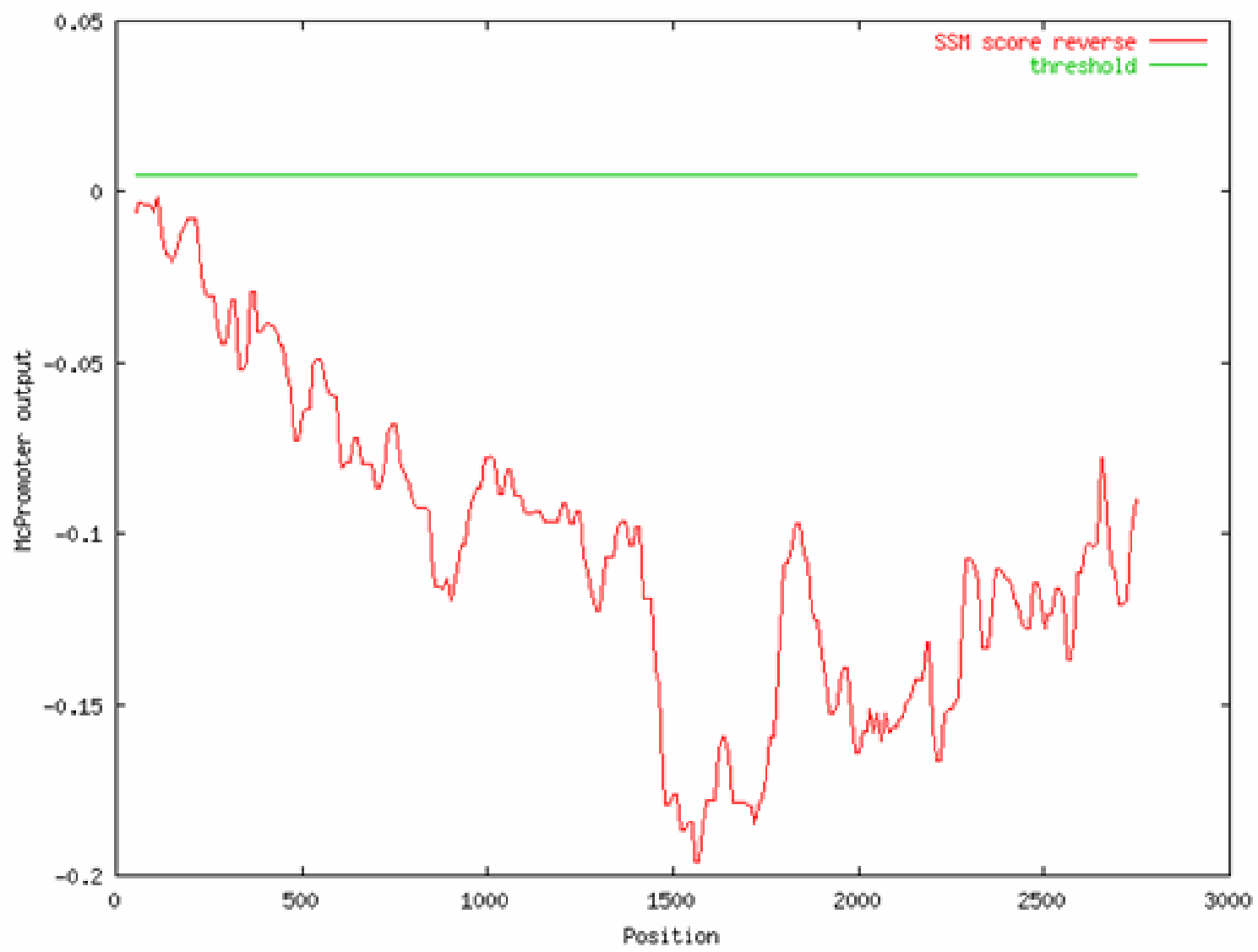

Fig. 4 Mcpromoter promoter prediction software analysis: Around $3 \mathrm{~kb}$ upstream sequence of exon 1 of the Mecp2 gene was analysed by 'Mcpromoter promoter prediction software' to identify the putative promoter of Mecp2 gene for the transgenic constructs. The output of McPromoter is a list of predicted transcription start sites. The score which is printed next to the predicted site is the output of the predictor and lies between approximately -0.5 and 0.1 , larger values being better. The threshold defines a minimum 
score for a promoter to be reported. If there are multiple predictions within 500 bases, only the best one is showed.

The $3 \mathrm{~kb}$ upstream sequence seemed to contain some transcription factor binding sites and possible regulatory elements from the analysis. Towards that, a mouse genomic fragment (around $120 \mathrm{~Kb}$ ) contained in the BAC clone B22804 (kindly gifted by Dr. Matthias Platzer, Jena, Germany, (Reichwald et al., 2000)) was digested with EcoRI restriction enzyme and a unique $6.2 \mathrm{~Kb}$ resulting fragment was shot-gun cloned into pUC19 vector. The mouse genomic fragment in the BAC clone contained all the exons of Mecp2 gene along with the flanking sequences and one other neighbouring gene on either sides. Opsin 1 gene was present on the 5' side of the Mecp 2 gene and a truncated part of Interleukin 1 receptor associated kinase (Irak 1) gene on the 3' side (Fig. 5). The $3 \mathrm{~Kb}$ upstream sequence along with a part of exon 1 was subcloned from the above mentioned clone by another restriction digestion with EcoRI and BsrBI to a promoterless pEGFP1 mammalian expression vector from Clontech, USA, containing EGFP protein as the reporter. This final clone was used in transfection assays to check for the promoter activity by the expression of EGFP.

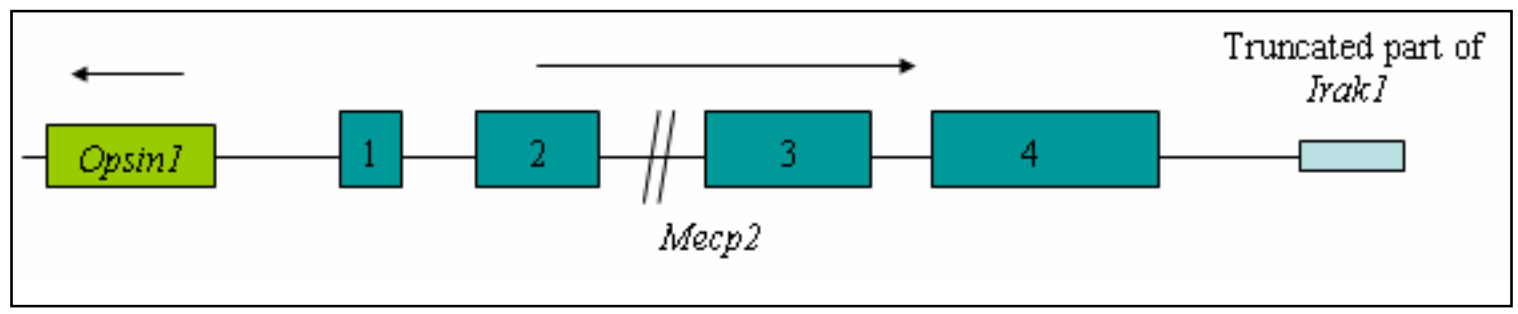

Fig. 5 Schematic representation of the genomic fragment in the BAC clone: The BAC clone (B22804), Gene Acc. No. af121351 containing a genomic fragment which encompasses the Mecp 2 gene having all the 4 exons with $O p \sin 1$ gene on the 5' side and a truncated part of Interleukin 1 receptor associated kinase (Irak 1) gene on the 3' side. The direction of the transcription is shown by the arrows.

\subsubsection{Expression analysis of the Mecp2 in different cell lines}

Before checking the promoter activity of the $3 \mathrm{~kb}$ upstream sequence in pEGFP1, different cell lines were tested for the expression of Мecp 2 to be used for the transfection. A mouse neuroblastoma cell line, NS20Y, a human cervical carcinoma cell line, HeLa, along with mouse embryonal teratocarcinoma cell line (F9), mouse kidney cell line 
(NPI), and mouse fibroblast cell line (3T3) were checked for expression of the Mecp2 gene by RT-PCR using Mecp2_Mus_RT_For (binds in the 5' UTR) forward primer and Mecp2_Mus_RT_Rev3 (binds in the exon 4) reverse primer. All the tested cell lines expressed Mecp 2 transcript except F9 cell line. Then, NS20Y and HeLa cell lines were selected depending upon the strength of expression of the Mecp2 gene for transient transfection assays (Fig. 6).

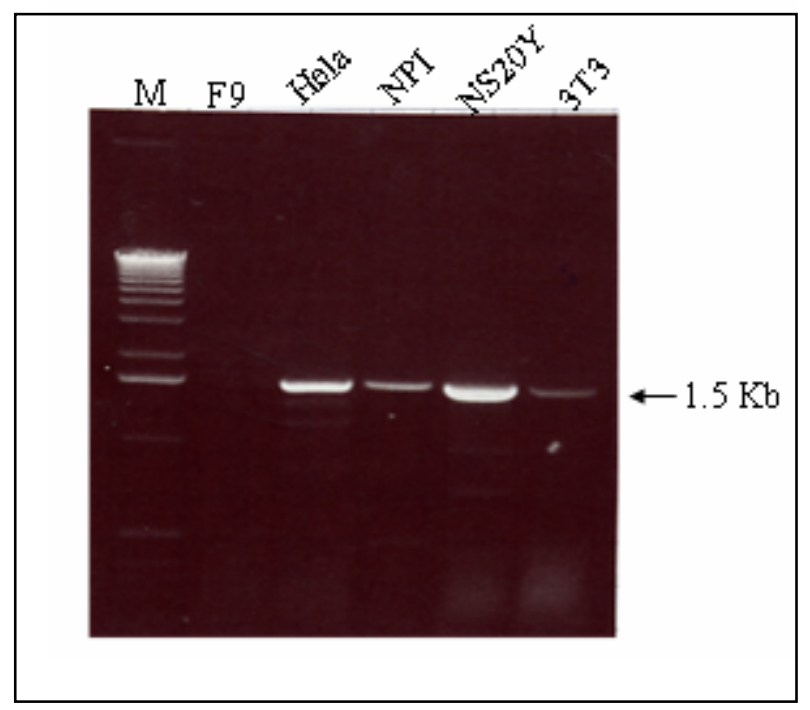

Fig. 6 RT-PCR analysis of the Mecp2 gene in different cell lines: The expression of the Mecp2 mRNA transcripts were checked by reverse transcriptase PCR analysis using RNA from mouse embryonal teratocarcinoma (F9), human cervical carcinoma (HeLa), mouse kidney cell line (NPI), mouse neuroblastoma (NS20Y) and mouse fibroblast cell line (3T3). Except the F9, all the other tested cell lines expressed Mecp 2 mRNA. M: $1 \mathrm{~Kb}$ DNA molecular weight marker.

\subsubsection{Transient transfection assay for Mecp2 promoter analysis}

The $3 \mathrm{~Kb}$ upstream sequence cloned in pEGFP1 vector was then transiently transfected into NS20Y and HeLa cell lines to check for the promoter activity. A pEGFP_C1 vector which expresses the EGFP protein under the control of a constitutive CMV (Cyto Megalo Virus) promoter was used as a positive control for the transfection. But there was no significant promoter activity for the $3 \mathrm{~kb}$ upstream sequence (Fig. 7). 

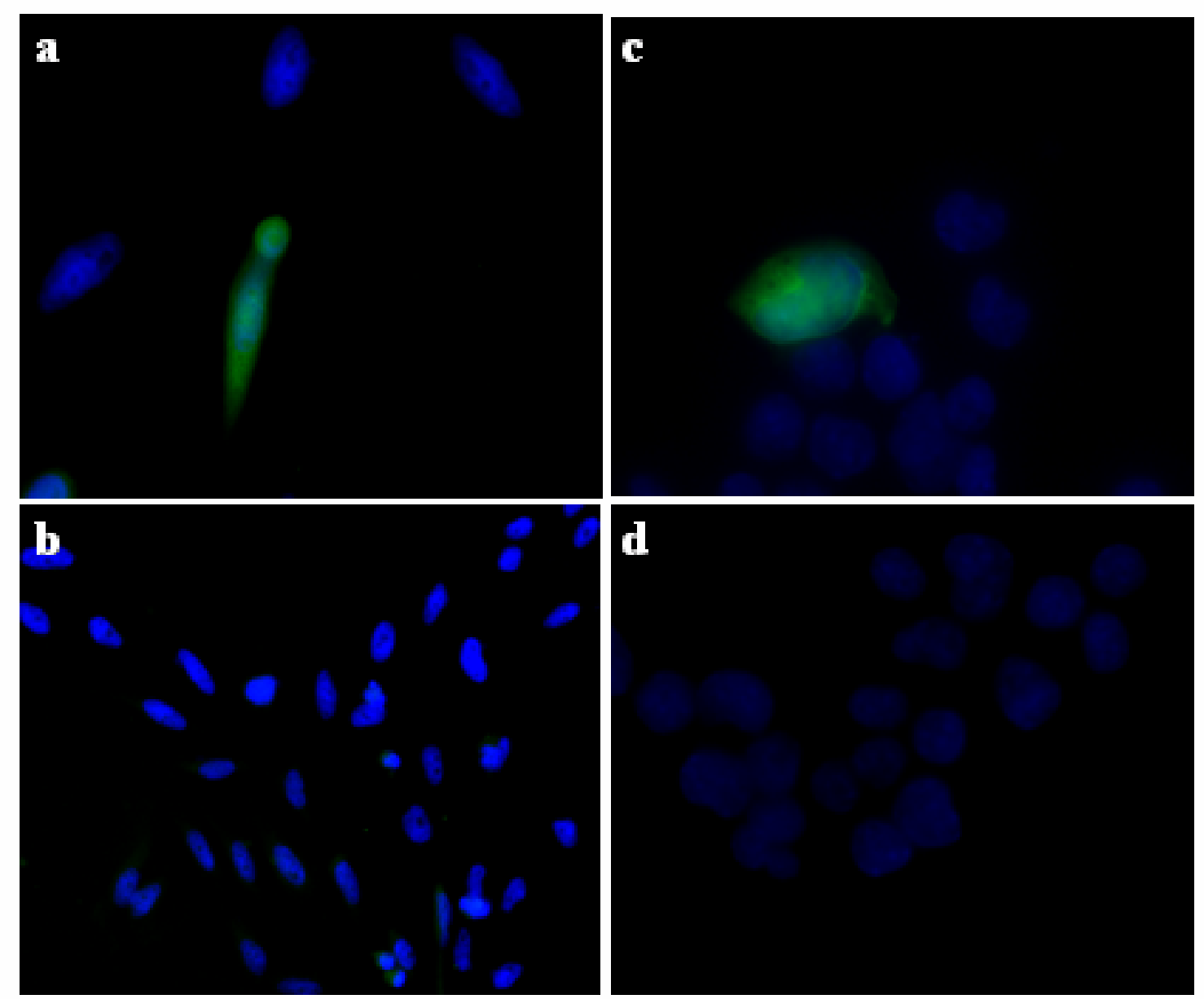

Fig. 7 Transient transfection assay for promoter analysis: The $3 \mathrm{~Kb}$ upstream sequence of exon 1 of the Mecp 2 gene cloned in the promoterless pEGFP1 vector was transiently transfected into HeLa (b) and NS20Y (d) cell lines to check for the promoter activity. pEGFP_C1 vector was used as a positive control for the transfection in HeLa (a) and NS20Y cell lines (c). Blue colour represents the DAPI staining of the nuclei and green colour represents the fluorescence from the EGFP reporter.

\subsubsection{Verification of the expression of exon 1 of the Мecp2 gene}

The exon1 of Mecp 2 gene was recently described (Reichwald et al., 2000). Also there was no significant promoter activity for the $3 \mathrm{~Kb}$ upstream sequence of the exon 1 . So, a careful analysis of the sequence of exon 1 and intron 1 of the Mecp 2 gene was done to identify the regulatory element. The expression of the exon 1 of Mecp 2 gene in the cell lines (NS20Y, HeLa) was checked by RT-PCR (Fig. 8) using Mecp2_RT_EX1_Maus_F (binding specifically in exon 1) forward primer and Mecp2_Mus_RT_Rev3 (binding in the exon 4) reverse primer amplifying the Mecp 2 mRNA transcript from exon 1 to exon4. 
After the expression of exon 1 of Mecp 2 gene in the cell lines was confirmed, the presence of a highly conserved (between mouse and human (80\%)) $1 \mathrm{~Kb}$ intronic region immediately downstream of the exon 1 was observed (Fig. 9). Then, an attempt was made to sequence the conserved region in Rett patients who had no mutation in MECP2 gene. But since the region was extremely GC-rich, it was not successful. And while the process was underway, the discovery of two isoforms of Mecp2 protein derived from alternative splicing between exon 1 and exon 2 of the Mecp 2 gene that vary in abundance between brain and non-brain tissue was reported (Mnatzakanian et al., 2004). Altogether, it was very difficult to identify the exact regulatory elements involved in the expression of the Mecp2 gene. So, the whole length gene contained in the genomic fragment of the BAC clone was used to create the transgenic construct.

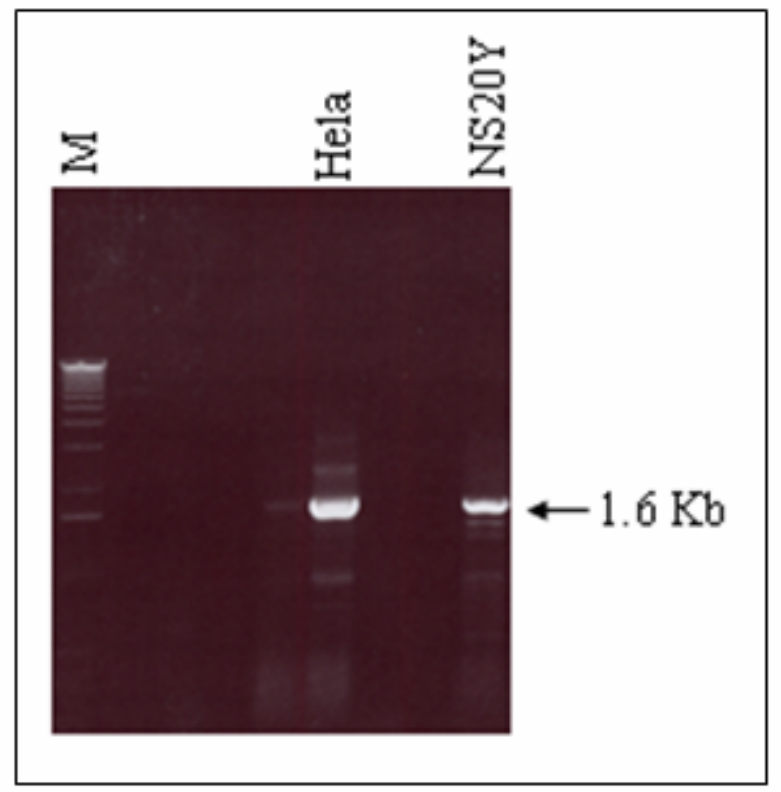

Fig. 8: RT-PCR analysis of expression of exon 1 of Mecp2 gene: The expression of the exon 1 of Mecp2 mRNA was confirmed by reverse transcriptase PCR analysis using RNA from human cervical carcinoma (HeLa) and mouse neuroblastoma (NS20Y) cell lines. M: 1 Kb DNA molecular weight marker. 
(a)

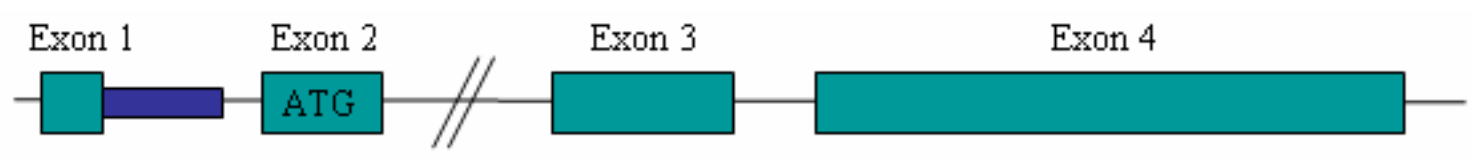

(b)

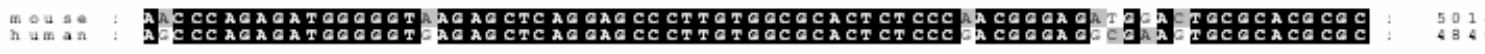

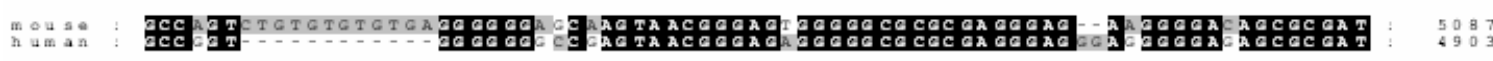

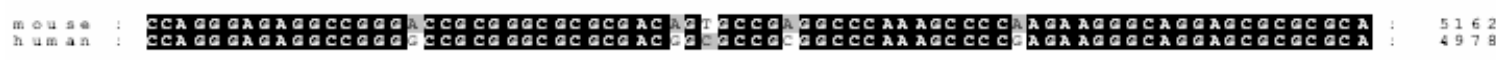

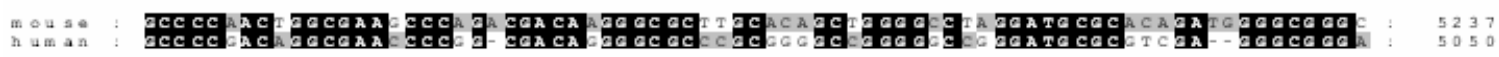

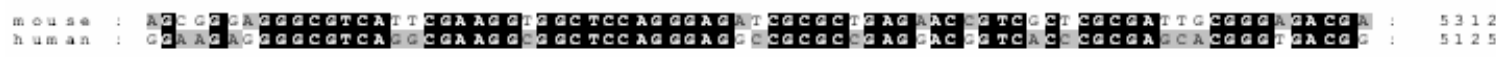

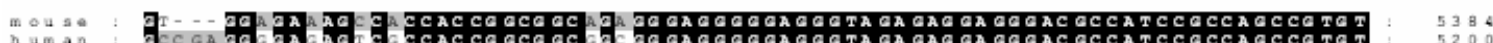

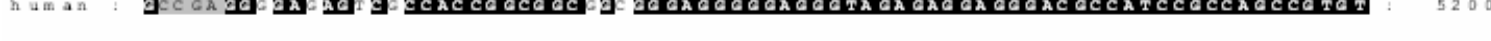

mous
in
h $\mathrm{m}$ an

mous
h $\mathrm{H}$ an

mous a
muman

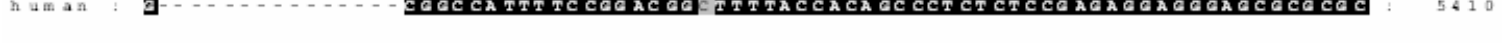

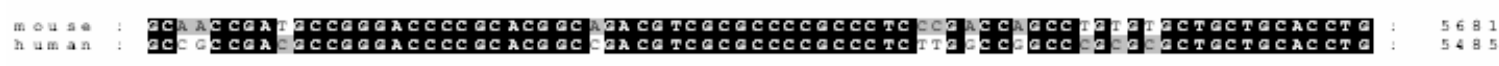

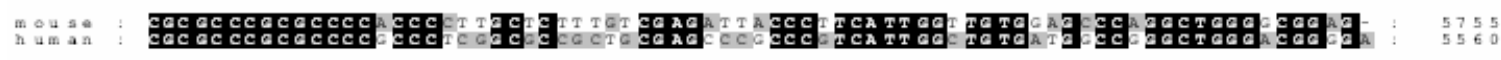

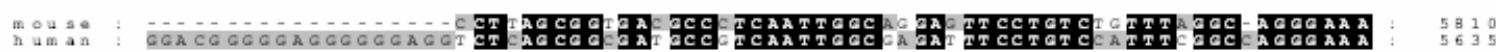

mous $\begin{gathered}\text { mo } \\ \text { hum }\end{gathered}$

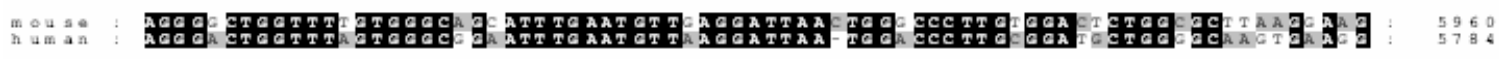

mous
hum
un

Fig. 9 The highly conserved intronic region: The pictorial representation of the Mecp2 gene showing the highly conserved $1 \mathrm{~Kb}$ intronic region immediately downstream of exon 1 in the blue box (a). The sequence similarity of the intronic region between mouse and human (80\%) (b).

\subsubsection{BAC transgenesis for Mecp2 gene}

Getting to know about the complex structure of the Mecp2, BAC transgenesis was opted to proceed with. It would be advantageous since a genomic clone tends to give more physiologic expression patterns than cDNA inserts, escaping from transgene silencing by integration into heterochromatin regions of the genome. The aim of the project was to produce transgenic mouse models overexpressing Mecp 2 tagged in frame by EGFP as a 
reporter to obtain an appropriate functional analysis of Mecp2. Since it was nearly impossible to clone EGFP cassette downstream of the Mecp2 in the genomic fragment by normal restriction digestion, the genomic BAC clone was genetically engineered by an inducible homologous recombination technique in E.coli called GET recombination (facilitated by the genes lamda $\boldsymbol{g a m}, \operatorname{rec} \boldsymbol{E}$ and $\operatorname{rec} \boldsymbol{T}$ ) to fuse the EGFP cassette downstream of the Mecp2. During the recombination of the EGFP cassette, along with the stop codon of Mecp 2 gene around $1 \mathrm{~Kb}$ sequence immediately downstream in the 3' UTR was deleted (Fig. 10).

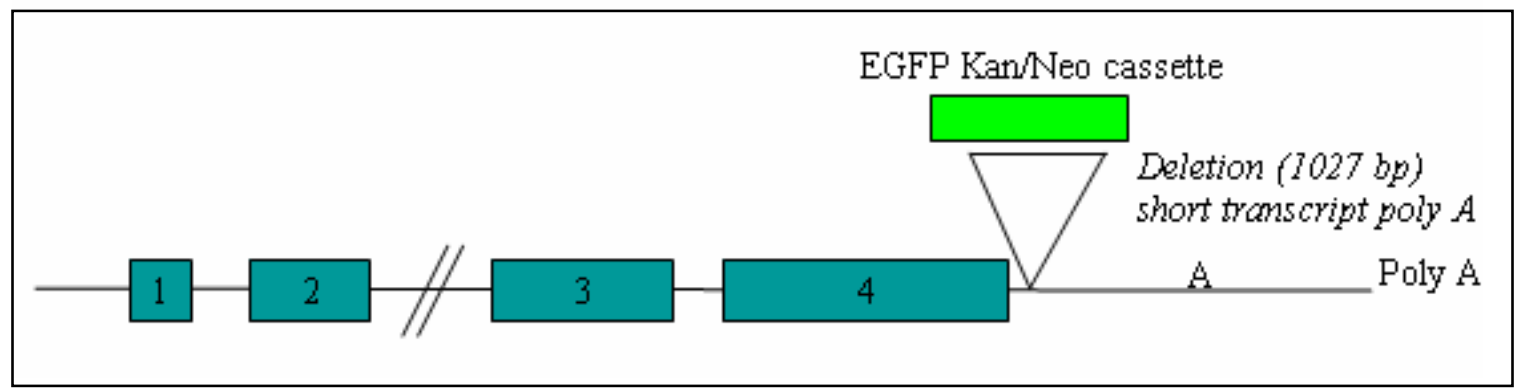

Fig. 10 Diagramatic representation of the GET recombination of EGFP cassette in Mecp2 gene: The GET recombination was performed to recombine the EGFP cassette including Kan/Neo selection marker downstream of the Mecp2 gene as a fusion construct. While recombining the EGFP cassette, along with the stop codon around $1 \mathrm{~Kb}$ sequence immediately downstream in the 3' UTR was deleted enclosing a short poly A signal of Mecp2 gene.

\subsubsection{Creation of the transgenic constructs by GET recombination}

Three transgenic constructs, one expressing the wild type (WT) Mecp2 and two truncated forms of the gene (to mimic the mutations found in Rett patients) were designed. The constructs were named as,

1. Mecp2_WT_EGFP -- $\quad$ for expressing WT Mecp2.

2. Mecp2_270_EGFP -- C-terminal truncation, after 270 amino acids supposed to disturb the Nuclear Localization Signal (NLS), an ectopically expressing protein causing a severe phenotype in Rett patients.

3. Mecp2_400_EGFP -- C-terminal truncation, after 400 amino acids causing a milder phenotype in Rett patients. 
The GET recombination was performed as described in section 2.2.8 and 4.1.2. The EGFP cassette used was amplified from the pEGFP1 vector from Clontech, USA, which contains the EGFP ORF, HSV (Herpes Simplex Virus) polyadenylation signal which can be used by the transgene and the Kan/Neo antibiotic selection marker genes to screen the recombinants. The primers used for amplifying the EGFP cassette contained around 50 bp of homology arms to the target site in the BAC clone B22804 by PCR based add-on mutagenesis. For the Mecp2_270_EGFP and Mecp2_400_EGFP mutation constructs, only the 5 ' homologous primer was designed in a different way to contain the homologous region binding on exon 4 (last exon) of Mecp2 gene which creates a corresponding deletion during recombination after 200 and 400 aminoacids of Mecp2 respectively. Also, the primers had two glycine codons between the mutated Mecp2 protein and the EGFP protein to facilitate the proteins virtually to be independent during folding and functioning. The amplified EGFP cassette (900 ng of the gel extracted PCR product) was electroporated into electro-competent DH10B E.coli cells containing the BAC clone and the pGET plasmid which facilitates the recombination. The positive clones were screened by plating the cells in Kanamycin (Kan) selection marker.

The integration of the EGFP cassette after due recombination was confirmed by EGFP Kan/Neo primers (EGFP_Rev1 and Kan_check_F1) and flanking primers away from the recombination region on either sides (MeCP2_check_F1 on exon 4 and MeCP2_check_R1 on 3' UTR of Mecp2 gene) (as illustrated in Fig. 11, Fig. 12 and Fig. 13). Thus, a recombination was performed to recombine the EGFP cassette downstream of the Mecp 2 gene as a fusion construct. The transgenic constructs were then checked for the expression by transfecting into cell lines. 
(a)
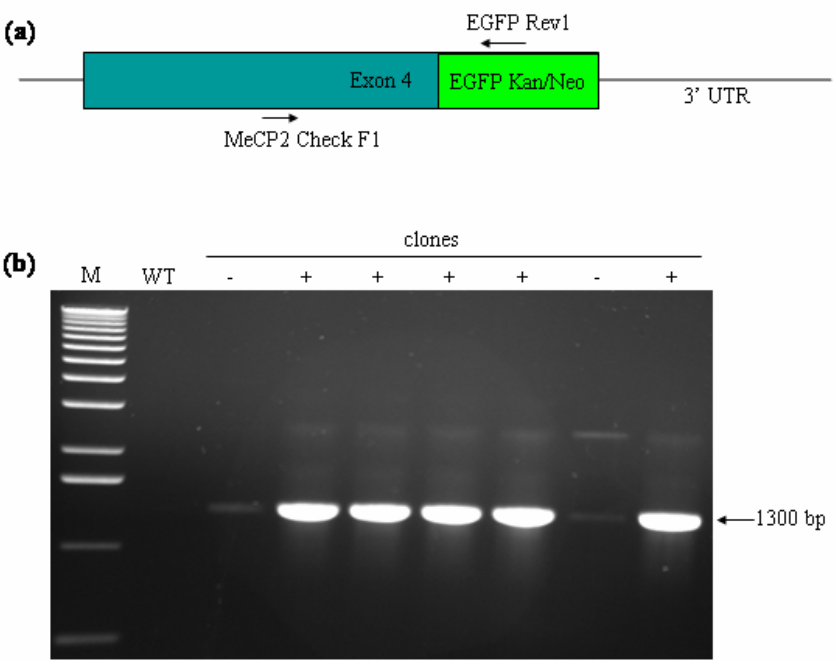

Fig. 11 Verifying the recombination of EGFP Kan/Neo cassette by PCR on 5' side: The integration of the EGFP cassette after due recombination as a fusion with exon 4 of Mecp 2 gene was confirmed by MeCP2_check_F1 primer binding on exon 4 of Mecp2 away from the recombination region and EGFP_Rev1 primer as shown graphically in (a) and the agarose gel picture of the positive clones (b). WT: wild type, M: $1 \mathrm{~Kb}$ DNA molecular weight marker, +: positive clones, -: negative clones.

(a)

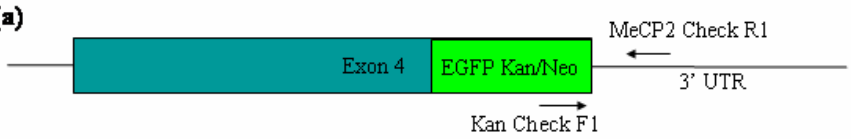

(b)

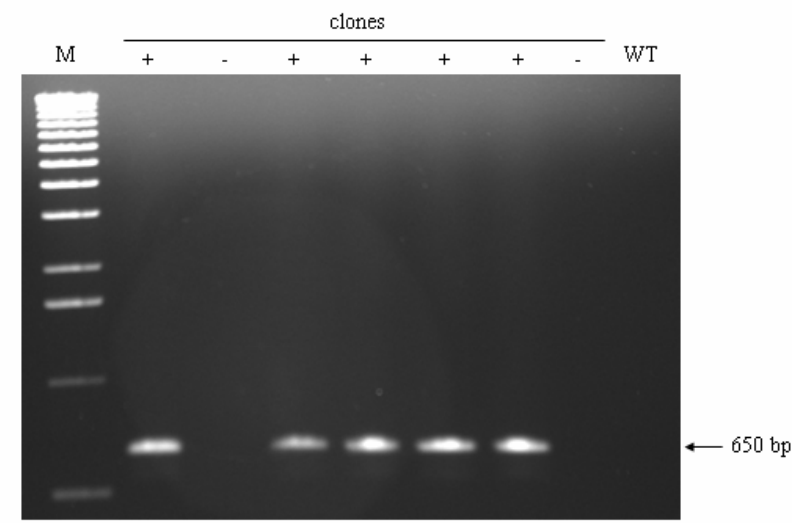

Fig. 12 Verifying the recombination of EGFP Kan/Neo cassette by PCR on 3' side: The integration of the EGFP cassette after due recombination as a fusion with exon 4 of Mecp 2 gene was confirmed by Kan_check_F1 primer and MeCP2_check_R1 primer binding on 3' UTR of Mecp2 away from the recombination region as shown graphically in (a) and the agarose gel picture of the positive clones (b). WT: wild type, M: $1 \mathrm{~Kb}$ DNA molecular weight marker, +: positive clones, -: negative clones. 
(a)

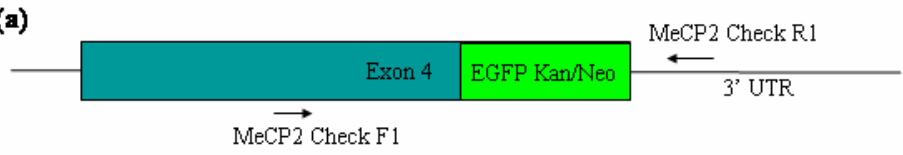

(b)

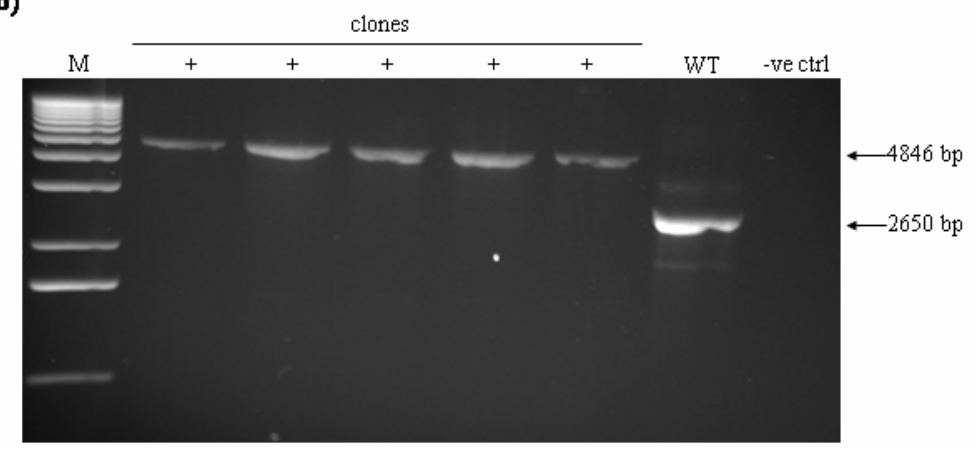

Fig. 13 Verifying the recombination of EGFP Kan/Neo cassette by PCR using flanking primers: The integration of the EGFP cassette after due recombination as a fusion with exon 4 of Mecp2 gene was confirmed by MeCP2_check_F1 and MeCP2_check_R1 primers binding on exon 4 and 3'UTR of Mecp2 respectively, away from the recombination region as shown graphically in (a) and the agarose gel picture of the positive clones (b). WT: wild type, M: $1 \mathrm{~Kb}$ DNA molecular weight marker, +: positive clones, -: negative clones, -ve ctrl: null (water) control.

\subsubsection{Transfection of the transgenic construct in the cell lines}

To ensure that the transgenic construct expresses the transgene aptly, the Mecp2_WT_EGFP transgenic BAC construct was tried transfecting in NS20Y neuroblastoma cell line through electroporation. But the electroporation of the huge genomic construct could not be demonstrated. Another attempt was made to transfect the construct using an E.coli strain capable of entering and delivering large DNA constructs directly into the mammalian cells (Narayanan and Warburton, 2003) exploiting the invasin gene from Yersinia pseudotubercularis. But since the strain with invasin gene should be handled under proper regulations, the permission to work with the strain was denied in the institute and so the transgenesis was executed at once without checking for the expression of the transgenic construct. 


\subsubsection{Modification of the transgenic constructs}

Since the engineered genomic BAC clone also contained Opsin 1 and Irakl genes, the constructs underwent further modifications for the transgenesis. Opsin 1 and Irakl genes in the genomic BAC clone were deleted by additional GET recombinations using the zeocin selection cassette (containing the homology arms and Zeocin antibiotic marker gene driven by EM7 promoter). Initially, Opsin 1 gene was deleted with zeocin selection cassette designed to be flanked with MluI restriction sites, not present anywhere in the BAC clone, which enable the specific removal of zeocin cassette by restriction digestion and religation and to use the same cassette for further recombination to delete Irak1. But the specific removal of zeocin cassette using MluI restriction enzyme after the deletion of Opsin 1 was extremely difficult because of the large number of background bacterial colonies obtained due to the undigested BAC clone after transformation of the digested clone. Moreover, since it was a negative selection the colonies had to be screened by replica plating in LB agar plates with and without zeocin antibiotic. So, the specific removal of zeocin cassette using MluI restriction digestion and religation was not possible until the cassette was digested internally using a rare cutter, RsrII, during the process. The cassette used for the deletion of the Irakl gene had another rare cutter, namely AscI (Fig. 14). Thus, the repeated GET recombination steps helped to delete the other genes in the genomic fragment and the construct was ready for the transgenesis. 
(a) First recombination

Truncated part of Irak1

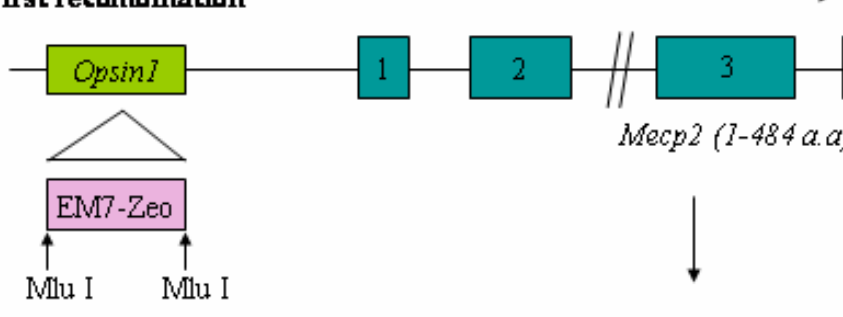

(b) Digestion and religation

Truncated part of Irak1

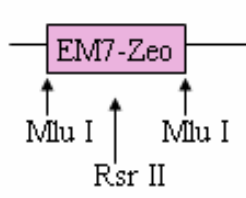

(c) Secand recambinatim

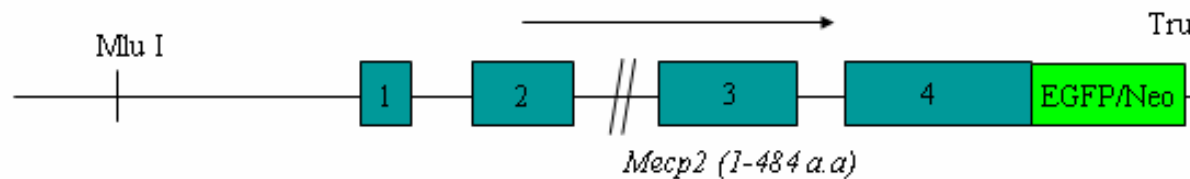

(d) Final construct

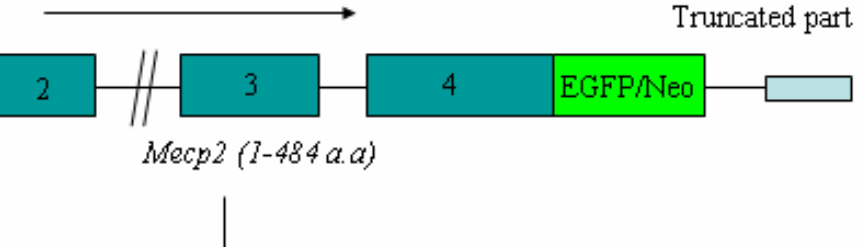

Truncated part of Irak1

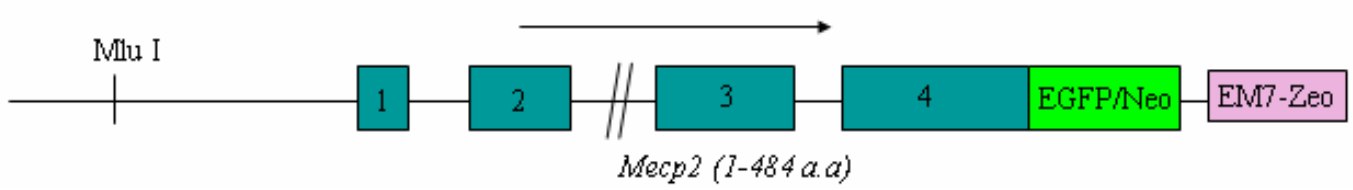

Fig. 14 Graphical representation of the modification of the transgenic construct: The engineered genomic BAC clone also contained Opsin 1 and Irakl genes. After recombining EGFP Kan /Neo cassette (a), the Opsin 1 and Irakl genes in the genomic BAC clone were deleted by additional GET recombinations using the zeocin selection cassette, which is shown graphically in (b) and (c), respectively. Initially, Opsin 1 gene was deleted with zeocin selection cassette designed to be flanked with MluI restriction sites. The zeocin cassette was digested internally by RsrII then and the same cassette was used for the deletion of the Irakl gene having AscI sites. The final construct after the modifications is shown in (d).

\subsubsection{The final constructs for transgenesis}

After all the modifications, the final constructs for transgenesis were checked for any rearrangements and multiple integrations by digesting the constructs with HindIII enzyme (Fig. 15) and performing a Southern blotting using an 5' external probe for Mecp2 gene (Fig. 16) and an EGFP probe (Fig. 17). For generating the 5' external probe, a fragment of 600 bp was amplified by PCR, using primers Bac Mecp2 ext_5_F and Bac Mecp2 
ext_5_R. The PCR fragment was cloned in pGEM-T-Easy vector and then extracted with EcoRI restriction enzyme. This external probe recognizes a $3.0 \mathrm{~kb}$ fragment in case of wild type $\mathrm{BAC}$ clone and $3.7 \mathrm{~Kb}$ in case of recombinant clone in Southern blot hybridization after digestion of genomic DNA with HindIII enzyme. The results indicated that there were no rearrangements and multiple integrations because of the recombination. The final constructs were then (Fig. 18) linearised with MluI enzyme and given to the Max-Planck Institute for Experimental Medicine, Goettingen, Germany, for pronuclear microinjections into fertilized mouse oocytes.

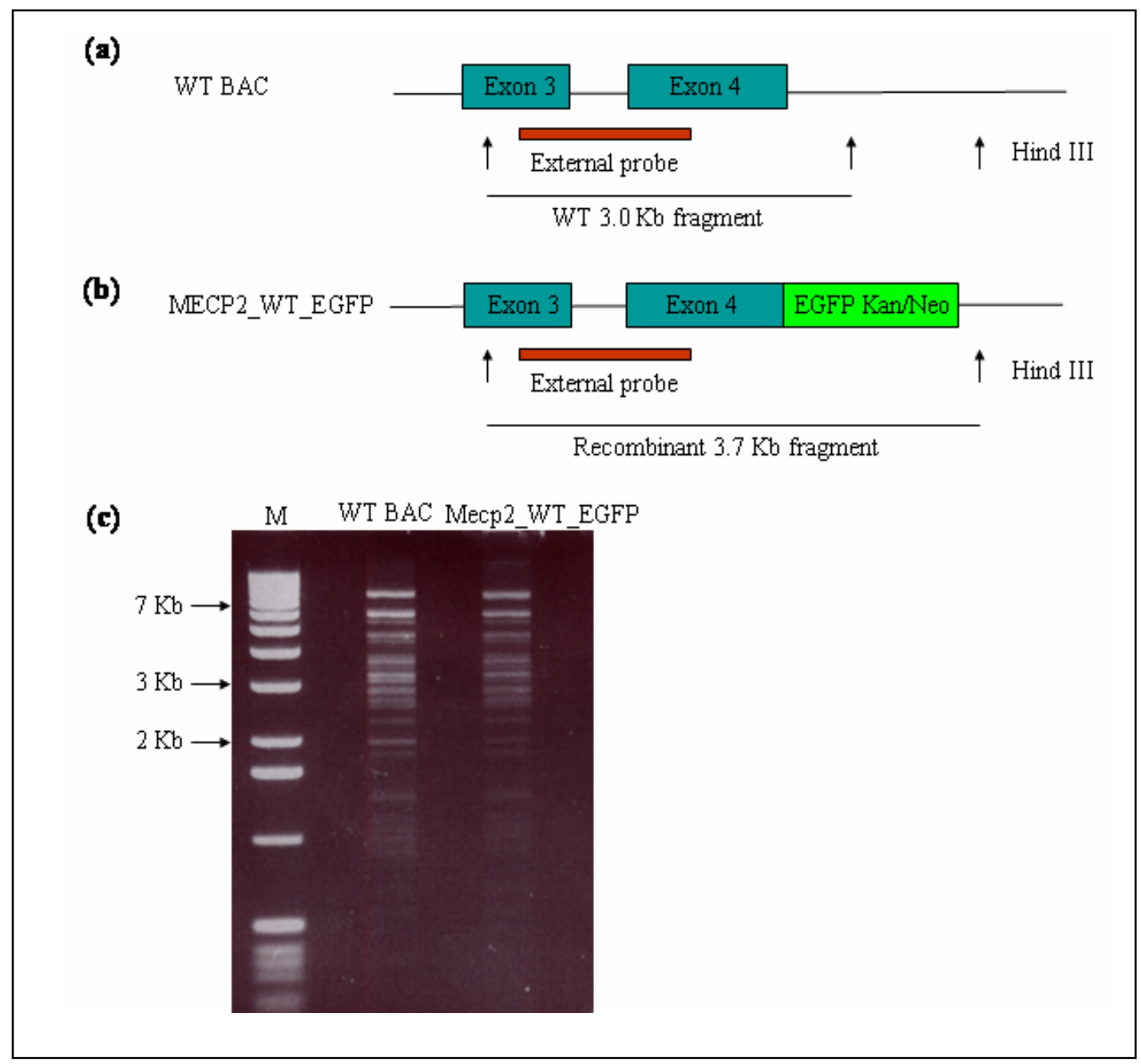

Fig. 15 Checking the transgenic constructs for any rearrangements and multiple integrations during the recombination: Few of the HindIII restriction sites in the WT BAC clone are diagrammatically represented and it is also depicted that HindIII cuts twice in the selected region in the 3' UTR of Mecp2 (a). 
In the Mecp2_WT_EGFP transgenic construct, HindIII cuts only at one site in the selected region in the 3' UTR of Mecp 2 because of the deletion of HindIII site along with the deletion of $1 \mathrm{~kb}$ region in the 3' UTR during recombination of EGFP Kan/Neo cassette (b). The external probe shown as a red block should recognize a $3.0 \mathrm{~kb}$ band in case of wild type $\mathrm{BAC}$ clone and $3.7 \mathrm{~kb}$ in recombinant clone during Southern hybridization. The agarose gel electrophoresis of HindIII digested WT BAC clone and the Mecp2_WT_EGFP transgenic construct is depicted as well (c). M: 1 Kb DNA molecular weight marker.

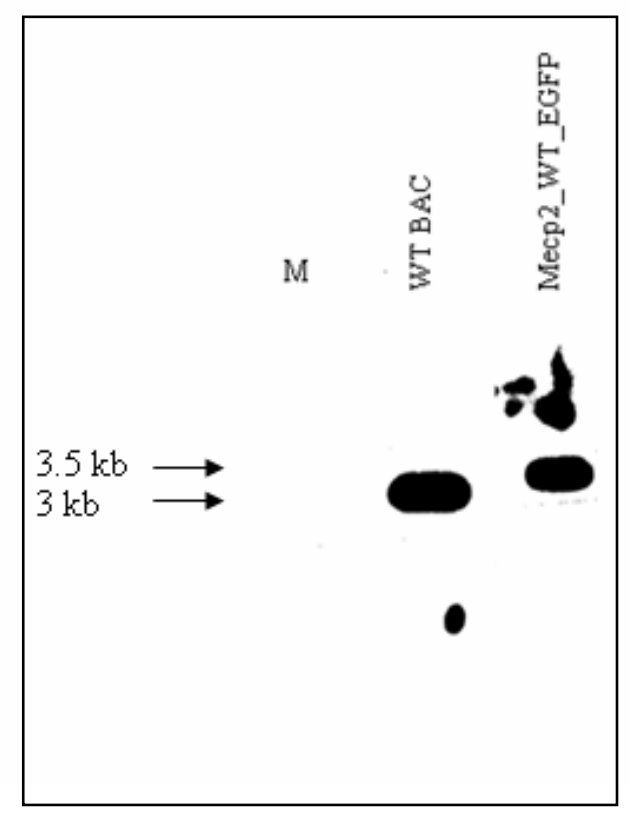

Fig. 16 Checking the transgenic constructs for any rearrangements by Southern blotting: The HindIII digested constructs were subjected to Southern blotting and checked for any rearrangements during the recombination using an 5' external probe for Mecp2 gene. The external probe detected around $3.5 \mathrm{~Kb}$ fragment in the WT BAC clone whereas in the Mecp2_WT_EGFP transgenic construct because of the deletion of the HindIII site along with the deletion of $1 \mathrm{~Kb}$ region in the 3' UTR during recombination, around 700 bp higher band was detected proving no rearrangements in the transgenic construct during recombination. 


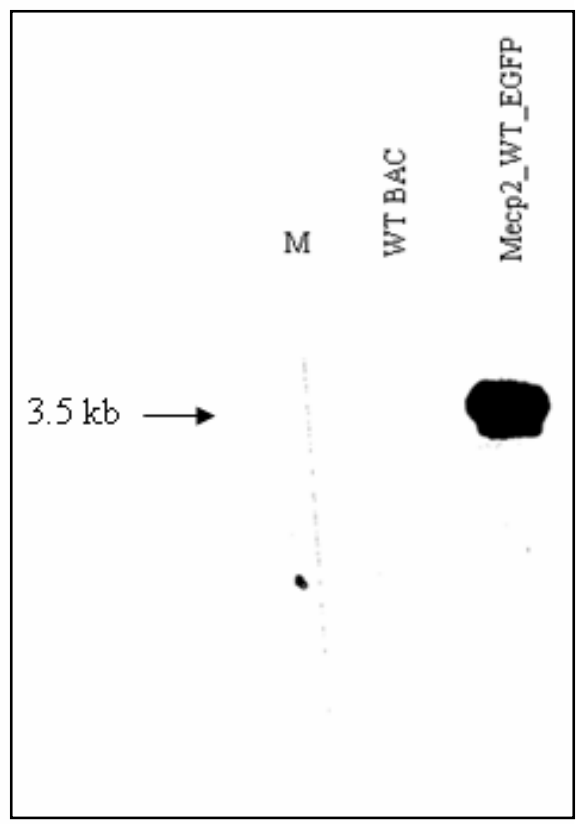

Fig. 17 Checking the transgenic constructs for multiple integration by Southern blotting: The HindIII digested constructs were subjected to Southern blotting and checked for multiple integration during the recombination using an EGFP probe which identified only a single band in the transgenic construct.

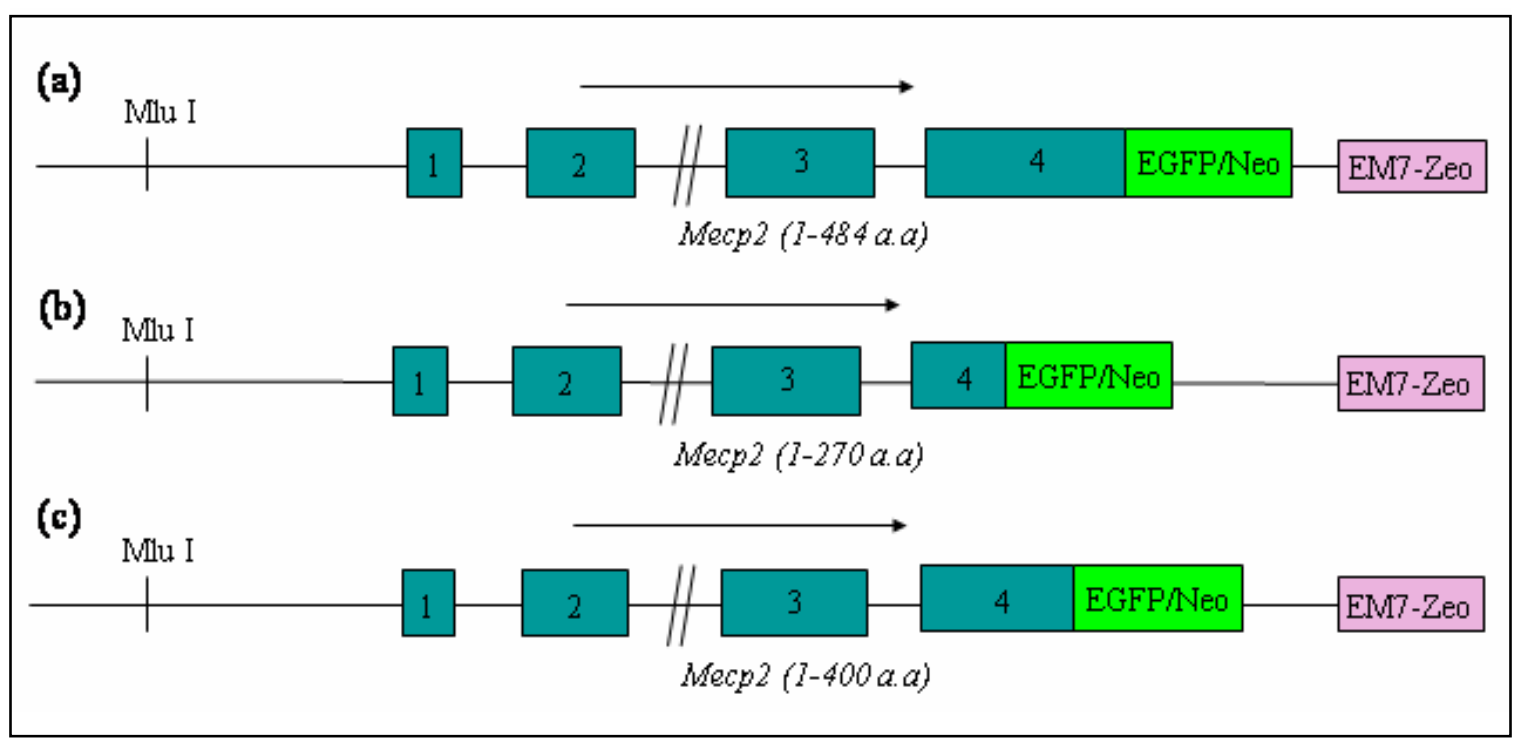

Fig. 18 Final transgenic constructs: The pictorial representation of the final transgenic constructs showing the Mecp2, having 1-484 amino acids (a) and different deletions of Mecp2 having 1-270 amino acids (b) and 1-400 amino acids (c), fused with EGFP reporter as transgenes. The transgenic constructs were then linearized using MluI and given for pronuclear microinjection. 


\subsubsection{Transmission and expression analysis of the transgene}

After the transgenic constructs were microinjected into male pronuclei which are bigger than the female pronuclei of the fertilized mouse oocytes of FVB/N and C57B16/N genetic background, the oocytes were transferred into the uteri of foster mothers of corresponding background, in the Max-Planck Institute for Experimental Medicine, Goettingen, Germany. The pups born were then screened for the presence of the transgene after 3-4 weeks of their age by extraction of the genomic DNA from their tail biopsies (around $1 \mathrm{~cm}$ ) and PCR analysis.

Out of the microinjection of Mecp2_WT_EGFP construct, 7 mice (founders) out of 119 pups (around 5\%) were found to contain the integration of the transgene in the genome. The 7 founders were then bred with WT mice of corresponding background to check for the transmission of the transgene in the first filial (F1) generation. And only 6 of the founders (Nr. 2, 6 39, 49 and 50) were transmitting the transgene. Regarding the Mecp2_270_EGFP construct out of 5 founders which were transmitting the transgene, 2 could not breed and only 3 were bred further. For the Mecp2_400_EGFP construct no founders were transmitting the transgene. The average litter size of the Mecp2_WT_EGFP; Mecp2_270_EGFP \& Mecp2_400_EGFP founder breedings was around $10.8,12.4$ and 9.4 respectively.

As a next step, one heterozygous animal from each F1 generation was sacrificed to test for the expression of transgene. Since the expression of Mecp2 has a vital role in the brain, whole protein from brain of the animal was extracted and subjected to Western blotting. A MeCP2 C-terminal peptide polyclonal antibody from Upstate, USA, was used for the Western blot analysis and it was found that 3 Mecp2_WT_EGFP transgenic founder lines (Line 2, 39 and 49) out of the 6 were expressing the transgene (Fig. 19a). Since the transgene had been fused with EGFP reporter in every case, an EGFP Cterminal peptide polyclonal antibody from Sigma, USA, was used as well to countercheck the expression of the transgene (Fig. 19b). 
But the signals produced in the Western blot analysis by the above said antibodies for the detection of the Mecp2_WT_EGFP transgenic protein were very weak. And in the case of the Mecp2_270_EGFP mutation construct, the expression of transgene was completely undetectable. The Mecp2_270_EGFP transgenic protein could be seen easily only with the EGFP antibody in the Western blot because of the same size of the Mecp2_270_EGFP protein with the endogenous Mecp2 protein. Since the antibodies were not effective enough, the expression of the Mecp2_270_EGFP protein could not be observed although the transcripts could be amplified and all the Mecp2_270_EGFP founder lines were abandoned till a new antibody was raised from the recombinant $\mathrm{MeCP} 2$ protein produced in the laboratory. Later, only the Mecp2_270_EGFP transgenic construct was given for second micro-injection to obtain new founders and the Mecp2_400_EGFP construct was not proceeded further. The second microinjection of Mecp2_270_EGFP construct yielded 3 founders. One founder line (Line 20) transmitting the transgene has to be checked for the expression by Immunohistochemistry. The other two founders (Nr. 35 and 45) have to be checked for the transmittance of the transgene.

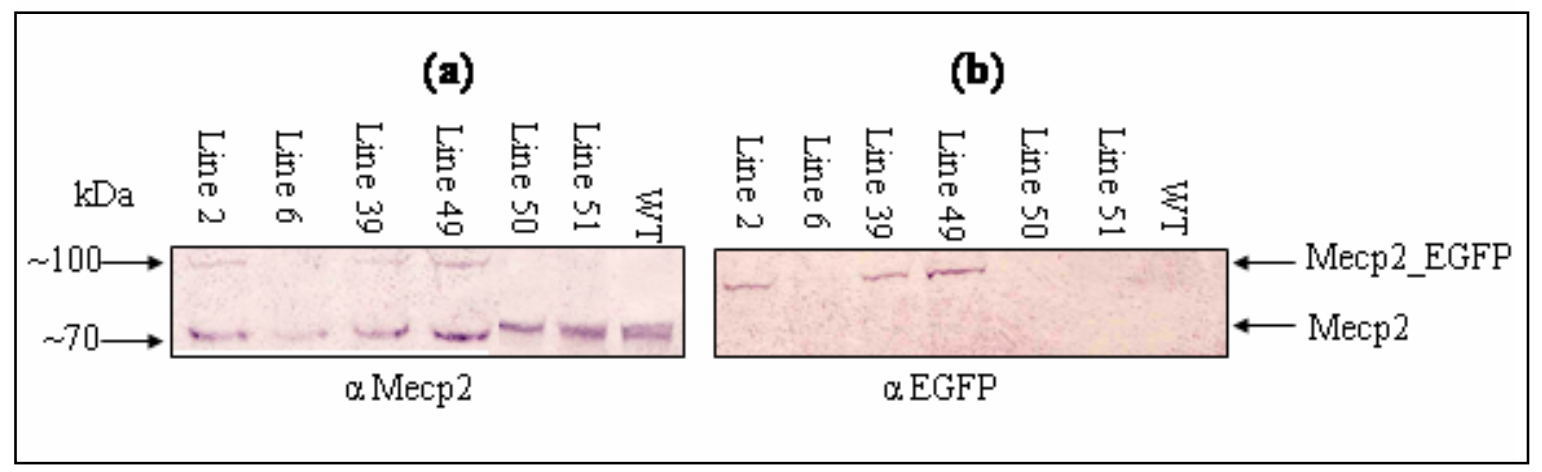

Fig. 19 Western blot analysis for the expression of Mecp2_WT_EGFP transgene: The whole brain extract from the transgenic animals in F1 generation (Line 2, 6, 49, 39, 50 and 51) was analysed by Western blotting and probed with MeCP2 antibody (a) and counterchecked with an EGFP antibody (b). It was found that 3 founder lines (Line 2, 39 and 49) out of the 6 were expressing the transgene. 


\subsubsection{Mode of inheritance of the Mecp2_WT_EGFP transgene}

Breeding of heterozygous mice with wild type mice was performed. Then the mice were genotyped using the genomic DNA obtained from tail biopsies with Mecp2_check_F1 and EGFP_Rev1 primers. The litter size was approximately 11.2 for Mecp2_WT_EGFP mouse line 2 and 9.7 for Mecp2_WT_EGFP mouse line 49. The ratio of wild type, heterozygous was approximately 1:1 in the breeding. In Mecp2_WT_EGFP transgenic mouse line $2(\mathrm{FVB} / \mathrm{N})$, among the 270 offsprings tested (in 24 throws), 142 were wild type $(52 \%)$ and 128 were heterozygous (47\%) mice. In the case of Mecp2_WT_EGFP transgenic mouse line $49(\mathrm{C} 57 \mathrm{~B} 16 / \mathrm{N})$, among the 151 offsprings tested (in 16 throws), 82 were wild type (54\%) and 69 were heterozygous (46\%) mice. And also from the heterozygous (HE) with wild type (WT) breedings, no change in the sex ratio of the offsprings was noted both in Mecp2_WT_EGFP mouse line 2 (FVB/N) (Table 1) and Mecp2_WT_EGFP mouse line 49 (C57B16/N) (Table 2).

\begin{tabular}{|c|c|c|}
\hline \multirow{2}{*}{} & Female & Male \\
\hline \multirow{2}{*}{ WT } & $72=51 \%$ & $70=49 \%$ \\
\cline { 2 - 3 } & \multicolumn{2}{|c|}{$142=52 \%$} \\
\hline \multirow{2}{*}{ HE } & $61=48 \% \quad 67=52 \%$ \\
\cline { 2 - 3 } & \multicolumn{2}{|c|}{$128=47 \%$} \\
\hline \multirow{2}{*}{$133=49 \%$} & $137=51 \%$ \\
\hline
\end{tabular}

Table 1: Statistical analysis of genotype distribution of Mecp2_WT_EGFP transgene (line 2, FVB/N genetic background) in Heterozygous (HE) $\mathrm{x}$ wild type (WT) breeding: Breeding of heterozygous animals with wild type did not show any significant statistical differences in the sex ratio and also no deviation from Mendelian ratio was observed. 


\begin{tabular}{|c|c|c|}
\hline & Female & Male \\
\hline \multirow{2}{*}{ WT } & $45=55 \%$ & $37=45 \%$ \\
\hline & \multicolumn{2}{|c|}{$82=54 \%$} \\
\hline \multirow{3}{*}{$\mathrm{HE}$} & $34=49 \%$ & $35=51 \%$ \\
\hline & \multicolumn{2}{|c|}{$69=46 \%$} \\
\hline & $79=52 \%$ & $72=48 \%$ \\
\hline
\end{tabular}

Table 2: Statistical analysis of genotype distribution of Mecp2_WT_EGFP transgene (line 2, C57B16/N genetic background) in Heterozygous (HE) x Heterozygous (HE) breeding: Interbreeding of heterozygous animals did not show any significant statistical differences in the sex ratio and also no deviation from Mendelian ratio was observed.

However, the heterozygous Mecp2_WT_EGFP transgenic mouse line $2(\mathrm{FVB} / \mathrm{N})$ was breeding faster than the mouse line $49(\mathrm{C} 57 \mathrm{~B} 16 / \mathrm{N})$ mice. So, transgenic mouse line 2 $(\mathrm{FVB} / \mathrm{N})$ were intercrossed to obtain homozygous animals. There seemed to be no significant reduction in litter size 9.1 in comparison to matings of wild type animals. Then, the homozygousity of the transgenic animals were analysed by test breeding experiments with the WT mice. The progenies were checked for their genotype. If all the progenies were transgenic, the transgenic parent mouse was considered to be homozygous. Twenty mice (10 female mice and 10 male mice) were selected for the study. The ratio of wild type, heterozygous and homozygous was approximately 1:2:1 (Table 3). 


\begin{tabular}{|c|c|c|}
\hline & Female & Male \\
\hline \multirow{2}{*}{ WT } & $4=67 \%$ & $2=33 \%$ \\
\hline & \multicolumn{2}{|c|}{$6=30 \%$} \\
\hline \multirow{2}{*}{$\mathrm{HE}$} & $4=44 \%$ & $5=56 \%$ \\
\hline & \multicolumn{2}{|c|}{$9=45 \%$} \\
\hline \multirow{3}{*}{$\mathrm{HO}$} & $2=40 \%$ & $3=60 \%$ \\
\hline & \multicolumn{2}{|c|}{$5=25 \%$} \\
\hline & $10=50 \%$ & $10=50 \%$ \\
\hline
\end{tabular}

Table 3: Statistical analysis of genotype distribution of Mecp2_WT_EGFP transgene (line49, C57B16/N genetic background) in Heterozygous (HE) $x$ wild type (WT) breeding: Breeding of heterozygous animals with wild type did not show any significant statistical differences in the sex ratio and also no deviation from Mendelian ratio was observed.

And the average litter size of the interbreeding of homozygous Mecp2_WT_EGFP transgenic mouse line $2(\mathrm{FVB} / \mathrm{N})$ was $5.4 \%$ and was used to maintain the line. Unless indicated the heterozygous transgenic mice were used for the further investigations.

\subsubsection{Production of recombinant MeCP2 protein and raising antibody}

The production of the MeCP2 protein has been carried out in E.coli strain Rosetta2 (DE3) using pET vectors from Novagen, USA. The constructs carrying the human MECP2 cDNA sequence were very low expressing in the E.coli. To reach a reliable protein production, a synthetic $M E C P 2$ gene which was completely codon optimized for the E.coli was created by Dr. Prakasha Kempaiah in the lab. This strategy along with 
optimized growth conditions (growing in LB medium containing $1.5 \mathrm{~g} / \mathrm{L}$ of Meat extract for overnight in $30^{\circ} \mathrm{C}$ shaker incubator) allowed increasing the protein production up to 200 folds. The protein was produced with Strep-tag II at the C-terminus and 6His-tag at the N-terminus and duly purified using affinity chromatography columns from IBA, Goettingen, Germany, according to the manufacturer's protocol. Then the antibody was raised against the recombinant protein in rabbit with the help of Eurogentec, Köln, Germany. The antiserum from the terminal bleed of the MeCP2 protein injected rabbit was checked for the specificity by tittering against a WT mouse brain extract. A dilution to 1:5000 of the antiserum was standardized for probing the Western blot. In the WT mice, a single band at $70 \mathrm{kDa}$, corresponding to the endogenous Mecp2 and in Mecp2_WT_EGFP transgenic animals, also a band at $100 \mathrm{kDa}$ corresponding to Mecp2_WT_EGFP transgenic protein was detected (Fig. 20). And for the detection of EGFP, a different EGFP polyclonal commercial antibody from Abcam, USA, was used for further experiments.

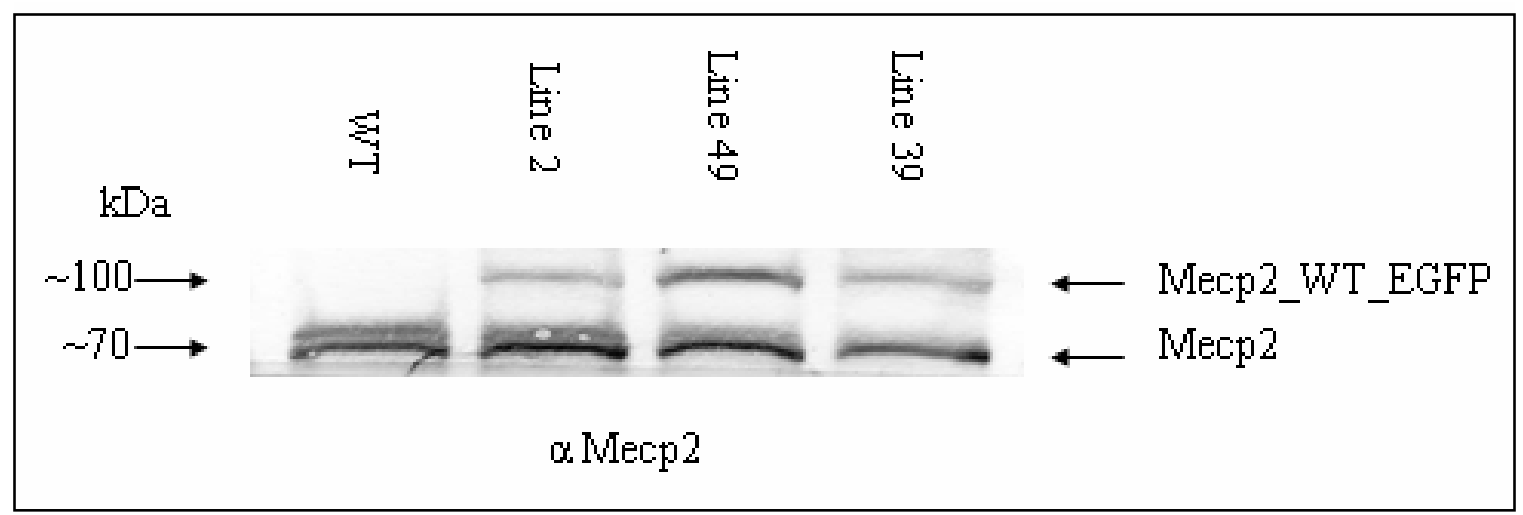

Fig. 20 Western blot analysis of Mecp2_WT_EGFP transgenic animals with the new MeCP2 antibody: The efficiency of the polyclonal antibody raised against the recombinant MeCP2 was checked by probing the brain extracts of the Mecp2_WT_EGFP transgenic animals (Line2, 49 and 39) in the Western blot. In the WT, a single band at $70 \mathrm{kDa}$, corresponding to the endogenous Mecp2 and in Mecp2_WT_EGFP transgenic animals, also a band at $100 \mathrm{kDa}$ corresponding to Mecp2_WT_EGFP transgenic protein was detected. The efficiency of the new MeCP2 antibody was high. From the blot, it seemed that there is a correlation between expression level and copy number of the transgene. 


\subsubsection{Immunohistochemical analysis of the transgenic mouse brain cortex}

Additionally, to study the expression and steady state distribution of the transgenic protein, an immunohistochemical analysis was performed. Brain cortical slices from an adult (around two months old) transgenic animal was examined for direct EGFP fluorescence and also stained for Mecp2 to verify the colocalization with EGFP (Fig. 21a-d). Thus the transgenic Mecp2_WT_EGFP displayed the same pattern of sub-cellular localization with the endogenous Mecp2 and distributed to the heterochromatic foci of the nuclei.
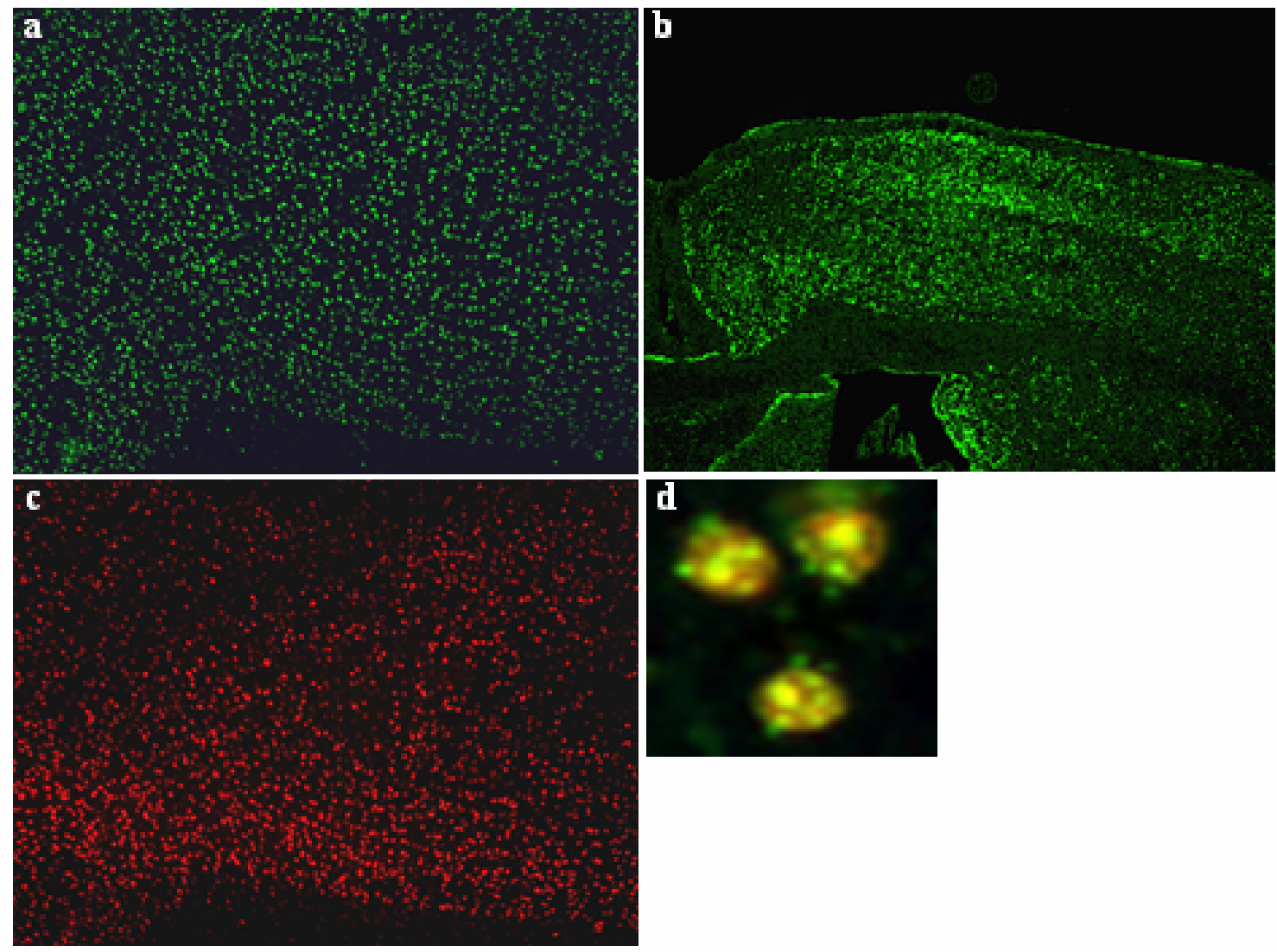

Fig. 21 Immunohistochemical analysis of the Mecp2_WT_EGFP transgenic animal brain cortical slices: Brain cortical slice from an adult Mecp2_WT_EGFP transgenic animal was examined for direct EGFP fluorescence (20X magnification) (a), and with a higher magnification (40X) of the same (b) and also stained for Mecp2 (c) to verify the colocalization with EGFP (60X magnification) (d). Thus the transgenic Mecp2_WT_EGFP displayed the same pattern of sub-cellular localization with the endogenous Mecp2. 


\subsubsection{Analysis of number of transgene copies and integrations by Real-Time PCR}

Gene quantification of the integrated transgene in transgenic mice genome was carried out by real time PCR analysis (using Mecp2_EX3_mouse_F1 and Mecp2_Mus_RT_Rev2 primers binding on the Exon 3 and 4 of Mecp2 gene respectively). The DNA copies of the transgene were normalized to DNA copies of mouse GAPDH gene. A detailed analysis of the copy number and number of integration of the transgene in the F1 transgenic animals were performed by comparing with the founder parent and siblings. As far as the Mecp2_WT_EGFP transgenic mouse lines were concerned, the results of the real-time PCR revealed the copy number of the transgene to be, 'one' for mouse line 2 and, 'two copies' for line 39 and line 49 (Fig. 22). The number of integration of the transgene was, 'one' in all these cases.

The presence of the transgene in the autosome was also explored which was further confirmed by breeding experiments. A male founder mouse transmitting the copies of the transgene to the transgenic progenies of both the sex ruled out the possibility of existence of the transgene in sex chromosomes. Because of the added advantage of the BAC transgenesis, Mecp2_WT_EGFP mouse line 2 contained one copy and a single integration of the transgene which mimics the WT situation of the endogenous Mecp2 gene. So the line $2(\mathrm{FVB} / \mathrm{N})$ was selected for further studies and line $49(\mathrm{C} 57 \mathrm{B16} / \mathrm{N})$ (having two copies and a single integration of the transgene) as one of the counterpart. 


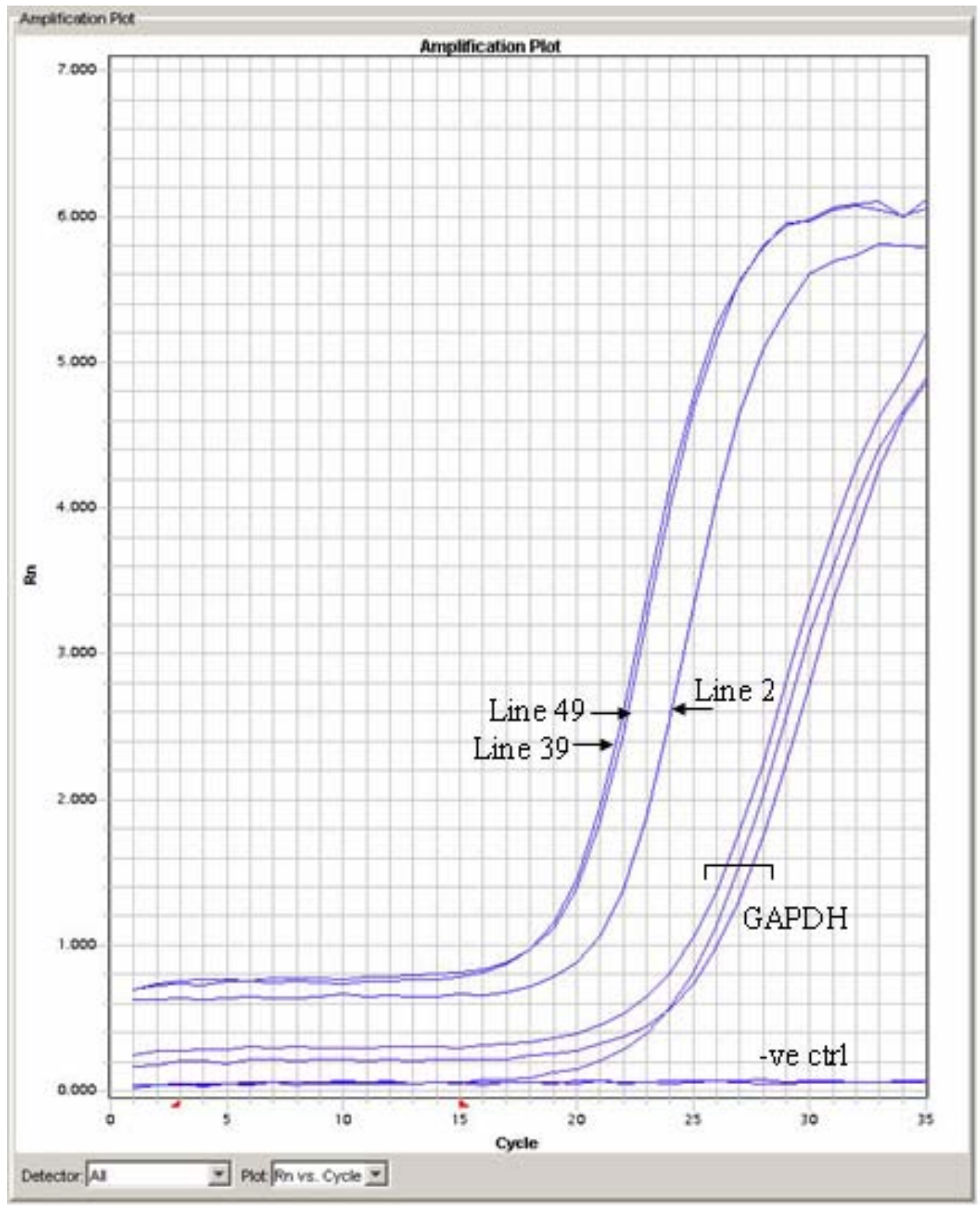

Fig. 22 Analysis of the copy number of Mecp2_WT_EGFP: PCR detection in Real Time is shown as an amplification plot. Amplification was performed from the transgenic mice genomic DNA, the target gene was Mecp 2 and the endogenous control was GAPDH. The calculation of a value termed $\Delta \mathrm{Rn}$ used the following equation: $\Delta \mathrm{Rn}=\mathrm{Rn}^{+}-\mathrm{Rn}^{-}$, where $\mathrm{Rn}^{+}=$emission intensity of reporter/emission intensity of quencher at any given time in the reaction tube, and $\mathrm{Rn}^{-}=$emission intensity of reporter/emission intensity of quencher measured before PCR amplification in the same reaction tube. During early cycles of PCR amplification, $\Delta R n$ values remained at baseline. When sufficient hybridization probe had been cleaved, intensity of reporter fluorescent emission increased. Most PCR amplifications reached a plateau phase of reporter fluorescent emission at high cycle numbers. The amplification plot was examined at a point representing the log phase of product accumulation. This was done by assigning an arbitrary threshold 
based on the variability of baseline data. Roughly, earlier the amplification in the PCR cycles, more the copy of the analyzed gene. A male (XY) mouse from each Mecp2_WT_EGFP transgenic mouse line was taken for the representative graph. The Mecp2_WT_EGFP mouse line 2 is interpreted to have one copy and Mecp2_WT_EGFP mouse line 49 and 39 are interpreted to have two copies of the transgene. -ve ctrl: negative control.

\subsubsection{Genotyping of the transgenic mice}

The genotypes of Mecp2_WT_EGFP (BAC) transgenic mice were analysed by PCR amplification of the specified allele from the genomic DNA extracted from mouse tails using Kan_check_F3 and Mecp2_check_R1 primers as described in section 2.2.9. And the integrity of the genomic DNA samples were controled by amplifying with primers Ctrl Mecp2_F1 and Ctrl Mecp2_R1 (Fig. 23).

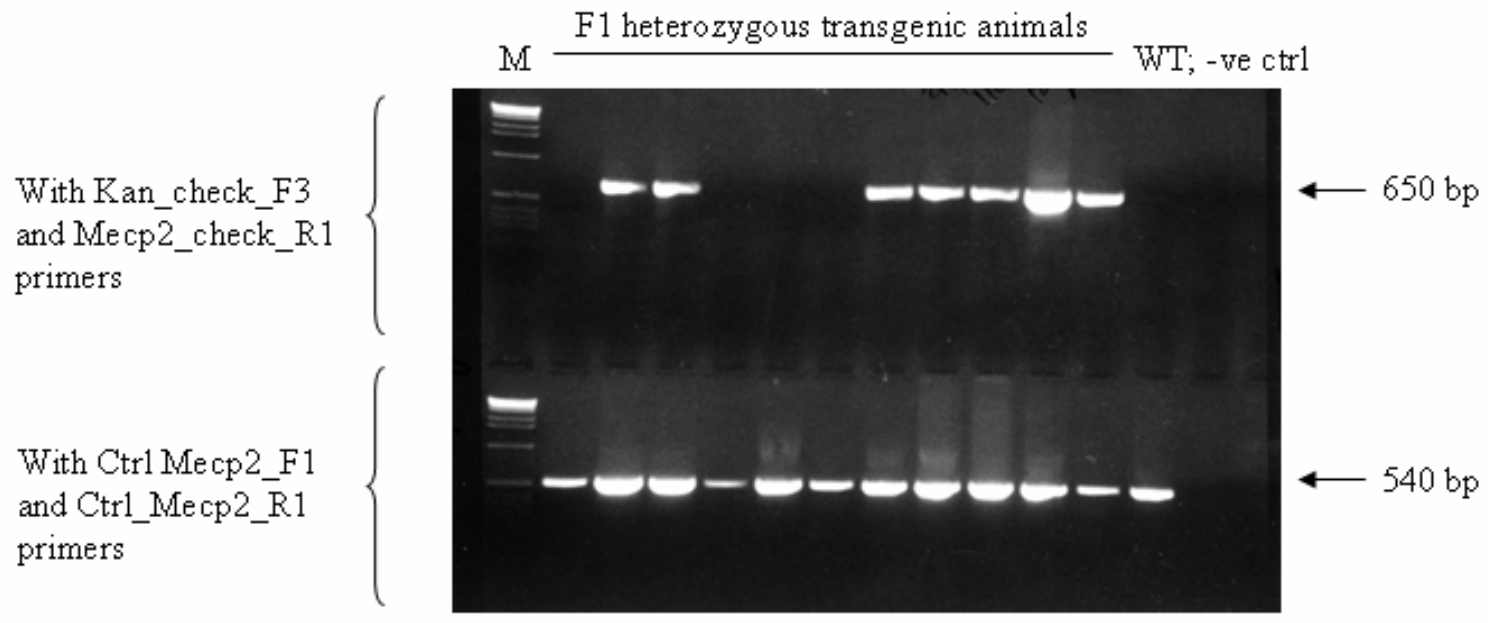

Fig. 23 Genotyping PCR analysis of the transgenic mice: The Mecp2_WT_EGFP (BAC) transgenic mice were genotyped regularly with primers Kan_check_F3 and Mecp2_check_R1 which yielded a PCR product of about $650 \mathrm{bp}$. As a control PCR for the integrity of the genomic DNA samples, Ctrl Mecp2_F1 and Ctrl Mecp2_R1 primers were used by amplifying a $540 \mathrm{bp}$ from the exon 4 of the WT Mecp2 gene. The representative agarose gel electrophoresis picture of the genotyping PCR products from F1 transgenic animals is shown in the figure, WT: wild type, M: $1 \mathrm{~kb}$ DNA molecular weight marker, -ve ctrl: null (water) control. 


\subsubsection{Regulation of expression of the transgene}

Multi-tissue Western blot analysis was performed using different tissue extracts from adult Mecp2_WT_EGFP (Line 2) transgenic animals. The experiment was designed to verify if the regulation of expression of the transgenic protein mimics that of the endogenous Mecp2. As in the WT mouse, Mecp2_WT_EGFP transgenic protein was high in brain, and lung, low in kidney and undetectable in liver (Fig. 24). So, the expression of the transgene was analogous to that of the endogenous Mecp2 regulation pattern.

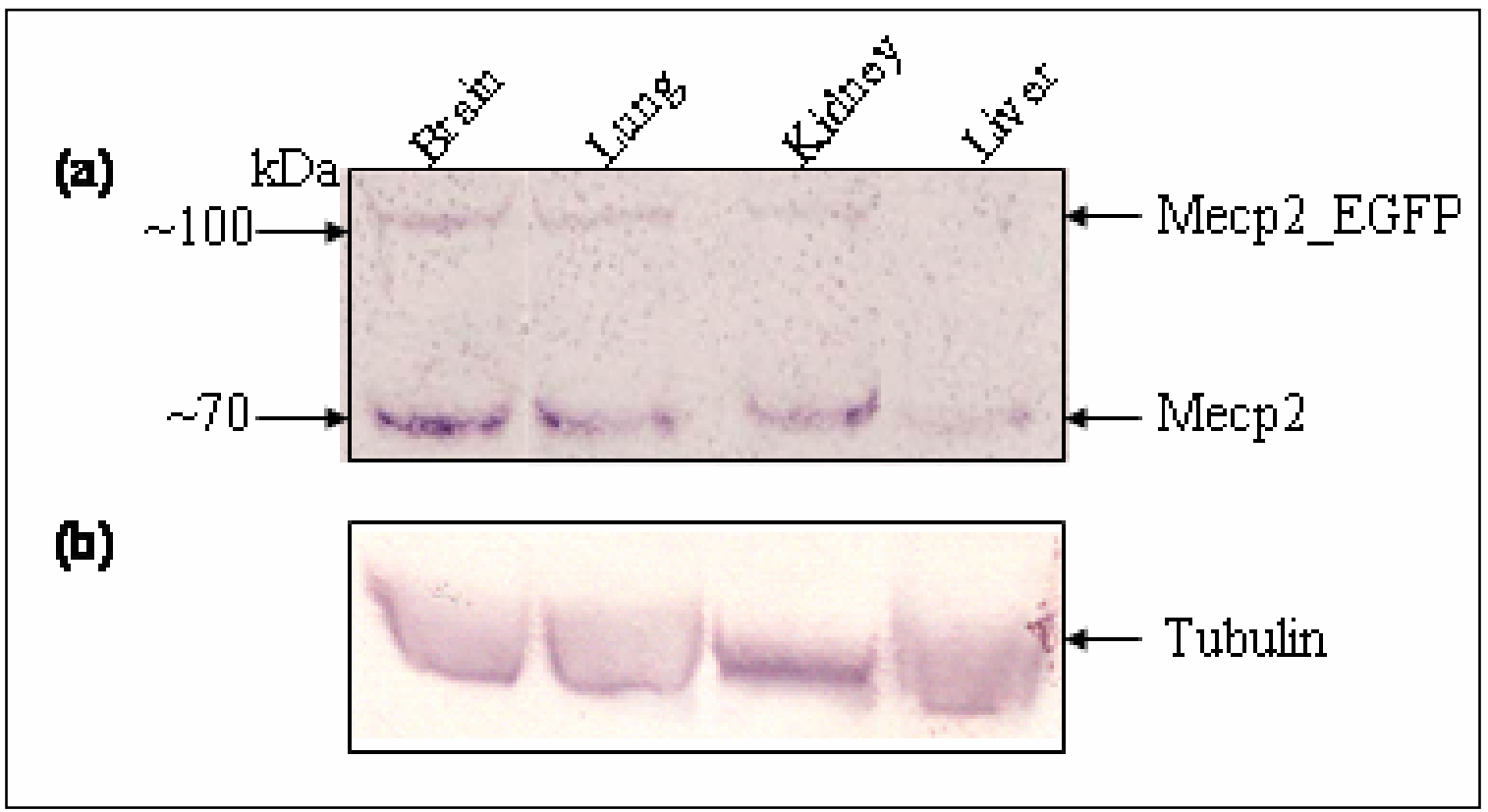

Fig. 24 Multi-tissue Western blot analysis: The regulation of expression of the transgene was verified by performing Western blot analysis using protein extracts from brain, lung, kidney and liver of adult Mecp2_WT_EGFP transgenic animals with the raised MeCP2 antibody. Tubulin was used as a standard to show equal loading of the protein. As in the WT mouse, Mecp2_WT_EGFP transgenic protein was high in brain and lung, low in kidney and undetectable in liver.

\subsubsection{Transgenic protein profiling in comparison with other marker proteins}

Furthermore, to observe the protein profiling of Mecp2_WT_EGFP transgenic protein, immunohistochemical analysis was carried out along with other marker proteins in the mouse brain. Floating sections from Hippocampal region of an adult (around two months old) Mecp2_WT_EGFP (Line2) transgenic animal was performed and immunostained 
with a Glial cell marker GFAP (Glial Fibrillary Acidic Protein) (Fig. 25a) and Neuroaxonal marker MAP2 (Microtubule Associated Protein 2) (Fig. 25b). The direct EGFP fluorescence from the Mecp2_WT_EGFP transgenic protein and the immunofluorescence against the marker proteins revealed the transgenic protein profiling exclusively in the neurons and to the nuclei and not in the glial cells or in the axons of the neurons. The EGFP fluorescence interpreted in the study was further confirmed by immunostaining with MeCP2 antibody (Fig. 25c).
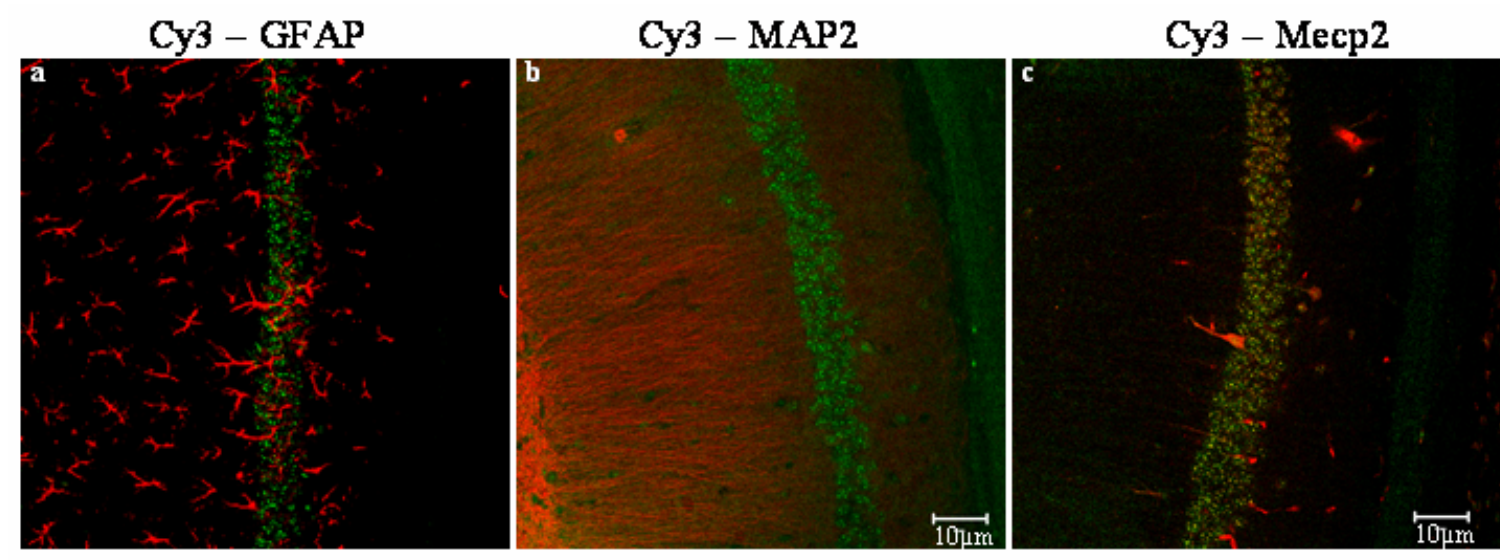

Fig. 25 Immunohistochemical analysis for transgenic protein profiling: Floating sections from Hippocampal region of an adult Mecp2_WT_EGFP (Line 2) transgenic animal was performed and immunostained with an anti-GFAP antibody (Glial cell marker) (a), anti-MAP2 antibody (neuro-axonal marker) (b) and also marked with Mecp2 antibody (c). Cy3: secondary antibody for the immunostaining.

\subsubsection{Histone acetylation status of the transgenic animals by HDAC assays}

Overexpressing Mecp2 may cause histone hypoacetylation, because Mecp2 can form a complex with transcriptional co-repressors and Histone Deacetylases (HDACs) that may influence nucleosome structure (Mimi et al., 2001, Shahbazian et al., 2002). Antibodies against acetylated histone $\mathrm{H} 3$ peptide (Ac H3) and acetylated histone H4K16 peptide (Ac H4) were employed for the assay to check whether the histones were hypoacetylated in the adult ( 2 months old) transgenic ( $\mathrm{T} /-)$ mouse brain. On the Western blot, unexpectedly, acetylated histone $\mathrm{H} 3$ and $\mathrm{H} 4$ bands appeared to be of same intensity in Mecp2_WT_EGFP transgenic mouse line 2 (Fig. 26) and was the same with line 49. Western blot analysis of the tubulin run in parallel with the samples confirmed the equal 
loading of the protein extract. Quantitation of the signals by densitometry was used to calculate the intensity of Ac H3 and Ac H4 signals. Data from independent experiments showed a consistent result versus control samples and it indicates that there is no significant change in the acetylation status in the adult Mecp2_WT_EGFP transgenic (T/-) mouse lines as compared to the wild type mice.

(a)

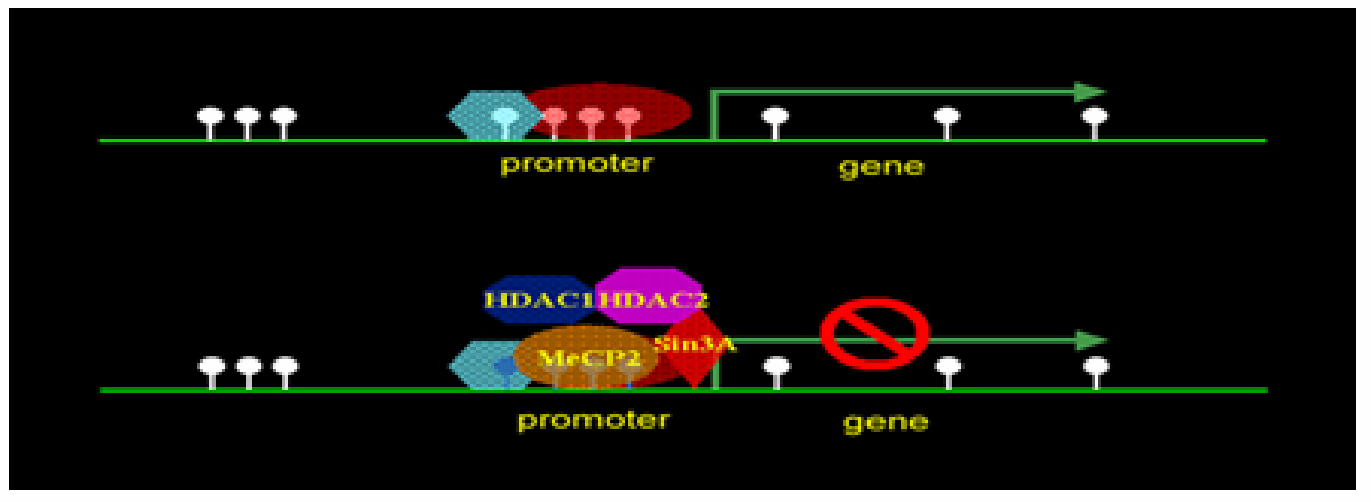

(b)

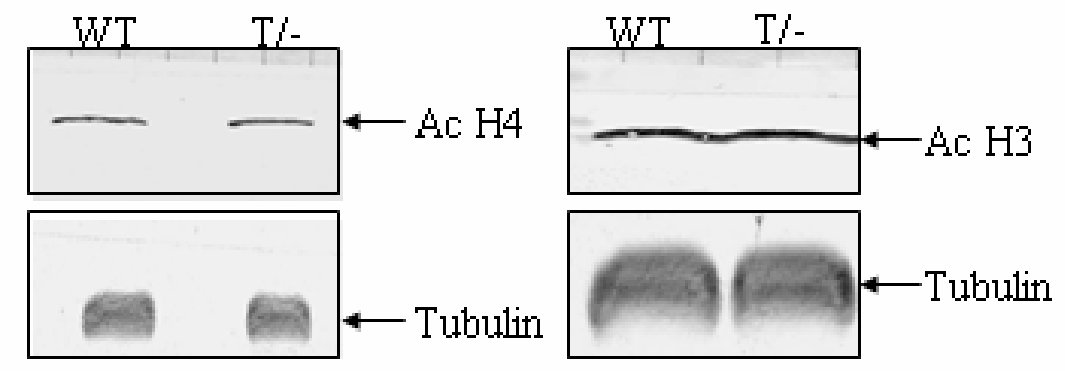

Fig. 26 Histone Deacetylase (HDAC) assays: The diagrammatic representation of the mechanism of histone deacetylation with the Mecp2 binding in the $\mathrm{CpG}$ islands of the promoter region of a gene and transcriptional repression by recruiting Histone deacetylase enzymes (HDAC) and co-repressor Sin3A (a). The brain extract from adult Mecp2_WT_EGFP transgenic (T/-) mouse line 2 was studied with antibodies against acetylated histone $\mathrm{H} 3$ peptide (Ac H3) and acetylated histone H4K16 peptide (Ac H4) (b). Western blot analysis of the tubulin run in parallel with the samples confirmed the equal loading of the protein extract. No significant change was observed in the acetylation status.

\subsubsection{Elucidation of the functionality of the transgene by rescue experiments}

To clarify the functionality of the Mecp2_WT_EGFP transgenic protein, rescue experiments were planned. In principle, it was to notice whether the Mecp2_WT_EGFP 
transgenic protein was really functional and could rescue the Mecp2 knockout mouse. The Mecp 2 knockout mouse is known to have severe neurological phenotypes mimicking the Rett patients and die prematurely after 6 to 10 weeks of age. But when the heterozygous Mecp2_WT_EGFP transgenic mice (Line 2) (T/-; +/y) were crossed to the Mecp $2+/-$ knockout heterozygous female mice, it could rescue the phenotype seen in the knockout mice and had a prolonged life span of about 1 year, as witnessed in about 9 independent breedings. As an example the most characteristic feature of hindlimb clasping seen in the knockout mice was not observed in the rescued mice $(\mathrm{T} /-;-/ \mathrm{y})$ (Fig.27). The adult rescued mice were also able to breed and transmit the transgene to the progenies. The experiment yielded reproducible results in 7 different independent breedings and the average litter size of the rescue mice breeding with WT mice was approximately 7.2. Western blot analysis was performed with MeCP2 antibody in the rescued mice to further prove the expression of only the Mecp2_WT_EGFP transgenic protein in the brain tissue (Fig. 28).
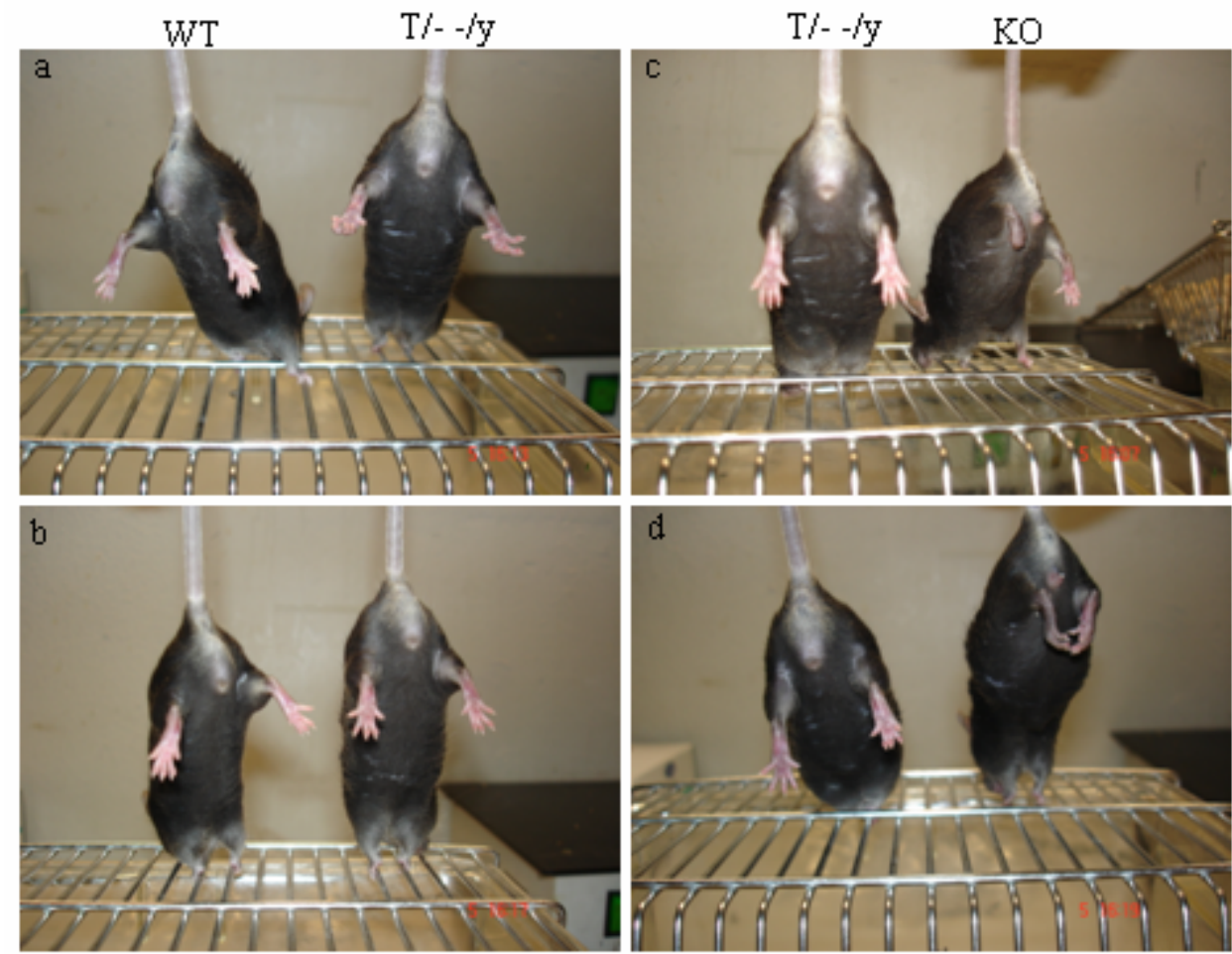

Fig. 27 Rescue experiment: To show the functionality of the Mecp2_WT_EGFP transgenic protein, rescue experiments were done. The heterozygous Mecp2_WT_EGFP transgenic mice (Line 2) (T/-; +/y) were crossed to the Mecp2 +/- knockout heterozygous female mice. The rescued mice (T/-; -/y) (2 months old) 
were indistinguishable from their WT littermates ( $a$ and $b$ ). Hindlimb clasping seen in the knockout mice was not seen in the rescued mice (T/-; - /y) (c and d).

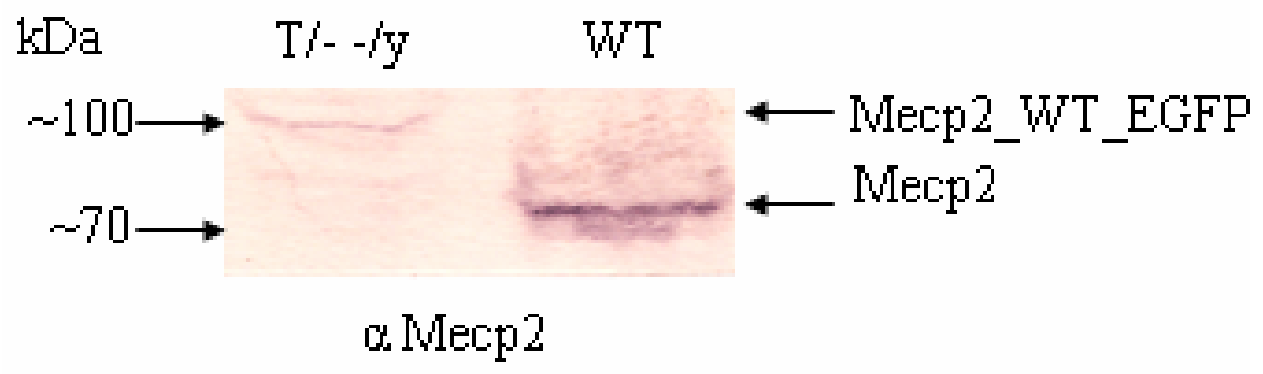

a Tubulin

Fig. 28 Western blot analysis of the rescued mouse brain: Western blot analysis was carried out with $\mathrm{MeCP} 2$ antibody in the rescued mouse $(\mathrm{T} / \mathrm{-}-\mathrm{y})$ to further prove the expression of only the Mecp2_WT_EGFP transgenic protein in the brain tissue. Tubulin was used as a control.

\subsubsection{Phenotypical analysis of the transgenic animals}

The level of activity and anxiety-like behavior of transgenic animals were evaluated using an open field test. Roughly three time points in the age of the mice $(10,20,30$ postnatal weeks) were taken into consideration. Mice were placed in the center of a 100x100 cm open field space and the data were collected in a time period of $5 \mathrm{~min} .3$ transgenic animals from Mecp2_WT_EGFP transgenic mouse line 2 and 3 WT littermate mice were taken for the study. The Mecp2_WT_EGFP transgenic mouse line 2 which expresses Mecp2 at 2 fold of WT levels, at around 9 weeks of age, were slightly hyperactive and showed increased levels of anxiety. The transgenic animals traveled more distances and spend more time walking in the open field tests when compared to the WT littermate. However, 22 weeks old transgenic mice showed increased vertical activity, i.e. rearing, which was taken to indicate less anxiety, these mice became hypoactive and died around 1.3 years of age. This finding displayed that Mecp2 expression should be tightly regulated in vivo, and that even mild overexpression of this 
protein is detrimental. In addition, these results hold the possibility that duplications or gain-of-function mutations in MECP2 might bring about X-linked delayed-onset neurobehavioral disorders in human.

\subsubsection{EGFP FACS analysis of the transgenic mouse brain cells}

The transgenic mice created can be used to identify or track Mecp2+/EGFP + cells and especially can have an extended feasibility of separation of Mecp2+/EGFP+ cells from other cell types by FACS (Fluorescence Activated Cell Sorting). Enzymatic (Papain) dissociation of the brain tissue as described in section 2.2.13, yielded viable, fluorescent cells which can be sorted by FACS for further characterization and essentially for gene expression studies. Independent sorts were conducted of dissociated brain of Mecp2_WT_EGFP transgenic mice. In the experiment, fluorescent Mecp2 brain cells were readily separated from other cell types, yielding a homogenous population of fluorescent cells.

\subsubsection{Measurement of Mecp2+/EGFP+ cell number by FACS sorting}

A single cell suspension was prepared from whole brain of an adult ( 2 months old) Mecp2_WT_EGFP transgenic mouse from mouse lines 2 and 49 and the percentage of Mecp2+/EGFP+ cells was measured by FACS. Flow cytometric analysis revealed that the total cell suspension comprised around $7.2 \%$ of the Mecp2+/EGFP+ cells from whole brain in the case of Mecp2_WT_EGFP transgenic mouse line 2 (containing single copy of the transgene) (Fig. 29). Further analyses on 5 additional transgenic littermates gave similar results. And the sorted cells constituted around $14.8 \%$ of the total cell suspension from whole brain in the case of Mecp2_WT_EGFP transgenic mouse line 49 (containing two copies of the transgene) (Fig. 30). Propidium iodide staining of dissociated cells indicated the cell viability to be $98 \%$ confirming that the mechanistic pressures exerted on cells during FACS had no effect on their viability. The range of negative signals (autofluorescence) was determined using WT brain cells as a control. 


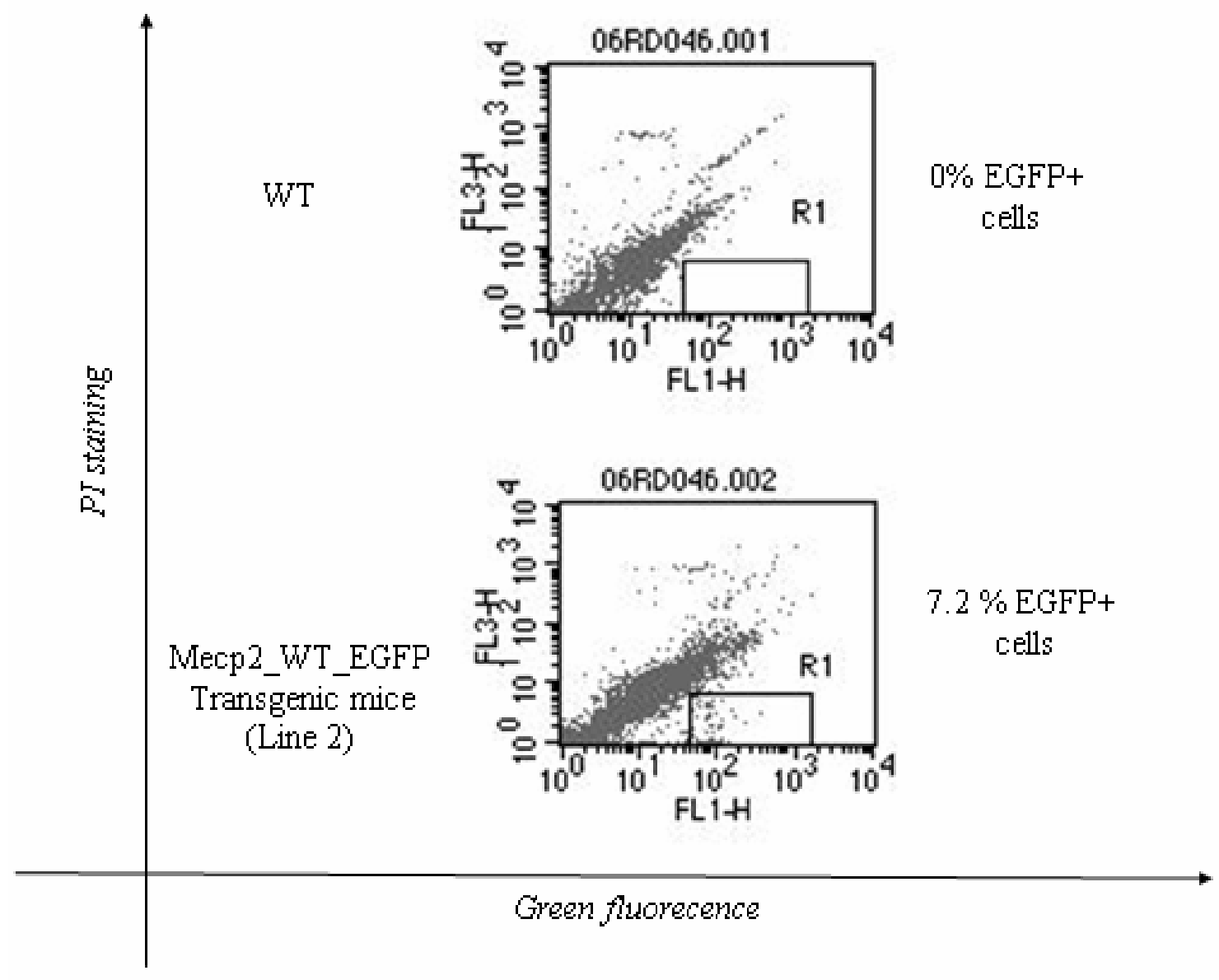

Fig. 29 FACS sorting of transgenic mouse (line 2) brain cells: Flow cytometric analysis of a single cell suspension prepared from whole brain of an adult Mecp2_WT_EGFP transgenic mouse (lower panel) was performed and the percentage of Mecp2+/EGFP+ cells was measured. FL1-H: medium wavelength channel for EGFP, FL3-H: Channel for Propidium iodide (PI) staining on the FACS. Fluorescence intensity is expressed in arbitrary units on a logarithmic scale. The range of negative signals (autofluorescence) was determined using WT cells as a control (upper panel). $7.2 \%$ of the brain cells were positive for EGFP in the case of Mecp2_WT_EGFP transgenic mouse line 2. 


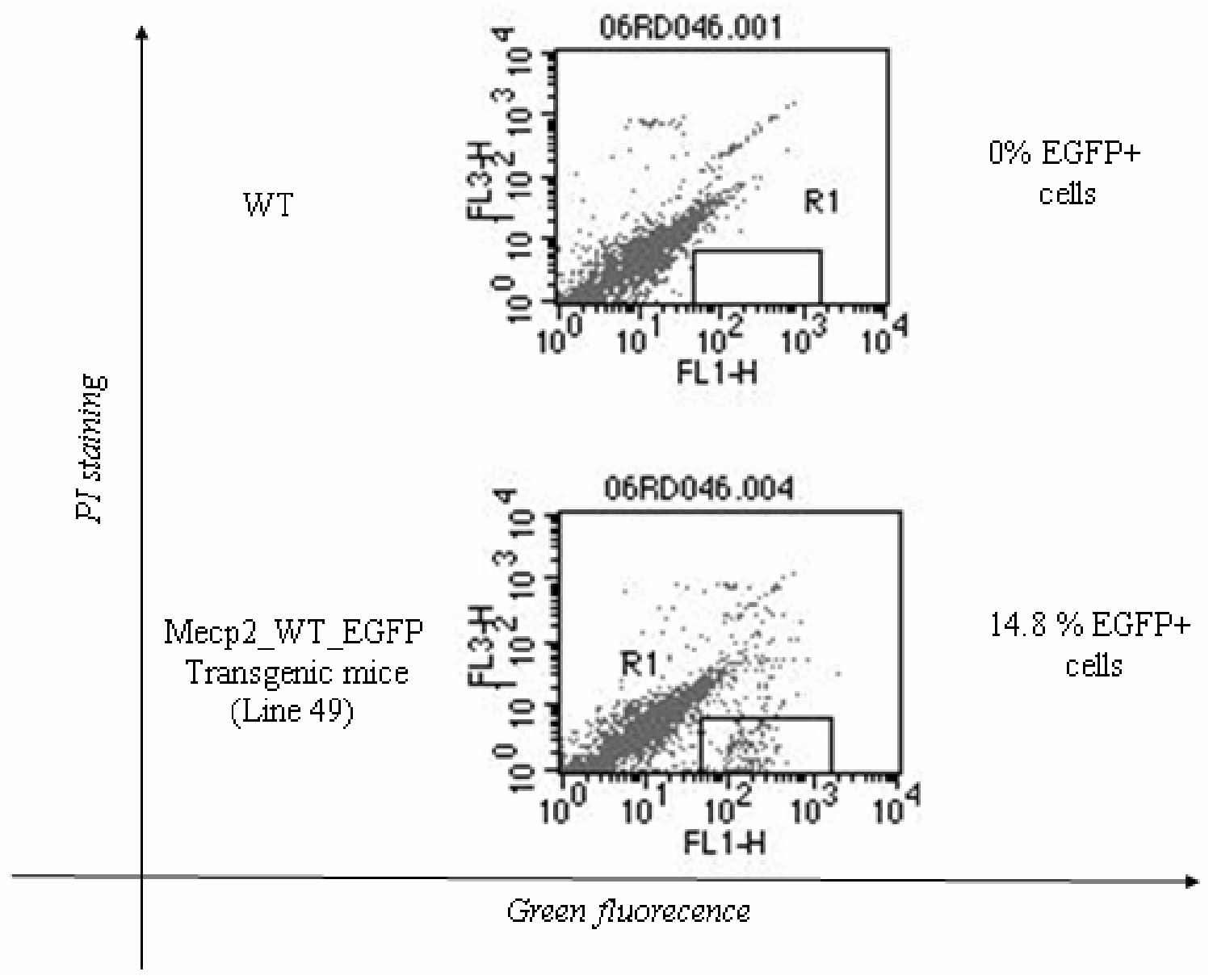

Fig. 30 FACS sorting of transgenic mouse (line 49) brain cells: Flow cytometric analysis of a single cell suspension prepared from whole brain of an adult Mecp2_WT_EGFP transgenic mouse (lower panel) was performed and the percentage of Mecp2+/EGFP+ cells was measured. FL1-H: medium wavelength channel for EGFP, FL3-H: Channel for Propidium iodide (PI) staining on the FACS. Fluorescence intensity is expressed in arbitrary units on a logarithmic scale. The range of negative signals (autofluorescence) was determined using WT cells as a control (upper panel). $14.8 \%$ of the brain cells were positive for EGFP in the case of Mecp2_WT_EGFP transgenic mouse line 49.

\subsubsection{Culturing the FACS-isolated cells}

About 10,000 EGFP+ cells were FACS-isolated directly in the primary neuronal plating medium (in a maximum time of about $20 \mathrm{~min}$ to keep the cells alive) from adult Mecp2_WT_EGFP transgenic mice (Line 2). The sorted cells were plated on chambered glass slides and allowed to grow in the culture medium for $24 \mathrm{hrs}$ at $37^{\circ} \mathrm{C}, 5 \% \mathrm{CO}_{2}$ 
incubator. Confocal photomicrographs of FACS-isolated Mecp2+/EGFP+ cells in culture, under bright field and fluorescence optics, indicated that the cultures contained viable, homogenous population of EGFP-labeled (Mecp2_WT_EGFP) cells that were capable of attachment to the substratum (Fig. 31). But during the course of subsequent immunohistochemical analysis, the cells were extremely difficult to process and particularly after the treatment with Triton X-100, they tend to lose the adherence capacity even in poly-L-ornithine coated culture slides. So, further standardizations were attempted to adhere the cells directly to the slides.

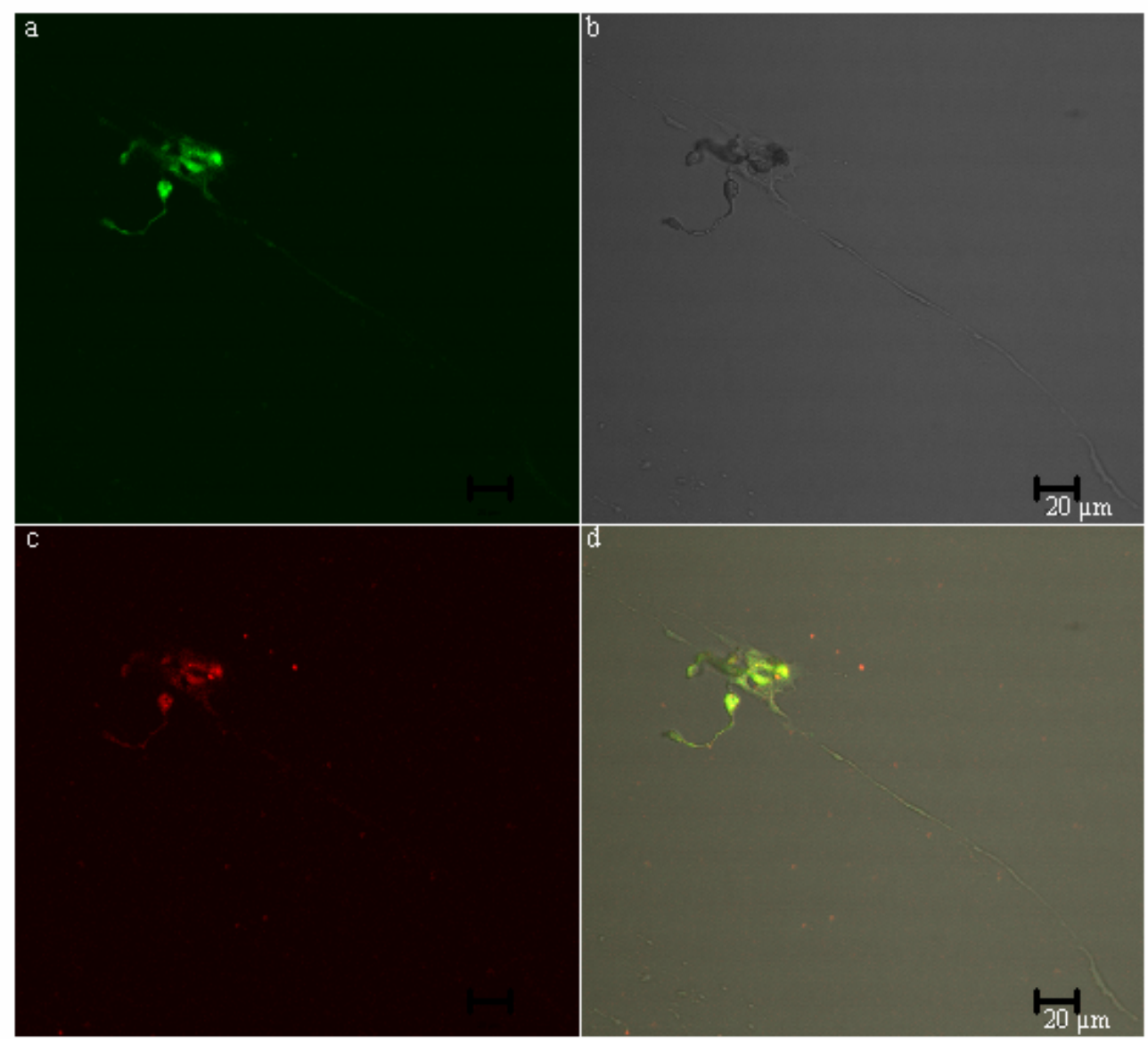

Fig. 31 Confocal images of the cultured FACS isolated cells: The FACS-isolated cells from adult Mecp2_WT_EGFP transgenic mice (Line 2) were plated on chambered glass slides and allowed to grow in the culture medium for $24 \mathrm{hrs}$ at $37^{\circ} \mathrm{C}, 5 \% \mathrm{CO}_{2}$ incubator. Confocal photomicrographs of FACS-isolated Mecp2+/EGFP+ cells in culture were taken under fluorescence optics using EGFP filter (a), under bright field (b), and were proved by staining with anti-MeCP2-Cy3 antibody (c). The merged picture (d) was also shown. 


\subsubsection{Characterization of Mecp2+/EGFP+ cells}

To increase the feasibility of flow-sorting and immediate attachment of the cells to the glass slides for further examinations, about 10,000 EGFP+ cells were FACS-isolated directly in DPBS as mentioned before, from adult Mecp2_WT_EGFP transgenic mice (Line 2). The cells were divided into 2 X 5000 cells and spun at $800 \mathrm{xg}$ for $15 \mathrm{~min}$ to the glass slides individually with a special centrifuge known as cyto-spin. Then the identity of FACS sorted Mecp2+/EGFP+ cells from adult Mecp2_WT_EGFP transgenic mice (Line 2) on the glass slides were studied using different markers by immunostaining. As a preliminary approach towards characterization, in collaboration with the department of Neurophysiology, Unviersity of Goettingen, Germany, two major neurotransmitter systems, namely Glutaminergic receptor system (excitatory transmission) (Fig. 32) and GABAergic receptor system (inhibitory transmission) (Fig. 33) were immunostained with respective antibodies for the investigation. The receptor systems were well stained but the lack of adherence capacity of the centrifuged cells on the glass slides made the study difficult to extrapolate the percentage of Mecp2+/EGFP+ cells to the percentage of different types of neurons. 


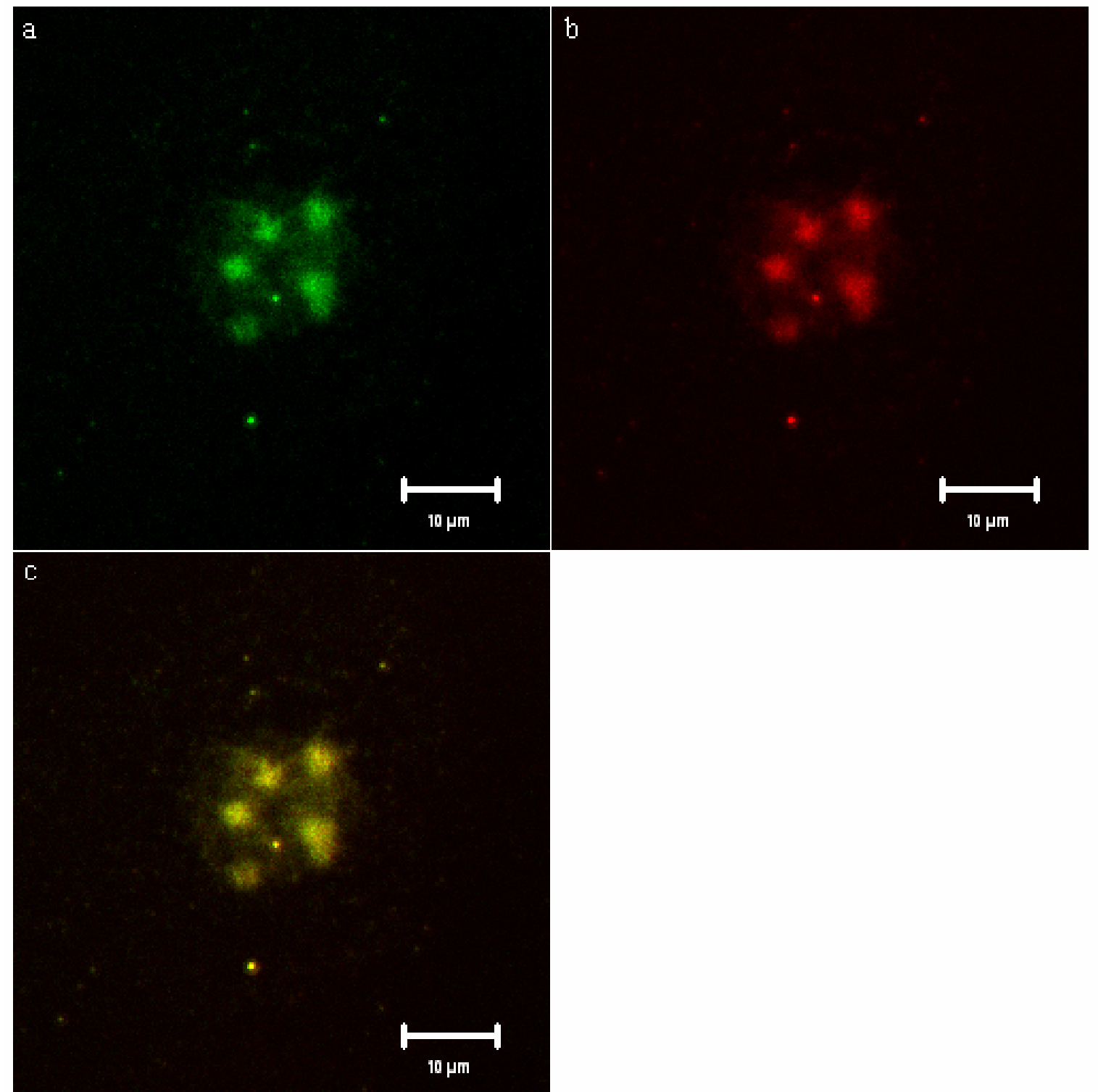

Fig. 32 Confocal images of the FACS sorted cells immunostained for excitatory neurotransmitter system: FACS sorted cells were directly spun to the glass slides with Cyto-spin. Then the FACS sorted cells from adult Mecp2_WT_EGFP transgenic mouse (Line 2) brain in the slides were characterized using glutamate receptor protein marker by immunostaining. Confocal photomicrographs of FACS sorted cells in the slides were taken under fluorescence optics using EGFP filter (a), using anti-Glutamate receptor protein-Cy3 antibody (b) and the merged picture (c) is also shown. 


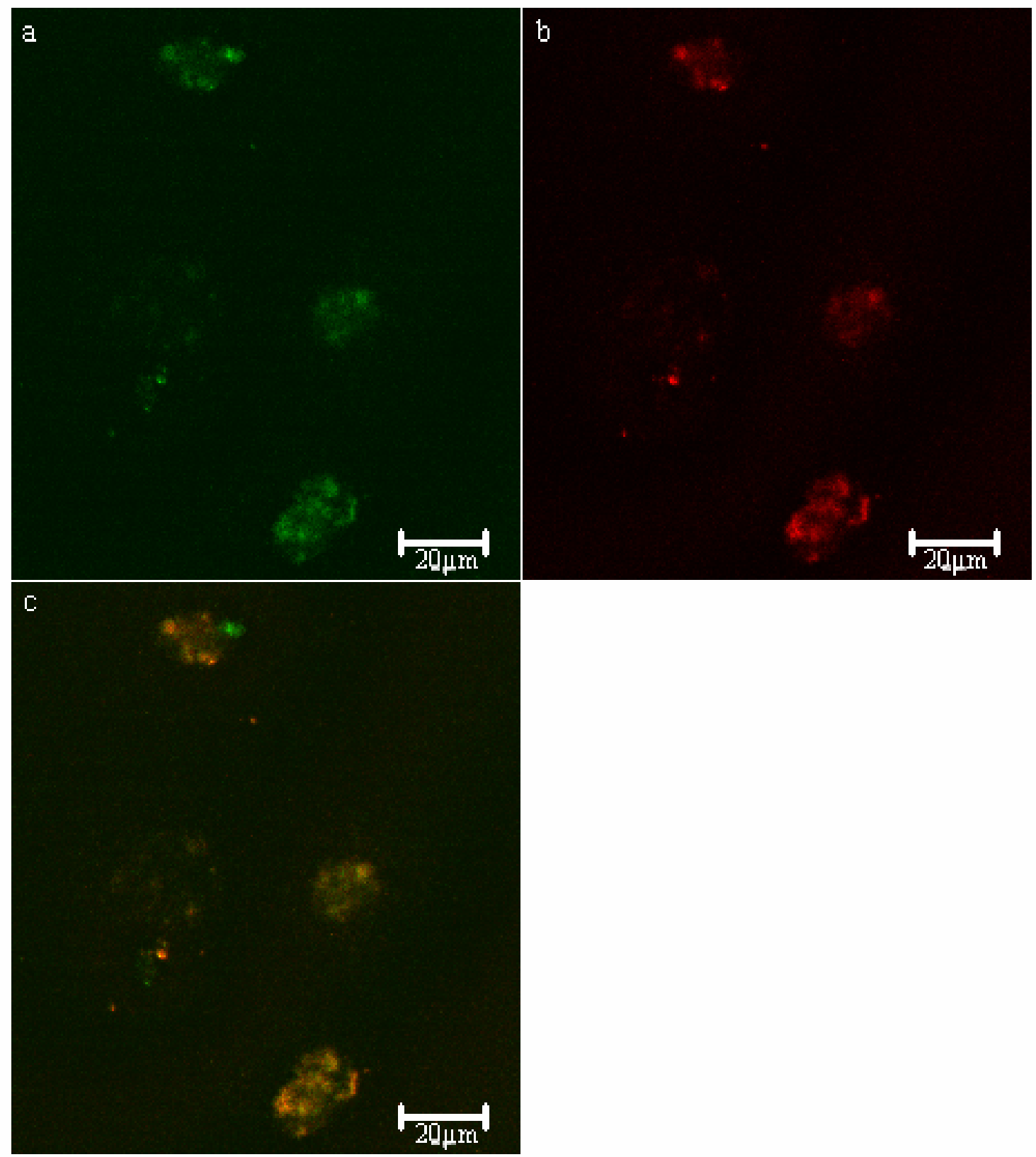

Fig. 33 Confocal images of the FACS sorted cells immunostained for inhibitory neurotransmitter system: FACS sorted cells were directly spun to the glass slides with Cyto-spin. Then the FACS sorted cells from adult Mecp2_WT_EGFP transgenic mouse (Line 2) brain in the slides were characterized using GABA receptor protein marker by immunostaining. Confocal photomicrographs of FACS sorted cells in the slides were taken under fluorescence optics using EGFP filter (a), using anti-GABA receptor proteinCy3 antibody (b) and the merged picture (c) is also shown. 


\subsubsection{Organotrophic and primary neural cultures from the transgenic mice brain}

In vitro cultures, namely the organotrophic and primary neuronal cultures, from the Mecp2_WT_EGFP transgenic mouse (Line 2) brain were established in collaboration with the department of Neurophysiology, Unviersity of Goettingen, Germany. When the organotrophic culture from hippocampal region of the Mecp2_WT_EGFP transgenic mouse (Line 2) brain tissue at p6 stage was prepared, most of the cells showed the correct presence of the Mecp2_WT_EGFP protein in the nucleus (Fig. 34a) but surprisingly in few cells, the EGFP fluorescence was found exclusively in the cytoplasm in contrast to the normal localization in the nucleus (Fig. 34b). And when the primary neuronal cell culture was prepared from the same mouse line at p21 stage, some of the cells demonstrated the presence of the Mecp2_WT_EGFP protein still in the cytoplasm. The EGFP fluorescence was further proved by immunostaining with MeCP2 antibody (Fig.35a and 35b). This interesting redistribution of Mecp2_WT_EGFP protein from the nucleus to the cytoplasm in vitro has to be validated further. One of the possible explanations could be the culture conditions including the medium composition which has to be verified.

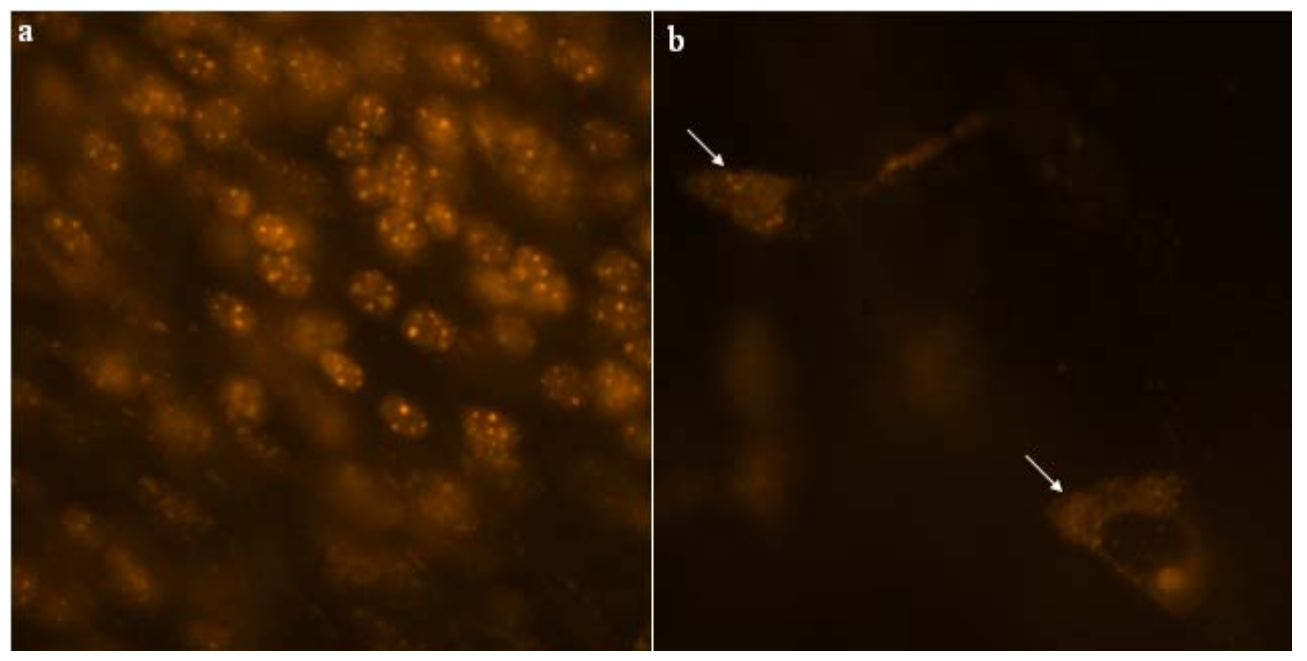

Fig. 34 Organotrophic culture from hippocampal region of the transgenic mice: Organotrophic culture from hippocampal region of the Mecp2_WT_EGFP transgenic mouse (Line 2) brain tissue at p6 stage was prepared. Confocal imaging showed the nuclear localization of Mecp2_WT_EGFP in most of the cells (a) 
but in few cells the EGFP fluorescence was found exclusively in the cytoplasm as indicated by the arrows(b).

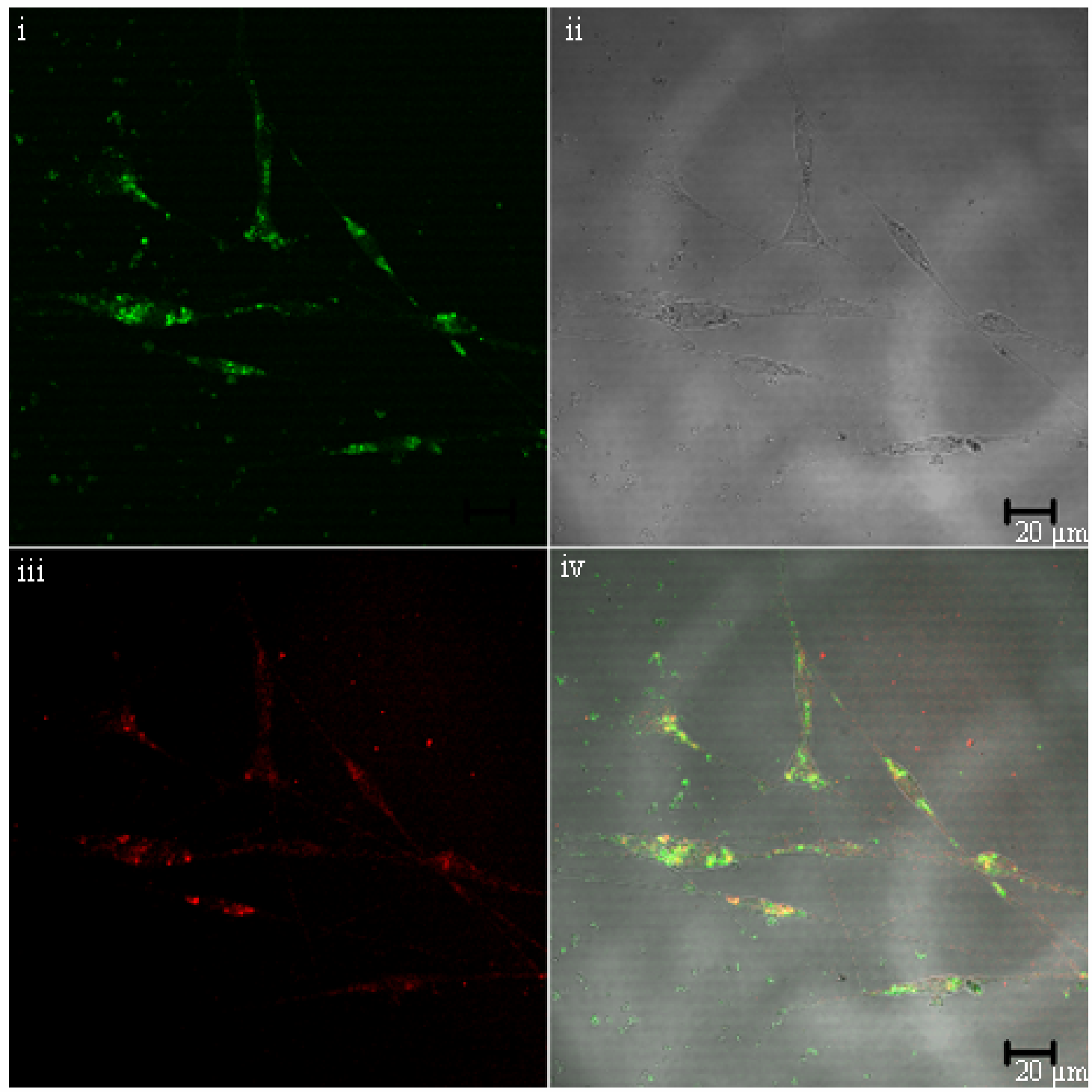

Fig. 35a Primary neuronal cell culture of the transgenic mice: The Mecp2_WT_EGFP transgenic mice (Line 2) primary neuronal cell cultures were prepared at p21 stage. By confocal imaging some cells were still found to contain the EGFP staining (i) exclusively in the cytoplasm which was further validated by immunostaining with MeCP2 (iii). The bright field (ii) and the merged images (iv) were also shown. 


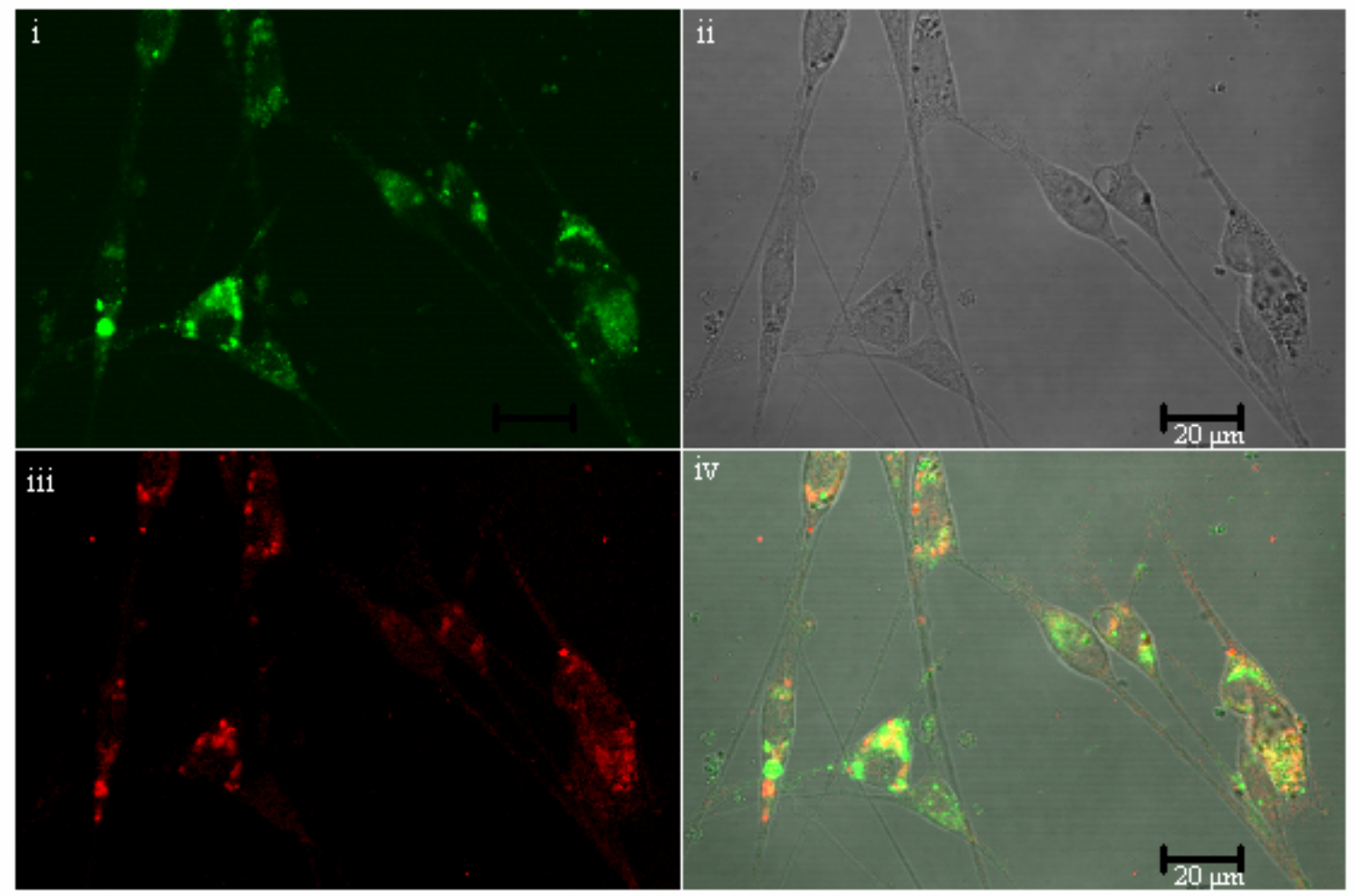

Fig. 35b Primary neuronal cell culture of the transgenic mice: The Mecp2_WT_EGFP transgenic mice (Line 2) primary neuronal cell cultures were prepared at p21 stage. A slightly higher magnified confocal imaging was done for the cells which were found to contain the EGFP staining (i) exclusively in the cytoplasm and was further validated by immunostaining with MeCP2 (iii). The bright field (ii) and the merged images (iv) are also shown.

\subsubsection{Imaging of Mecp2 at the synapses}

Intended for imaging Mecp2 at the synapses, Mecp2_WT_EGFP transgenic organotrophic cultures were produced from the hippocampal region of the homozygous transgenic mouse (Line 2) brain at p6 stage. The idea was to first shortly transfect two adjoining and probably communicating (by synapses) neurons with pDsred vector (Clontech, USA). The pDsred vector constitutively expresses the Dsred protein staining in the whole neurons and giving an outline during the imaging. Thus the distribution of the EGFP from the red fluorescence in the neurons could be differentiated. A preliminary experiment was done with a transfection time of $6 \mathrm{hrs}$, but the red and EGFP fluorescence became indistinguishable because of the strong signal from Dsred (Fig. 36). The result 
affirms a standardization of the transfection period less than $6 \mathrm{hrs}$ which would help to obtain a comprehensible representation.

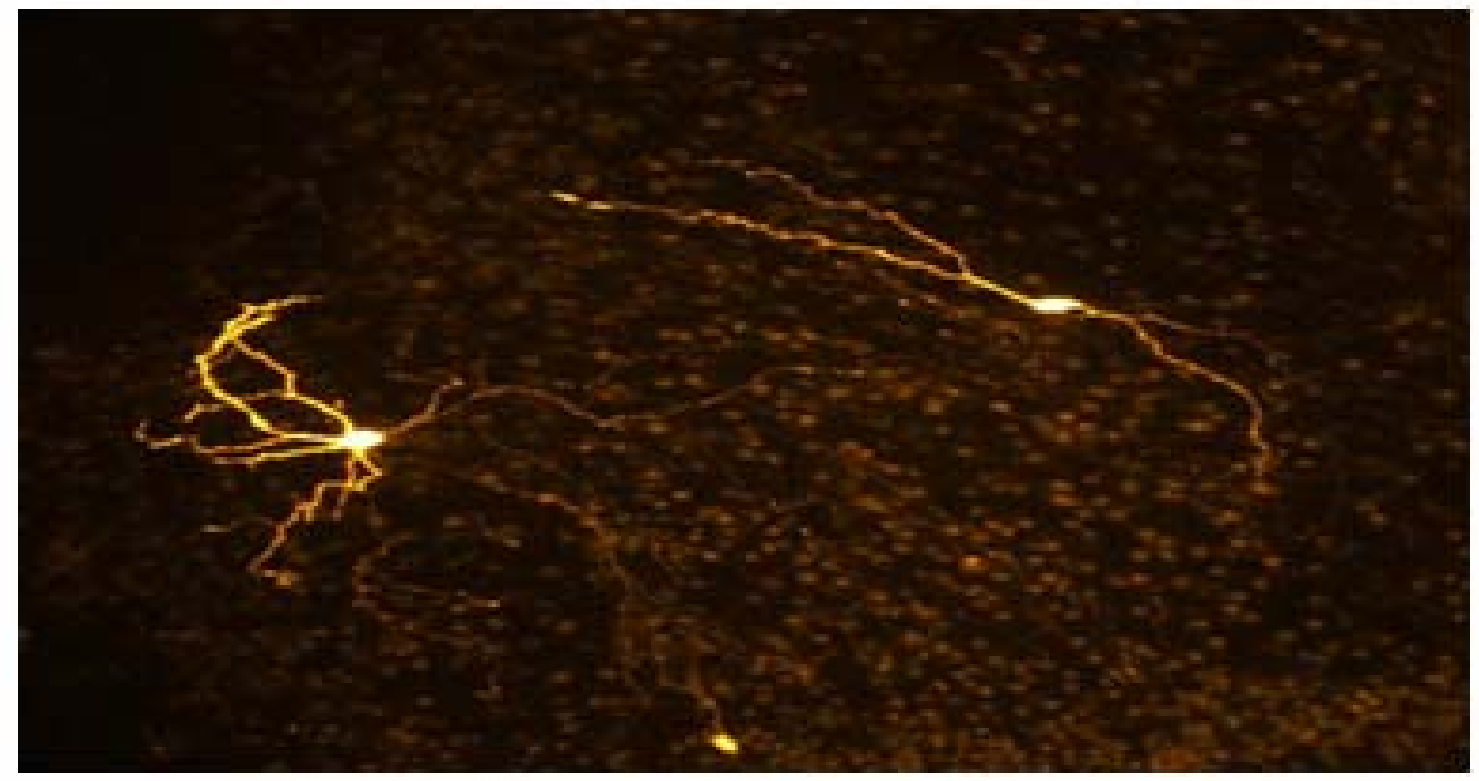

Fig. 36 Transfection of pDsred vector in the organotrophic culture of the transgenic mice: Mecp2_WT_EGFP transgenic mouse (Line 2) organotrophic cultures were produced from the hippocampal region at $\mathrm{p} 6$ stage. Two adjoining neurons were shortly transfected with pDsred vector to differentiate the distribution of the EGFP fluorescence from the Dsred stained neurons. A bright signal for Dsred masking the EGFP fluorescence signal was observed.

\subsection{Knockin construct for the most frequent mutation of the MECP2 gene}

A T158M point mutation, most frequently found in Rett patients, in the exon 4 of the Mecp2 gene was tried to be incorporated in the BAC clone B22804 (around $120 \mathrm{~Kb}$ ) by add-on mutagenesis using PCR technique with GenomiPhi (bacteriophage Phi29) DNA polymerase which could amplify large genomic frgaments as such. But the amplification of whole BAC DNA was not continuous in the trials.

Then the knockin construct was aimed using GET recombination with homologous primers as mentioned in section 2.1.9. The strategy employed includes a recombination in the target region of mutagenesis with a rpsL cassette (encoding S12 ribosomal protein, a target of the antibiotic streptomycin) created by add-on mutagenesis amplification and the counter selection, hence exploiting the genotype of the E.coli strain DH10B 
encompassing the BAC clone (Fig. 37a-d). And towards making the final targeting knockin construct a loxp_Kan/neo_loxp cassette was created as well (Fig. 38). But the system did not work in the counter selection due to huge unspecific background.

(a)

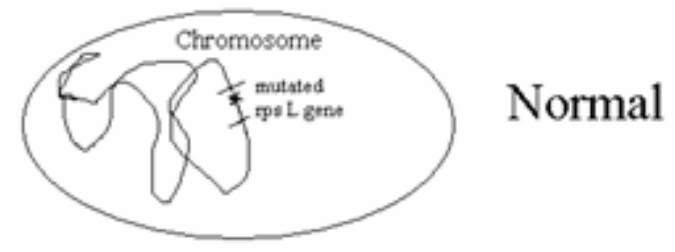

\section{E.coli DH10B strain (strep res.)}

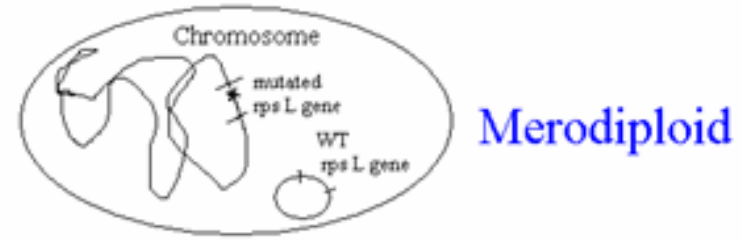

\section{E.coli DH10B strain (strep. sensitive)}

(b)

WT Mecp2 gene in BAC Clone B22804

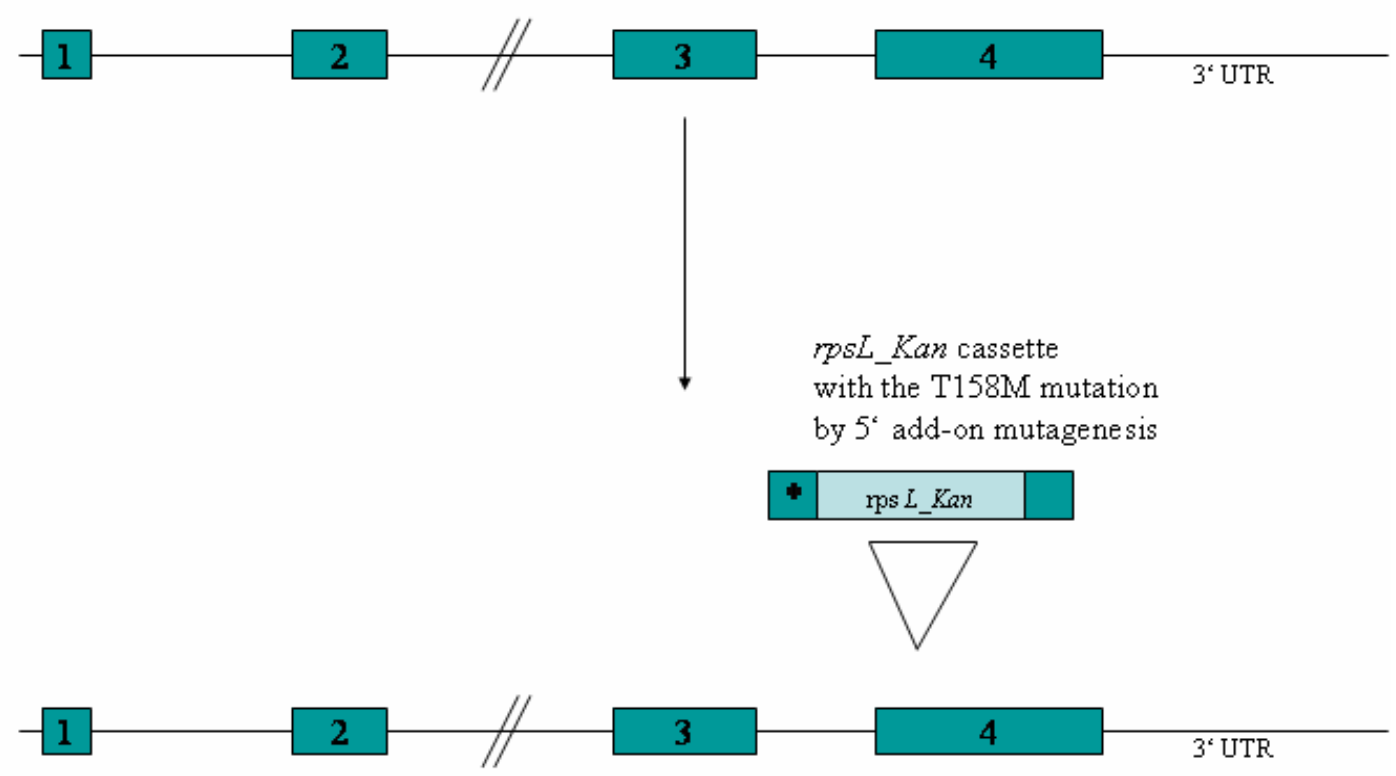


(c)
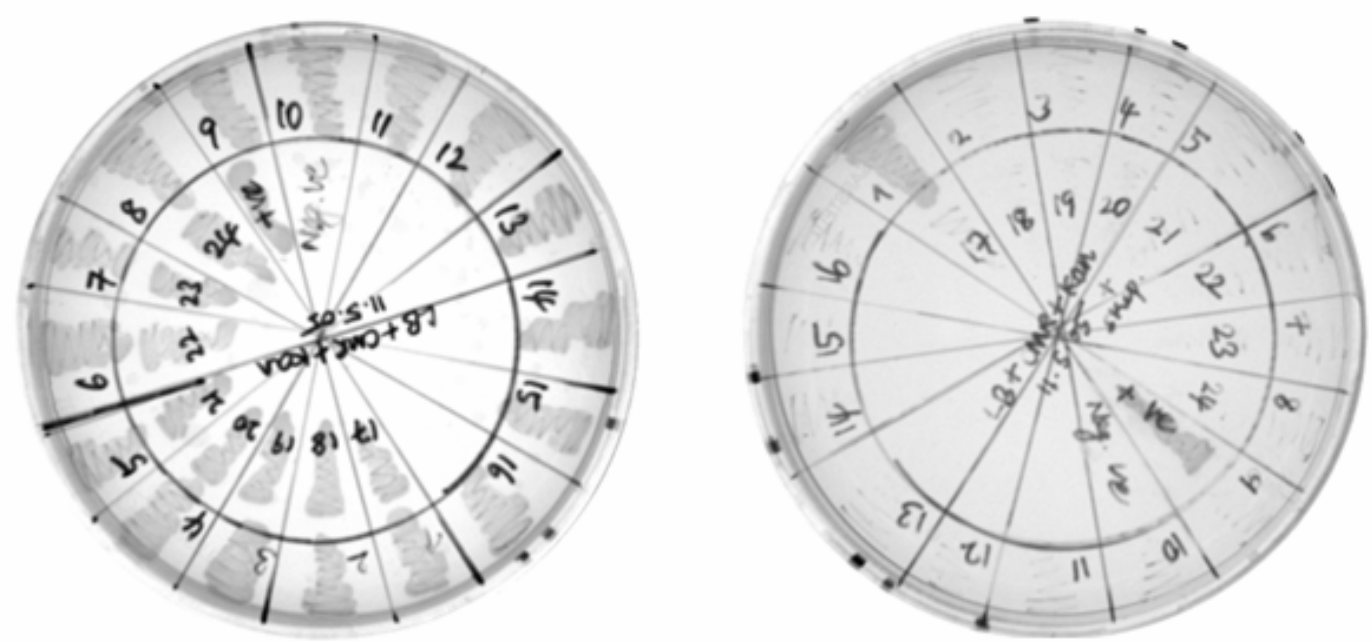

(d)

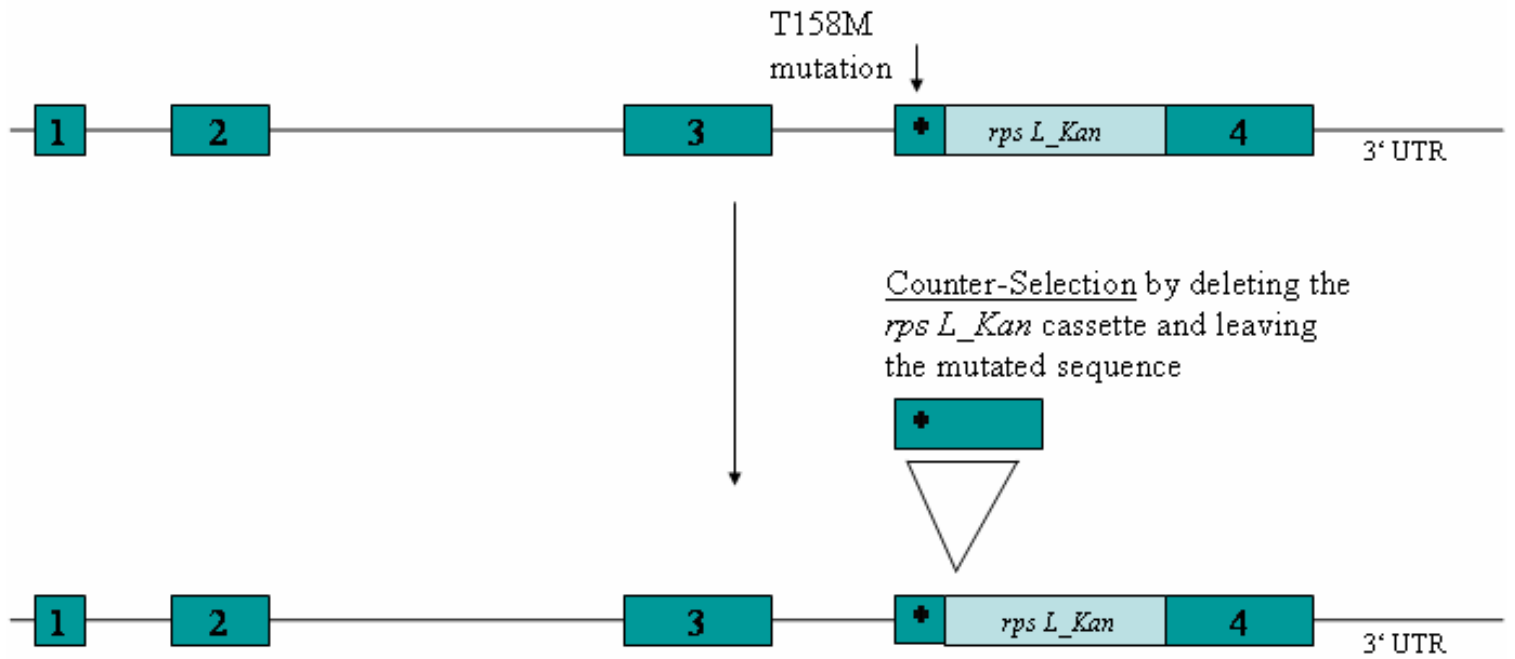

Fig. 37 Schematic representation of the rpsL counterseletion:

(a) Genotype of E.coli DH10B (F- mcrA D(mrr-hsdRMS-mrcBC) f80lacZDM15 DlacX74 deoR recAl endA1 araD139 D(ara-leu)7697 galU galK l rpsL nupG) shows the mutation in rpsL gene conferring resistance to the antibiotic streptomycin which has been exploited for the rpsL counterseletion. Most of the commonly used E. coli strains (DH10B, HS996, DH12S, TOP10 _..) carry a mutation in the rpsL gene. 
(b) The diagrammatic representation of the knockin strategy using rpsL counterseletion. A T158M point mutation in the exon 4 of the Mecp2 gene, was tried to be incorporated in the BAC clone B22804 (around $120 \mathrm{~Kb}$ ) by GET recombination.

(c) Replica plating after the recombination in the target region of mutagenesis with a rpsL cassette created by add-on mutagenesis amplification and the counter selection.

(d) The diagram explaining the counterseletion with the rpsL system.

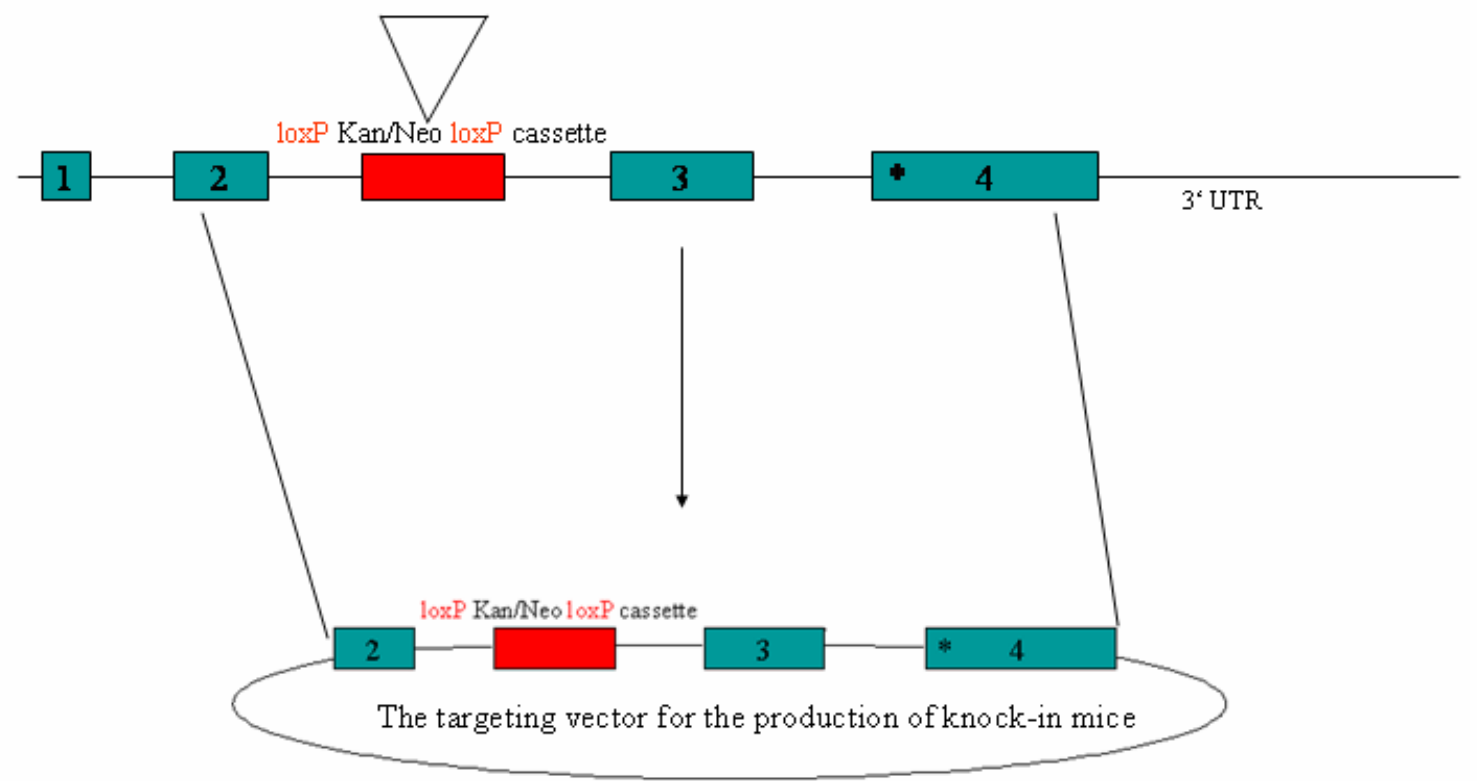

Fig. 38 The final targeting knockin construct: Towards making the knockin construct a loxp_Kan/neo_loxp cassette was created to be recombined in the intron 2 of Mecp2 gene in BAC clone 22804.

The same strategy was tried with thyA (Fig.39) and Ara-ccdB-Zeo (L-Arabinose inducible ccdB killer gene with zeocin cassette) systems but none of them was reliable because of the unspecific background. Lastly, a mutagenesis with direct recombination of MluI_Zeo_MluI cassette (zeocin amplified by add-on mutagenesis and flanked by MluI restriction sites not present anywhere in the BAC clone, enabling the specific removal of zeocin cassette) and religation of the construct leaving the residual MluI restriction site in the intron 3 was performed. This final strategy also turned out to be negative in the second step of religation and propagation. So, no clones with the mutation could be obtained. 
(a)

\section{Mechanism of Counter-selection}

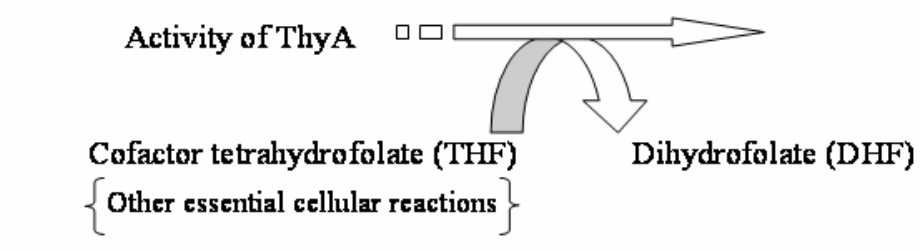

Trimethoprim drug

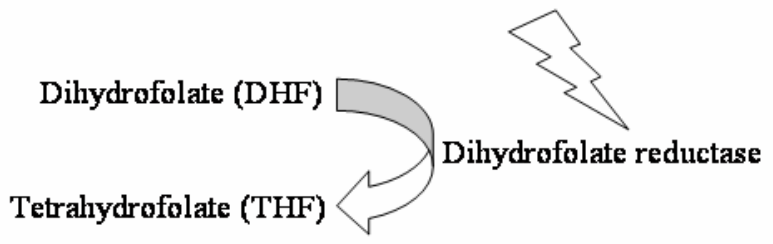

(b)
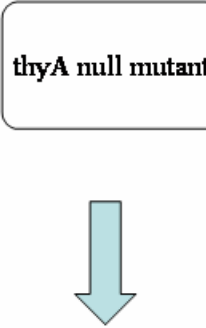

Growth media with thymine
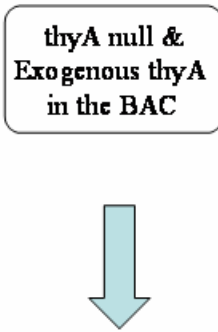

Growth media widhent thymine
thyA null \&

Residual mutation

in the BAC.

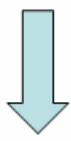

Growth media with thymine \& trimetheprin

The Stage of Counter-selection

Fig. 39 The diagrammatic representation of the thyA selection system:

(a) Diagram showing the mechanism of counterseletion in thyA system with trimethoprim drug.

(b) Thymidylate synthase is involved in the de novo synthesis of dTTP from dUMP. Without thyA the cell is unable to synthesise DNA and, therefore, will not grow in minimal growth media. Thus, in a thyA-null E.coli mutant (thyA), recombinants containing an exogenous thyA gene can be selected for (positive selection) by culture in growth medium in the absence of thymine. When thymine is provided, de novo dTTP synthesis can proceed without the need for ThyA function. 


\subsection{Identifying the target sequences of MeCP2 protein}

Chromatin Immunoprecipitation (ChIP) assay in HeLa cell line overexpressing MeCP2_EGFP (isofrom 2) fusion protein from pCMV-Mecp2_EGFP construct was performed in the laboratory by Ms. Katrin Tanzhaus. One of the possible targets was identified to be the gene LOC91663 encoding a hypothetical protein BC013995, mapping on chromosome 19, at 19q13.42 according to Refseq. So Gel Electrophoretic Mobility Shift Assays (GEMSA) were carried out for the putative binding region in the prospective gene LOC91663. Since MeCP2, a chromosomal protein, binds to methylated DNA and the characteristic feature being that it can bind specifically even to a single methyl-CpG dinucleotide pair and not influenced by sequences flanking the methyl$\mathrm{CpGs}$, the putative oligo designed for the binding region was $\mathrm{CpG}$ methylated in vitro by M.SssI (CpG) methylase.

Although a mobility shift was detected in the gel electrophoresis of the radioactive methylated putative oligo incubated with HeLa cell extract overexpressing the Mecp2_EGFP fusion protein, a supershift could not be noticed when the MeCP2 antibody from Upstate, USA, or a monoclonal MeCP2 antibody from Sigma, USA, was used along with the HeLa cell extract (Fig. 40). 


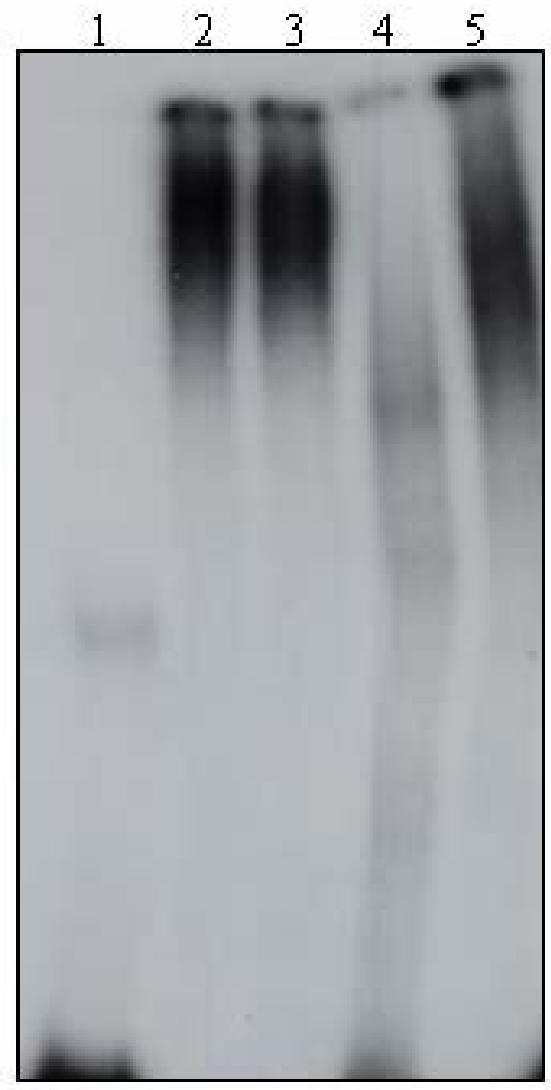

Fig. 40 Gel Electro Mobility Shift Assay (GEMSA) for the gene LOC91663: A mobility shift was detected in the gel electrophoresis of the radioactive methylated putative oligo designed for the binding region, when it was incubated with HeLa cell extract overexpressing the Mecp2_EGFP fusion protein, but a supershift could not be noticed when the MeCP2 antibody was used along with the HeLa cell extract 1.Negative control with only radio-active methylated oligo. 2.Radio-active methylated oligo with Hela extract (Positive Control). 3.Radio-active methylated oligo with Hela extract and MeCP2 antibody (Supershift). 4.Specific competition of positive control by unlabelled methylated oligo. 5.Non-Specific competition of positive control by AP-2 oligo. 


\subsection{Mecp2 in Reproductive biology}

It was described that the testes of Mecp2 null males were always internal (Guy et al., 2001). And the neurologically affected Mecp2 null mice were unable to breed, but little is known about the fertility and the role of Mecp2 in reproductive biology. Hence, efforts were made to understand the function of the Mecp2 protein in reproductive biology.

\subsubsection{Studies in Mecp2 knockout mice.}

The sperm count was studied in Mecp 2 knockout mice cauda epidymis and was found to possess around $2.3 \times 10^{6}$ sperms. And the morphology of the sperms was measured by calculating the normal and the abnormal sperm count. The abnormal sperm count was found to be around 11\%. Also the testosterone level in Mecp2 null mice was found to have no significant difference when compared to the WT mice (Table 4).

\begin{tabular}{|l|l|}
\hline WT animals & Testosterone $[\mathrm{ng} / \mathrm{ml}]$ \\
\hline WT 1 & 0,11 \\
\hline WT 2 & 0,51 \\
\hline WT 3 & 0,24 \\
\hline WT 4 & 0,95 \\
\hline WT 5 & 3,17 \\
\hline WT 6 & 0,10 \\
\hline WT 7 & 0,38 \\
\hline WT 8 & 17,3 \\
\hline WT 9 & 1,13 \\
\hline WT 10 & 2,81 \\
\hline
\end{tabular}

\begin{tabular}{|l|l|}
\hline Mecp2 Knockout mice & Testosterone $[\mathrm{ng} / \mathrm{ml}]$ \\
\hline KO 1 (haemolysed) & 3,24 \\
\hline KO 2 (haemolysed) & 5,77 \\
\hline KO 3 & 3,19 \\
\hline KO 4 & 0,97 \\
\hline
\end{tabular}


Table 4 shows the testosterone level in $\mathrm{ng} / \mathrm{ml}$ of the serum from Mecp 2 null mice and the WT mice thus displaying no significant difference. WT: wild type, KO: knockout.

The histological and electron microscopical examination of the testes of Mecp2 null mice at postnatal day 30 showed no obvious abnormalities (Fig. 41).
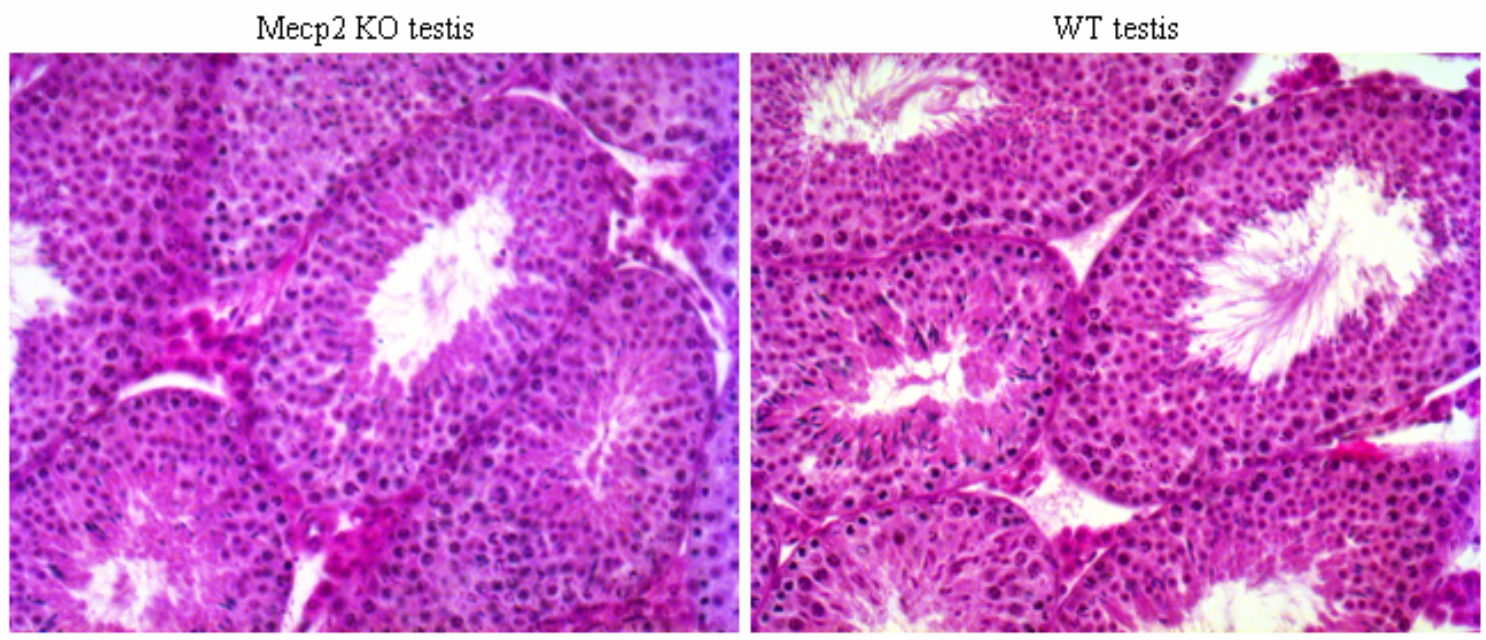

Fig. 41 Electronmicroscopical examination of the Mecp2 knockout (KO) and WT testes: The cross section of HE stained Mecp2 knockout and WT testis at postnatal day 30 was histologically examined using an electronmicroscope. No obvious abnormalities could be obsereved.

\subsubsection{Mecp2 in mouse testicular development and ovary}

RNA was extracted from postnatal days 5, 10, 15, 20, 25, 30 and adult stages of WT mice testes and checked for the presence of the Mecp 2 transcripts in each time period by RTPCR analysis using Mecp2_Mus_RT_For and Mecp2_Mus_RT_Rev1 primers. The expression of the transcript was observed from postnatal day 5 (Fig. 42). The RT-PCR analysis was extended to study the expression of the Mecp 2 transcript in adult ovary and $\mathrm{W} / \mathrm{W}^{\mathrm{v}}$ mutant mouse testis which lacks $c$-Kit gene and thus have no spermatogenesis. And the presence of the transcript was further confirmed in ovary and $\mathrm{W} / \mathrm{W}^{\mathrm{v}}$ mutant testis (refer Fig. 42). But the protein was very less expressed in testis and ovary as ascertained by Western blot analysis of the protein extract from the tissues. And when immunohistochemistry was performed with the WT mouse testis and ovary sections, no prominent signal could be detected with MeCP2 antibody from Upstate, USA. 


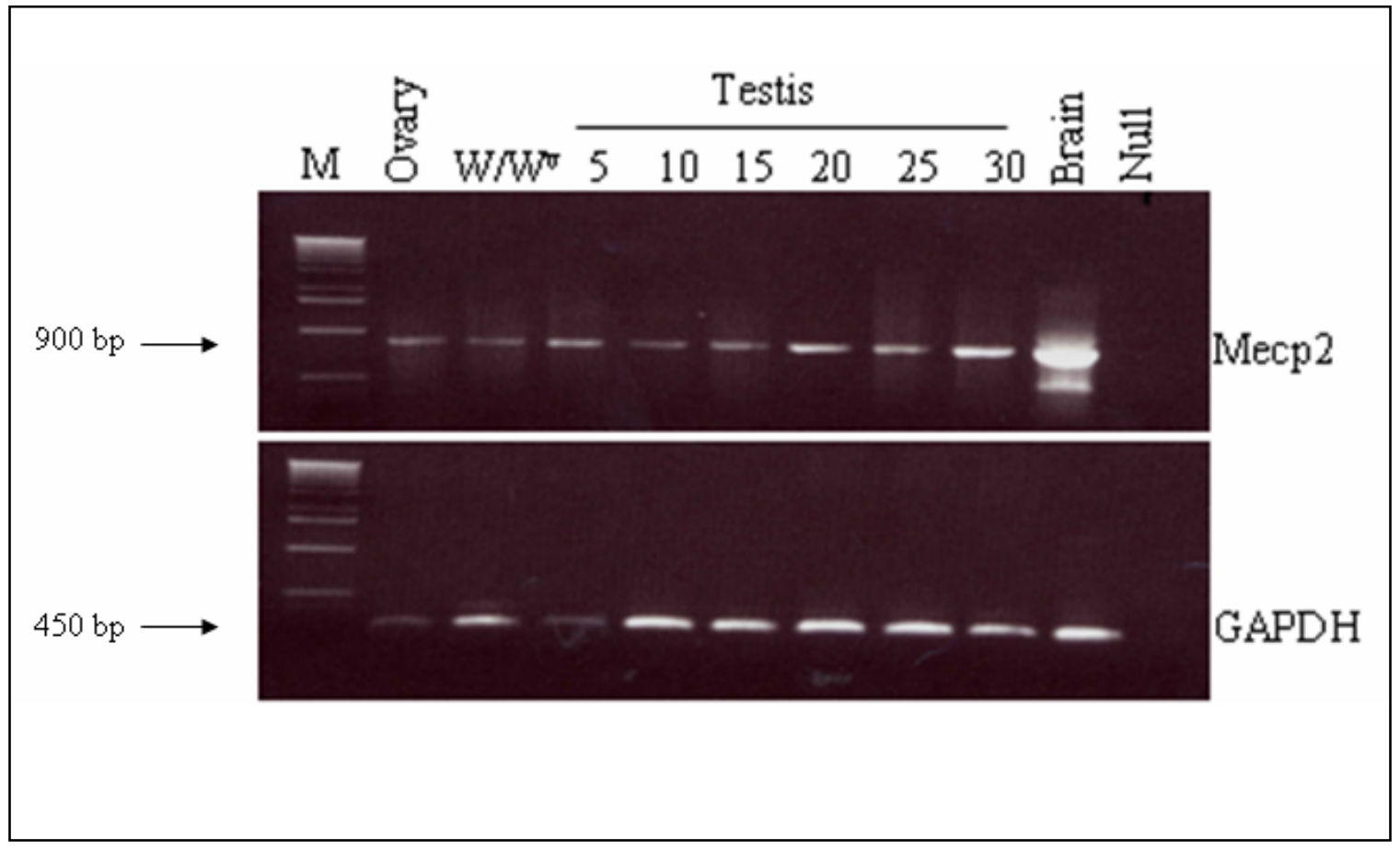

Fig. 42 RT-PCR analysis of Mecp2 gene in mouse testicular development and ovary: RNA was extracted from postnatal days 5, 10, 15, 20, 25, 30 and adult stages of WT mouse testis and checked for the presence of the Mecp2 transcripts in each time period by RT-PCR analysis. The expression of the transcript was observed from postnatal day 5 and was further confirmed in $\mathrm{W} / \mathrm{W}^{\mathrm{v}}$ mutant mouse testis and adult ovary as well. GAPDH gene was amplified as a control PCR with GAPDH_F and GAPDH_R primers. M: $1 \mathrm{~Kb}$ DNA molecular weight marker. Null control: The PCR amplification with water instead of input RNA/DNA.

\subsubsection{Presence of the protein in mouse oocytes and preimplantation embryos}

The immunostaining with $\mathrm{MeCP} 2$ antibody was carried out from one cell stage through cell stage 8 till the embryonic day 3.5 of mouse embryonal development. The presence of Mecp2 was observed from one cell stage onwards (Fig. 43i-v). RT-PCR analysis from the WT unfertilized oocytes showed the presence of the transcript as well. So the presence of maternal storage RNA should be evaluated further. 
(i)

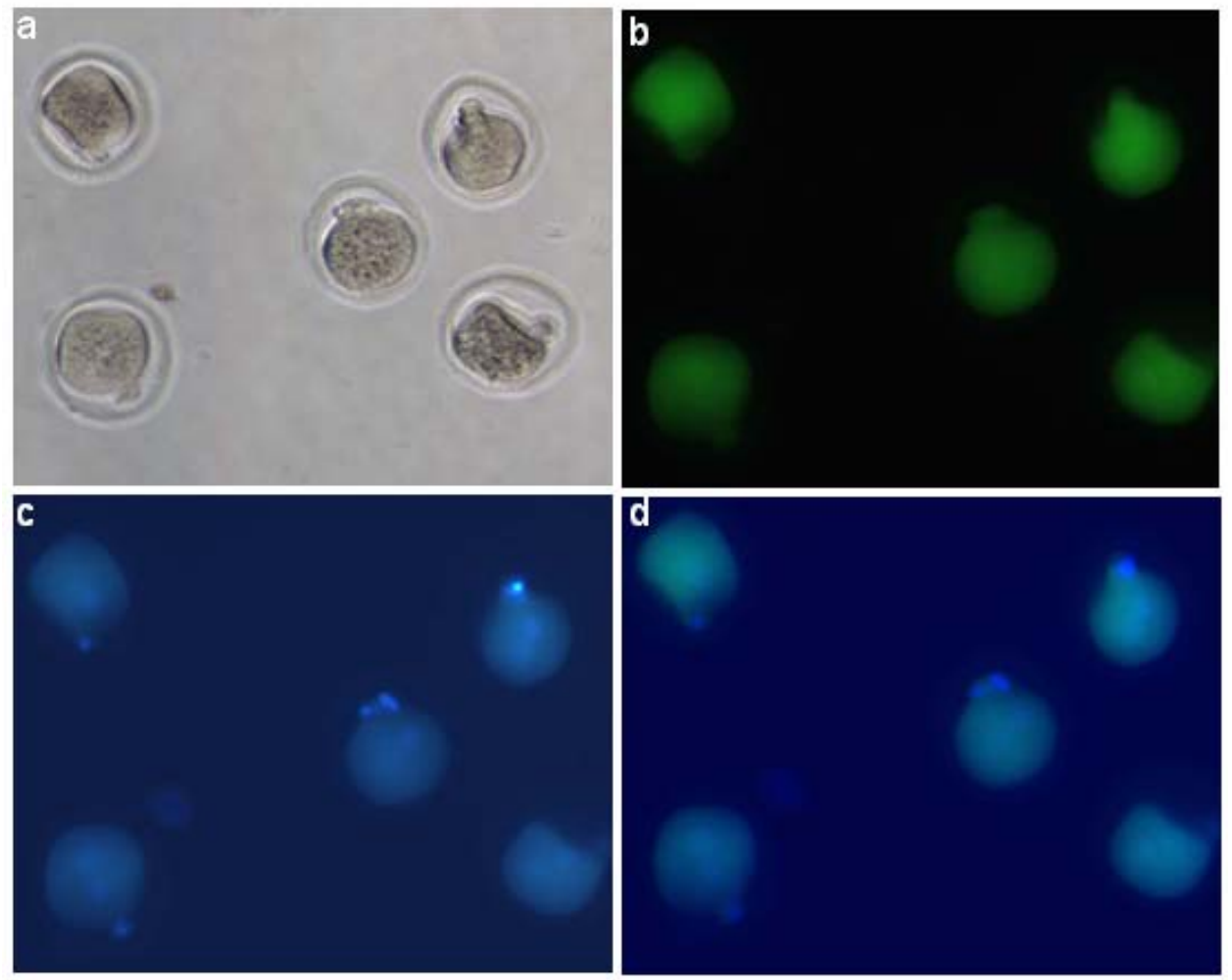

(ii)

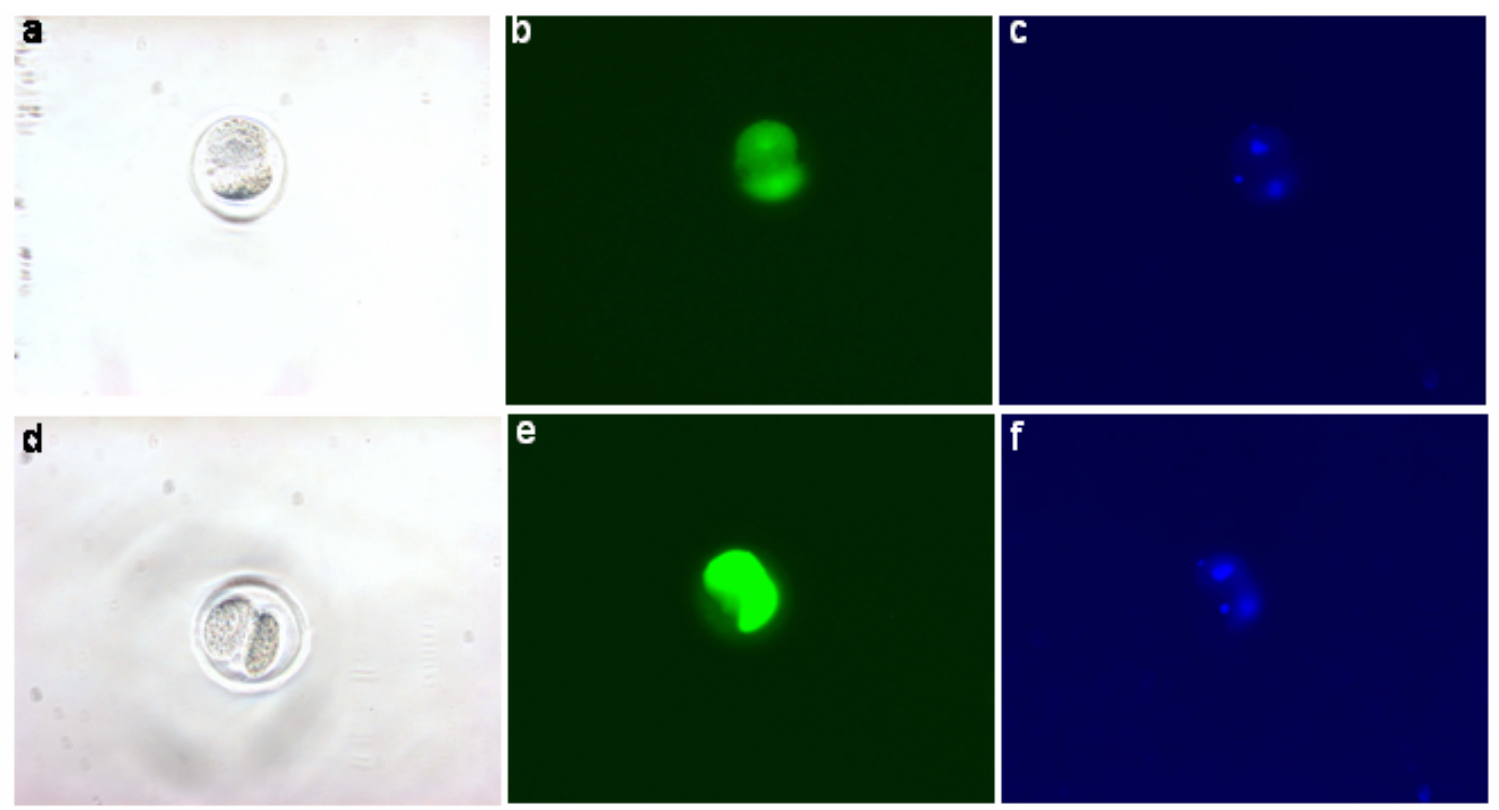


(iii)
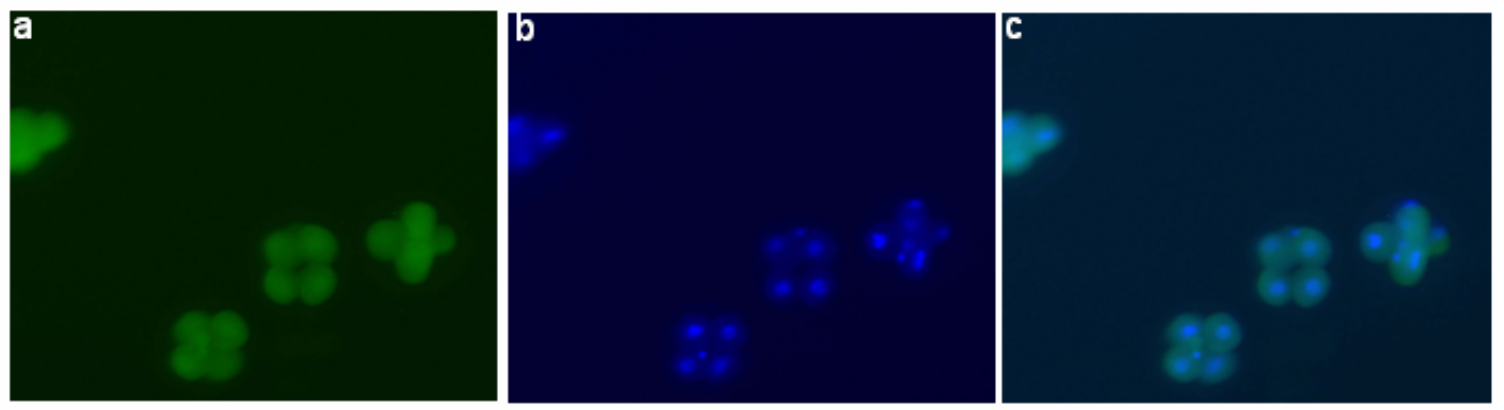

(iv)
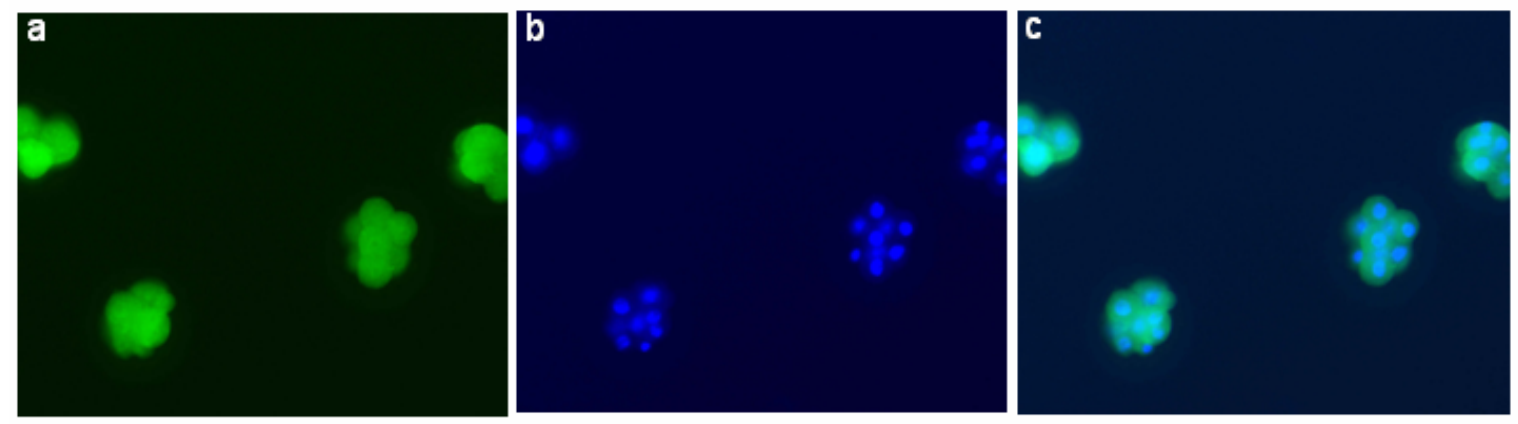

(v)
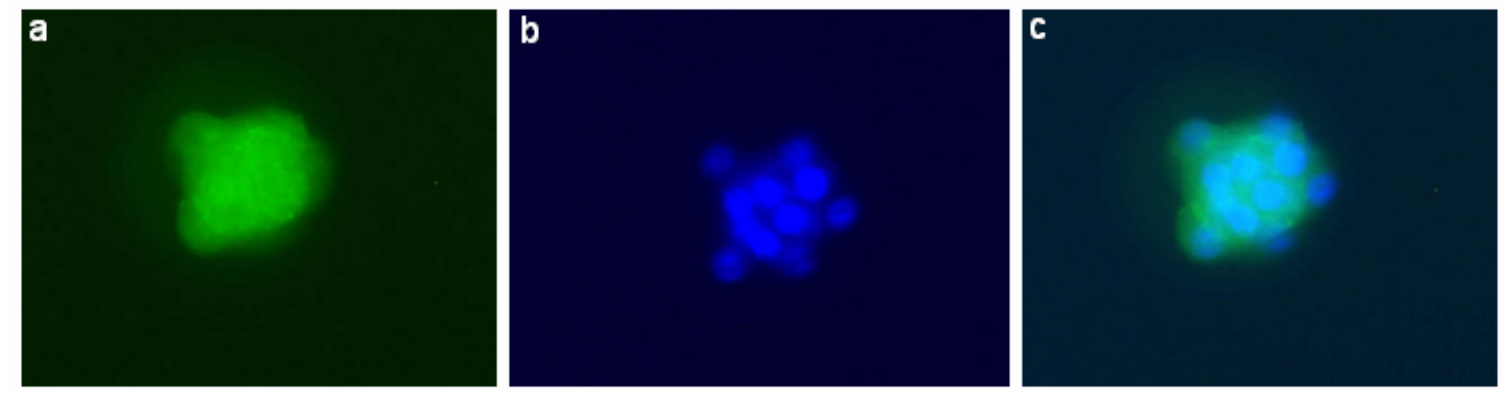

Fig. 43 Immunostaining of mouse oocytes and pre-implantation embryos for Mecp2: The immunostaining with $\mathrm{MeCP} 2$ antibody was carried out from one cell stage or mouse embryonic stage 0.5 (i), two cell stage or mouse embryonic stage 1.5 (ii), four cell stage or mouse embryonic stage 2.5 (iii) and eight cell stage (iv) and till the embryonic day 3.5 (v). The presence of Mecp2 was observed from one cell stage onwards. a-d panels of the corresponding pictures show FITC staining for Mecp2 (green), DAPI for nucleus (blue), bright field and the overlay images. 


\subsubsection{Mecp2 in mouse embryonic stem (ES) cells}

Since the Mecp2 staining was observed till the mouse embryonic day 3.5, the presence of the protein in the undifferentiated embryonic stem cells was also checked. Immunostaining using $\mathrm{MeCP} 2$ antibody in WT mouse embryonic stem cells showed the signals in the nuclei (Fig. 44).
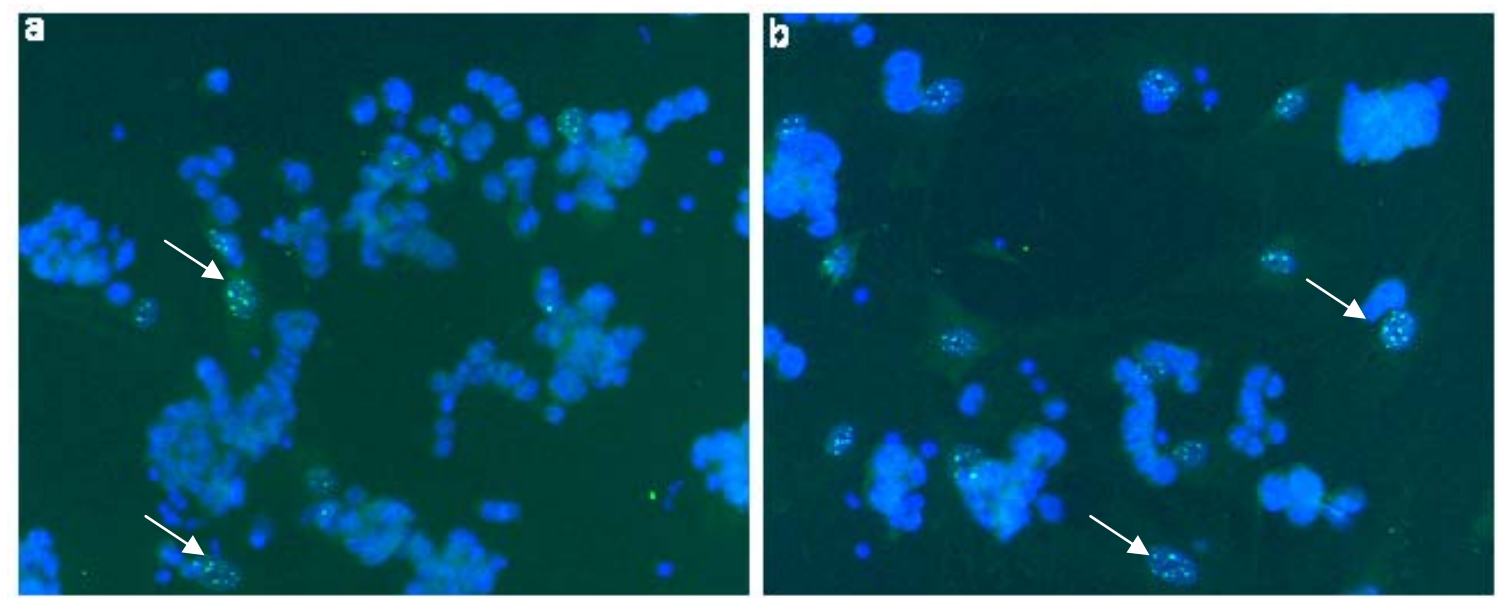

Fig. 44 Immunostaining of Mecp2 in mouse embryonic stem cells: Immunostaining was perfomed using MeCP2 antibody in WT mouse undifferentiated embryonic stem cells which showed the presence of Mecp2 in the nuclei.

\subsubsection{Mecp2 in unfertilized oocytes}

To study the presence of Mecp2 transcript in unfertilised oocytes, 100 unfertilised oocytes were collected from adult CD-1 female mice (20-24 hrs post-hCG hormone injection of the superovulated adult CD-1 female mice, by administration of PMS and 46$48 \mathrm{hrs}$ later injection with $2.5 \mathrm{ml}$ hCG hormone). The oocytes were then treated with Hyaluronidase enzyme thus digesting the zona pellucida and cummulus cells to avoid the possible contamination of genomic DNA. Then the total RNA of the oocytes was isolated using a kit from Amersham Biosciences, England, and directly subjected to single step RT- PCR with Mecp2_EX3_F3 and Mecp2_check_473m_R primers. The RT-PCR amplification resulted in a $377 \mathrm{bp}$ long product from the transcript. To further prove the amplification from RNA, the same PCR was repeated with the genomic DNA of the CD_1 female mice which in turn resulted in a product of $864 \mathrm{bp}$ due to the presence of 
around $500 \mathrm{bp}$ third intronic region of the Mecp 2 gene between the primer binding sites (Fig. 45). Therefore it was demonstrated that Mecp2 transcripts are present in unfertilized oocytes.

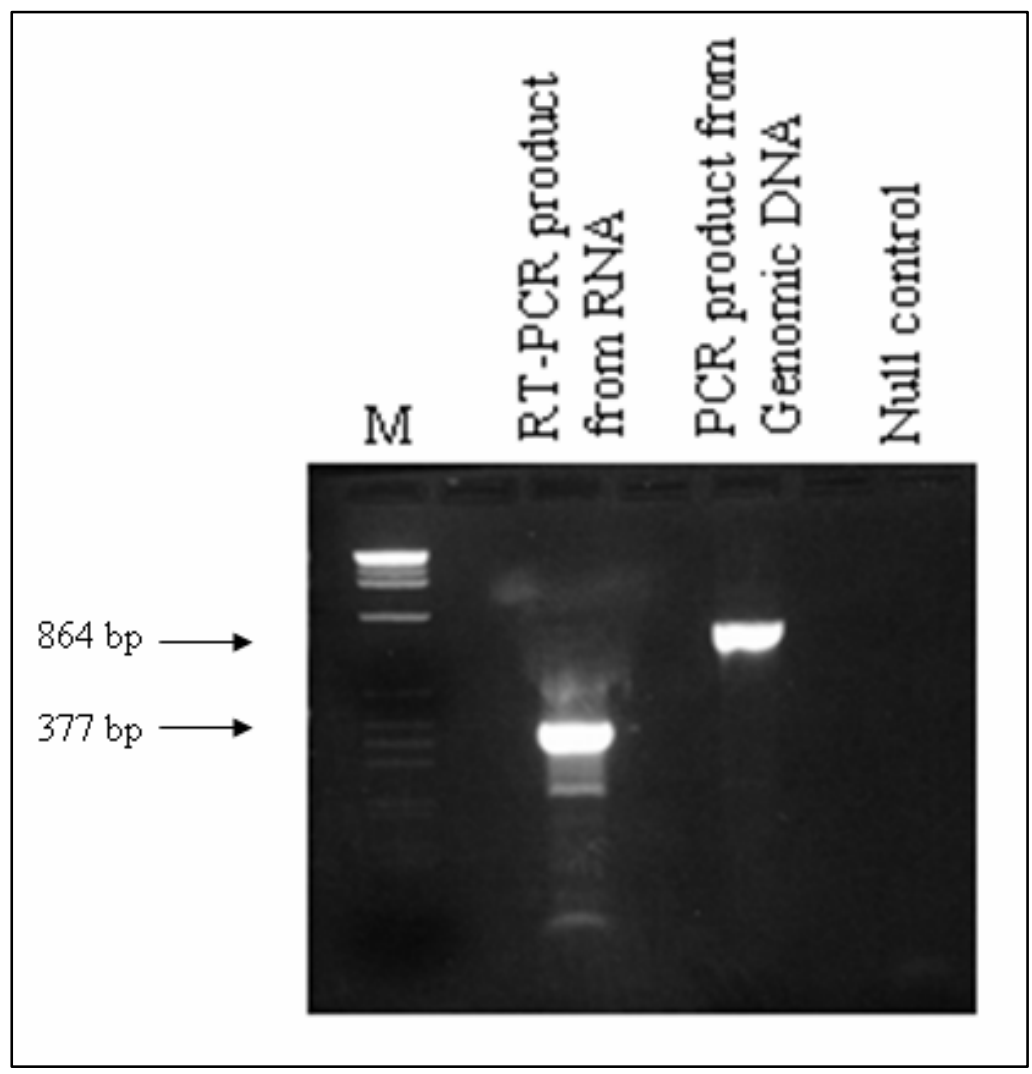

Fig. 45 Analysis of Mecp2 transcripts in unfertilized oocytes: To check the presence of Mecp2 transcript in the unfertilized oocytes, total RNA was isolated and analysed by single step RT-PCR with Mecp2_EX3_F3 and Mecp2_check_473m_R primers. The RT-PCR amplification resulted in a 377 bp long product from the transcript. To verify the amplification from RNA, the same PCR was repeated with the genomic DNA of the CD_1 female mice which in turn resulted in a product of $864 \mathrm{bp}$ due to the presence of around $500 \mathrm{bp}$ third intronic region of the Mecp 2 gene between the primer binding sites. M: $1 \mathrm{~Kb}$ DNA molecular weight marker. Null control: The PCR amplification with water instead of input RNA/DNA.

\subsubsection{Mecp2 in mouse sperms}

Immunostaining of the WT mouse spermatozoa was done to check the presence of Mecp2 using the MeCP2 antibody from Upstate, USA. The images from the immunostaining showed the localization of the Mecp2 protein near the acrosome (Fig.46(i)). And the results were the same in WT testis cell suspension (Fig. 46(ii)) and 
in decapacitated sperms (Fig. 46(iii)). Western blot analysis of the protein extracted from the WT mice sperms detected a band corresponding to the Mecp2 protein (Fig. 47). But when the immunostaining was done in Mecp2 knockout mouse sperms the results stated that the immunostaining was not specific since the same signals were observed as in WT sperms, may be due to the sticky nature of the acrosome (Fig. 48). These results have to be validated in the Mecp2_WT_EGFP transgenic mice.

(i)
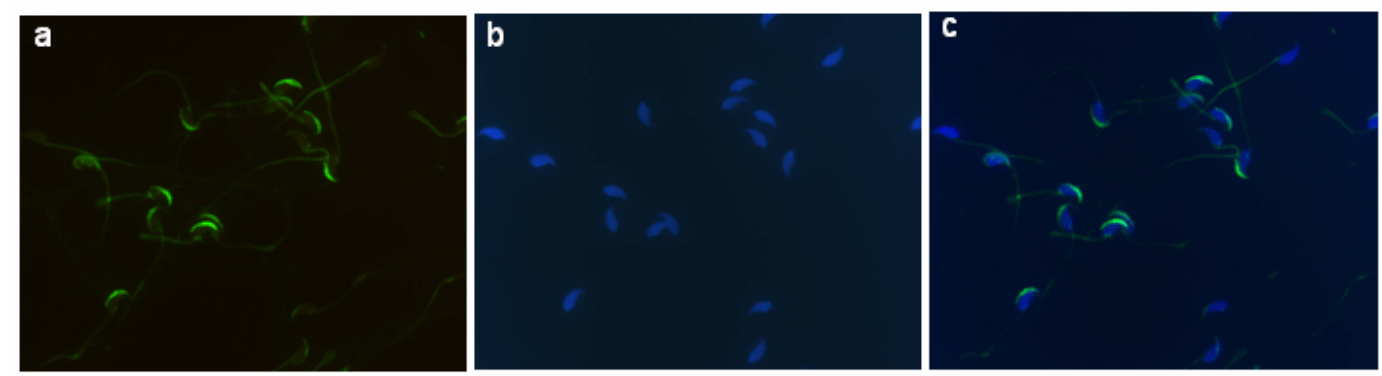

(ii)
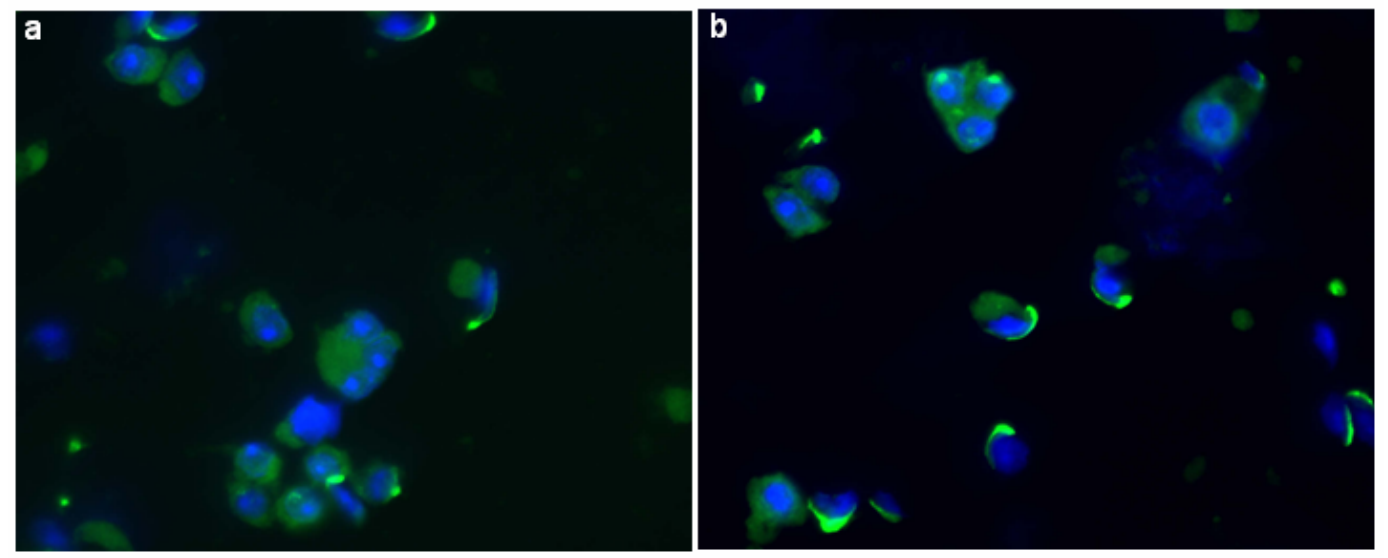

(iii)
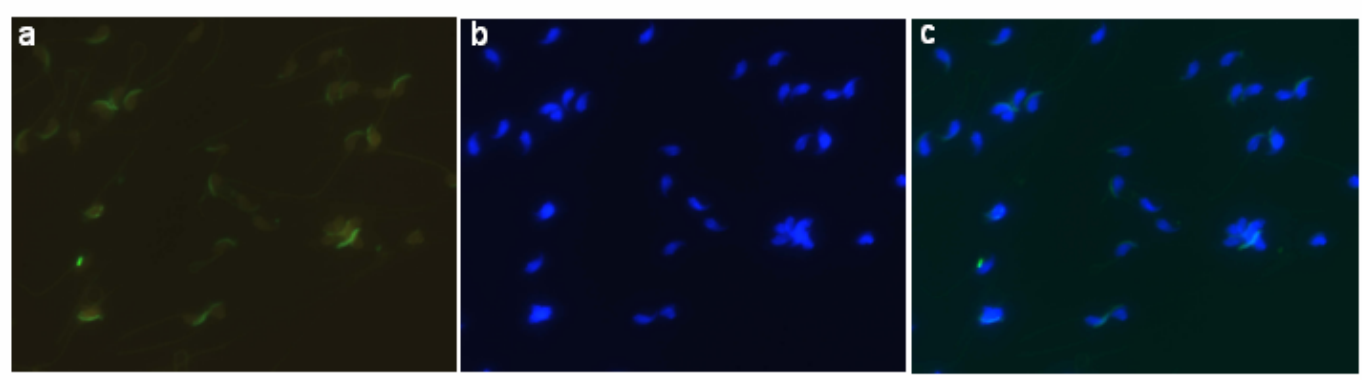

Fig. 46 Immunostaining of Mecp2 in mouse spermatozoa: Immunostaining of the WT mouse sperms was done to check the presence of Mecp2 using the MeCP2 antibody. The images showed the localization 
of the Mecp2 protein near the acrosome (i), in WT testis cell suspension (ii) and in decapacitated spermatozoa (iii). a-c panels of the corresponding pictures show FITC staining for Mecp2 (green), DAPI for nucleus (blue) and the overlay images.

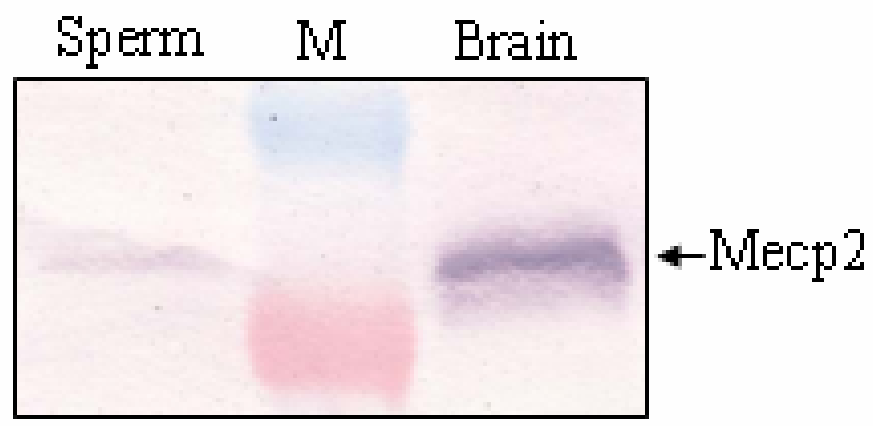

Fig. 47 Western blot analysis of the mouse sperm protein: Protein was extracted from the WT mouse spermatozoa and in the Western blot analysis a band corresponding to the Mecp2 protein was detected. The total protein extract from the brain was used as a positive control. M: prestained protein ladder.
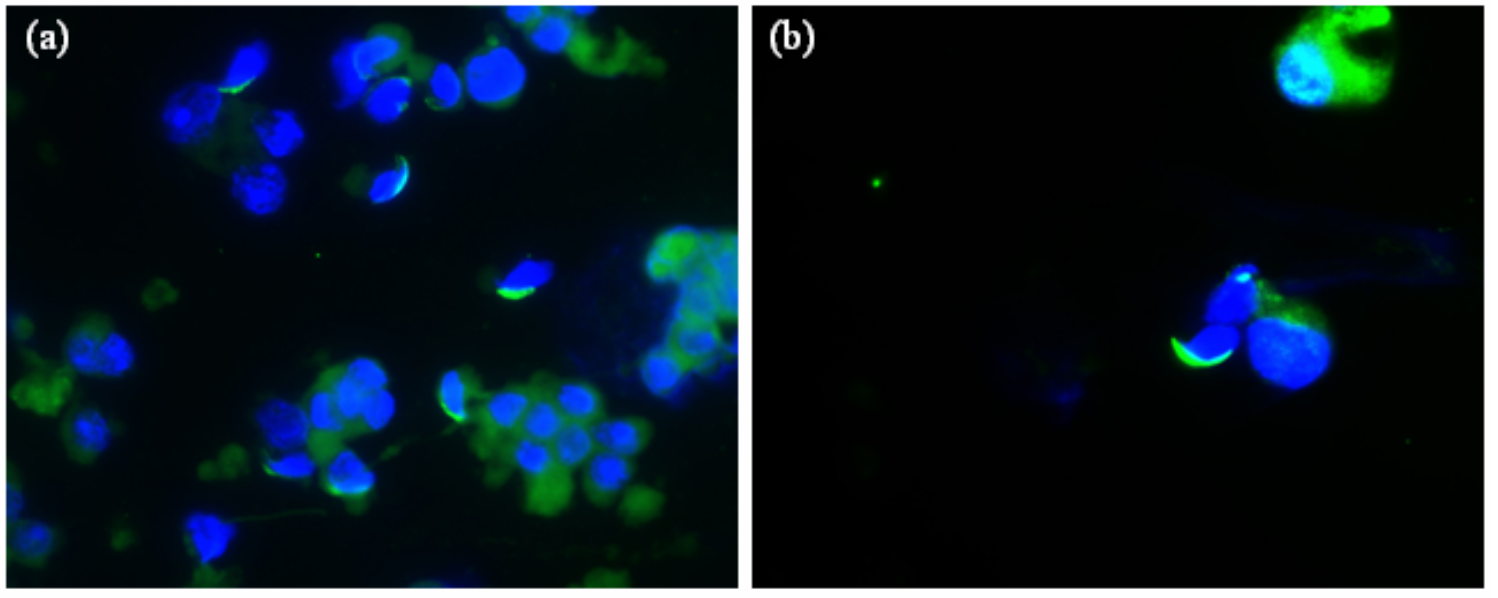

Fig. 48 Immunostaining of Mecp2 knockout mouse spermatozoa: (a) Immunostaining of Mecp2 knockout mouse spermatozoa was done to verify the results obtained from the WT mice sperms. A high resolution image was also shown (b). The results stated that the immunostaining was not specific since the same signals were observed both in the WT and knockout mouse spermatozoa. 


\section{Discussion}

The study was intended to produce transgenic mouse models expressing Mecp2 tagged with EGFP as a reporter to further characterize and obtain an appropriate functional analysis of Mecp2. The ability to accurately examine shifts in gene expression in CNS which is likely to occur in neurological diseases, for instance Rett syndrome, would be substantially improved by the ability to separate neurons by FACS or microdissection methods utilizing markers of cell lineage. To address this difficulty, transgenic mouse models have been engineered to express Mecp2 fused with EGFP under the control of the putative endogenous promoter. The transgenic constructs have been generated by engineering a BAC clone (B22804) containing the entire Mecp2 gene of the mouse and flanking sequences, by GET recombination.

\subsection{Creation and characterization of transgenic mouse models for Mecp2 gene}

\subsubsection{Promoter analysis of Mecp2 gene}

The Mcpromoter program (Ohler et al., 2001) predicted endogenous promoter region of Mecp2 was analyzed by transfection assays but a significant promoter activity was not found. Consequently a careful analysis of the sequence of intron 1 was performed to identify the regulatory elements and the expression of recently described exon1 (Reichwald et al., 2000) was also verified. In the meantime, different isoforms of Mecp2 derived from alternative splicing between exon 1 and exon 2 were reported which made the analysis of promoter region much more complicated (Mnatzakanian et al., 2004). Because of the complex structure of the Mecp2 gene, a BAC clone (B22804) encompassing a mouse genomic fragment containing the whole length Mecp 2 gene with the flanking sequences was chosen for transgenesis. And the genomic fragment in the BAC clone was engineered to have the EGFP in frame with the Mecp2 gene by a homologous recombination technique called GET recombination.

\subsubsection{GET recombination and generation of transgenic constructs}

Escherichia coli vectors that can contain large inserts, such as bacterial artificial chromosomes (BACs), P1 vectors and P1 artificial chromosomes (PACs), offer several 
advantages for functional genomics. They can carry sufficient DNA to encompass most eukaryotic genes, including all cis-acting regulatory elements in a single molecule. However, conventional cloning methods rely on the use of restriction enzymes and in vitro purification steps, which preclude engineering of large molecules. So, the usefulness of such molecules has been limited until recently. GET recombination is a method that permits precise engineering of DNA molecules of any size, including very large ones such as BACs/P1 Artificial chromosomes in the E.coli (Orford et al., 2000). It relies on homologous recombination in vivo in E.coli and allows a wide range of modifications with DNA molecules at any chosen position.

GET recombination, an inducible recombination system in E.coli DH10B by expression of the bacteriophage lambda gam gene (inhibitor of rec BCD nuclease ) and E.coli recE and recT from an L-Arabinose promoter on plasmid pGETrec has been used for the study (Orford et al., 2000). The GET recombination method only requires two segments of around 50 nucleotides of homology, flanking the DNA fragment to be cloned. Therefore, efficient and precise introduction of PCR fragments carrying a selectable marker and a reporter gene into specific sites could be accomplished (Fig. 49a and Fig. 49b). Intending to produce transgenic mouse models overexpressing Mecp2 tagged in frame with EGFP as a reporter, it was nearly impossible to clone EGFP cassette downstream of the Mecp2 in the genomic fragment by normal restriction digestion, the genomic BAC clone was then genetically engineered by GET recombination. 
(a)

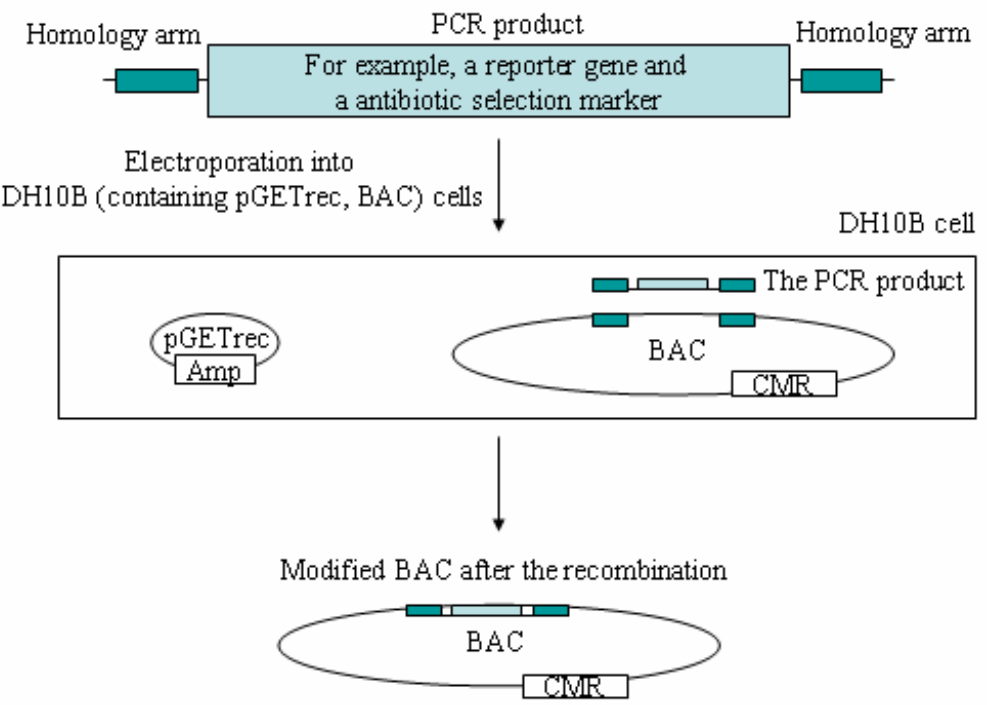

(b)
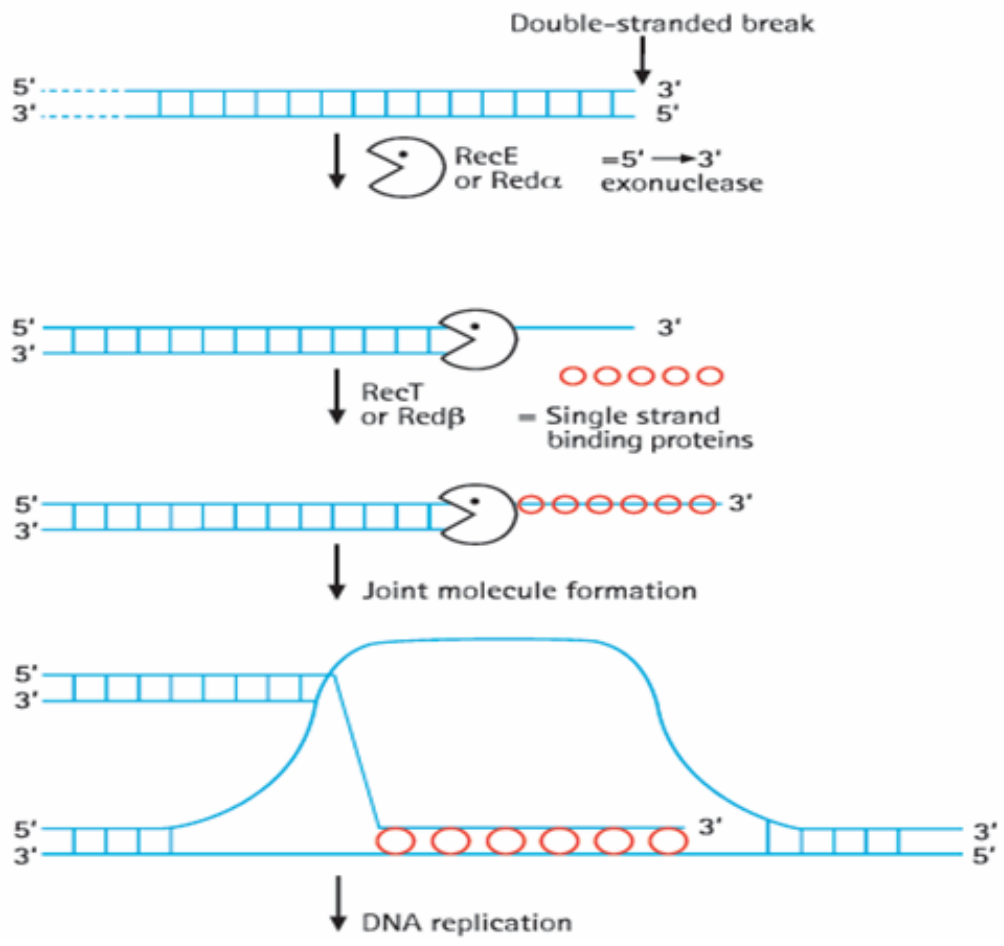

Fig. 49 Diagrammatic illustration of GET recombination and the mechanism: The GET recombination is an inducible recombination system in E.coli DH10B which only requires two segments of around 50 nucleotides of homology, flanking the DNA fragment to be cloned. Through this method introduction of PCR fragments carrying a selectable marker and a reporter gene into specific DNA region of interest is possible (a). pGETrec: Plasmid 'pGETrec' which facilitates the recombination, Amp: Ampicillin, CMR: Chloramphenicol, BAC: Bacterial Articficial Chromosome vector (carrying a huge genomic fragment). 
GET recombination is facilitated by pGETrec plasmid encoding bacteriophage lambda $\boldsymbol{g}$ am gene and E.coli $r e c \boldsymbol{E}$ and $r e c \boldsymbol{T}$ genes from a tightly regulated and inducible L-Arabinose promoter. The gam is an inhibitor of rec BCD nuclease which cleaves foreign DNA entering an E.coli cell, recE gene, an 5'-3' exonuclease digests the DNA strand of the PCR fragment from 5' end to 3' direction, and recT is a single strand binding protein which binds the single strand of the PCR fragment left out of the recE digestion. Accordingly recombination takes place then, by joint molecule formation and replication (b). (Gene bridges, Stewart $\mathrm{AF})$.

Out of the GET recombination, three transgenic constructs were generated with EGFP tag, one expressing the WT Mecp2 gene (Mecp2_WT_EGFP) and the other two expressing the truncated forms which represents the mutations found in Rett patients. The mutation constructs were designed to express the C-terminal truncated proteins after 270 amino acids (Mecp2_270_EGFP) and 400 amino acids (Mecp2_400_EGFP) of Mecp2, respectively. Then the transgenic constructs underwent a series of modifications to delete the flanking genes on either sides of the gene. The constructs did not have any rearrangements and multiple integrations during the recombination which was checked by Southern blotting before the pronuclear microinjection.

\subsubsection{Establishment of transgenic mouse lines}

After the transmission and expression analysis of the transgene, 3 transgenic founder lines (Line 2, 39 and 49) were established for Mecp2_WT_EGFP transgenic construct. Since the expression of Mecp2_270_EGFP mutation construct was undetectable and the Mecp2_400_EGFP failed to transmit the transgene, the two mutation lines were discontinued. But after an efficient polyclonal antibody against MeCP2 recombinant protein was raised for the detection of the transgenic proteins, the Mecp2_270_EGFP was reinjected for the transgenesis.

The mode of inheritance of the Mecp2_WT_EGFP transgenic animals including the litter size and sex ratio was proven to be normal. The copy number and the number of integration studies of the Mecp2_WT_EGFP transgenic construct in the animals revealed that the mouse lines had single integration in all the cases but the copy number was one in line 2 and two in mouse lines 39 and 49. Depending upon the breeding of the mouse 
lines, line 2 and line 49 were taken into consideration for further studies. Moreover, line 2 having a single copy and integration of the transgene was promising to continue functional analysis.

The regulation of the expression of the transgene was verified using multi tissue Western blot analysis in comparison with the expression of the endogenous Mecp2 gene. The analysis showed that the expression was high in brain and lung, low in kidney and undetectable in liver. Subsequently, the transgenic protein profiling by immunostaining with the other marker proteins of CNS demonstrated the neuronal specific expression and intracellular localization of the protein in mouse brain. This observation was in line with the fact that even if $\mathrm{MeCP} 2$ is found in most tissues and cell types, highest expression levels are detected in the brain, where it is primarily present in neurons but not in glia (Akbarian et al., 2001; Coy et al., 1999).

The degree of histone deacetylation was higher in areas of the brain that contained the highest level of expression of $\mathrm{MeCP} 2$. These results support the notion that the chromatin and transcriptional repression is regulated by MeCP2 (Shahbazian et al., 2002a). So, a HDAC assay was carried out in the Mecp2_WT_EGFP transgenic brain to control the biochemical activity of the transgenic protein but the experiment showed no significant degree of histone deacetylation. This might have resulted by functional redundancy of other methylated-DNA binding proteins like MBD1 and MBD2. MBD2, which usually functions as a transcriptional activator in the presence of a wild type $\mathrm{MeCP} 2$. In addition, double-mutants carrying targeted disruption of Mecp2 and $M b d 2$ genes develop the same phenotype as Mecp2 null mutants (Guy et al., 2001), suggesting that there is a broad redundancy of function. Consequently breeding experiments of Mecp2_WT_EGFP transgenic animals with male Mecp2 null mice rescued the phenotype of the later and thereby displayed the functionality of the transgene as some previous reports (Collins et al., 2004; Giacometti et al., 2007; Luikenhuis et al., 2004). One copy of the Mecp2 transgene led to the complete rescue of all assessed phenotypes in Mecp2 null animals. They had a normal lifespan and showed normal physical development. The rescued animals showed no signs of hypoactivity, tremors, or any other physical symptoms 
typically associated with RTT, even at an advanced age of 6 months or more. We therefore conclude that exogenous expression of Mecp2 from autosome is sufficient to alleviate the phenotype in Mecp2 mutant mice.

The phenotypic analysis of the Mecp2_WT_EGFP transgenic animals which express Mecp2 at two fold of wild type levels showed hyperactivity, more anxiety in the earlier stage of their life and later turned hypomobile before they died around 1.3 years of age. This result emphasizes that the regulation of expression of Mecp2 is very crucial and was in accordance with the finding that a mild overexpression of $M E C P 2$ in wild type was detrimental (Collins et al., 2004).

\subsubsection{EGFP FACS analysis of the transgenic mouse brain cells}

Using the Mecp2_WT_EGFP transgenic mouse model, Mecp2+/EGFP+ cells were successfully separated by EGFP FACS. The measurement of Mecp2+ cells in the mouse brain could be accomplished as well. And the FACS isolated cells were able to be cultured in vitro.

Subsequently, a novel characterization of Mecp2+ cells in the CNS was carried out. The differential counting of Mecp2+ cell types, for example, the percentage of Mecp2 expressing neurons having different neurotransmitter systems throughout the mouse development was thought to reveal the specific role of Mecp2 in RTT. The vital role of posterior part of the hypothalamus through GABAergic and glutamergic neurotransmission in the regulation of homeostatic processes of the internal environment and furthermore, in the regulation of blood pressure and heart rate has been reported in various species (Sitniewska et al., 2002). Recent finding suggest that Mecp2 might play an important role for the proper functioning of GABAergic interneurons in the hypothalamus (Cassel et al., 2004). It provides a possible explanation for the occurrence of epileptic seizures commonly observed in RTT (Naidu, 1997) because loss of hilar GABAergic interneurons is the most consistent deficit in patients and in experimental models of temporal lobe epilepsy (Buckmaster et al., 2002). Johnson et al (Johnson et al., 2005) described that Rett syndrome is a genetic disorder of synapse development, 
especially synapses that use glutamate and GABA as neurotransmitters. Few other reports have even shown that the balance between excitation (Glutamergic) and inhibition (GABAergic) in a major class of cortical neurons is shifted to favor inhibition over excitation in Mecp2-mutant mice (Blue et al., 1999; Dani et al., 2005). The signaling pathways that link the lack of MeCP2 to a shift in the balance between excitation and inhibition remain obscure and presently no quantitative data exist stating about the percentage of GABAergic and glutamergic neurons expressing Mecp2. So, initial experiments in the Mecp2_WT_EGFP transgenic animals paved the way to characterize Mecp2+ cells expressing the GABA and glutamergic neurotransmitter receptor systems by immunostaining.

\subsubsection{Elucidation of the subcellular distribution of Mecp2}

Several studies have analysed the spatio-temporal distribution of MeCP2 in the brains of mice (Shahbazian et al., 2002b), macaque monkeys (Akbarian, 2003) and humans (Balmer et al., 2003; Shahbazian et al., 2002b). All these data indicate that MeCP2 expression is low or absent in immature neurons, astrocytes and oligodendrocytes, then steadily increases during neuronal maturation to reach a high level that is maintained throughout life. Recent finding showed that several transcription factors like Mecp2, with expression in the CNS and other organs, may have an unique neuronal distribution characterized by both nuclear and synaptic localizations as well (Aber et al., 2003; Paratcha et al., 2000). And it was proposed that MeCP2 may link synaptic activity and transcriptional regulation in neurons. Organotrophic and primary neuronal cultures from the transgenic mouse brain demonstrated the potential of the transgenic animals to investigate the intracellular localization of Mecp2 especially in the CNS. It would be promising to image Mecp2 at the synapses by exploiting the EGFP tagged transgenic protein in a real time analysis. Also the transgenic mouse model offers a feasibility of live cell imaging. 


\subsubsection{Mecp2 in brainstem}

Following the phase of regression, each of the cardinal features of Rett syndrome may be mild or severe, including intellectual disability, brainstem cardio-respiratory dysregulation, disturbances of muscle tone, limb contractures, scoliosis and reduction in linear and brain growth. The clinical aspects also include epilepsy that may be severe or absent. Twenty percent of deaths are sudden and unexpected in otherwise robust people, with evidence mounting that disturbed cardiorespiratory regulation plays a significant role in these premature deaths (Julu et al., 2001; Kerr et al., 1997). The same regulatory disturbance, possibly within the brainstem, may also account for early deaths in the severely affected males (Kerr et al., 2001). So far, very few findings had been reported regarding the role of Mecp2 in brainstem. To understand the task of Mecp2 in brainstem development, immunohistochemical analyses with other marker proteins of different postnatal developmental stages (p1, p7, p21 and p40 days) of Mecp2_WT_EGFP transgenic mice brainstem along with the WT littermate controls are in progression in collaboration with the department of Neurophysiology, in the University of Goettingen.

\subsection{The importance of mouse models for Rett syndrome}

So far, many mouse models for Rett syndrome had been produced. Using Cre-lox technology, Chen et al (2001) and Guy et al (2001), generated three mouse models of Rett syndrome with fully deleted Mecp 2 sequences (i.e. Mecp 2 knockout mice) each with different mutation type and phenotype severity for a better understanding of the function of Mecp2. Mutant mice showed a period of apparently normal development followed by severe progressive neurological dysfunction leading to death at 7-10 weeks. Mutation of Mecp 2 restricted to neuronal lineages resulted in a phenotype indistinguishable from that of mice lacking Mecp2 in all tissues, demonstrating that absence of normal protein function in neurons is sufficient to cause disease. Mice in which MeCP2 was deleted in nestin-positive neural precursors (and their progeny, i.e. all neurons and glia) displayed a phenotype indistinguishable from that seen in MeCP2-null mice, indicating that the primary site of action for MeCP2 is in the brain. Furthermore, Chen et al (2001) produced mice in which the Mecp2 gene was only deleted in cells expressing calcium/calmodulindependent protein kinase II ( $\propto-\mathrm{CaMKII})$ gene, a kinase specifically present in postmitotic 
neurons. The $a$ CamKII promoter is normally active in postnatal excitatory neurons of the forebrain, hippocampus and brainstem, and to a much lesser degree in the cerebellum (Silva et al., 1999), although the exact distribution and strength of its activity within the forebrain can vary from one transgenic line to another (Tsien et al., 1996). These mice appeared normal until $\sim 3$ months of age, at which time they began to display ataxic gait and reduced nocturnal activity. Histological analysis revealed reduced brain weights and smaller neuronal cell bodies in cortex and hippocampus. Interestingly, these phenotypes were not seen in the cerebellum where aCamKII was not expressed.

Together with the growing body of protein expression data, these murine studies leave little doubt that the primary (if not the only) site of action for MECP2 function is in neurons. Two recently published studies have taken this conclusion one step further by delimiting the stage of development at which defects in MeCP2-deficient neurons first appear (Kishi and Macklis, 2004; Matarazzo et al., 2004). By isolating neuronal precursors from murine embryos and then inducing them to differentiate in culture, Kishi and Macklis et al (2004) found no evidence for defects in the proliferation or fate decisions of neuronal precursors in the absence of $\mathrm{MeCP} 2$, a finding that contrasts with the situation in the frog Xenopus laevis where $\mathrm{xMeCP} 2$ is required for embryonic development (Stancheva et al., 2003). Rather, these authors found evidence that MeCP2 is important for maturation and maintenance of postmitotic neurons in murine brains (Kishi and Macklis, 2004).

Shahbazian et al (2002) inserted a stop codon into Mecp2 at the nucleotide position corresponding to amino acid 309, thereby generating a mouse with a truncating mutation of Mecp2 $\left(\operatorname{Mecp}^{308}\right)$. This mutation caused a milder phenotype than that shown by the previous two mouse models, and in male mice it recapitulated many of the neurological phenotypes seen in girls with Rett syndrome. For instance, the mice appear normal until about six weeks of age, after which they develop forepaw stereotypies, slowly progressive motor dysfunction (Shahbazian et al., 2002a), social behavior impairments (Moretti et al., 2005), and learning and memory deficits (Moretti et al., 2006). 
To investigate the cell biological mechanisms and developmental stages regulated by Mecp2 in neurons, Matarazzo et al (2004) studied the maturation of the olfactory system. They showed that Mecp2 knockout mice demonstrate a transient delay in the differentiation of olfactory neurons, and abnormalities of axonal targeting in the olfactory bulb, suggesting that Mecp2 mediates a crucial function in the final stages of neuronal development. Recent data showed that neuronal electrophysiological abnormalities are present in all three mouse models of Rett syndrome (Asaka et al., 2006; Dani et al., 2005; Moretti et al., 2006), demonstrating that neuronal dysfunction is part of the pathogenesis of the disease. In addition, Mecp $2^{308}$ mice were shown to have deficits of memory and spatial learning (Moretti et al., 2006), suggesting that the cognitive disturbances that are characteristic of Rett syndrome can be modeled in these mice.

Expression of Mecp2 in post-mitotic neurons of Mecp2-null mice was shown to be sufficient to restore normal neurological function, indicating that Mecp2 deficiency in peripheral tissues does not significantly influence disease manifestations and suggesting that Mecp2 plays no essential role in the early stages of brain development (Luikenhuis et al., 2004). However, two fold overexpression of MECP2 in wild type mice resulted in the development of progressive neurological deterioration with seizures, motor dysfunction and reduced survival (Collins et al., 2004). This finding indicates that Mecp2 levels must be tightly regulated in vivo and has important implications for gene therapy.

However up-to-date, except our model there is no transgenic mouse model expressing the mouse Mecp 2 gene to have a better regulation of expression under the control of the endogenous promoter is available. Furthermore no reports regarding the comprehensive characterization of the Mecp2 expressing (Mecp2+) cells have been made so far. Hence, we aimed to produce transgenic mouse models expressing mouse Mecp 2 tagged with EGFP as a reporter to have an appropriate functional analysis and further dissect the function of Mecp2 protein. And till now there is no study to isolate only the Mecp2 expressing (Mecp2+) cells for transcriptomics analysis. Hence, we have come up with an approach to isolate only the Mecp2 expressing (Mecp2+/EGFP+) cells using EGFP FACS with our transgenic mouse models for transcriptome analysis. 


\subsubsection{Summary of existing and expected Mecp2 animal models}

Table 5 Mecp2 mouse models

\begin{tabular}{|c|c|c|c|c|}
\hline \multirow{2}{*}{$\begin{array}{l}\text { Existing mouse } \\
\text { models }\end{array}$} & \multicolumn{3}{|c|}{ Phenotype } & \multirow{2}{*}{ Comments } \\
\hline & Onset & Survival & Symptoms & \\
\hline \multirow{2}{*}{$\begin{array}{l}\text { Mecp } 2 \text { deletion } \\
\text { (Chen et al, } \\
\text { 2001; Guy et al, } \\
\text { 2001) }\end{array}$} & $\begin{array}{c}6 \text { weeks }(-/ y) \text { and } \\
(-/-)\end{array}$ & $\begin{array}{c}10 \\
\text { weeks }\end{array}$ & \multirow{2}{*}{$\begin{array}{l}\text { Ataxia, } \\
\text { reduced } \\
\text { motor } \\
\text { activity, } \\
\text { tremors, } \\
\text { hind limb } \\
\text { clasping }\end{array}$} & $\begin{array}{c}\text { Lack of } \\
\text { MeCP2 causes } \\
\text { RTT-like } \\
\text { phenotypes in } \\
\text { mice; disease }\end{array}$ \\
\hline & 6 months $(+/-)$ & $\begin{array}{l}\text { Normal } \\
\text { lifespan }\end{array}$ & & $\begin{array}{c}\text { females } \\
\text { depends upon } \\
\text { time, not } \\
\text { developmental } \\
\text { stage }\end{array}$ \\
\hline \multirow{2}{*}{$\begin{array}{l}\text { Mecp2-Nestin- } \\
\text { CRE deletion } \\
\text { (Chen et al, } \\
2001 \text {; Guy et al, } \\
\text { 2001) }\end{array}$} & $\begin{array}{c}6 \text { weeks }(-/ y) \text { and } \\
(-/-)\end{array}$ & $\begin{array}{c}10 \\
\text { weeks }\end{array}$ & \multirow{2}{*}{$\begin{array}{c}\text { Same as } \\
\text { Mecp2 } \\
\text { deletion }\end{array}$} & RTT is due to \\
\hline & 6 months $(+/-)$ & $\begin{array}{l}\text { Normal } \\
\text { lifespan }\end{array}$ & & $\begin{array}{c}\mathrm{MeCP} 2 \text { in } \\
\text { brain }\end{array}$ \\
\hline $\begin{array}{c}\text { Mecp2-CamK- } \\
\text { CRE deletion } \\
\text { (Chen et al, } \\
\text { 2001) }\end{array}$ & 3 months $(-/ y)$ & $\begin{array}{l}\text { Normal } \\
\text { lifespan }\end{array}$ & $\begin{array}{l}\text { Ataxia, } \\
\text { reduced } \\
\text { nocturnal } \\
\text { activity }\end{array}$ & $\begin{array}{l}\text { RTT is due to } \\
\text { absence of } \\
\text { MeCP2 in } \\
\text { post-mitotic } \\
\text { neurons }\end{array}$ \\
\hline $\begin{array}{c}\mathrm{MeCP} 2 \\
\text { truncation } \\
\text { (Shahbazian et } \\
\text { al, 2002) }\end{array}$ & $\begin{array}{c}4 \text { months } \\
\left(\mathrm{MeCP} 2^{308} / \mathrm{y}\right)\end{array}$ & $\begin{array}{l}90 \% 10 \\
\text { months }\end{array}$ & $\begin{array}{c}\text { Progressive } \\
\text { motor and }\end{array}$ & $\begin{array}{c}\text { Truncated } \\
\text { protein found } \\
\text { in many RTT } \\
\text { cases also } \\
\text { produces RTT- }\end{array}$ \\
\hline
\end{tabular}




\begin{tabular}{|c|c|c|c|c|}
\hline & \multirow[b]{3}{*}{$\begin{array}{c}10 \text { months } \\
\left(\mathrm{MeCP} 2^{308} / \mathrm{MeCP} 2\right)\end{array}$} & \multirow[b]{3}{*}{$\begin{array}{l}\text { Normal } \\
\text { lifespan }\end{array}$} & \multirow[t]{2}{*}{$\begin{array}{c}\text { activity } \\
\text { dysfunction. }\end{array}$} & \multirow{3}{*}{$\begin{array}{c}\text { like } \\
\text { phenotypes in } \\
\text { mice }\end{array}$} \\
\hline & & & & \\
\hline & & & $\begin{array}{c}\text { Milder, } \\
\text { variable } \\
\text { phenotypes }\end{array}$ & \\
\hline $\begin{array}{c}\text { Mecp2 } \beta-\mathrm{Tau} \\
\text { homozygous } \\
\text { transgene } \\
\text { expression } \\
\text { (Luikenhuis et } \\
\text { al, 2004) }\end{array}$ & 9 months & $\begin{array}{l}\text { Normal } \\
\text { lifespan }\end{array}$ & $\begin{array}{l}\text { Small size, } \\
\text { ataxia, } \\
\text { tremors }\end{array}$ & $\begin{array}{l}\text { MeCP2 is not } \\
\text { essential for } \\
\text { early } \\
\text { development. } \\
\text { Overexpression } \\
\text { is detrimental }\end{array}$ \\
\hline \multirow{2}{*}{$\begin{array}{c}M E C P 2 \\
\text { overexpression } \\
\text { (Collinset al, } \\
2004)\end{array}$} & \multicolumn{2}{|c|}{$\begin{array}{l}\text { Depending upon expression } \\
\text { levels }\end{array}$} & \multirow{2}{*}{$\begin{array}{l}\text { Progressive } \\
\text { neurological } \\
\text { disorder }\end{array}$} & \multirow{2}{*}{$\begin{array}{l}\text { Overexpression } \\
\text { is detrimental } \\
\text { Enhanced } \\
\text { learning in } \\
\text { mildly } \\
\text { overexpressing } \\
\text { animals }\end{array}$} \\
\hline & From days to weeks & $\begin{array}{l}\text { From 3- } \\
20 \\
\text { weeks to } \\
\text { normal } \\
\text { lifespan }\end{array}$ & & \\
\hline \multicolumn{4}{|l|}{$\begin{array}{l}\text { Expected mouse } \\
\text { Models }\end{array}$} & Outlook \\
\hline $\begin{array}{l}\text { MeCP2 deletion } \\
\text { brain region- } \\
\text { specific }\end{array}$ & $?$ & $?$ & $?$ & $\begin{array}{c}\text { What } \\
\text { symptoms are } \\
\text { caused by lack } \\
\text { of MeCP } 2 \text { in } \\
\text { specific brain } \\
\text { areas? }\end{array}$ \\
\hline
\end{tabular}




\begin{tabular}{|c|c|c|c|c|}
\hline $\begin{array}{l}\text { Postsymptomatic } \\
\qquad \mathrm{MeCP} 2 \\
\text { replacement }\end{array}$ & $?$ & $?$ & $?$ & $\begin{array}{c}\text { Can } \\
\text { phenotypes be } \\
\text { reversed after } \\
\text { they appear in } \\
\text { mice? }\end{array}$ \\
\hline $\begin{array}{l}\text { Mecp2e1-null } \\
\text { Mecp2e2-null }\end{array}$ & $?$ & $?$ & $?$ & $\begin{array}{c}\text { Do the two } \\
\text { different } \\
\text { isoforms have } \\
\text { different } \\
\text { functions? }\end{array}$ \\
\hline $\begin{array}{c}\text { Bdnf } \\
\text { overexpression } \\
\text { Dlx5 } \\
\text { overexpression } \\
\text { (both two-fold) }\end{array}$ & $?$ & $?$ & $?$ & $\begin{array}{l}\text { What aspects } \\
\text { of the Mecp2- } \\
\text { null phenotype } \\
\text { are explained } \\
\text { by } \\
\text { misexpression } \\
\text { of these target } \\
\text { genes? }\end{array}$ \\
\hline
\end{tabular}

RTT, Rett syndrome; MeCP2, ; MeCP2, methyl-CpG-binding protein 2; MeCP2 ${ }^{308}$ MeCP2 protein truncation after 308 aminoacids; Tau, microtubule-associated protein gene; CRE, Cre-recombinase gene; CamK, calcium/calmodulin-dependent protein kinase II gene; Bdnf, brain-derived neurotrophic factor gene; Dlx5, distal-less homeobox 5 gene. (Caballero et al, 2005)

\subsubsection{Prospective knockin model for the most frequent mutation of the MECP2 gene}

Till now, there is no mouse model having a point mutation in Mecp2. Eventually a prospective knock in model for the most frequent mutation, a T158M point mutation, of the Mecp2 gene was attempted in the laboratory. This mouse model would help to find neuropathology of the mutated protein found in many RTT cases. 


\subsubsection{Potential forthcoming transgenic mouse models for the $M E C P 2$ gene}

No finding has been reported yet, investigating the significance and function of the two different isoforms of Mecp2. However, previous research has demonstrated that $\mathrm{MeCP} 2 \mathrm{e} 2$ is sufficient to rescue MeCP2 deficiency in Mecp2 null mice. Despite differences in homology, the nuclear localization of $\mathrm{MeCP} 2$ isoforms was found to be identical for both MeCP2e1 and e2. The question of whether the variants may each have unique functions remains to be answered definitively.

Towards that, creating genomic $\mathrm{BAC} / \mathrm{PAC}$ transgenic constructs by taking advantage of the Mecp2 gene splicing between exon 1 and 2, would be valuable. The intention is to produce two different transgenic splice variants by unique reporter fusions with either of the exons using GET recombination. And the design is to have two different transgenic Mecp2 protein isoforms, one with EGFP and the other with Ds-Red N-terminal fusions replacing the start codon of Mecp2, in the same animal and have a study for the two isoforms individually and collectively.

\subsection{Identifying the target sequences of MeCP2 protein}

Transcriptional profiling failed to identify profound changes of gene expression in the brain of Mecp2 knockout mice (Tudor et al., 2002). Surprisingly, in these mice, minor changes in gene expression were found that became significant only when groups of genes were analyzed together (Tudor et al., 2002). Subsequent studies using a variety of approaches identified several putative target genes of MeCP2 in rodents and/or humans (Chen et al., 2003; Horike et al., 2005; Martinowich et al., 2003; Nuber et al., 2005; Samaco et al., 2005). For example, a candidate approach identified overexpression of brain-derived neurotrophic factor (BDNF) in Mecp2 knockout neurons in culture. Interestingly, recent data showed that BDNF protein levels are decreased and not increased, in the brain of Mecp 2 knockout mice. These apparently contradictory results can be explained by the observation that Mecp2 knockout mice show reduced neuronal activity and this might decrease $B D N F$ expression. Thus, in vivo neuronal dysfunction might counteract the direct effect of loss of Mecp2 function on BDNF transcription, with the net effect of reducing BDNF brain levels (Chang et al., 2006). Mecp2 deficiency was 
also shown to cause reduced expression of Ube3a (ubiquitin protein ligase E3A) and Gabrb3 ( $\beta 3$ GABA receptor) in mouse brain (Samaco et al., 2005); however, the mechanism of this effect remains unclear. Dlx5 and glucocorticoid-regulated genes were shown to be improperly regulated in the brain of mutant mice and this effect was thought to be directly based on the binding of Mecp2 to the regulatory regions of these genes. Overall, the magnitude of these transcriptional effects is small; however, it remains possible that subtle changes of gene expression contribute to some aspects of the Rett syndrome phenotype. To date, there is no evidence linking a specific transcriptional change caused by loss of Mecp2 function to a phenotypic abnormality characteristic of the disease.

Several additional MeCP2-interacting proteins were subsequently identified, including the transcription factor TFIIB, the proto-oncogenic protein c-ski, the DNA methyltransferase DNMT1, the histone methyltransferase Suv39H1, and Brahma, a component of the SWI-SNF chromatin remodeling complex (Fuks et al., 2003; Kaludov and Wolffe, 2000; Kimura and Shiota, 2003; Kokura et al., 2001). However, in the absence of functionally relevant genetic targets of $\mathrm{MeCP} 2$, the biological relevance of these interactions remains unclear. For instance, analysis of nuclear extracts from rodent tissues, cultured cells and Xenopus laevis oocytes revealed that only a small fraction of MeCP2 interacts with Sin3a, and that the interaction is not stable (Klose and Bird, 2004). $\mathrm{MeCP} 2$ purified from rat brain did not stably associate with any proteins and behaved consistently as a monomeric protein with an elongated shape (Klose and Bird, 2004). These findings demonstrate that $\mathrm{MeCP} 2$ is not an obligate or stable component of the $\mathrm{Sin} 3 \mathrm{a}$ co-repressor complex and suggest that $\mathrm{MeCP} 2$ might interact with a diverse range of cofactors.

Recent results suggest that the function of $\mathrm{MeCP} 2$ might be more complex than previously anticipated. For instance, purified recombinant $\mathrm{MeCP} 2$ was shown to have a high-affinity RNA binding activity that is mutually exclusive to its methyl-CpG-binding properties and does not require the methyl-CpG-binding domain (Jeffery and Nakielny, 2004). Interestingly, although the biological significance of a MeCP2-RNA complex 
remains to be elucidated, recent data indicated that MeCP2 interacts with the RNAbinding protein $\mathrm{Y}$ box-binding protein 1 (YB1) and regulates splicing of reporter minigenes (Young et al., 2005). Importantly, aberrant RNA-splicing patterns were identified in Mecp 2 mutant mice (Young et al., 2005). The finding that MeCP2 regulates transcription and splicing of some of its targets suggests the existence of multiple layers of epigenetic regulation.

Table 6 Mecp2 target genes found so far

\begin{tabular}{|c|c|c|c|c|c|c|}
\hline Gene & Species & $\begin{array}{l}\text { Unigene } \\
\text { cluster }\end{array}$ & Function & $\begin{array}{c}\text { Tissue in } \\
\text { which gene is } \\
\text { expressed }\end{array}$ & $\begin{array}{c}\text { Change in } \\
\text { expression } \\
\text { level caused } \\
\text { by MeCP2 }\end{array}$ & References \\
\hline BDNF & Mouse & Mm.1442 & $\begin{array}{l}\text { Survival, } \\
\text { neuronal } \\
\text { plasticity }\end{array}$ & $\begin{array}{l}\text { Cultured } \\
\text { neurons }\end{array}$ & $\begin{array}{l}\text { Upregulated * } \\
\text { 2-fold }\end{array}$ & $\begin{array}{l}\text { (Chen et al., } \\
2003 ; \\
\text { Martinowich } \\
\text { et al., 2003) }\end{array}$ \\
\hline hairy2 & Xenopus & X1.25977 & $\begin{array}{l}\text { Neuronal } \\
\text { differentiation }\end{array}$ & Whole embryo & $\begin{array}{l}\text { Downregulated } \\
-2 \text {-fold }\end{array}$ & $\begin{array}{l}\text { (Stancheva } \\
\text { et al., 2003) }\end{array}$ \\
\hline Fkbp5 & Mouse & Mm.276405 & $\begin{array}{l}\text { Hormonal } \\
\text { signaling }\end{array}$ & $\begin{array}{l}\text { Brain ( } 74 \text { days } \\
\text { of age) }\end{array}$ & $\begin{array}{l}\text { Upregulated } \\
2.26 \text {-fold }\end{array}$ & $\begin{array}{l}\text { (Nuber et al., } \\
2005 \text { ) }\end{array}$ \\
\hline IGF2 & Human & Hs. 147470 & $\begin{array}{l}\text { Cell } \\
\text { proliferation }\end{array}$ & $\begin{array}{l}\text { Lymphoblastoid } \\
\text { cells }\end{array}$ & $\begin{array}{l}\text { Upregulated } \\
2.21 \text {-fold }\end{array}$ & $\begin{array}{l}\text { (Ballestar et } \\
\text { al., 2005) }\end{array}$ \\
\hline DLX5 & Human & Hs.99348 & $\begin{array}{l}\text { Transcription } \\
\text { factor }\end{array}$ & $\begin{array}{l}\text { Lymphoblastoid } \\
\text { cells }\end{array}$ & $\begin{array}{l}\text { Upregulated * } \\
\text { 2-fold }\end{array}$ & $\begin{array}{l}\text { (Makedonski } \\
\text { et al., 2005) }\end{array}$ \\
\hline$\overline{D l x} 5$ & Mouse & $\mathrm{Mm} .4873$ & $\begin{array}{l}\text { Transcription } \\
\text { factor }\end{array}$ & Brain & $\begin{array}{l}\text { Upregulated * } \\
\text { 2-fold }\end{array}$ & $\begin{array}{l}\text { (Makedonski } \\
\text { et al., 2005) }\end{array}$ \\
\hline Dlx6 & Mouse & Mm.5152 & $\begin{array}{l}\text { Transcription } \\
\text { factor }\end{array}$ & Brain & $\begin{array}{l}\text { Upregulated } \\
\text { 2-fold }\end{array}$ & $\begin{array}{l}\text { (Klose et al., } \\
2005 \text { ) }\end{array}$ \\
\hline Ube3a & Mouse & Mm.9002 & Proteolysis & Brain & $\begin{array}{l}\text { Downregulated } \\
-2 \text {-fold }\end{array}$ & $\begin{array}{l}\text { (Makedonski } \\
\text { et al., 2005) }\end{array}$ \\
\hline UBE3A & Human & Hs. 22543 & Proteolysis & Brain $(2-20$ & Downregulated & (Makedonski \\
\hline
\end{tabular}




\begin{tabular}{|l|l|l|l|l|l|l|}
\hline Sgk1 & Mouse & Mm.28405 & $\begin{array}{l}\text { Cellular stress } \\
\text { response }\end{array}$ & $\begin{array}{l}\text { Brain (74 days } \\
\text { of age) }\end{array}$ & $\begin{array}{l}\text { Upregulated } \\
3.44-f o l d\end{array}$ & $\begin{array}{l}\text { (Nuber et al., } \\
\text { 2005) }\end{array}$ \\
\hline MPP1 & Human & Hs.305360 & $\begin{array}{l}\text { Signal } \\
\text { transduction }\end{array}$ & $\begin{array}{l}\text { Lymphoblastoid } \\
\text { cells }\end{array}$ & $\begin{array}{l}\text { Upregulated } \\
\text { 3.32-fold }\end{array}$ & $\begin{array}{l}\text { (Ballestar et } \\
\text { al., 2005) }\end{array}$ \\
\hline
\end{tabular}

BDNF, brain-derived neurotrophic factor; DLX, distal-less homeobox; Fkbp5, FK506-binding protein 5; IGF2, insulin-like growth factor 2; MeCP2, methyl-CpG-binding protein 2; MPP1, palmitoylated membrane protein 1; Sgk1, serum/glucocorticoid kinase 1; Ube3a, ubiquitin protein ligase E3A. (Bienvenu and Chelly, 2006).

In our study some possible target genes for MeCP2 were analyzed by ChIP assays in $\mathrm{HeLa}$ cell line over expressing MeCP2-EGFP fusion protein. Binding of MeCP2 to one of the candidate genes, LOC91663 encoding a hypothetical protein BC013995 was substantiated by GEMSA experiments.

The extraordinary complexity and heterogeneity of the mammalian nervous system significantly limits the power of the transcriptional profiling for gene expression analyses. Because many distinct neuronal and non-neuronal cells are highly intermixed, microarray analyses of a given brain region either during development, behavioral or pharmacological manipulation or subsequent to a disease process only provide a composite view of gene expression. For example, if a gene is expressed at low or moderate levels in a single cell type, even a large change in its expression may not be detected because it is below the abundance level measurable by microarrays. Additionally, changes in gene expression in one cell type may be masked by opposing changes in another cell type. Thus, critical and significant gene expression alterations within a single neuronal population often elude detection in microarray analyses using complex brain tissues (Mirnics et al., 2004). Even when such expression changes are identified in experiments using whole brain tissue, we must rely on extensive post-hoc analysis to determine whether they are caused by changes in cellular composition, 
whether they reflect a change in gene expression within a subset of cells or all cells, or a combination of both.

Microarray studies using purified neuronal populations provide a powerful alternative to study cell type-specific gene expression in the mammalian brain. Recent advances in bacterial artificial chromosome (BAC)-mediated transgenesis in mice (Yang et al., 1997) allow relatively high-throughput genetic labeling of distinct neuronal populations in the brain using fluorescent reporter proteins (gene expression nervous system atlas, GENSAT; (Gong et al., 2003). It is therefore particularly important to have a parallel and highly efficient methodology, like FACS, that could use this invaluable resource for cell type-specific expression profiling in the developing and mature mammalian brain. Therefore we opted to isolate only the Mecp2 expressing (Mecp2+/EGFP+) cells using EGFP FACS with our transgenic mouse models for transcriptome analysis. The drawback of using a whole tissue or a composite cell culture for the comparative expression analysis (Matarazzo and Ronnett, 2004; Tudor et al., 2002) of a differentially expressed gene within and among the different cell types of the tissue, like Mecp2 gene, would be overcome by separating the Mecp2_WT_EGFP+ cells for the study in comparison with Mecp2_270_EGFP+ cells (Mutant cells), both in the Mecp2 (endogenous) knockout background.

\subsection{Mecp2 in reproductive biology}

The investigations showed the presence of Mecp2 transcripts in the unfertilized mouse oocytes. But the exact expression of the Mecp2 should be differentiated from the maternal storage RNA. Towards that, some single nucleotide polymorphisms (SNP) between different mouse strains through celera database have to be found. Then the selected strains could be crossed and the RNA expression of the specific cross in the embryonal stages can be analyzed by genotyping the transcripts out of the hybrid. Furthermore, the Mecp2 also seemed to be present in the mouse sperm. 


\subsection{Measurement of the size of specific affected neurons in Rett syndrome}

Expression studies also indicate that $\mathrm{MeCP} 2$ is involved in the differentiation of neuronal cells, including dendritic arborization and the development and maintenance of dendritic arborization, rather than in cell-fate decisions (Armstrong et al., 1995; Armstrong et al., 1998; Kishi and Macklis, 2004). Consistent with this, studies of human postmortem tissue have shown less complex dendritic arborizations, smaller neurons and a reduction of dendritic spines of cortical neurons in patients with Rett syndrome (Armstrong et al., 1998; Kishi and Macklis, 2004) which could be due to defects in either the maturation of neurons or the maintenance of their differentiated state. To address the issue further, more advantageously, our Mecp2_270_EGFP mutant mouse model would provide the ability to compare the size of specific neurons expressing the mutant Mecp2 marked with EGFP, with the neurons in Mecp2_WT_EGFP model.

\section{6. $\quad$ Future perspectives}

Current data suggest that the study of MeCP2 function in Rett syndrome is likely to shed light on mechanisms of epigenetic memory in neurons. Thus, a key challenge for the future will be the identification of genes regulated by $\mathrm{MeCP} 2$ in the brain, and the elucidation of the mechanisms by which $M E C P 2$ mutations give rise to the characteristic features of Rett syndrome. Furthermore, the Mecp2_270_EGFP transgenic mouse model would facilitate to comprehend the role of the mutated protein in the pathogenesis of Rett syndrome. It would assist in finding out the possible neuropathogical interaction of the mutant protein with some factors when it is localized in the cytoplasm. This could be performed by immunoprecipitation of the mutant protein in the transgenic mice in the Mecp2 (endogenous) knockout background. 


\section{Summary}

The $\mathrm{MeCP} 2$ protein is a transcriptional repressor binding to methylated cytosines and modifying the chromatin structure. $M E C P 2$ gene was eventually found to be the cause of 95\% of Rett Syndrome cases. Patients with Rett syndrome show symptoms of neuronal dysfunction of the autonomic system. In spite of its ubiquitous expression, it is believed to have some unique functions in the neurons. But till now, very less is known about the role of MeCP2 in neuronal cells and the mechanism by which it brings about the deteriorating disorder. The transcriptional profiling of the knock-out mouse model for Rett syndrome reveals subtle transcriptional changes in the brain and so far very less target genes for Mecp2 have been found.

Animal models become inevitable to investigate the mechanism of human diseases. Two knockout lines and a knockin mouse for a truncated mutation showing some symptoms which mimics RTT syndrome have been created. Recently another mouse model is produced which express Mecp2 under the control of a neuron-specific promoter (promoter for Tau protein). And the transgenic expression of the Mecp2 in wild type post-mitotic neurons resulted in symptoms of severe motor dysfunction but the expression in Mecp2 mutant mice, however, rescued the RTT phenotype. Therefore, we started to produce transgenic mouse models expressing Mecp2 tagged with EGFP as a reporter to further characterize Mecp2. The transgenic constructs have been generated by engineering a BAC clone (B22804) containing the entire Mecp2 gene of the mouse and flanking sequences, by GET recombination.

Our present aim is to characterize and obtain an appropriate functional analysis of Mecp2 by two different transgenic mouse models. First mouse model over-expresses the wildtype Mecp2 labeled at c-terminus with EGFP protein. The second transgenic model overexpresses an early truncated (human mutation) Mecp2 protein, lacking the nuclear localization signal, also labelled at the c-terminus with the EGFP-protein. The investigation of the transgenic mouse lines shall allow the spatio-temporal analysis of the Mecp2 protein by tracing the EGFP protein. Moreover, the transgenic mouse model 
which ectopically expresses an early truncated Mecp2 protein will help to understand the etiology behind the pathogenesis of the Rett syndrome.

Although Mecp2 is more predominantly expressed in the brain, it doesn't seem to express in all the cells including glial cells. So, presently, we are trying to isolate the Mecp2+ / EGFP+ specific brain cells by Fluorescence Activated Cell Sorting (FACS) using our unique transgenic mouse models and to characterize the identity of them using different markers by immunostaining. A transcriptomics approach using the Mecp2+ / EGFP+ cell sub-population between our two transgenic models would validate the regulation of already found target genes or determine new target genes specifically. Further analysis will be done in the following directions: Live cell imaging of Mecp2 at the synapses, Analysis of Mecp2+ / EGFP+ cells in the respiratory network through the mouse development, Determining the size of the neurons expressing the transgenic proteins. 


\section{Bibliography}

Aber, K.M., Nori, P., MacDonald, S.M., Bibat, G., Jarrar, M.H., and Kaufmann, W.E. (2003). Methyl-CpG-binding protein 2 is localized in the postsynaptic compartment: an immunochemical study of subcellular fractions. Neuroscience 116, 7780.

Akbarian, S. (2003). The neurobiology of Rett syndrome. Neuroscientist 9, 57-63.

Akbarian, S., Chen, R.Z., Gribnau, J., Rasmussen, T.P., Fong, H., Jaenisch, R., and Jones, E.G. (2001). Expression pattern of the Rett syndrome gene MeCP2 in primate prefrontal cortex. Neurobiology of disease 8, 784-791.

Amir, R.E., Van den Veyver, I.B., Schultz, R., Malicki, D.M., Tran, C.Q., Dahle, E.J., Philippi, A., Timar, L., Percy, A.K., Motil, K.J., et al. (2000). Influence of mutation type and X chromosome inactivation on Rett syndrome phenotypes. Annals of neurology $47,670-679$.

Amir, R.E., Van den Veyver, I.B., Wan, M., Tran, C.Q., Francke, U., and Zoghbi, H.Y. (1999). Rett syndrome is caused by mutations in X-linked MECP2, encoding methyl-CpG-binding protein 2. Nature genetics 23, 185-188.

Ariani, F., Mari, F., Pescucci, C., Longo, I., Bruttini, M., Meloni, I., Hayek, G., Rocchi, R., Zappella, M., and Renieri, A. (2004). Real-time quantitative PCR as a routine method for screening large rearrangements in Rett syndrome: Report of one case of MECP2 deletion and one case of MECP2 duplication. Hum Mutat 24, 172-177.

Armstrong, D., Dunn, J.K., Antalffy, B., and Trivedi, R. (1995). Selective dendritic alterations in the cortex of Rett syndrome. Journal of neuropathology and experimental neurology 54, 195-201.

Armstrong, D.D., Dunn, K., and Antalffy, B. (1998). Decreased dendritic branching in frontal, motor and limbic cortex in Rett syndrome compared with trisomy 21. Journal of neuropathology and experimental neurology 57, 1013-1017.

Asaka, Y., Jugloff, D.G., Zhang, L., Eubanks, J.H., and Fitzsimonds, R.M. (2006). Hippocampal synaptic plasticity is impaired in the Mecp2-null mouse model of Rett syndrome. Neurobiology of disease 21, 217-227.

Ballestar, E., Ropero, S., Alaminos, M., Armstrong, J., Setien, F., Agrelo, R., Fraga, M.F., Herranz, M., Avila, S., Pineda, M., et al. (2005). The impact of MECP2 mutations in the expression patterns of Rett syndrome patients. Human genetics 116, 91104. 
Balmer, D., Goldstine, J., Rao, Y.M., and LaSalle, J.M. (2003). Elevated methylCpG-binding protein 2 expression is acquired during postnatal human brain development and is correlated with alternative polyadenylation. Journal of molecular medicine (Berlin, Germany) 81, 61-68.

Bienvenu, T., Carrie, A., de Roux, N., Vinet, M.C., Jonveaux, P., Couvert, P., Villard, L., Arzimanoglou, A., Beldjord, C., Fontes, M., et al. (2000). MECP2 mutations account for most cases of typical forms of Rett syndrome. Hum Mol Genet 9, 1377-1384.

Bienvenu, T., and Chelly, J. (2006). Molecular genetics of Rett syndrome: when DNA methylation goes unrecognized. Nature reviews 7, 415-426.

Blue, M.E., Naidu, S., and Johnston, M.V. (1999). Altered development of glutamate and GABA receptors in the basal ganglia of girls with Rett syndrome. Experimental neurology 156, 345-352.

Buckmaster, P.S., Yamawaki, R., and Zhang, G.F. (2002). Axon arbors and synaptic connections of a vulnerable population of interneurons in the dentate gyrus in vivo. The Journal of comparative neurology 445, 360-373.

Carney, R.M., Wolpert, C.M., Ravan, S.A., Shahbazian, M., Ashley-Koch, A., Cuccaro, M.L., Vance, J.M., and Pericak-Vance, M.A. (2003). Identification of MeCP2 mutations in a series of females with autistic disorder. Pediatric neurology 28, 205-211.

Cassel, S., Revel, M.O., Kelche, C., and Zwiller, J. (2004). Expression of the methyl-CpG-binding protein $\mathrm{MeCP} 2$ in rat brain. An ontogenetic study. Neurobiology of disease $15,206-211$.

Chang, Q., Khare, G., Dani, V., Nelson, S., and Jaenisch, R. (2006). The disease progression of Mecp2 mutant mice is affected by the level of BDNF expression. Neuron 49, 341-348.

Chen, R.Z., Akbarian, S., Tudor, M., and Jaenisch, R. (2001). Deficiency of methyl-CpG binding protein-2 in CNS neurons results in a Rett-like phenotype in mice. Nature genetics 27, 327-331.

Chen, W.G., Chang, Q., Lin, Y., Meissner, A., West, A.E., Griffith, E.C., Jaenisch, R., and Greenberg, M.E. (2003). Derepression of BDNF transcription involves calcium-dependent phosphorylation of MeCP2. Science 302, 885-889.

Cohen, D.R., Matarazzo, V., Palmer, A.M., Tu, Y., Jeon, O.H., Pevsner, J., and Ronnett, G.V. (2003). Expression of MeCP2 in olfactory receptor neurons is 
developmentally regulated and occurs before synaptogenesis. Molecular and cellular neurosciences 22, 417-429.

Collins, A.L., Levenson, J.M., Vilaythong, A.P., Richman, R., Armstrong, D.L., Noebels, J.L., David Sweatt, J., and Zoghbi, H.Y. (2004). Mild overexpression of MeCP2 causes a progressive neurological disorder in mice. Hum Mol Genet 13, 2679-2689.

Couvert, P., Bienvenu, T., Aquaviva, C., Poirier, K., Moraine, C., Gendrot, C., Verloes, A., Andres, C., Le Fevre, A.C., Souville, I., et al. (2001). MECP2 is highly mutated in X-linked mental retardation. Hum Mol Genet 10, 941-946.

Coy, J.F., Sedlacek, Z., Bachner, D., Delius, H., and Poustka, A. (1999). A complex pattern of evolutionary conservation and alternative polyadenylation within the long 3"-untranslated region of the methyl-CpG-binding protein 2 gene (MeCP2) suggests a regulatory role in gene expression. Hum Mol Genet 8, 1253-1262.

D'Esposito, M., Quaderi, N.A., Ciccodicola, A., Bruni, P., Esposito, T., D'Urso, M., and Brown, S.D. (1996). Isolation, physical mapping, and northern analysis of the Xlinked human gene encoding methyl CpG-binding protein, MECP2. Mamm Genome 7, 533-535.

Dani, V.S., Chang, Q., Maffei, A., Turrigiano, G.G., Jaenisch, R., and Nelson, S.B. (2005). Reduced cortical activity due to a shift in the balance between excitation and inhibition in a mouse model of Rett syndrome. Proc Natl Acad Sci U S A 102, 1256012565.

Fan, G., Beard, C., Chen, R.Z., Csankovszki, G., Sun, Y., Siniaia, M., Biniszkiewicz, D., Bates, B., Lee, P.P., Kuhn, R., et al. (2001). DNA hypomethylation perturbs the function and survival of CNS neurons in postnatal animals. J Neurosci 21, 788-797.

Free, A., Wakefield, R.I., Smith, B.O., Dryden, D.T., Barlow, P.N., and Bird, A.P. (2001). DNA recognition by the methyl-CpG binding domain of MeCP2. The Journal of biological chemistry 276, 3353-3360.

Fuks, F., Hurd, P.J., Wolf, D., Nan, X., Bird, A.P., and Kouzarides, T. (2003). The methyl-CpG-binding protein MeCP2 links DNA methylation to histone methylation. The Journal of biological chemistry 278, 4035-4040.

Giacometti, E., Luikenhuis, S., Beard, C., and Jaenisch, R. (2007). Partial rescue of MeCP2 deficiency by postnatal activation of MeCP2. Proc Natl Acad Sci U S A 104, 1931-1936. 
Gong, S., Zheng, C., Doughty, M.L., Losos, K., Didkovsky, N., Schambra, U.B., Nowak, N.J., Joyner, A., Leblanc, G., Hatten, M.E., et al. (2003). A gene expression atlas of the central nervous system based on bacterial artificial chromosomes. Nature 425, 917925.

Guy, J., Hendrich, B., Holmes, M., Martin, J.E., and Bird, A. (2001). A mouse Mecp2-null mutation causes neurological symptoms that mimic Rett syndrome. Nature genetics 27, 322-326.

Hagberg, B., Aicardi, J., Dias, K., and Ramos, O. (1983). A progressive syndrome of autism, dementia, ataxia, and loss of purposeful hand use in girls: Rett's syndrome: report of 35 cases. Annals of neurology 14, 471-479.

Hoffbuhr, K.C., Moses, L.M., Jerdonek, M.A., Naidu, S., and Hoffman, E.P. (2002). Associations between MeCP2 mutations, X-chromosome inactivation, and phenotype. Mental retardation and developmental disabilities research reviews 8, 99-105.

Horike, S., Cai, S., Miyano, M., Cheng, J.F., and Kohwi-Shigematsu, T. (2005). Loss of silent-chromatin looping and impaired imprinting of DLX5 in Rett syndrome. Nature genetics 37, 31-40.

Inano, K., Suetake, I., Ueda, T., Miyake, Y., Nakamura, M., Okada, M., and Tajima, S. (2000). Maintenance-type DNA methyltransferase is highly expressed in postmitotic neurons and localized in the cytoplasmic compartment. Journal of biochemistry $128,315-321$.

Jeffery, L., and Nakielny, S. (2004). Components of the DNA methylation system of chromatin control are RNA-binding proteins. The Journal of biological chemistry 279, 49479-49487.

Johnson, P.T., Brown, M.N., Pulliam, B.C., Anderson, D.H., and Johnson, L.V. (2005). Synaptic pathology, altered gene expression, and degeneration in photoreceptors impacted by drusen. Investigative ophthalmology \& visual science 46, 4788-4795.

Jones, P.L., Veenstra, G.J., Wade, P.A., Vermaak, D., Kass, S.U., Landsberger, N., Strouboulis, J., and Wolffe, A.P. (1998). Methylated DNA and MeCP2 recruit histone deacetylase to repress transcription. Nature genetics 19, 187-191.

Julu, P.O., Kerr, A.M., Apartopoulos, F., Al-Rawas, S., Engerstrom, I.W., Engerstrom, L., Jamal, G.A., and Hansen, S. (2001). Characterisation of breathing and associated central autonomic dysfunction in the Rett disorder. Archives of disease in childhood 85, 29-37. 
Kaludov, N.K., and Wolffe, A.P. (2000). MeCP2 driven transcriptional repression in vitro: selectivity for methylated DNA, action at a distance and contacts with the basal transcription machinery. Nucleic acids research 28, 1921-1928.

Kerr, A.M., Armstrong, D.D., Prescott, R.J., Doyle, D., and Kearney, D.L. (1997). Rett syndrome: analysis of deaths in the British survey. European child \& adolescent psychiatry 6 Suppl 1, 71-74.

Kerr, A.M., Belichenko, P., Woodcock, T., and Woodcock, M. (2001). Mind and brain in Rett disorder. Brain Dev 23 Suppl 1, S44-49.

Kimura, H., and Shiota, K. (2003). Methyl-CpG-binding protein, MeCP2, is a target molecule for maintenance DNA methyltransferase, Dnmt1. The Journal of biological chemistry $278,4806-4812$.

Kishi, N., and Macklis, J.D. (2004). MECP2 is progressively expressed in postmigratory neurons and is involved in neuronal maturation rather than cell fate decisions. Molecular and cellular neurosciences 27, 306-321.

Klose, R.J., and Bird, A.P. (2004). MeCP2 behaves as an elongated monomer that does not stably associate with the Sin3a chromatin remodeling complex. The Journal of biological chemistry 279, 46490-46496.

Klose, R.J., Sarraf, S.A., Schmiedeberg, L., McDermott, S.M., Stancheva, I., and Bird, A.P. (2005). DNA binding selectivity of $\mathrm{MeCP} 2$ due to a requirement for $\mathrm{A} / \mathrm{T}$ sequences adjacent to methyl-CpG. Molecular cell 19, 667-678.

Kokura, K., Kaul, S.C., Wadhwa, R., Nomura, T., Khan, M.M., Shinagawa, T., Yasukawa, T., Colmenares, C., and Ishii, S. (2001). The Ski protein family is required for MeCP2-mediated transcriptional repression. The Journal of biological chemistry 276, 34115-34121.

Kriaucionis, S., and Bird, A. (2003). DNA methylation and Rett syndrome. Hum Mol Genet 12 Spec No 2, R221-227.

Laccone, F., Junemann, I., Whatley, S., Morgan, R., Butler, R., Huppke, P., and Ravine, D. (2004). Large deletions of the MECP2 gene detected by gene dosage analysis in patients with Rett syndrome. Hum Mutat 23, 234-244.

Laccone, F., Zoll, B., Huppke, P., Hanefeld, F., Pepinski, W., and Trappe, R. (2002). MECP2 gene nucleotide changes and their pathogenicity in males: proceed with caution. Journal of medical genetics $39,586-588$. 
Lewis, J.D., Meehan, R.R., Henzel, W.J., Maurer-Fogy, I., Jeppesen, P., Klein, F., and Bird, A. (1992). Purification, sequence, and cellular localization of a novel chromosomal protein that binds to methylated DNA. Cell 69, 905-914.

Luikenhuis, S., Giacometti, E., Beard, C.F., and Jaenisch, R. (2004). Expression of MeCP2 in postmitotic neurons rescues Rett syndrome in mice. Proc Natl Acad Sci U S A $101,6033-6038$.

Makedonski, K., Abuhatzira, L., Kaufman, Y., Razin, A., and Shemer, R. (2005). $\mathrm{MeCP} 2$ deficiency in Rett syndrome causes epigenetic aberrations at the PWS/AS imprinting center that affects UBE3A expression. Hum Mol Genet 14, 1049-1058.

Martinowich, K., Hattori, D., Wu, H., Fouse, S., He, F., Hu, Y., Fan, G., and Sun, Y.E. (2003). DNA methylation-related chromatin remodeling in activity-dependent BDNF gene regulation. Science 302, 890-893.

Matarazzo, V., Cohen, D., Palmer, A.M., Simpson, P.J., Khokhar, B., Pan, S.J., and Ronnett, G.V. (2004). The transcriptional repressor Mecp2 regulates terminal neuronal differentiation. Molecular and cellular neurosciences 27, 44-58.

Matarazzo, V., and Ronnett, G.V. (2004). Temporal and regional differences in the olfactory proteome as a consequence of MeCP2 deficiency. Proc Natl Acad Sci U S A $101,7763-7768$.

Meloni, I., Bruttini, M., Longo, I., Mari, F., Rizzolio, F., D'Adamo, P., Denvriendt, K., Fryns, J.P., Toniolo, D., and Renieri, A. (2000). A mutation in the rett syndrome gene, MECP2, causes X-linked mental retardation and progressive spasticity in males. American journal of human genetics 67, 982-985.

Mirnics, Z.K., Caudell, E., Gao, Y., Kuwahara, K., Sakaguchi, N., Kurosaki, T., Burnside, J., Mirnics, K., and Corey, S.J. (2004). Microarray analysis of Lyn-deficient B cells reveals germinal center-associated nuclear protein and other genes associated with the lymphoid germinal center. J Immunol 172, 4133-4141.

Mnatzakanian, G.N., Lohi, H., Munteanu, I., Alfred, S.E., Yamada, T., MacLeod, P.J., Jones, J.R., Scherer, S.W., Schanen, N.C., Friez, M.J., et al. (2004). A previously unidentified MECP2 open reading frame defines a new protein isoform relevant to Rett syndrome. Nature genetics 36, 339-341.

Moog, U., Smeets, E.E., van Roozendaal, K.E., Schoenmakers, S., Herbergs, J., Schoonbrood-Lenssen, A.M., and Schrander-Stumpel, C.T. (2003). Neurodevelopmental disorders in males related to the gene causing Rett syndrome in females (MECP2). Eur J Paediatr Neurol 7, 5-12. 
Moretti, P., Bouwknecht, J.A., Teague, R., Paylor, R., and Zoghbi, H.Y. (2005). Abnormalities of social interactions and home-cage behavior in a mouse model of Rett syndrome. Hum Mol Genet 14, 205-220.

Moretti, P., Levenson, J.M., Battaglia, F., Atkinson, R., Teague, R., Antalffy, B., Armstrong, D., Arancio, O., Sweatt, J.D., and Zoghbi, H.Y. (2006). Learning and memory and synaptic plasticity are impaired in a mouse model of Rett syndrome. $\mathrm{J}$ Neurosci 26, 319-327.

Mullaney, B.C., Johnston, M.V., and Blue, M.E. (2004). Developmental expression of methyl-CpG binding protein 2 is dynamically regulated in the rodent brain. Neuroscience 123, 939-949.

Naidu, S. (1997). Rett syndrome: a disorder affecting early brain growth. Annals of neurology 42, 3-10.

Nan, X., Ng, H.H., Johnson, C.A., Laherty, C.D., Turner, B.M., Eisenman, R.N., and Bird, A. (1998). Transcriptional repression by the methyl-CpG-binding protein MeCP2 involves a histone deacetylase complex. Nature 393, 386-389.

Narayanan, K., and Warburton, P.E. (2003). DNA modification and functional delivery into human cells using Escherichia coli DH10B. Nucleic acids research 31, e51.

Neely, K.E., and Workman, J.L. (2002). Histone acetylation and chromatin remodeling: which comes first? Molecular genetics and metabolism 76, 1-5.

Neely MD, M.T., and (2002). CSF lipoproteins and Alzheimer's disease. J Nutr Health Aging 6(6), 383-391.

Nuber, U.A., Kriaucionis, S., Roloff, T.C., Guy, J., Selfridge, J., Steinhoff, C., Schulz, R., Lipkowitz, B., Ropers, H.H., Holmes, M.C., et al. (2005). Up-regulation of glucocorticoid-regulated genes in a mouse model of Rett syndrome. Hum Mol Genet 14, 2247-2256.

Ohler, U., Niemann, H., Liao, G., and Rubin, G.M. (2001). Joint modeling of DNA sequence and physical properties to improve eukaryotic promoter recognition. Bioinformatics (Oxford, England) 17 Suppl 1, S199-206.

Orford, M., Nefedov, M., Vadolas, J., Zaibak, F., Williamson, R., and Ioannou, P.A. (2000). Engineering EGFP reporter constructs into a $200 \mathrm{~kb}$ human beta-globin BAC clone using GET Recombination. Nucleic acids research 28, E84. 
Paratcha, G., de Stein, M.L., Szapiro, G., Lopez, M., Bevilaqua, L., Cammarota, M., de Iraldi, A.P., Izquierdo, I., and Medina, J.H. (2000). Experience-dependent decrease in synaptically localized Fra-1. Brain Res Mol Brain Res 78, 120-130.

Pelka, G.J., Watson, C.M., Christodoulou, J., and Tam, P.P. (2005). Distinct expression profiles of Mecp2 transcripts with different lengths of 3'UTR in the brain and visceral organs during mouse development. Genomics 85, 441-452.

Percy, A.K. (2002). Rett syndrome. Current status and new vistas. Neurologic clinics 20, 1125-1141.

Percy, A.K., and Lane, J.B. (2004). Rett syndrome: clinical and molecular update. Current opinion in pediatrics $16,670-677$.

Reichwald, K., Thiesen, J., Wiehe, T., Weitzel, J., Poustka, W.A., Rosenthal, A., Platzer, M., Stratling, W.H., and Kioschis, P. (2000). Comparative sequence analysis of the MECP2-locus in human and mouse reveals new transcribed regions. Mamm Genome $11,182-190$.

Rett, A. (1966). [On an until now unknown disease of a congenital metabolic disorder]. Die Krankenschwester 19, 121-122.

Samaco, R.C., Hogart, A., and LaSalle, J.M. (2005). Epigenetic overlap in autismspectrum neurodevelopmental disorders: MECP2 deficiency causes reduced expression of UBE3A and GABRB3. Hum Mol Genet 14, 483-492.

Schollen, E., Smeets, E., Deflem, E., Fryns, J.P., and Matthijs, G. (2003). Gross rearrangements in the MECP2 gene in three patients with Rett syndrome: implications for routine diagnosis of Rett syndrome. Hum Mutat 22, 116-120.

Shahbazian, M., Young, J., Yuva-Paylor, L., Spencer, C., Antalffy, B., Noebels, J., Armstrong, D., Paylor, R., and Zoghbi, H. (2002a). Mice with truncated MeCP2 recapitulate many Rett syndrome features and display hyperacetylation of histone $\mathrm{H} 3$. Neuron 35, 243-254.

Shahbazian, M.D., Antalffy, B., Armstrong, D.L., and Zoghbi, H.Y. (2002b). Insight into Rett syndrome: MeCP2 levels display tissue- and cell-specific differences and correlate with neuronal maturation. Hum Mol Genet 11, 115-124.

Sharma, R.P., Grayson, D.R., Guidotti, A., and Costa, E. (2005). Chromatin, DNA methylation and neuron gene regulation--the purpose of the package. J Psychiatry Neurosci 30, 257-263. 
Silva, G.A., Theriault, E., Mills, L.R., Pennefather, P.S., and Feeney, C.J. (1999). Group I and II metabotropic glutamate receptor expression in cultured rat spinal cord astrocytes. Neuroscience letters 263, 117-120.

Sitniewska, E.M., Wisniewska, R.J., and Wisniewski, K. (2002). Diabetesinduced changes of nitric oxide influence on the cardiovascular action of secretin. Regulatory peptides $105,163-172$.

Stancheva, I., Collins, A.L., Van den Veyver, I.B., Zoghbi, H., and Meehan, R.R. (2003). A mutant form of MeCP2 protein associated with human Rett syndrome cannot be displaced from methylated DNA by notch in Xenopus embryos. Molecular cell 12, 425-435.

Tsien, J.Z., Huerta, P.T., and Tonegawa, S. (1996). The essential role of hippocampal CA1 NMDA receptor-dependent synaptic plasticity in spatial memory. Cell $87,1327-1338$.

Tudor, M., Akbarian, S., Chen, R.Z., and Jaenisch, R. (2002). Transcriptional profiling of a mouse model for Rett syndrome reveals subtle transcriptional changes in the brain. Proc Natl Acad Sci U S A 99, 15536-15541.

Van Esch, H., Bauters, M., Ignatius, J., Jansen, M., Raynaud, M., Hollanders, K., Lugtenberg, D., Bienvenu, T., Jensen, L.R., Gecz, J., et al. (2005). Duplication of the MECP2 region is a frequent cause of severe mental retardation and progressive neurological symptoms in males. American journal of human genetics 77, 442-453.

Veldic, M., Caruncho, H.J., Liu, W.S., Davis, J., Satta, R., Grayson, D.R., Guidotti, A., and Costa, E. (2004). DNA-methyltransferase 1 mRNA is selectively overexpressed in telencephalic GABAergic interneurons of schizophrenia brains. Proc Natl Acad Sci U S A 101, 348-353.

Wan, M., Lee, S.S., Zhang, X., Houwink-Manville, I., Song, H.R., Amir, R.E., Budden, S., Naidu, S., Pereira, J.L., Lo, I.F., et al. (1999). Rett syndrome and beyond: recurrent spontaneous and familial MECP2 mutations at CpG hotspots. American journal of human genetics $65,1520-1529$.

Wolffe, A.P., Jones, P.L., and Wade, P.A. (1999). DNA demethylation. Proc Natl Acad Sci U S A 96, 5894-5896.

Yang, X.W., Model, P., and Heintz, N. (1997). Homologous recombination based modification in Escherichia coli and germline transmission in transgenic mice of a bacterial artificial chromosome. Nature biotechnology 15, 859-865. 
Young, J.I., Hong, E.P., Castle, J.C., Crespo-Barreto, J., Bowman, A.B., Rose, M.F., Kang, D., Richman, R., Johnson, J.M., Berget, S., et al. (2005). Regulation of RNA splicing by the methylation-dependent transcriptional repressor methyl-CpG binding protein 2. Proc Natl Acad Sci U S A 102, 17551-17558.

Yusufzai, T.M., and Wolffe, A.P. (2000). Functional consequences of Rett syndrome mutations on human MeCP2. Nucleic acids research 28, 4172-4179. 


\section{Resume}

Name:

E-Mail:

Date of Birth:

Place of Birth:

Nationality:

Sex:

Martial Status:

Permanent address:
Arunachalam, Jayamuruga Pandian

ajmpandian@gmail.com

March $26^{\text {th }}, 1977$

Madurai, India

Indian

Male

Married

58/2, Morappur Road,

Karimangalam,

Dharmapuri - 635 111,

Tamil Nadu, India

\section{Academic credentials}

2002 - Present

$2001-2002$
Doctoral studies towards the establishment and characterization of transgenic mouse models for Mecp2 gene causing Rett (RTT) syndrome, a neurodevelopmental disorder.

Institute for Human Genetics, University of Goettingen, Germany

Research Assistant

Department of Molecular Reproduction, Development \& Genetics, Indian Institute of Sciences (IISc), Bangalore, India.

Short-term trainee,

Olfactory Perception lab, National Center for Biological Sciences (NCBS), Bangalore, India. 
Junior Project Assistant

Department of Genetics, School of Biological Sciences, Madurai Kamaraj University (MKU), Tamil Nadu, India.

$1998-2000$

Master of Science in Integrated Biology

School of Biological Sciences, Madurai Kamaraj University (MKU), Tamil Nadu, India.

Summer Research Fellow,

Tamil Nadu Agricultural University (TNAU),

Coimbatore, Tamil Nadu, India.

$1995-1998$

Bachelor of Science in Botany, The American College, Madurai Kamaraj University (MKU), Tamil Nadu, India

Publication: A novel therapeutic approach by TAT-MeCP2 protein delivery prolongs the lifespan and rescues neuronal damage in a mouse model of Rett syndrome.

Prakasha Kempaiah, JM Pandian Arunachalam, Ralf Dressel, Alexander Mildner, Doron Merkler, Marco Prinz, and Franco Laccone. (Manuscript submitted to Nature Medicine Journal) 


\section{Acknowledgements}

I deeply thank Prof. Dr. med. Wolfgang Engel for his excellent supervision and for being my main examiner. I give my special thanks to PD Dr. Franco Laccone for his guidance throughout my studies.

I would like to thank PD Dr. S. Hoyer-Fender for being my co-referee. I also extend my gratitude to Prof. Dr. Ralf Ficner and Prof. Dr. Ernst Wimmer for evaluating my thesis.

My thanks to Prof. Dr. Ibrahim Adham and the people of the institute for their help and support.

I extend my thanks to Dr. Till Manzke, Dr. Salonikidis and Dr. Mathias Dutschmann for their help and kind interactions in and outside of the lab.

I greatly appreciate my colleagues Dr. Prakasha Kempaiah, Dr. Arvind Dev and Krishna Pantakani for creating a lovely and pleasant environment in the lab. I heartfully thank my friends Dr. Santhoshlakshmi Sridhar, Dr. Malaiyalam Mariappan, and Dr. Karthikeyan Radhakrishnan for creating a home out of home feeling.

My warm thanks to one of my comrade Dr. Sreedhar Kilaru, for his invaluable moral support. I would not fail to mention Dr. T.E.V. Balaji, for his good friendship.

Next to the Almighty and my late father, I solely dedicate everything to my love Dr. Subbulakshmi Chidambaram. Finally, I owe my deepest and loving thanks to all my family members. 